\title{
SENSE OF HOME
}

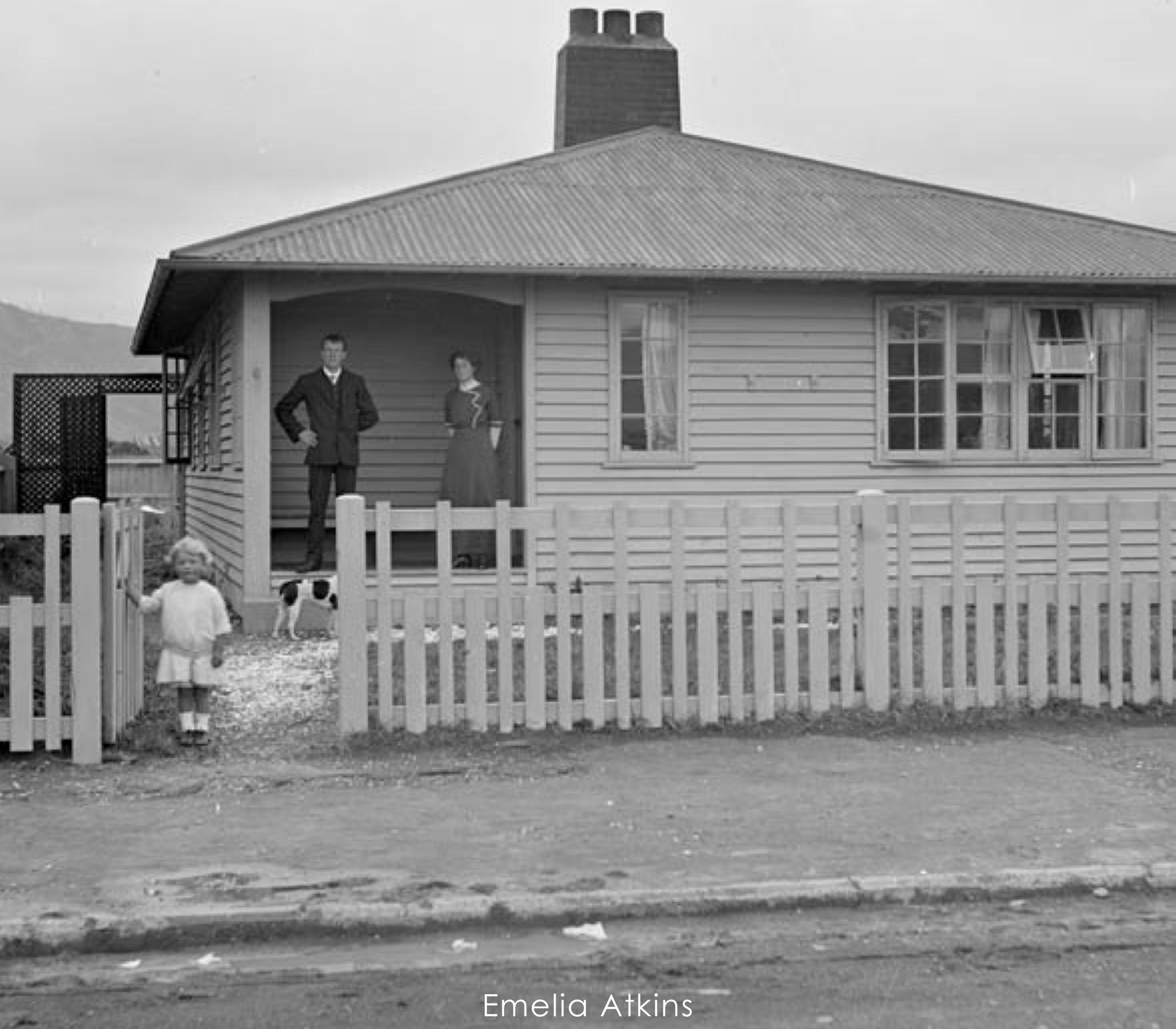







\title{
Sense of Home
}

\author{
by
}

Emelia Jane Atkins

A 120-point thesis

submitted to the Victoria University of Wellington

in partial fulfilment of the requirements for the

degree of Master of Architecture (Professional)

Victoria University of Wellington

School of Architecture 



\section{ACKNOWLEDGEMENTS}

Firstly, a thank you to my supervisor, Shenuka de Sylva, for guiding me through this thesis; providing me with insight and encouragement to push my research.

Thank you to everyone who has helped me see my research through to the end, your support, encouragement and patience has been much appreciated.

Finally, I would like to thank to my parents, and family, your assistance and care throughout this year has allowed me to achieve to the best of my ability. 



\section{ABSTRACT}

Quality atmospheric conditions and the ability to empower residents has been overlooked in recent social housing developments as they have been strongly economically focused. The demand for inner city social housing within New Zealand has been a pressing issue since the first worker's dwellings were built in Petone.

Social housing residents are known for their comparatively low incomes and high needs, but this should not mean that they have to dwell in a different standard of housing from other income earners.

Social housing is a reality for a growing portion of our society in New Zealand; the location and quality of housing should not be defined by social stigma and hierarchy. Architecture as a discipline has unique potential to critique existing social housing standards and create diversity of atmosphere that evoke a sense of empowerment amongst residents.

This research explores the manipulation of hybrid prefabrication systems, with the aim of empowering social housing residents through diverse atmospheric conditions. 




\section{CONTENTS}

Acknowledgements $\quad$ v

Abstract 2

1.0 Introduction 1

1.1 Aims \& Objectives $\quad 7$

1.2 Research Scope 8

1.3 Methodology 10

2.0 Social Housing, Empowerment \& Atmosphere 13

2.1 New Zealand Social Housing 14

2.2 Wellington Social Housing 16

2.3 Literature Review 19

3.0 Case Studies 29

3.1 Introduction 30

3.2 Triangle Road 33

3.2.1 What is the project?

3.2.2 What are the atmospheric qualities?

3.2.3 What are the construction techniques?

3.2.4 Summary

3.3 Greta Point

3.3.1 What is the project?

3.3.2 What are the atmospheric qualities?

3.3.3 What are the construction techniques?

3.3.4 Summary

$3.4 \quad$ Regent Park

3.4.1 What is the project?

3.4.2 What are the atmospheric qualities?

3.4.3 What are the construction techniques?

3.4.4 Summary

$3.5 \quad$ Zavos Corner

3.5.1 What is the project?

3.5.2 What are the atmospheric qualities?

3.5.3 What are the construction techniques?

3.5.4 Summary

3.6 Conclusions 
4.0 Context Analysis $\quad 61$

4.1 Urban Analysis 63

4.3 Contextual Diagrams 69

$\begin{array}{lll}4.3 & \text { Conclusions } & 70\end{array}$

5.0 Design Processes 73

5.1 Hybrid Prefabrication 76

5.1.1 XLam CLT

5.1.2 Metrapanel

5.1.3 UniPod

5.1.4 Conclusions

5.2 Massing Studies 82

5.2.1 Scheme 1

5.2.2 Scheme 2

5.3 UniPod Configuration Iteration Studies 102

5.4 ServiceBox 105

5.4.1 The Problem

5.4.2 The Solution

5.5 Dwelling Development Iteration Studies cont. 116

5.6 Formal Studies 118

$\begin{array}{lll}5.7 & \text { Evaluation } & 122\end{array}$

$\begin{array}{lll}6.0 & \text { Design Outcome } & 127\end{array}$

$\begin{array}{lll}6.1 & \text { Block A } & 135\end{array}$

6.2 Block B 139

$\begin{array}{lll}7.0 & \text { Conclusions } & 147\end{array}$

7.1 Critical Reflections 149

7.2 Scope \& Limitations 152

7.3 Future Developments 153

List of Figures 156

$\begin{array}{ll}\text { Bibliography } & 164\end{array}$ 


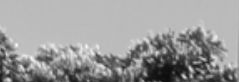
arontrats.

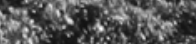
(6)

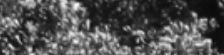

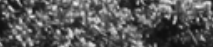
$4,4 \times 2$ 10:3isy

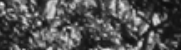
$x \rightarrow 2 \leq$ ans $4 x^{2}$ $7^{2}$ $\square$

s
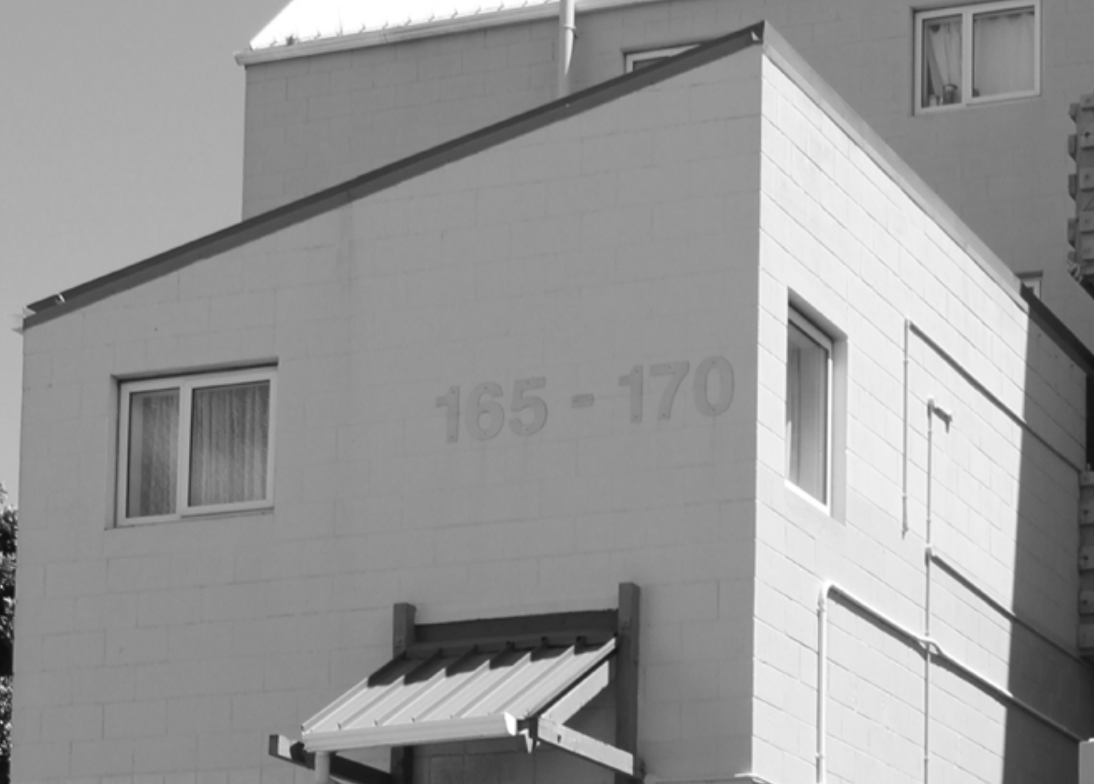

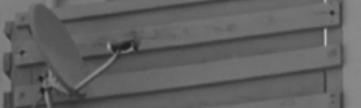

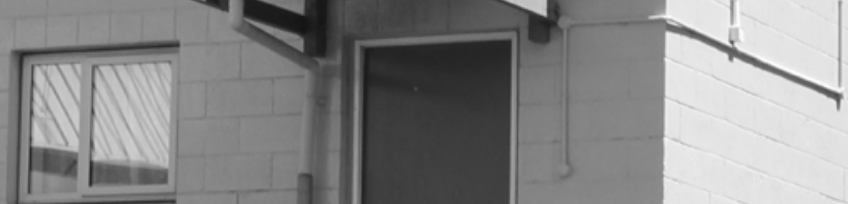

$\sqrt{\sqrt{\square}}$
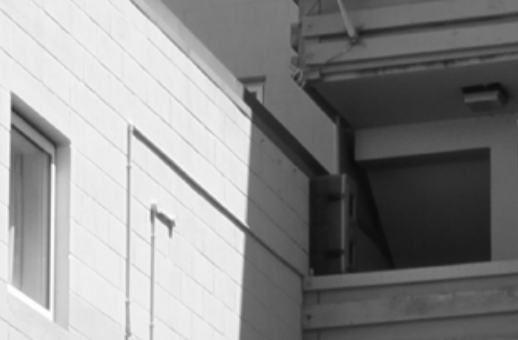

$\square$

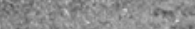

tinges

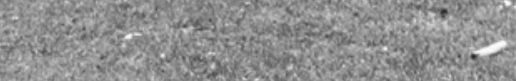

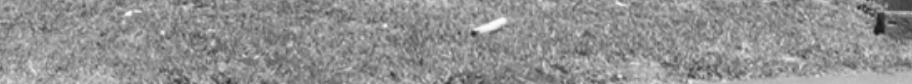

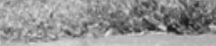
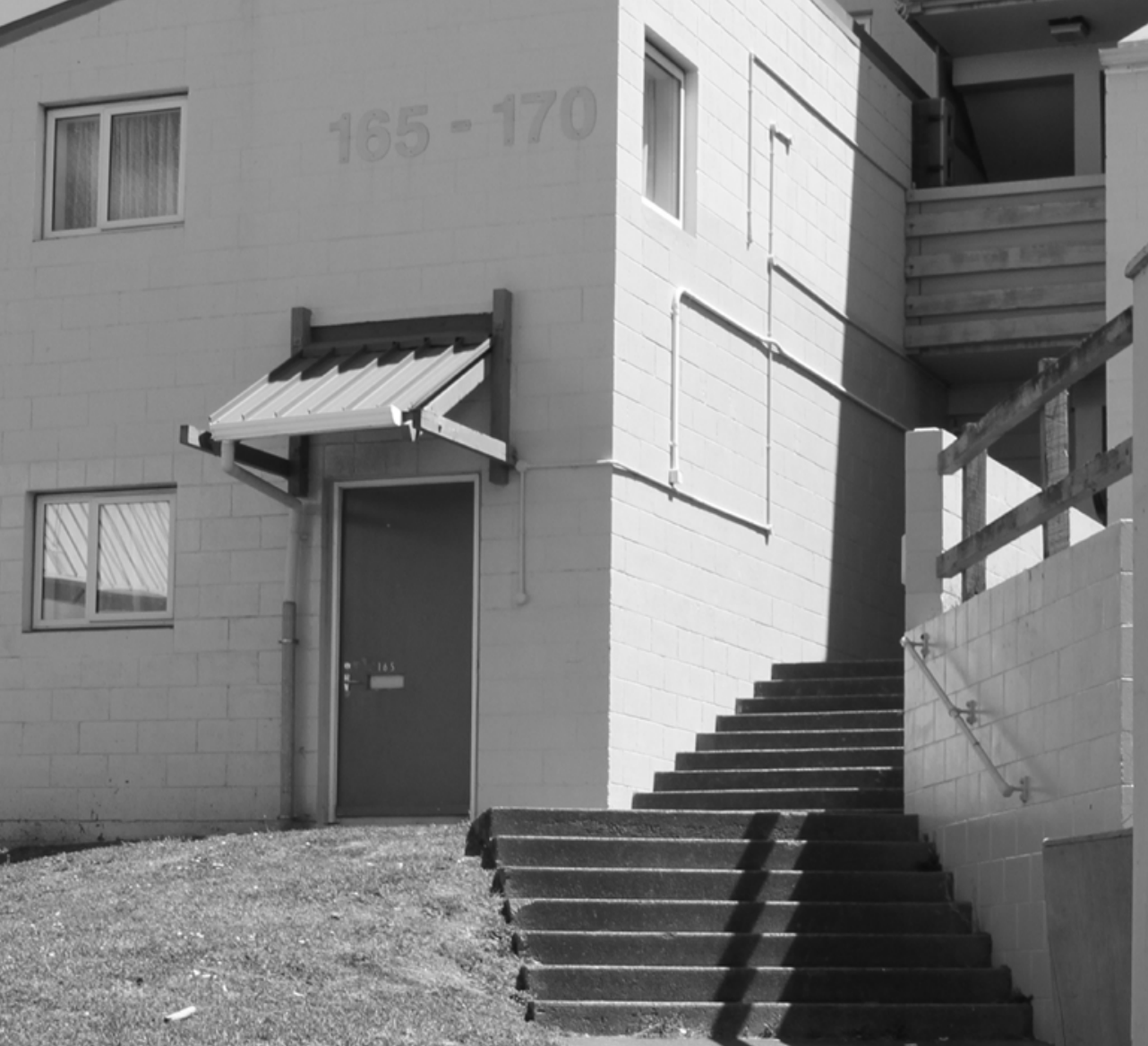

$$
-2, x+2,0
$$
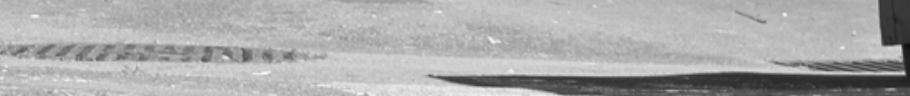


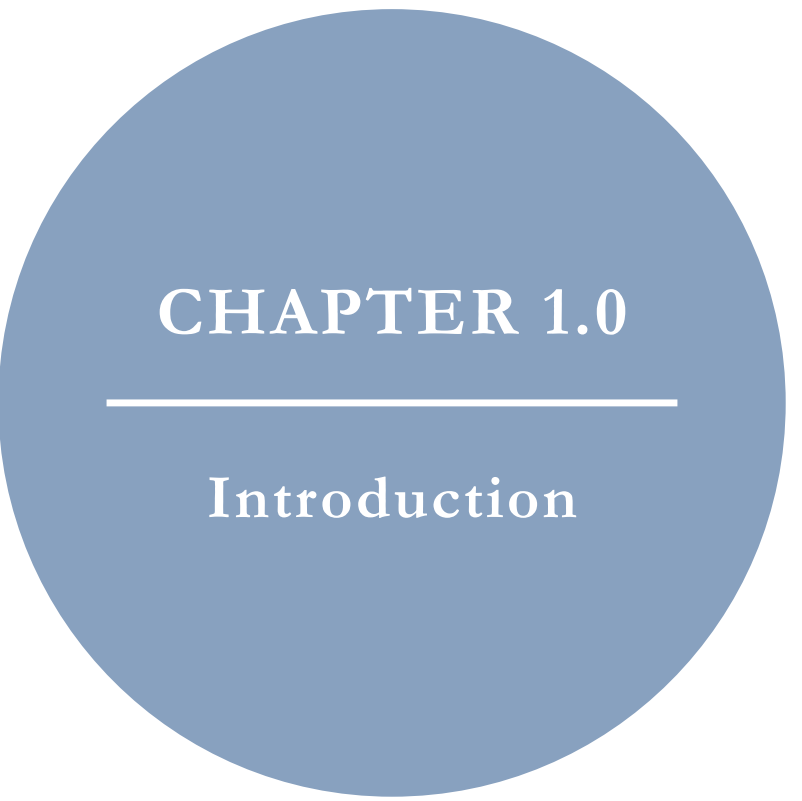


Over the last 30 years New Zealand has experienced a population growth larger than the world average, volatile immigration; an ageing population; cultural ethnic diversification; and a radical transformation of family structure. These factors all contribute to the increased demand for social housing (Housing affordability inquiry 82). The intensification of multiunit dwellings in Wellington has been one of the most rapid in the country.

Recent decades have witnesses a prefabrication and social housing shift away from each other disregarding the ideals of home and becoming more economically focused. Social housing tenants have comparatively low incomes and high needs yet developers are coming up short of their expectations. A significant body of research now affirms that providing a home for these tenants that meets their needs is a powerful tool in constructing an individual's identity and providing a sense of empowerment.

Despite this knowledge, social stigma's associated with prefabrication and social housing inhibit innovative design opportunities that may provide a sense of home. "The inquiry has... identified that the current approach to social housing in New Zealand will not provide sufficient support for many New Zealanders in need" (Housing affordability inquiry 5). Zavei and Jusan argue that "ignoring human motivational factors in home making may lead to individual and social dissatisfaction" (319). It is through prefabricated social housing that this research investigates how architects can provide quality atmospheric conditions to empower tenants.

Empowerment: | $\varepsilon \mathrm{m}^{\prime}$ paðəm(ə)nt $\mid n$.

1. To enable;

2. Potential given to someone to do something 


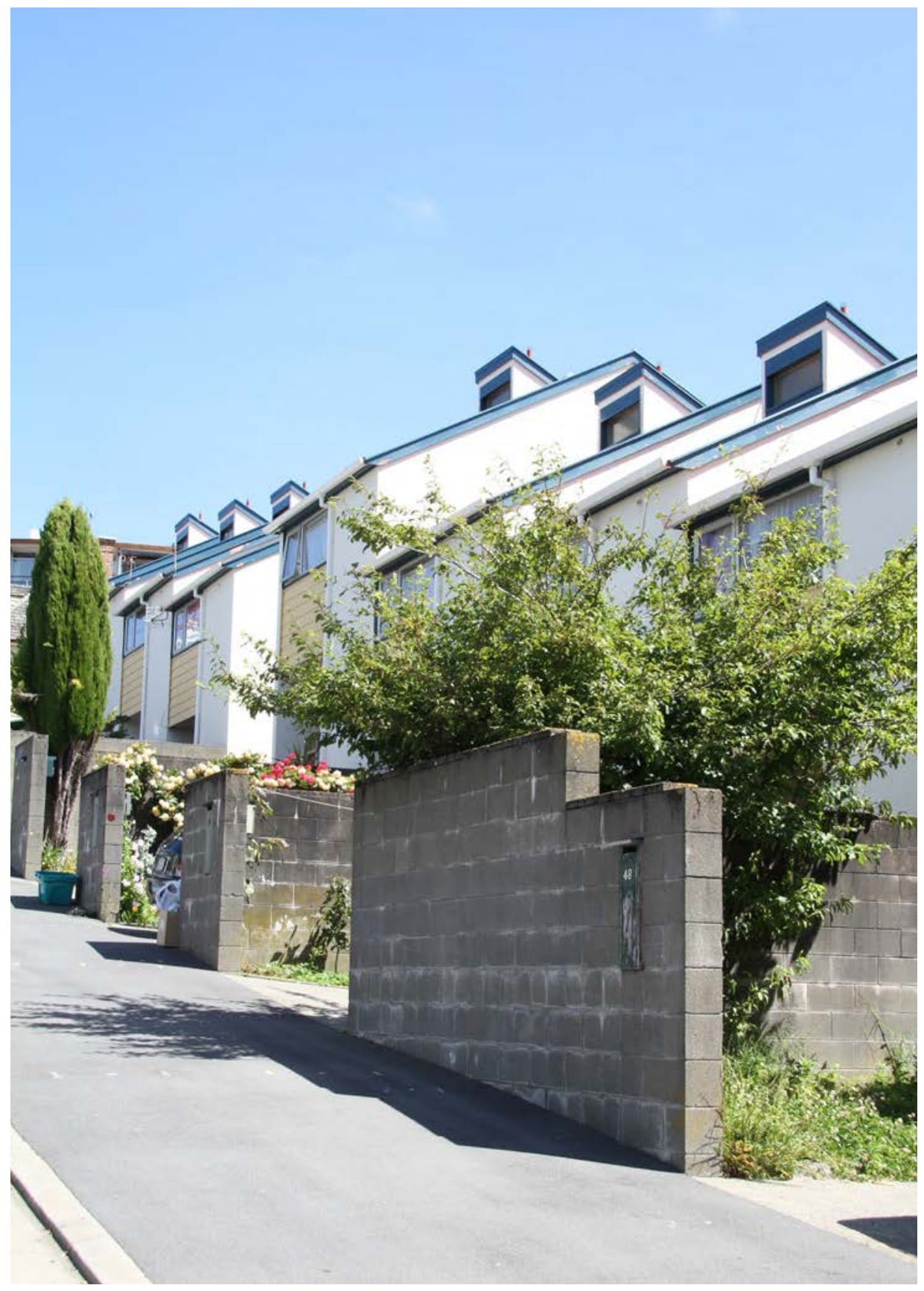

Figure 1.02. Nairn Street Council Flats in the process of redevelopment 

How might prefabrication be manipulated to create diversity of atmosphere to empower occupants of social housing? 


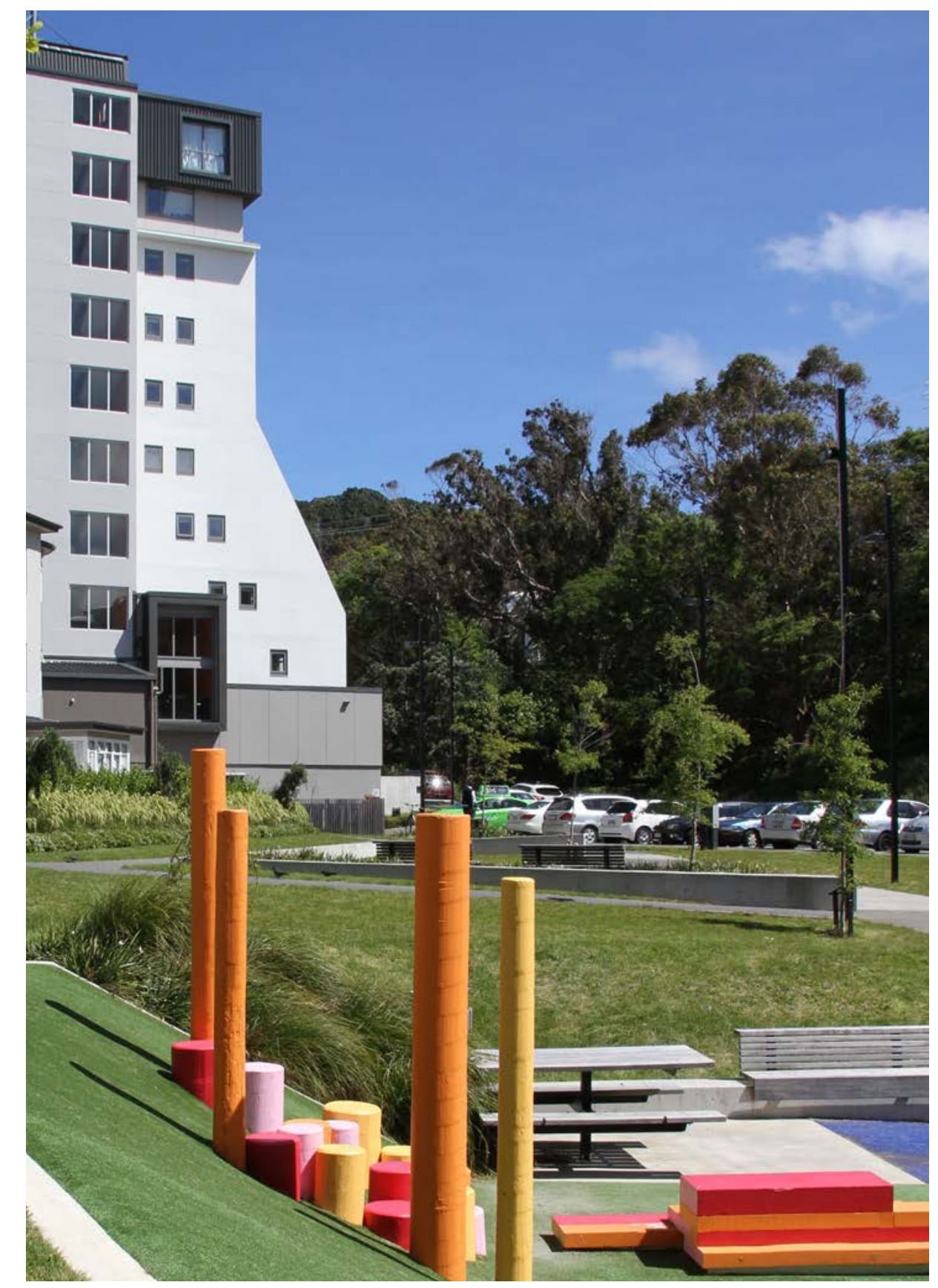

Figure 1.03. Central play park for various council housing in Mount Cook 


\section{1}

\section{AIMS \& OBJECTIVES}

The primary aim of this thesis is to identify what constitutes higher quality social housing that would empower residents by enhancing relationships.

This can be achieved through:

1. Diversity of atmosphere, within and outside the home.

2. A sense of empowerment, while providing a sense of security and community.

3. The opportunities of hybrid prefabrication and how these techniques can enhance the atmospheric conditions. 


\section{2}

\section{RESEARCH SCOPE}

This research focuses on the relationship between the built environment and the atmospheric conditions in social housing. Exploration includes the diverse atmospheric conditions needed to develop a sense of empowerment within the residents, and the opportunities of hybrid prefabrication methods.

This thesis explores how prefabrication can be utilised to provide quality construction with efficiencies that traditional construction cannot provide. The design solution for this research uses existing solutions to advocate universal design principles as best practice that can be used to establish a standard of the atmospheric conditions that can be achieved within this context of housing. 


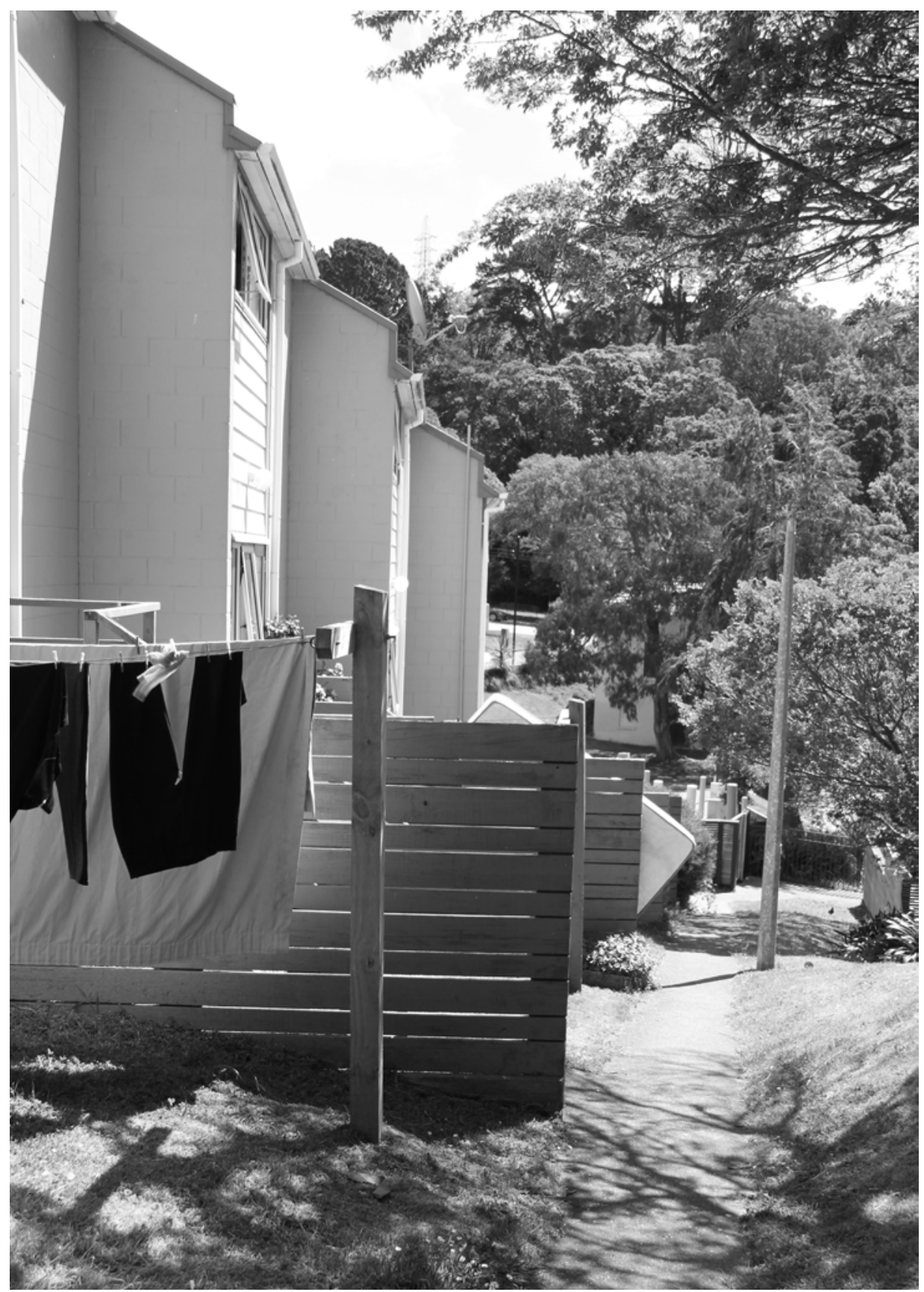

Figure 1.04. Nairn Street Council Flats outdoor space backs onto public walkway 


\section{3}

\section{METHODOLOGY}

The process behind this thesis is reflected through research and design experimentation at a series of key stages; firstly, a personal interest in prefabrication drove the design research into exploring issues of atmospheric conditions and empowerment in architecture. Secondly through literature review, in order to set up a design framework, thirdly to analysis a number of case studies against this framework to understand the effective solutions and the drawbacks of current multi-unit housing developments. Each of these key stages of research is responded through iterative design experimentation using sketching, digital modelling, digital diagramming, planning, programming and computer rendering of representative imagery.

Figure 1.05 illustrates the research process; highlighting the importance of each research stage. 


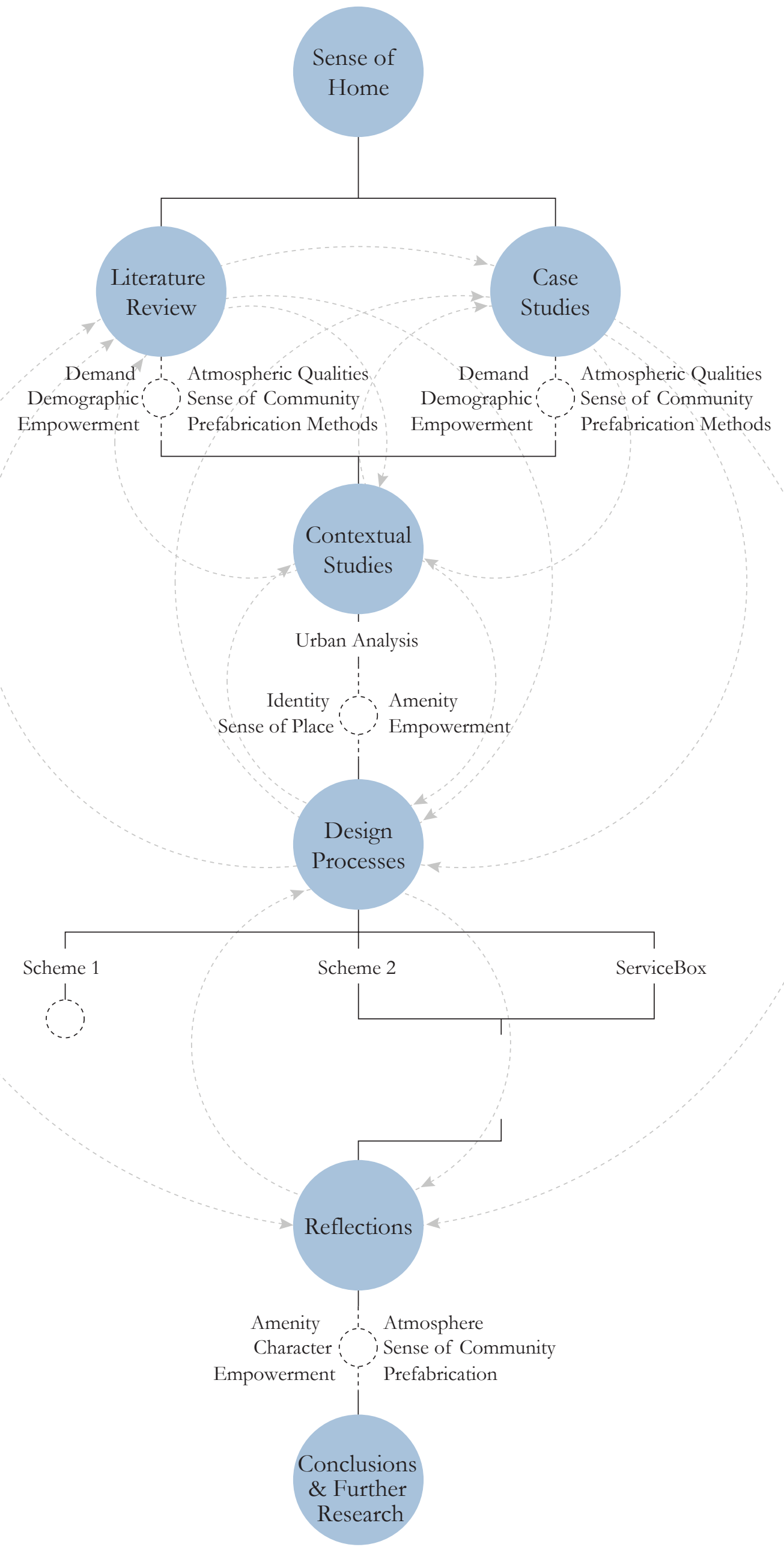




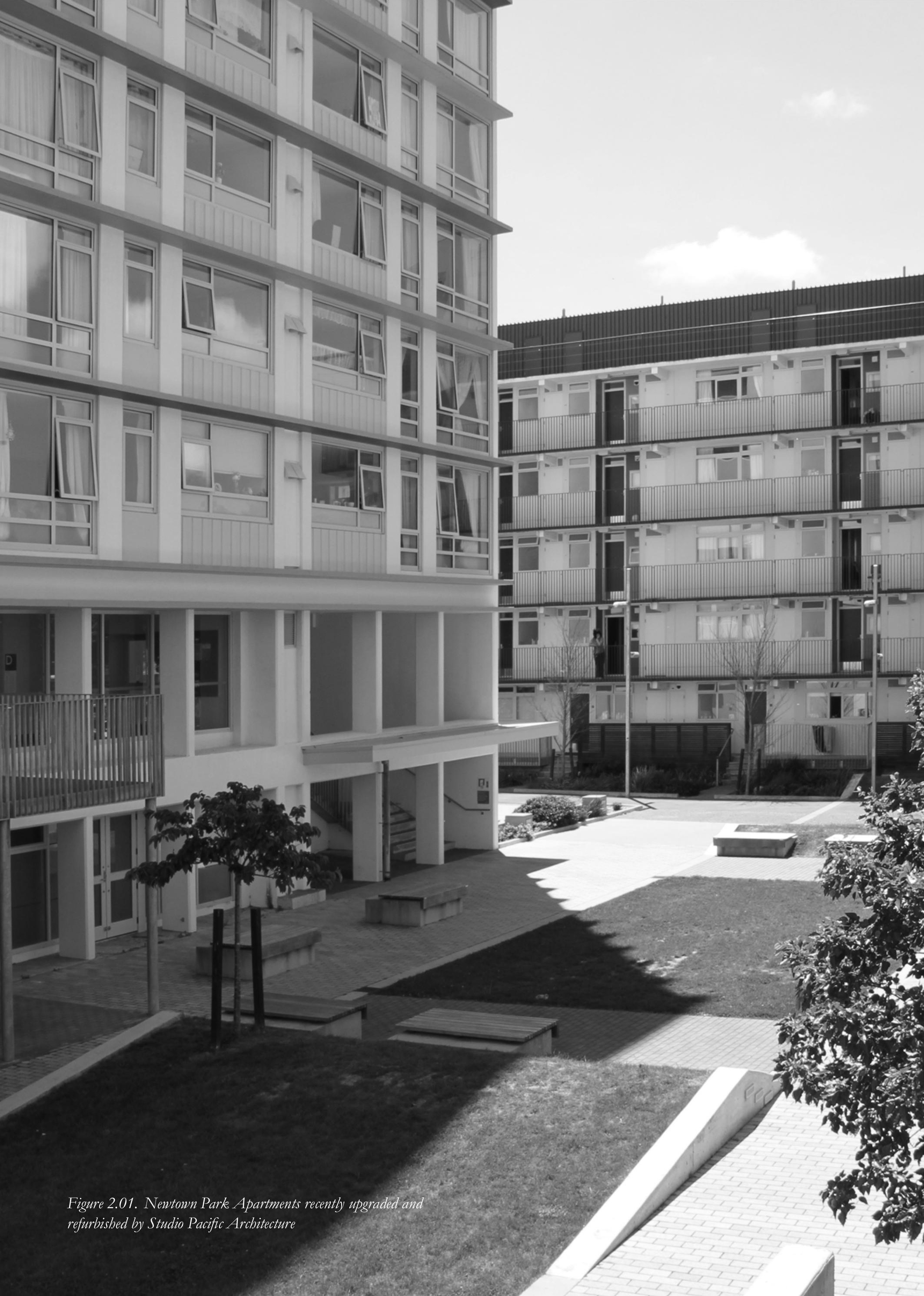


CHAP'TER 2.0

Social Housing, Empowerment, \& Atmosphere 


\section{1}

\section{NEW ZEALAND SOCIAL HOUSING}

\section{Background Analysis}

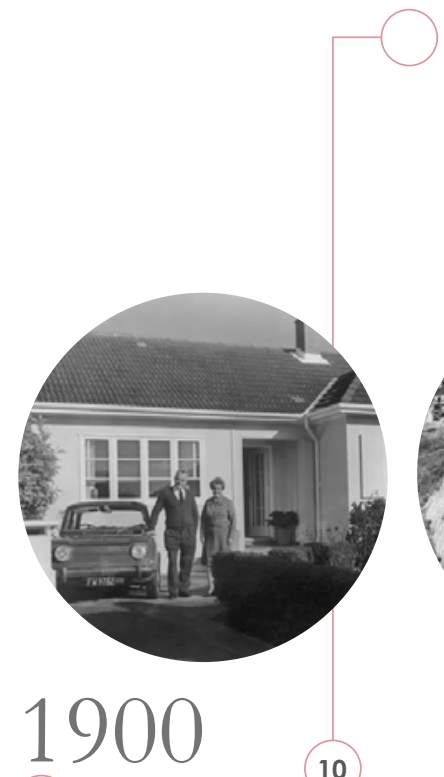

10

00

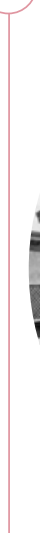
a new Workers' Dwelling Act.

Then withdraw it.

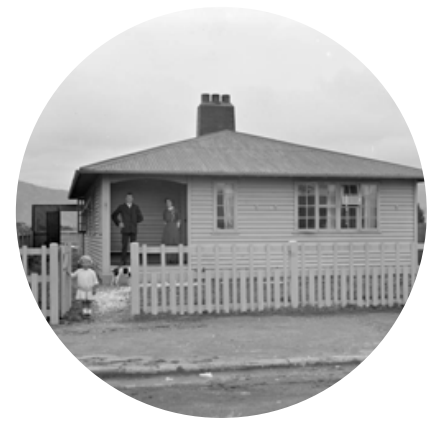

September 1937, Prime Minister opened the first state house in Miramar, Wellington.

1939 the first central city blocks, Centennial Flats, were established in Berhampore.

1923 saw new Californian bungalows spring up.

1920's the state was financing nearly half of the houses being built.

Railways programme

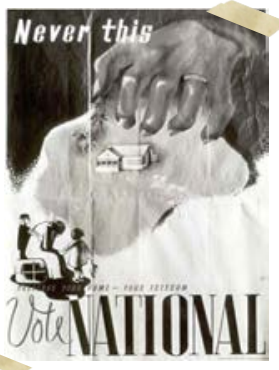

National promoted property ownership.

Labour governed 1957 and stopped state house sales.

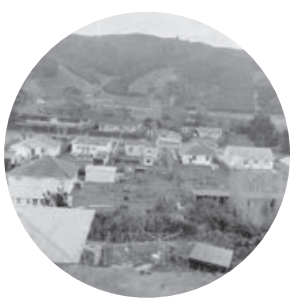

50

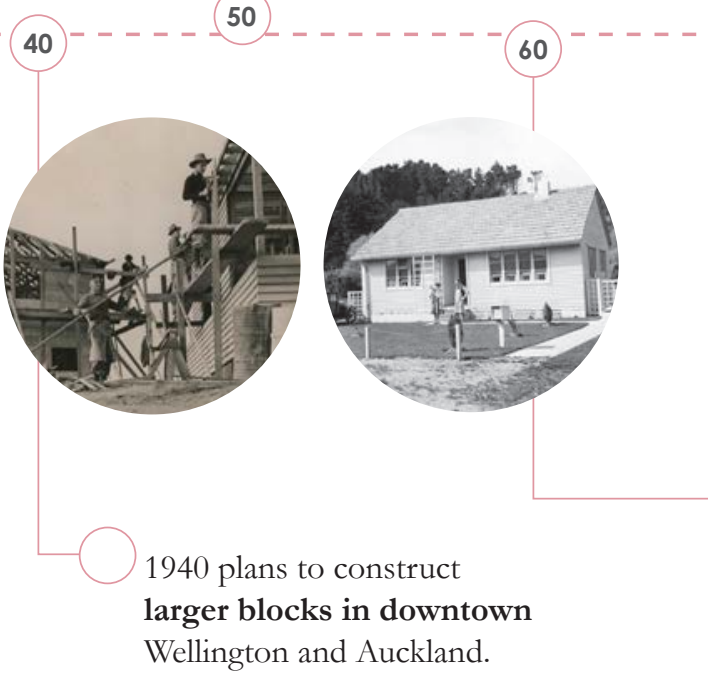

After 1944 the government began planning whole suburbs of state housing.

Workers dwellings were too far away and Worker's Dwelling was initiated. Act in 1905, erected in Patrick Street, Petone. failed to attract the people. 

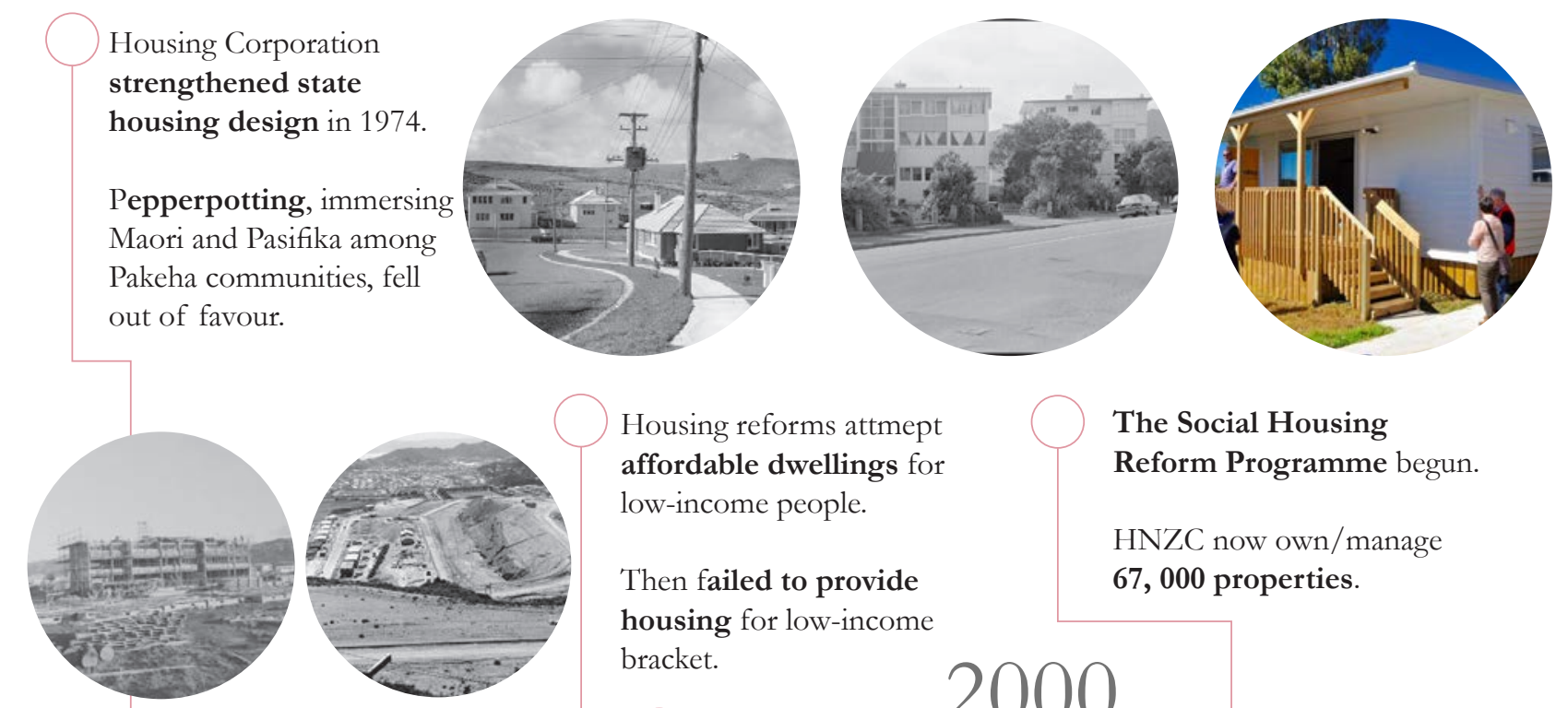

Housing reforms attmept low-income people.

Then failed to provide housing for low-income bracket.

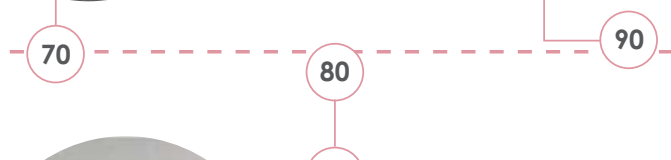
$\mp$ 베패패표

고

Housing would mix communities and blend state housing with private housing.

1969 survey concerning multi-unit living. Common areas, noise and privacy complaints.
Infill housing policy announced in 1986 to revitalise and reduce urban sprawl.

Petone dwellings protected - historical character in 1989.
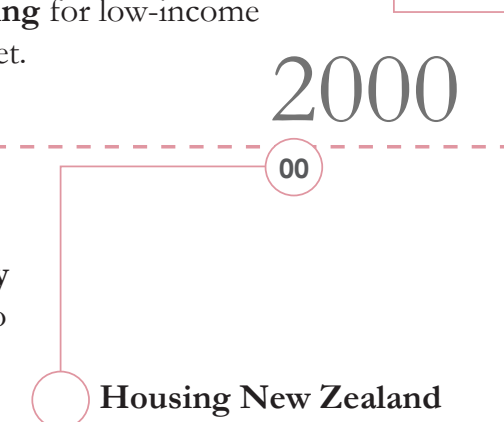

Housing New Zealand Corporations was established in 2001.

2005 , the centenary of state housing in New Zealand.
The Social Housing Reform Programme begun.

HNZC now own/manage 67, 000 properties.
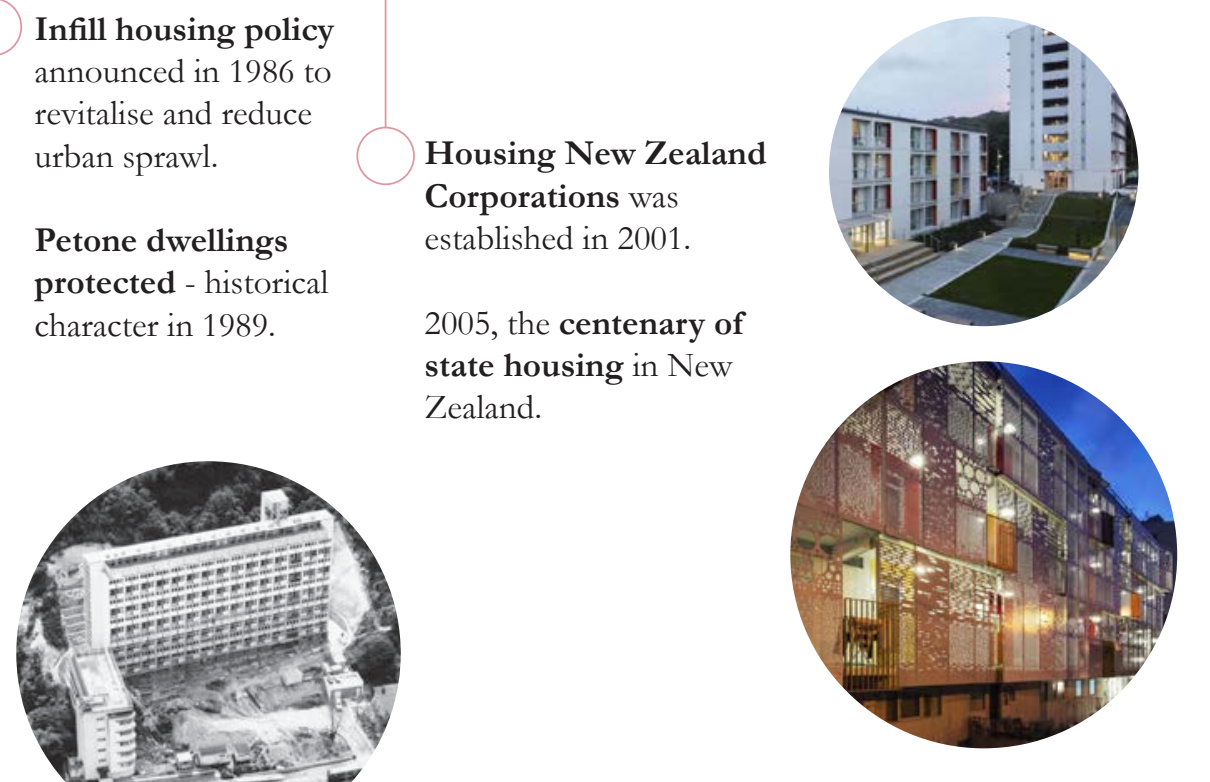

Figure 2.02. New Zealand Social Hosing timeline showing the progression of social housing in New Zealand from 1900 - today 


\section{2}

\section{WELLINGTON SOCIAL HOUSING Statistical Analysis}

In Wellington, the intensification of multi-unit dwellings has been one of the most rapid in the country, yet $51 \%$ of families living in New Zealand housing stock have reported major problems with their house or neighbourhood (Housing affordability inquiry 45-46).

The following statistics highlight the demand for social housing in Wellington City that is yet to be satisfied as recorded from the 2013 census data:

\section{1}

Families needing Social

Housing in Wellington

\section{9}

1 \& 2 bedrooms required within Wellington City

\section{3}

Families in need of housing are rated Priority A

A suitable living environment is made possible by meeting users' needs and preferences. It is necessary to investigate into the current social housing statistics appreciate the relationship between architectural attributes and the users' needs, to achieve a sense of home. Zavei and Jusan argue that the lack of attention to human motivations in housing originates from the diverse lifestyle and variety of needs (312). Today tenants are multi-cultural, with low-wage employment or no employment, and some physically and mentally affected re-established into the community; all relying on government support. It is important to design for the diverse needs of these tenants to be able to provide a sense of empowerment and an attachment to a community. 

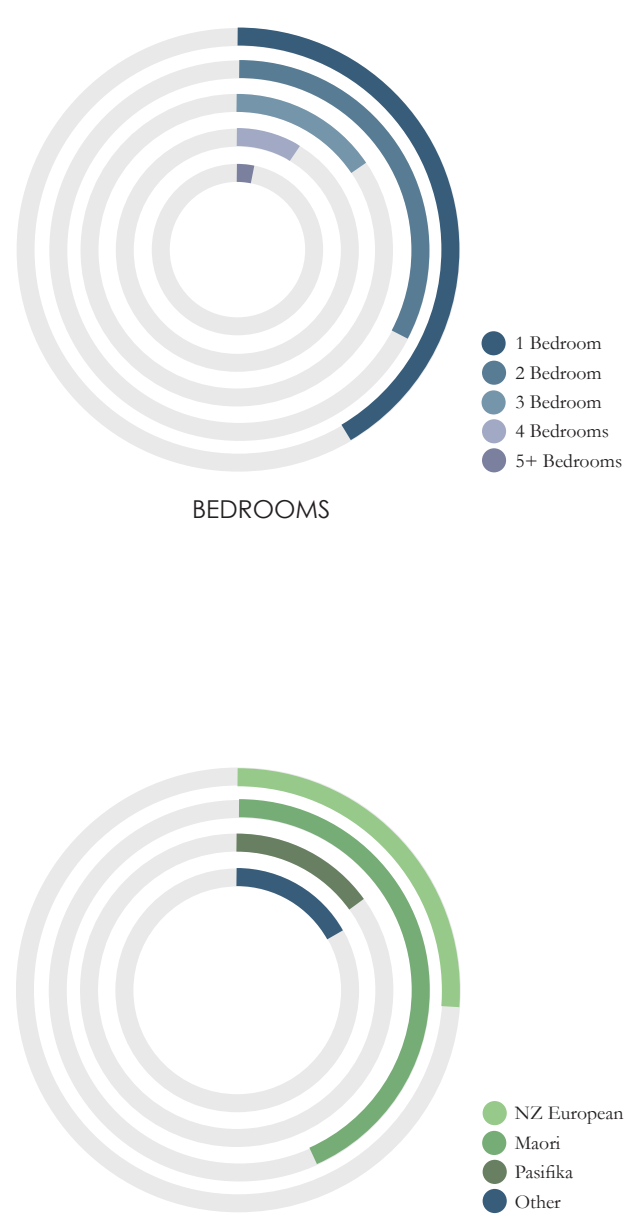

ETHNICITY

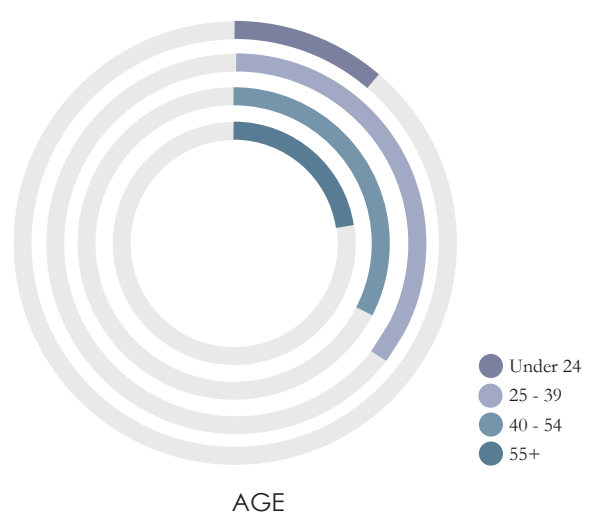

Figure 2.03. Graphs indicating the demographic in need of social housing within Wellington City 


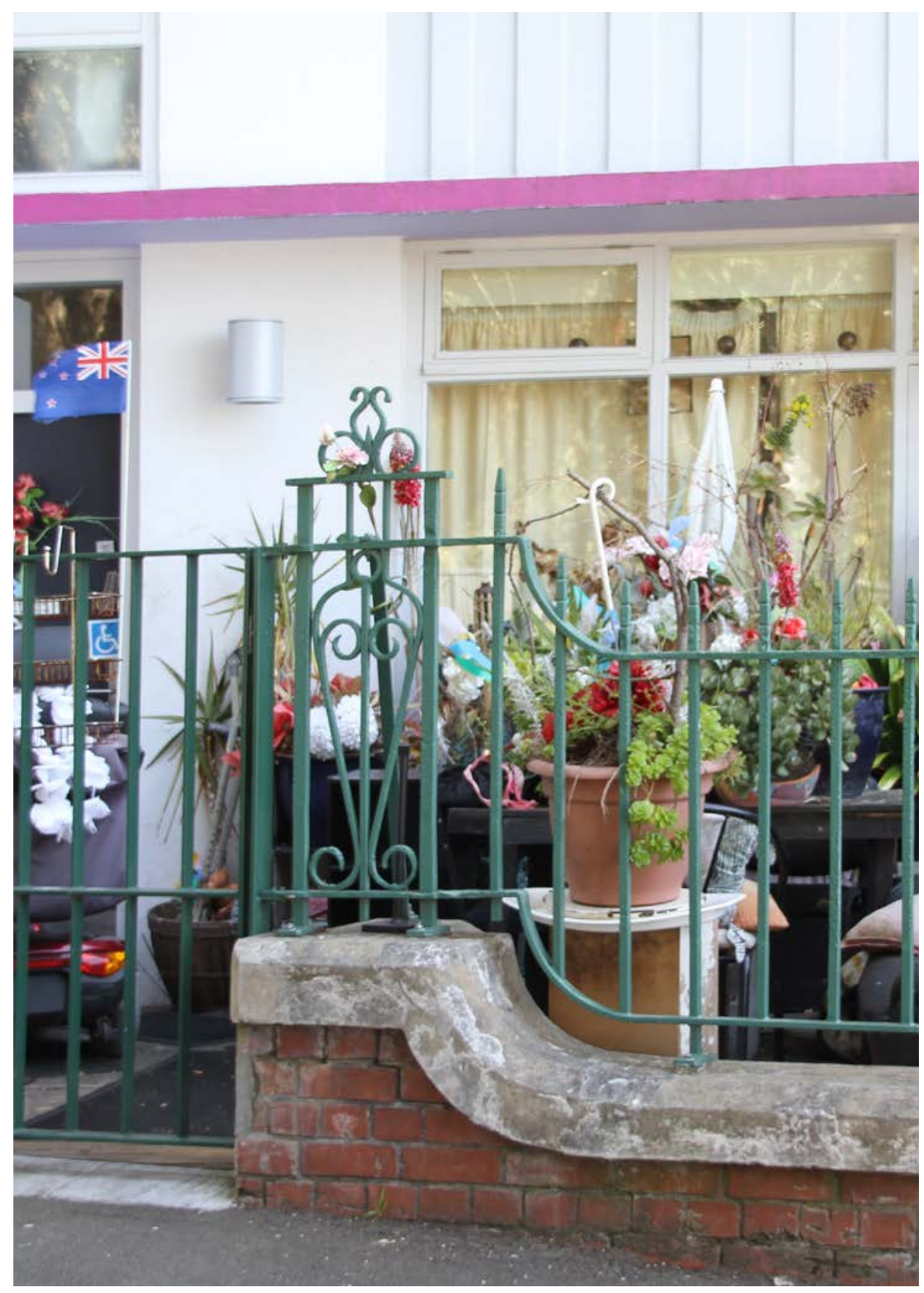

Figure 2.04. A tenants personal touch on their outdoor court in the Newtown Park Apartments 


\title{
2.3
}

\section{LITERATURE REVIEW}

\author{
New Zealand culture \\ Prefabrication is a method of construction \\ embedded into New Zealand culture. Since the \\ beginning of New Zealand settlement prefabrication \\ can be linked to influences from the pre-1800 \\ Maori and early European settlers. The early 1900's \\ saw prefabrication and social housing become \\ intrinsically linked with high quality construction, \\ materiality and a sense of home that was established \\ throughout New Zealand.
}

Today, it is those very qualities that are sought after within a home and yet developers are coming up short of expectations. As of recent prefabrication and social housing seem to be growing further apart leading to the demise of the desire for this type of housing. The concept of social housing has evolved from the 1900's single detached dwelling to today's medium density developments. However, the issue of creating quality affordable houses, especially within urban areas continues to be a problem (Schrader 7). Throughout the history of social housing in New Zealand we see this type of housing become densely configured units and move away from its traditional construction technique of prefabrication.

\section{Prefabrication stigma}

"It is important to establish a strong awareness surrounding prefabrication if it is going to flourish within New Zealand. The public, the industry and the government must be educated to develop a positive outlook on prefabrication within New Zealand". 
Prefabrication is increasingly seeking to abolish the social stigma associated with such housing and one significant way this is being attempted is with no compromise in the quality of construction. It is our experiences with temporary prefabricated classrooms and mass-produced kitset homes which are responsible for the social stigma associated with this type of construction and have led to a negative overview of prefabrication in New Zealand (Bell and Southcombe 41). It is the inferior atmospheric conditions associated with social housing that stigmatises it and has inspired the body of this research; as architects how can we design to empower social housing tenants through quality atmospheric conditions?

As the industry is in the slow process to abolish this stigma, it is important that prefabrication can provide an opportunity to make architecture as accessible, affordable, and sustainable for a wide demographic of New Zealanders as well as meeting the requirements for improved standards in materiality and construction.

\section{The role of prefabrication}

There are challenges to abolishing the stigmas associated with prefabrication that would promote widespread application of these methods in New Zealand. No one method of prefabrication will solve the issues of the construction and housing industry. A collaborative approach of multiple systems is more likely to develop increased efficiencies needed in this industry.

High standards of construction and quality are being achieved in medium-high income brackets but these same standards are not applied to low-income housing. Traditional construction methods are increasingly viewed as cost efficient as the time into prefabricated systems are considered time consuming and unachievable. However, traditional construction methods can be slow, unpredictable and there is 
more room for error. Architects Stephen Kieran and James Timberlake argue that the traditional construction methods are governed by one rule:

$$
\mathrm{Q} \text { (quality) } \mathrm{x} \mathrm{T} \text { (time) }=\mathrm{S} \text { ( scope) } \times \mathrm{C} \text { (cost) }
$$

These four factors are not amiss in prefabricated construction. Prefab. can offer more for less, as shown in figure 2.05 , to provide the quality of housing that satisfies the ideals of home.

Zumthor speaks in a poetic way about the collection of different materials in this world available to architects and designers to combine for creating better quality spaces (23). This notion alerts to "a way of bringing separate parts of the building together so that they formed their own attachments", to enable an expressive nature. This is a concept that can be applied to prefabrication; a collaborative system of building materials and components, integrated beautifully, so spaces are not defined entirely by its construction methods but by the collaborative nature of the materials and the components they form (Zumthor 43). Utilising various prefabrication systems, while focused on a collaborative approach, beings to create a diverse materiality palate, which in turn "react with one another ... so that the material composition gives rise to something unique" (Zumthor 25).

\section{Social housing stigma}

The stigma associated with social housing in New Zealand has developed a 'stamp' that we put on certain housing or neighbourhoods that is of a lower standard to those in its surroundings. Typically, these housing developments are pushed out of the cities and into the suburbs as inner city land is believed to be too valuable for such housing. Hobsonville Point, a new development in suburban Auckland, is an example of valuable land that was initially meant

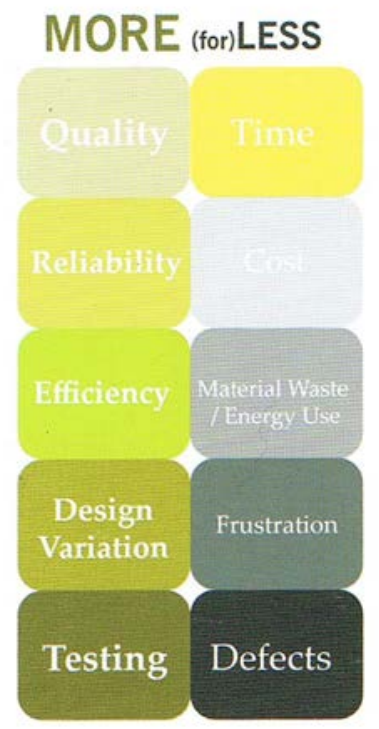

Figure 2.05. Prefab can offer more for less chart (Bell and Southcombe 38) 


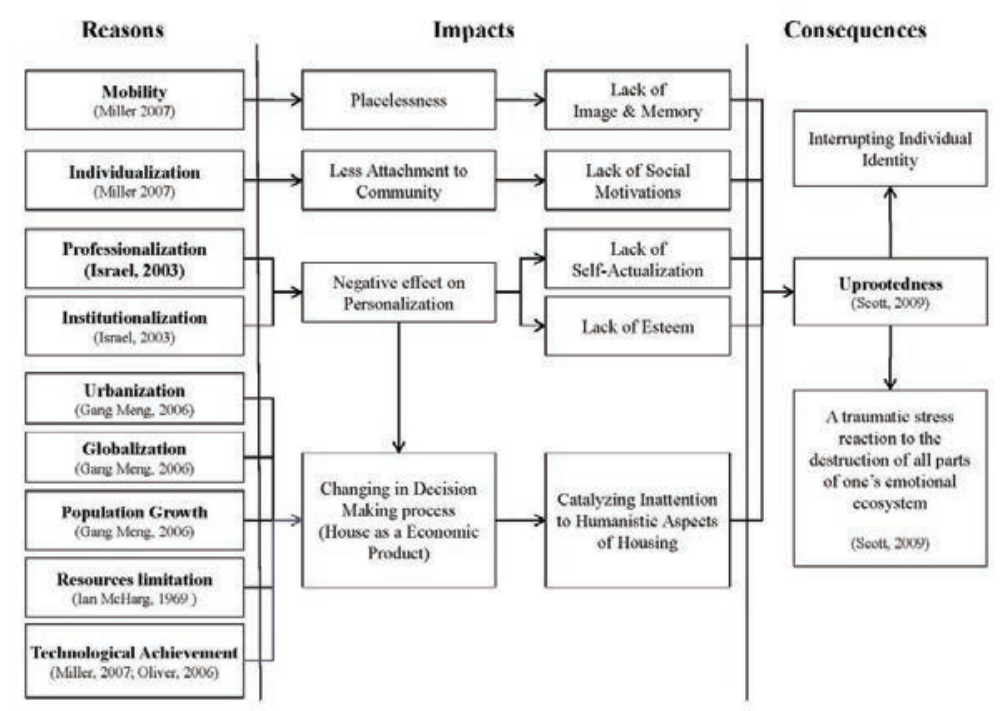

Figure 2.06. The reasons behind inattention to human motivational factors and the consequences (Zavei and Jusan 313)

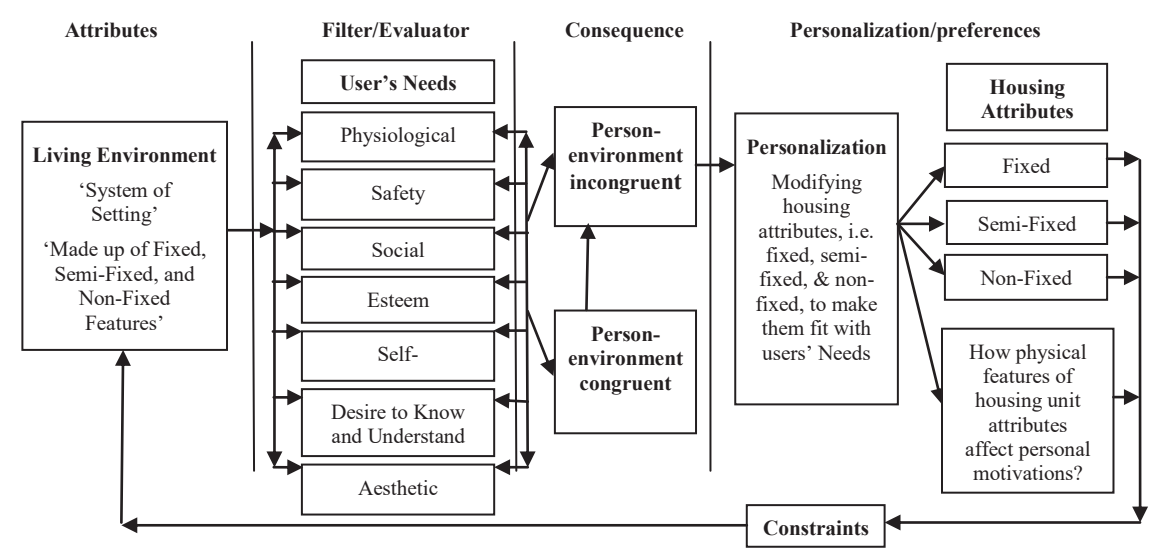

Figure 2.07. Theoretical model of personalisation in built environment (Zavei and Jusan 317) 
to develop a mixed community of affordable and social housing. The social housing aspect of his development has since been removed to provide around 4,500 affordable houses for families and retirement living (Schrader 31).

Social housing is a reality for a growing portion of our society and their location and quality of housing should not be defined by social stigma and the economic hierarchy within our society. It is evident that atmospheric ideals can be achieved in higher income housing yet these standards are not being transferred to social housing. Theory indicates that "the major shortcomings of current houses remains their inability to fully satisfy the needs of residents" (Zavei and Jusan 312). Abolishing social stigmas associated with social housing is the beginning of providing housing that empowers residents.

\section{Empowerment}

The empowerment of occupants and the humanistic aspects of living in has gradually decreased as social housing has become an economically focused product (Zaver and Jusan 312). A framework for future social housing must provide a balanced approach between the four well-beings of community; economic, social, environmental and cultural. (Bierre et al. 70) Linking Maslow's hierarchy of needs to the built environment, directs one to housing that has the potential to meets these criteria and supports a balanced approach to housing. Such an approach is influential in constructing an individual's identity, evoking a sense of empowerment and strengthening their sense of responsibility to society (Zavei and Jusan 312), in other words happier and healthier tenants.

The architect has an imperative role in developing a sense of dignity for the occupants where "space becomes place" (Kennedy 43). Social housing tenants have comparatively lower incomes and higher needs, however standards and quality of housing

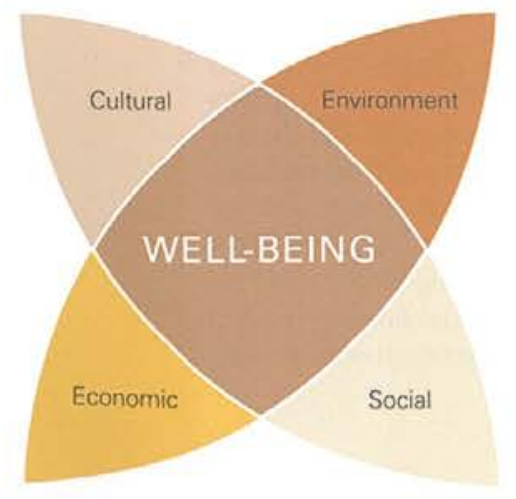

Figure 2.08. The 'four well-beings of community sustainability' model (Bierre et al. 70)

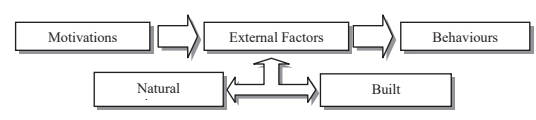

Figure 2.09. External fields as a transition between motivations and behavior (Zavei and Jusan 313) 
should not differ from other income earners.

Maslow's theory on human motivation explains the different levels of needs without superficial differences by focusing on the origins of human needs and by highlighting a universal definition of the motivations that drive human beings, as seen in figure 2.06. With these personal factors linked to the environmental conditions, personal motivation and empowerment of the occupants is achievable (Zavei and Jusan 313).

\section{Atmospheres}

It is accentuated in various literature that atmospheres are "perpetually forming and deforming, appearing and disappearing, as bodies enter into relation with one another. They are never finished, static or at rest" (Anderson 79). Literature from Wigley, Anderson and Böhme begin to describe atmosphere as something that is 'indeterminate' and 'intangible' surrounding buildings, clinging to material objects and emanating from objects and form as "some kind of sensuous emission of sound, light, heat, smell and moisture" (Wigley 18).

For Zumthor, it is an attentiveness to the atmosphere and mood that is an inevitable responsibility of the designer. Spaces can be described as "a 'ritual place,' ... a 'system of symbols,' a communicator of ideas" (Kennedy 43). Home is to offer a haven for its occupants while being able to communicate with viewers, residents, visitors as well as the immediate neighbourhood (Zumthor 7). Various literature has led to the identification of these generators as figure 2.10 identifies and shows the cyclical affect that they have on each other. 


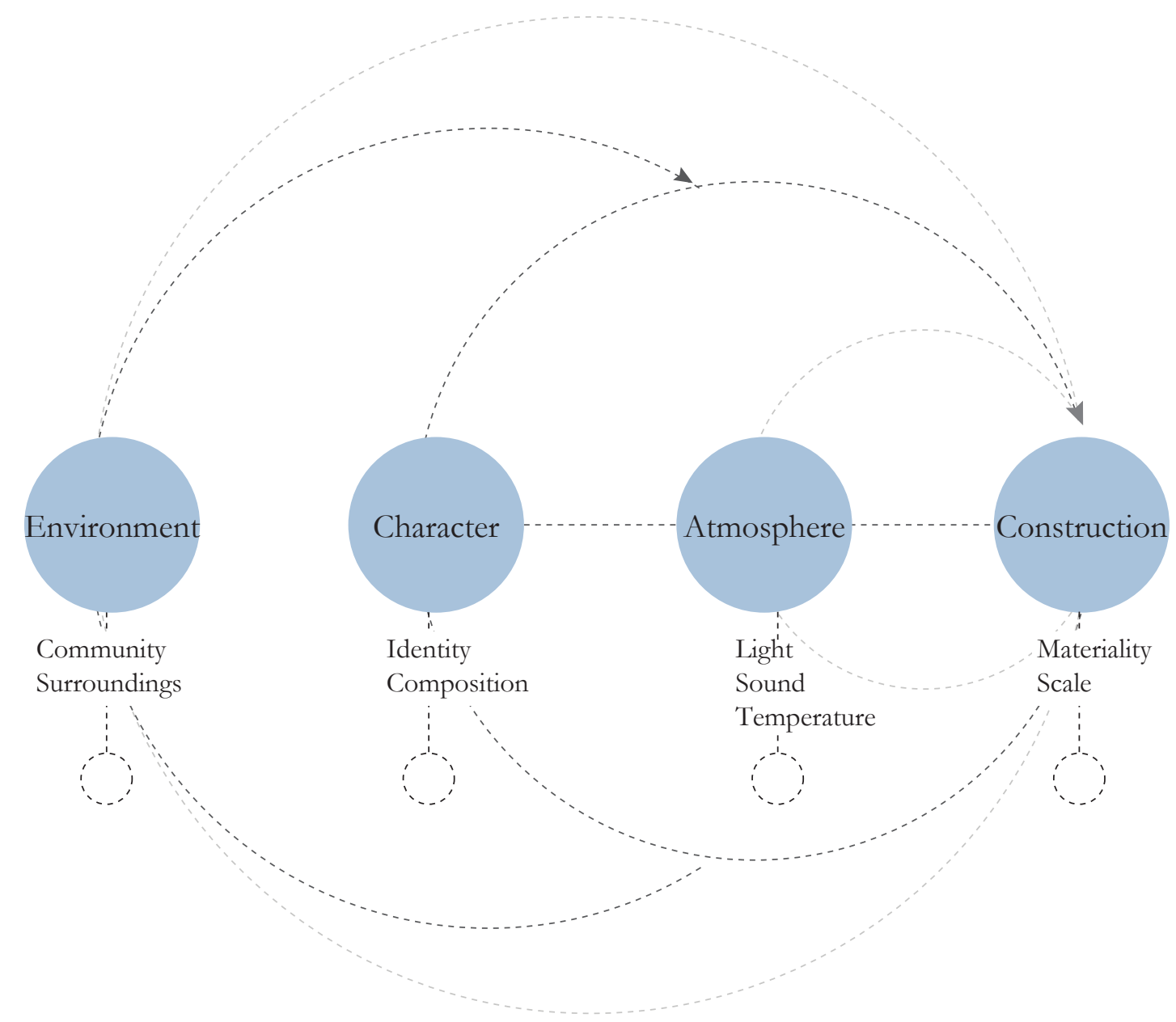

Figure 2.10. The four key aspects that are the atmospheric generators important for social housing and the cyclical affect each aspect has on each other 


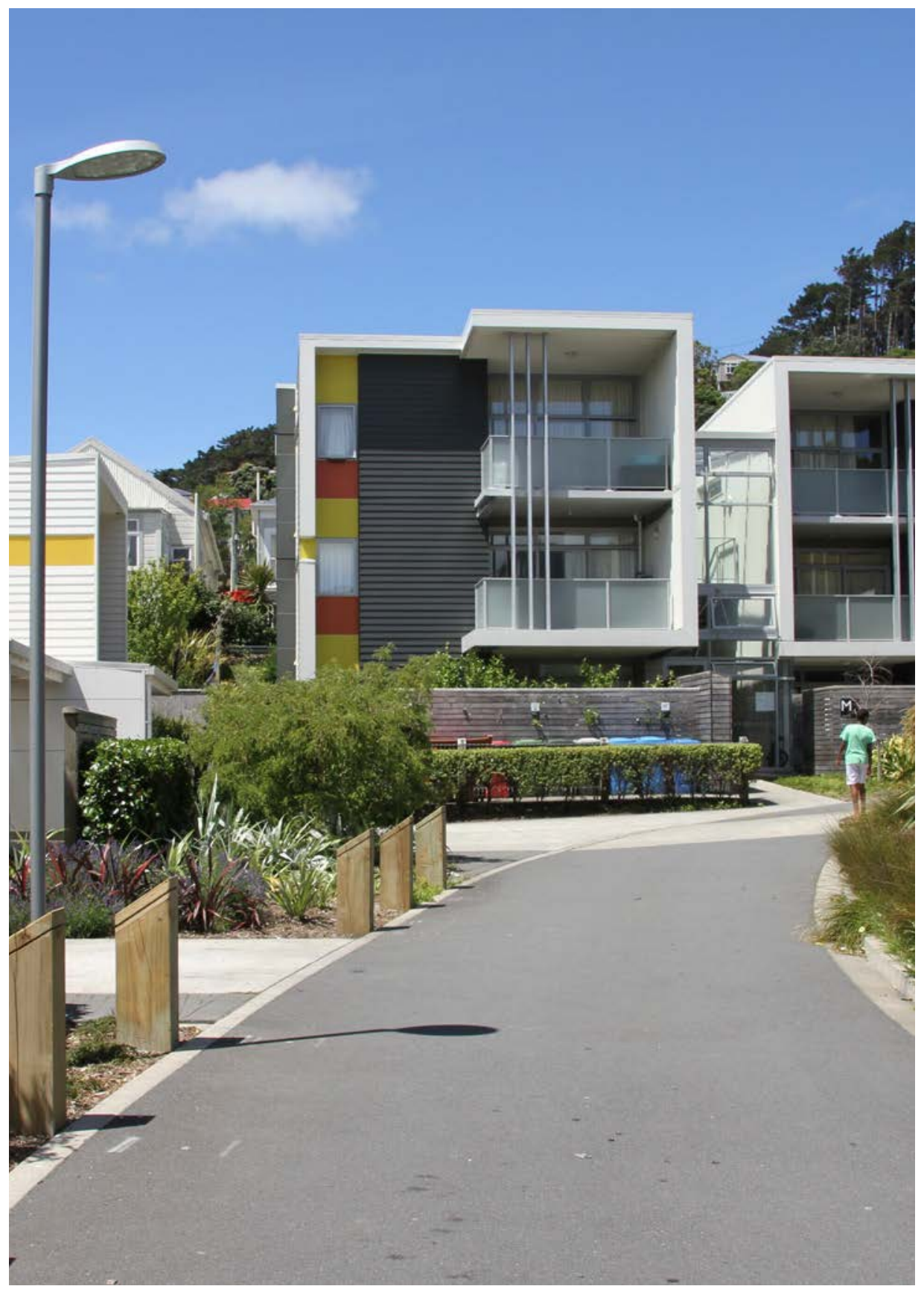

Figure 2.11. Regent Park was a new build that was a part of the Wellington City Council Housing Upgrade Project. 


\section{Conclusions}

This research has established:

a) the opportunities quality prefabricated systems offer social housing and for achieving modern medium density spatial ideals through better atmospheric conditions;

b) Social housing in New Zealand is economically driven and not meeting the atmospheric desires of its residents, leading to a lack of empowerment across this demographic;

c) atmospheric generators that empower residents and the community can be identified to define the positive atmospheric qualities desired for social housing.

This literature reviews the undeveloped potential for architectural research to explore diversity of atmosphere within social housing, providing an opportunity to empower and improve the lives of social housing tenants. 

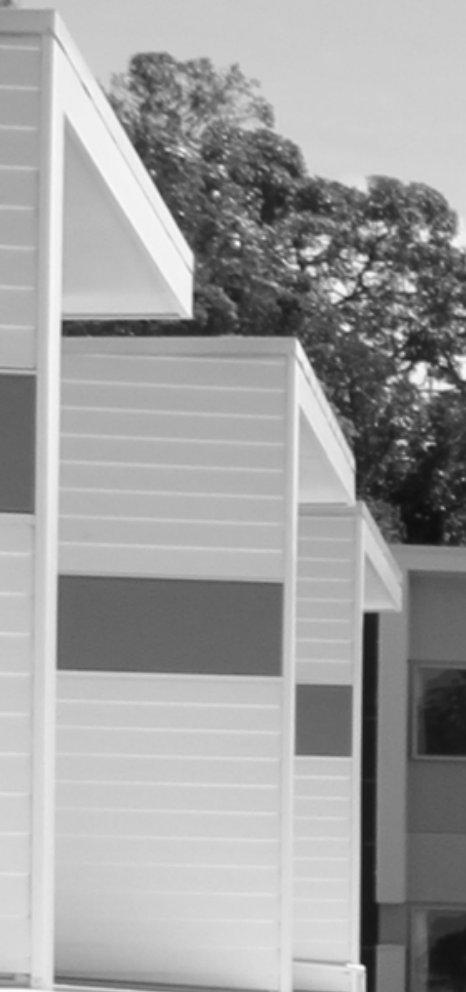
CHAPTER 3.0

Case Studies 


\section{1}

\section{INTRODUCTION}

Four different medium density housing precedents were researched to inform the design research:

1. Triangle Road

2. Te Aro Pā papakāinga

3. Regent Park

4. Zavos Corner

Critical reflection on these examples is an opportunity to identify potential design objectives concerning social housing, prefabrication, a sense of empowerment and atmospheric quality; for example, natural light, space planning, individualisation and architectural identity.

\section{Design Framework}

Focusing a wide range of ideas from literature reviews to those which are most relevant to this research has produced the following criteria. These criteria will serve as a framework to guide the design research the research objectives and review each case study.

Each criterion selected is seen to provide humanistic aspects to a living environment, and contribute towards a sense of empowerment. This framework provides a set of goals to drive the design development process, as well as creating a test to measure the success of design outcomes. 


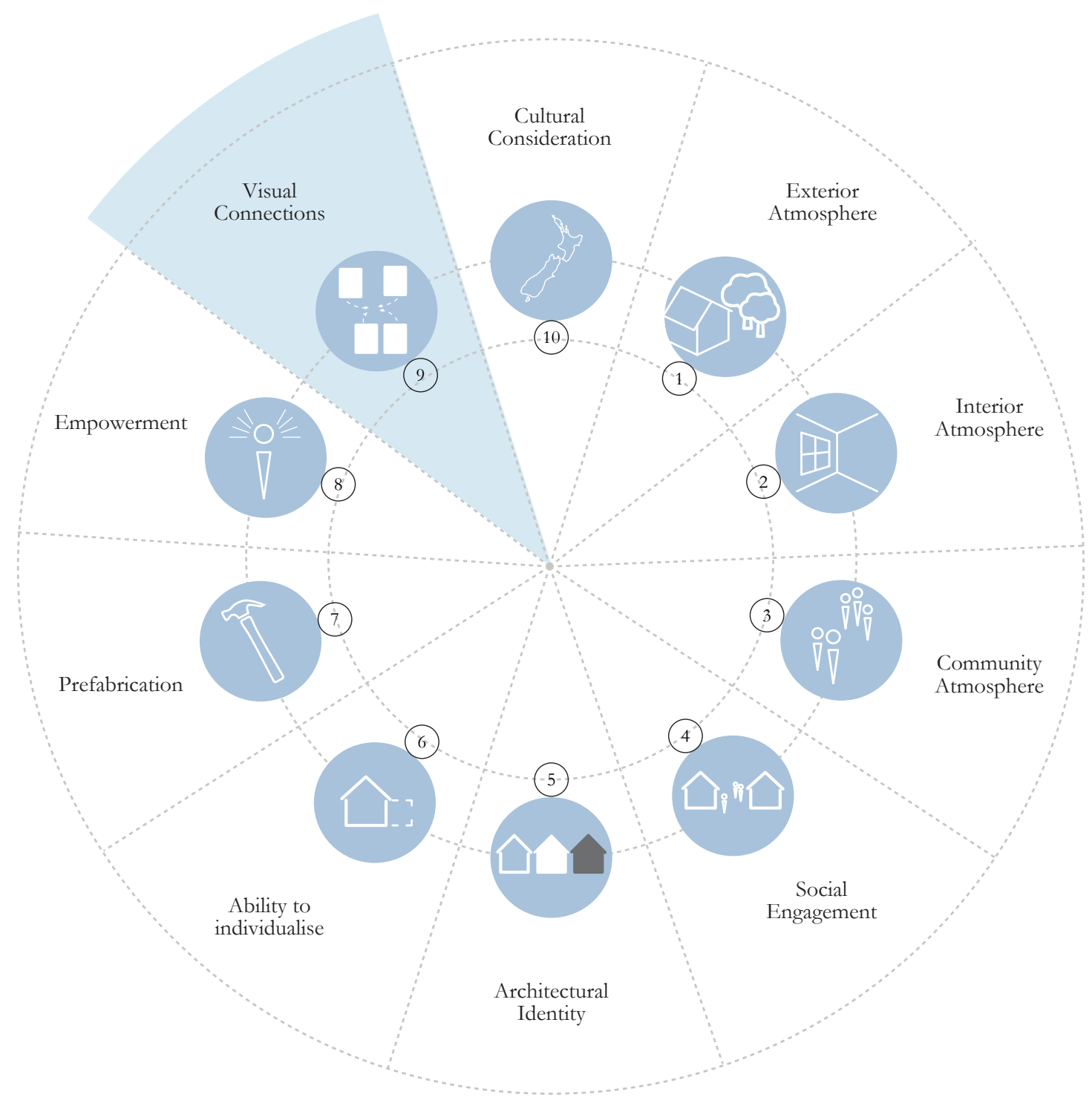

Figure 3.02. Design framework to evaluate the selected case studies, showing a seleced segment 

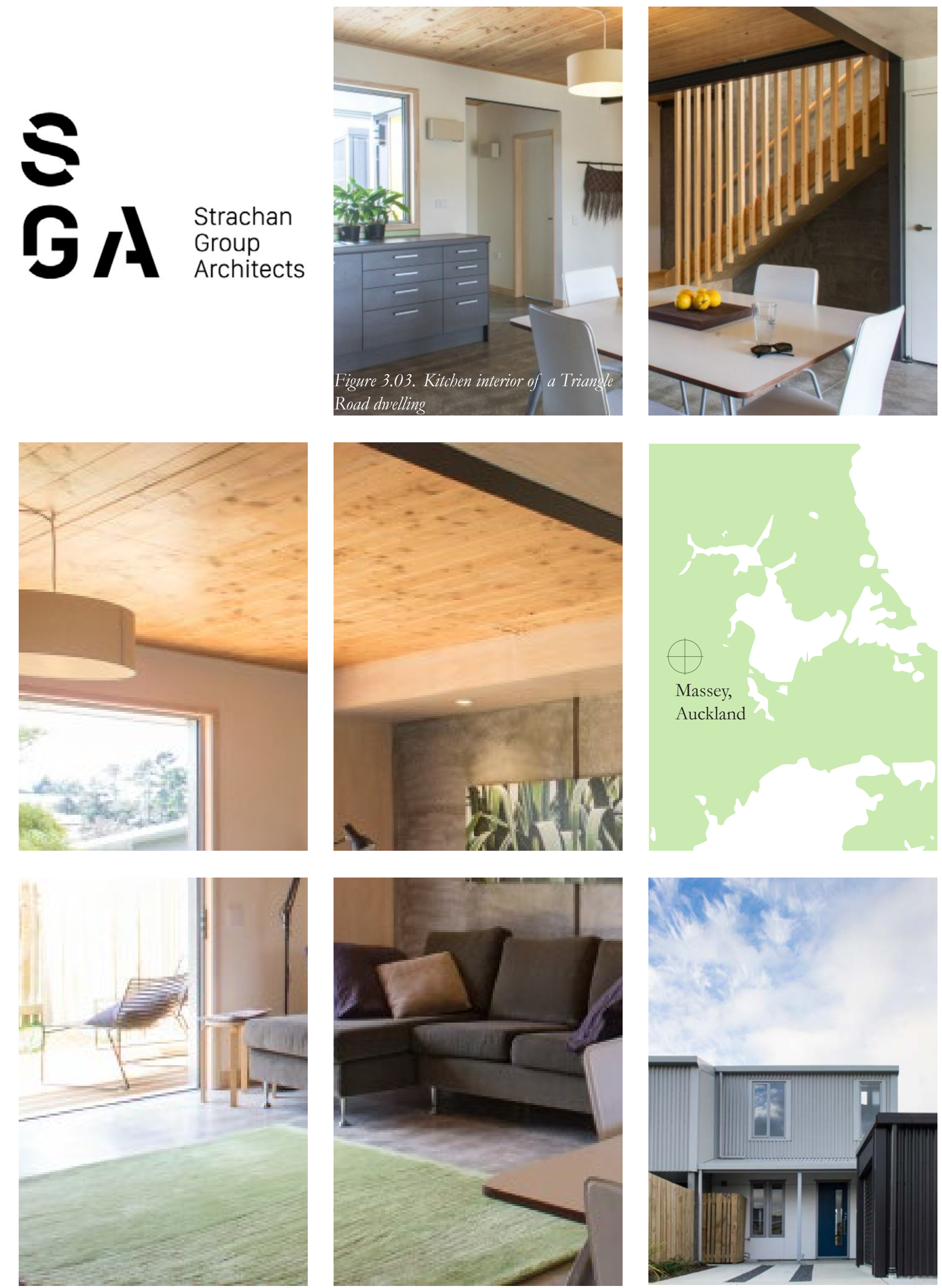

Figure 3.04. Living interior of a Triangle Road dwelling

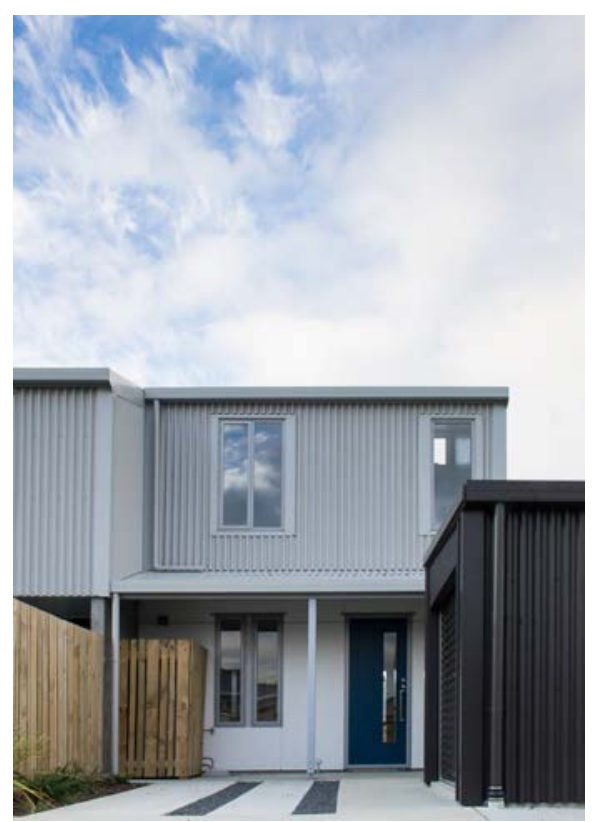

Figure 3.05. The homogenous exterior of Triangle Road dwellings 


\section{2}

TRIANGLE ROAD, Strachan Group Architects

Architect: Strachan Group Architects

Location: Triangle Road, Auckland

Size: 2, $200 \mathrm{~m}^{2}$

No. Dwellings: 10

Density: 45 dwellings per hectare 


\subsubsection{What is the project?}

Triangle Road is a Community Housing project for VisionWest Community Trust who offer community based services to some of West Auckland's most vulnerable residents. This project was designed to satisfy a number of objectives around construction methodology as well as offering an alternative approach to medium density housing in Auckland ("Triangle Road Community Housing" Community; sec. 1).

\subsubsection{What are the atmospheric qualities?}

Community: The community objectives of Triangle Road were "to provide greater opportunity for social interaction, passive surveillance and a greater sense of community" (Vision West Community Trust 1). This has been a successful aspect of the development that brings the occupants closer together while creating a community atmosphere that evokes a sense of pride. Each dwelling has a stepped façade entry that creates a focal entry point to each dwelling, however the materiality has a homogeneous aesthetic creating a row of housing that looks identical.

Exterior: The external atmospheric qualities of Triangle Road are not as successful at their interiors. The materiality and homogeneity of these dwellings develops a repetition that has no variation other than the depth of the façade. This alternating façade depth begins to relieve the eye as well as creating recessed individual entries for the dwellings. The aesthetics and materiality of the exterior don't provide a significant architectural identity; this could have been accentuated more through materiality, as well as height or form variations.

Interior: The interior atmospheric qualities of these dwellings offer much to be desired for prefabricated social housing in New Zealand. The interior treatment of the dwellings has helped to show that 

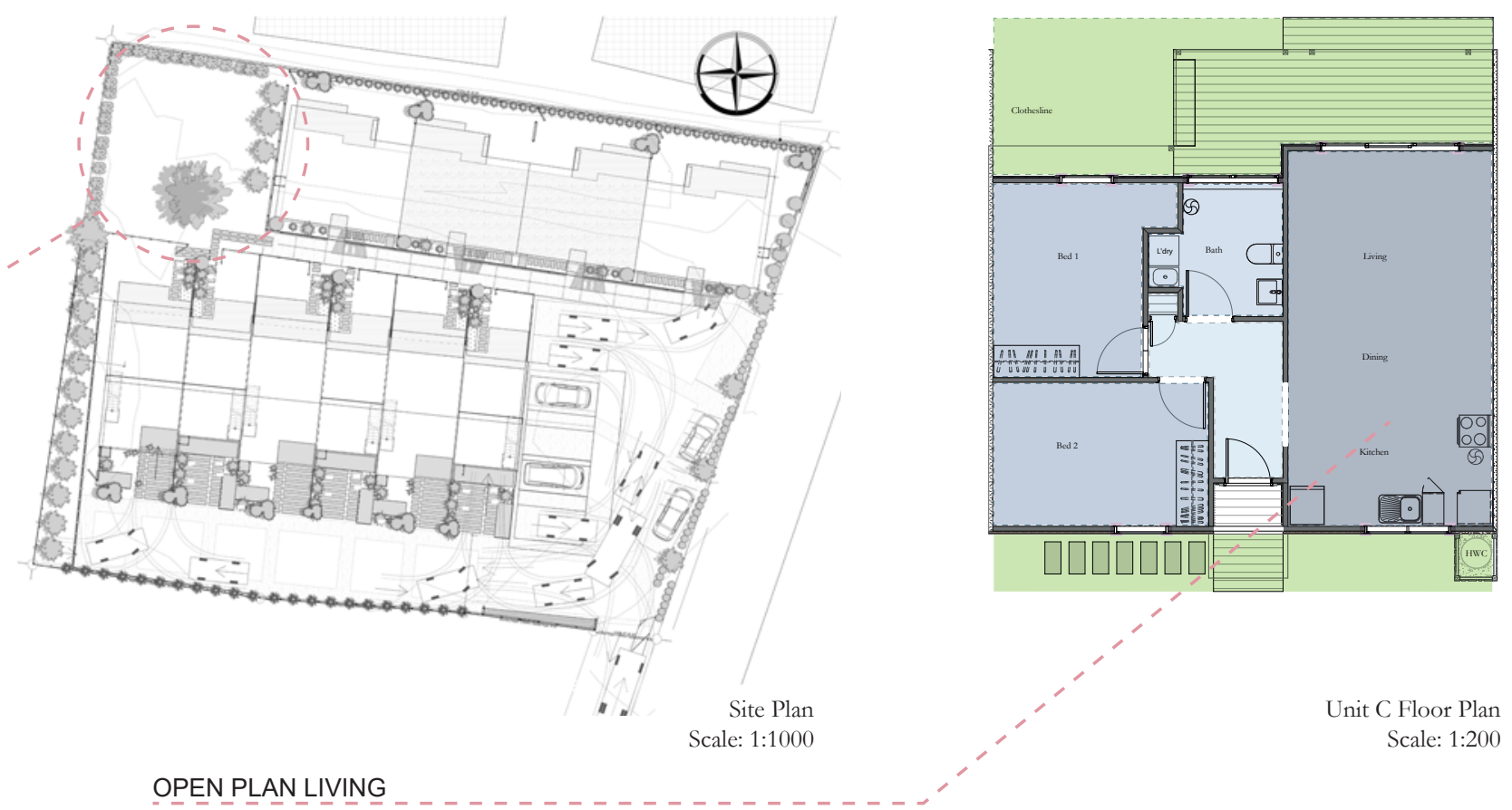

OPEN PLAN LIVING

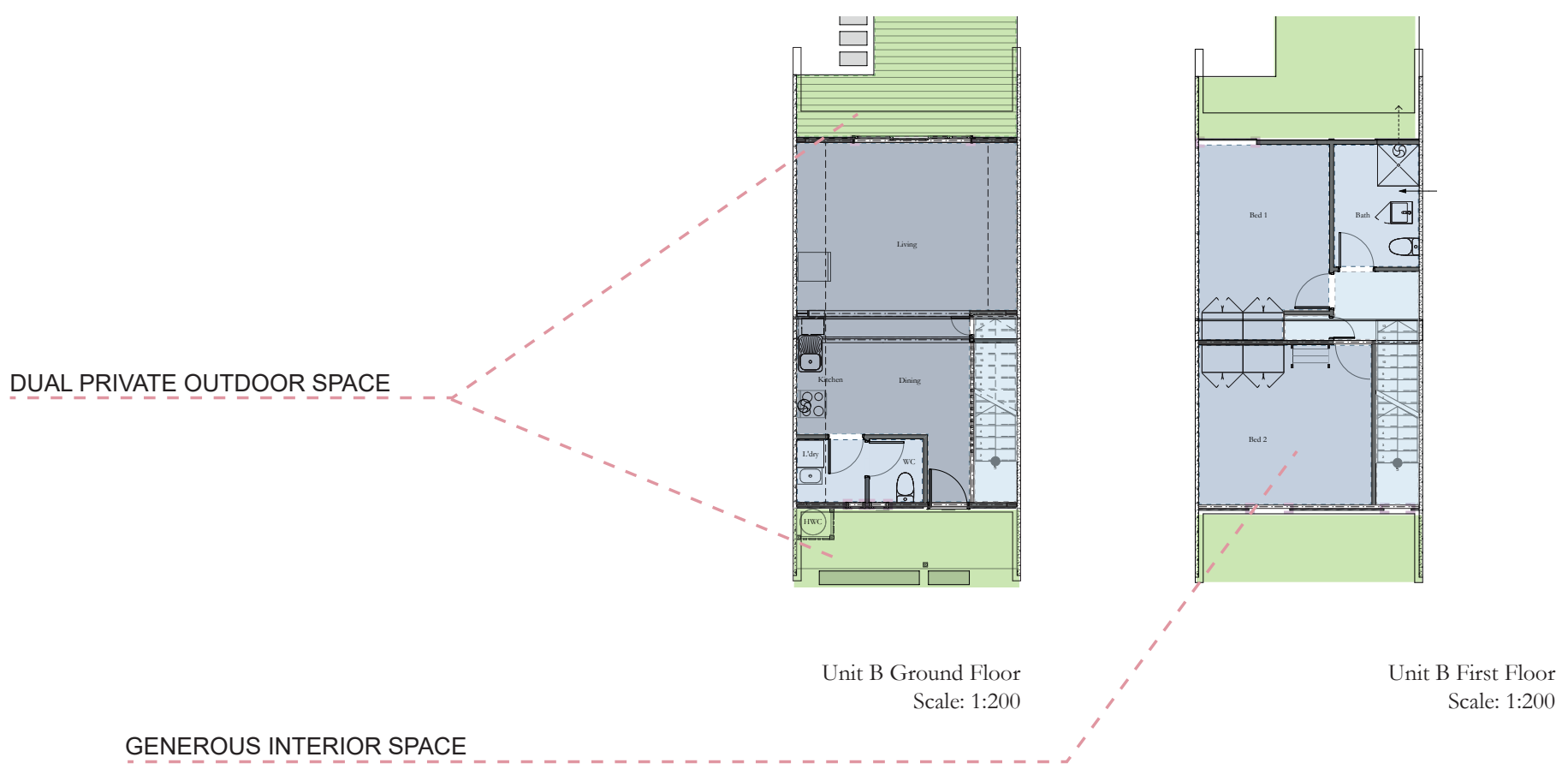

Figure 3.06. Site and floor plan analysis of Triangle Road 
atmosphere can be achieved within social housing and that construction systems have the ability to aid the aesthetics instead of controlling them. A successful sense of depth and spatial quality have been designed with the exposure of the primary structure, a warm material palate and light, bright open spaces. These dwellings have a compact footprint on their site but have been able to create light spaces to a high quality.

\subsubsection{What are the construction techniques?}

Triangle Road uses prefabrication methods to aid in their objectives around construction speed, innovation, and thermal performance. The primary structure of these dwellings are comprised of concrete floors, precast concrete inter-tenancy walks, prefabricated mid-floor panels of cross-laminated timber (CLT) and structurally insulated panel (SIP) roofing.

Triangle Road has been rather innovative by bringing multiple prefabricated systems together within these dwellings. Using multiple systems to complete one build is the next step into developing a more efficient building methodology for prefabricated social housing.

\subsubsection{Summary}

This project offers a "precedent in the on-going affordability vs. quality discussion" and is a great beginning for the desired atmospheric qualities desired in prefabricated social housing Auckland ("Triangle Road Community Housing" Community; sec. 1). The community and interior atmospheric qualities exceed the ideals needed to create a positive atmospheric conditions. 

$\begin{array}{llllll}W & A & L & K & E & R\end{array}$ DESIG N L T D
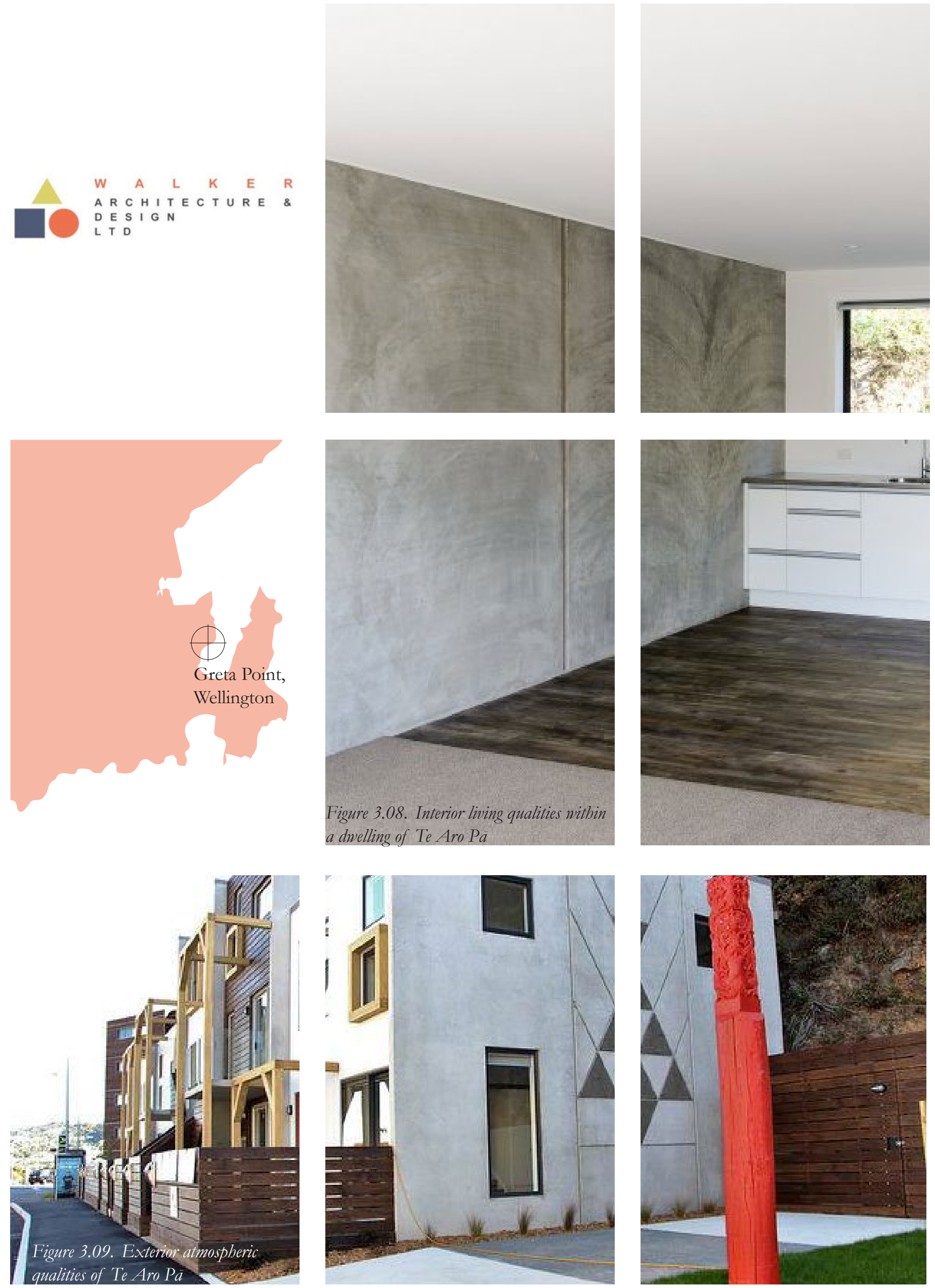


\section{3}

\section{TE ARO PĀ PAPAKĀINGA, Walker Architecture \& Design}

Architect: Roger Walker, Walker Architecture \& Design

Location: Great Point, Wellington

Size: $2,048 \mathrm{~m}^{2}$

No. Dwellings: 14

Density: 68 dwellings per hectare 


\subsubsection{What is the project?}

Te Aro Pā is Wellingtons first city papakāinga which is privately owned by the Te Aro Pā Trust. This housing development has been designed as social housing for the people who have a connection to the original Ngāti Ruanui and Taranaki Iwi. ("Te Aro Pà papakäinga - the power of partnership." News; sec 1) Roger Walker has shifted from his distinctive architectural style and has developed $\mathrm{Te}$ Aro Pā around the traditional Māori concept of whanaungatanga, kinship.

\subsubsection{What are the atmospheric qualities?}

Community: Due to the location, the row housing formation of this development begins to hinder the community atmospheric conditions possible for Te Aro Pā. Although private and shared space has been made available within the development for social interaction there is a significant lack of privacy within these spaces. Te Aro Pā has been backed up against a hill, without being blended into the existing community surroundings and has been left to stand out without changing the public perceptions of social housing.

Exterior: The exterior atmospheric qualities of $\mathrm{Te}$ Aro Pā provide an architectural identity which is not typical of Roger Walker. While this is not of Walkers usual aesthetic Te Aro Pā still stands out with stepped façade heights, materiality and irregular glazing proportions that create whimsical approach to traditional Maori concepts. This case study has shown that exterior atmospheric conditions are not complete without the surrounding being taken into consideration. It is crucial that an architectural identity is developed in response to its surrounding context to create a greater sense of community and dignity for its occupants, especially when dealing with a specific demographic for social housing.

Interior: The contemporary spaces have a cold

LINEAR CONFIGURATION LACK OF VISUAL CONNECTIVITY 

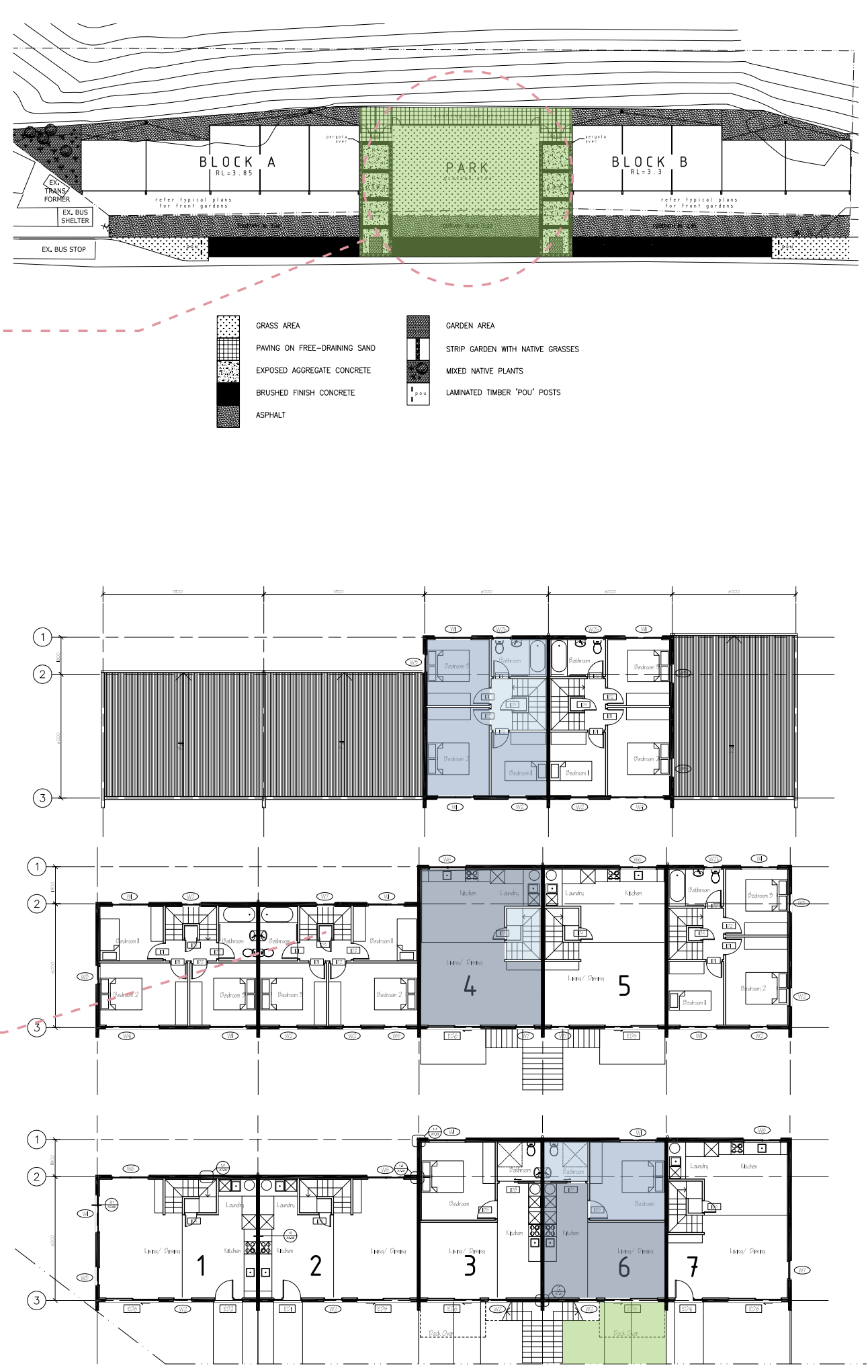
neutral colour palate and the atmospheric qualities have been compromised by the exposed structural walls and the irregular glazing proportions.

The glazing proportions limit the amount of daylighting resulting in a large impact on the interior atmospheric qualities of these dwellings. Te Aro Pā has reinforced the importance of solar gain within dwellings to improve the interior atmospheric qualities. Natural light levels have a significant impact on the atmospheric conditions and it is important to maximise the benefits of this when possible.

\subsubsection{What are the construction techniques?}

The primary construction of Te Aro Pà are the structural pre-cast concrete walls. These walls act as shear walls for the building as well as inter-tenancy walls between dwellings. Using this method of prefabrication this housing development was able to be constructed in less than six months.

This example of prefabrication within a new contemporary development shows how the structure can begin to dominate and affect the space. Although the shear walls allow for maximum space allotment within the building footprint, the decision to expose this materiality has had a significant effect on how the space is interpreted.

\subsubsection{Summary}

Overall, the Te Aro Pā has achieved something for Ngāti Ruanui and Taranaki Iwi people that has never been accomplished before, however, has it has failed to change the stigma of social housing. Te Aro Pà has been isolated in Greta Point without developing a relationship with the existing community surroundings. This case study has been significantly beneficial as it has helped to identify the new and existing issues with social housing. 


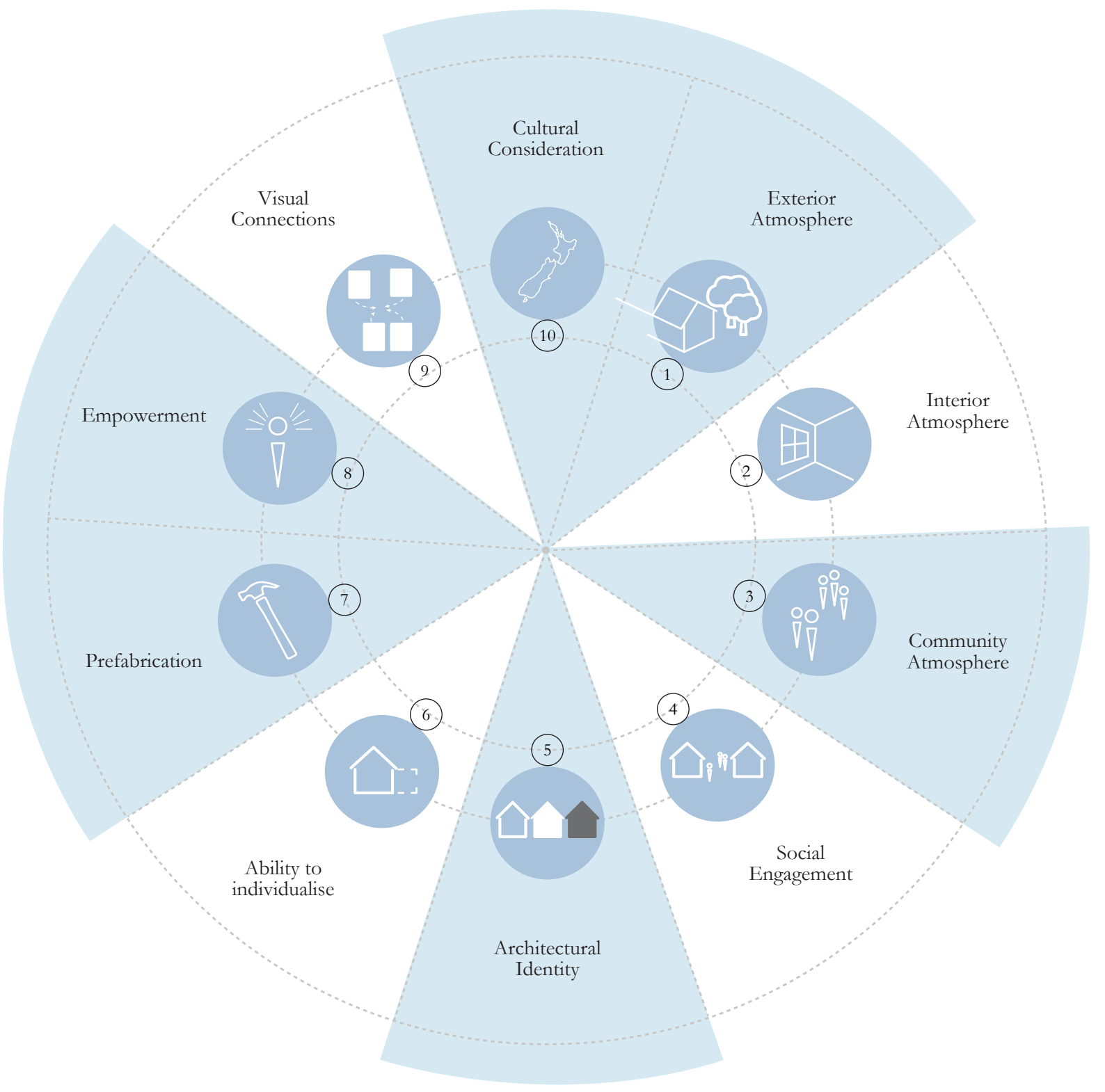

Figure 3.11. Te Aro Pā fulfilling six of the ten criteria, lacking in individualisation, social engagement, interior atmosphere as well as visual connections 

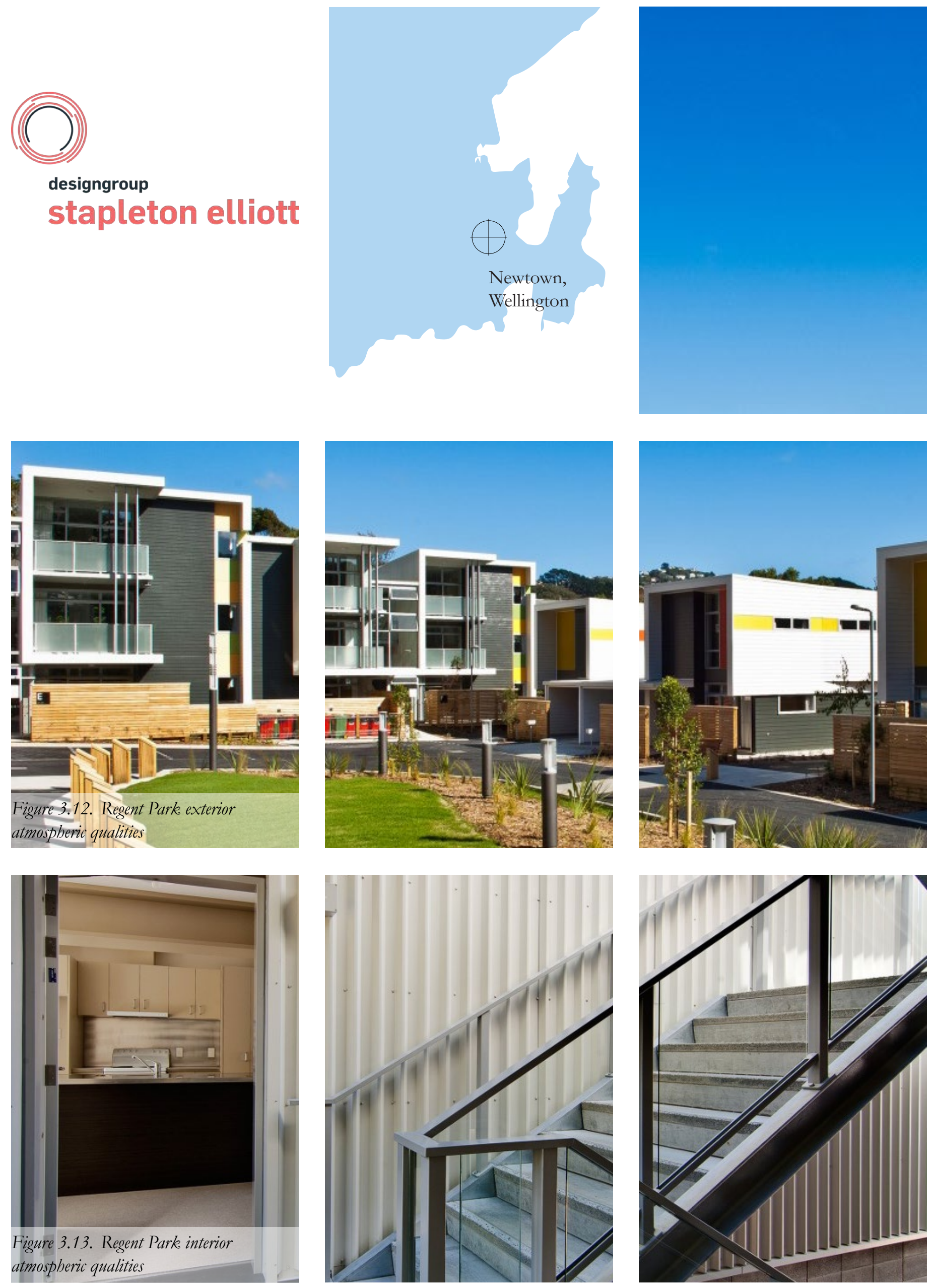


\title{
3.4
}

\section{REGENT PARK,}

\section{Design Group Stapleton Elliott}

\author{
Architect: Design Group Stapleton Elliott \\ Location: Newtown, Wellington \\ Size: $6,447 \mathrm{~m}^{2}$ \\ No. Dwellings: 27 \\ Density: 42 dwellings per hectare
}




\subsubsection{What is the project?}

Regent Park is a low income medium density social housing development undertaken by the Wellington City Council as part of an upgrade to their housing portfolio. Regent Park previously contained social housing that was not fit for purpose and architects, Design Group Stapleton Elliott, were responsible for the redevelopment. The development contains a range of various housing typologies that respond to a difficult site.

\subsubsection{What are the atmospheric qualities?}

Community: The biggest success of Regent Park is the public and private outdoor space. The built forms within this development have been pushed to the edges to allow for a self-enclosing public space that has passive surveillance from the transparent circulation towers and each dwelling in the complex. This provides the occupants with a sense of safety and community and is a huge asset for a social housing.

Exterior: The building forms and materiality have a contemporary architectural twist on traditional 19th century villas as a response to the site surroundings. This gives Regent Park an architectural identity within the wider community and a sense of belonging for its occupants. The extensive colour palate has been used as a colour code for the buildings which impairs on the atmospheric conditions as this is not typical of higher income housing developments. It is the colour coding that begins to define the development as a low-income social housing and continue the identity of social housing.

Interior: The interior atmospheric conditions within Regent Park are less than desirable due to the low quality finished and materiality. How these dwellings are fitted out have a huge impact on how we perceive 

bathroom/kitchen pod would be able to set a high quality standard throughout and increase the atmospheric qualities.

\subsubsection{What are the construction techniques?}

Regent Park was a development for the Wellington City Council using traditional construction methods. It is more common to use traditional methods in new council developments as it is increasingly viewed as a more reliable method of construction.

\subsubsection{Summary}

Regent Park's interior and exterior atmospheric qualities are an example of how atmosphere can be improved within social housing. The Regent development has some promising factors that have been put in place to provide the occupants with positive atmospheric qualities. However, there are still some significant disadvantages within this project such as its construction techniques, material quality, form and compact room sizes that make it a case study of great learning value. 


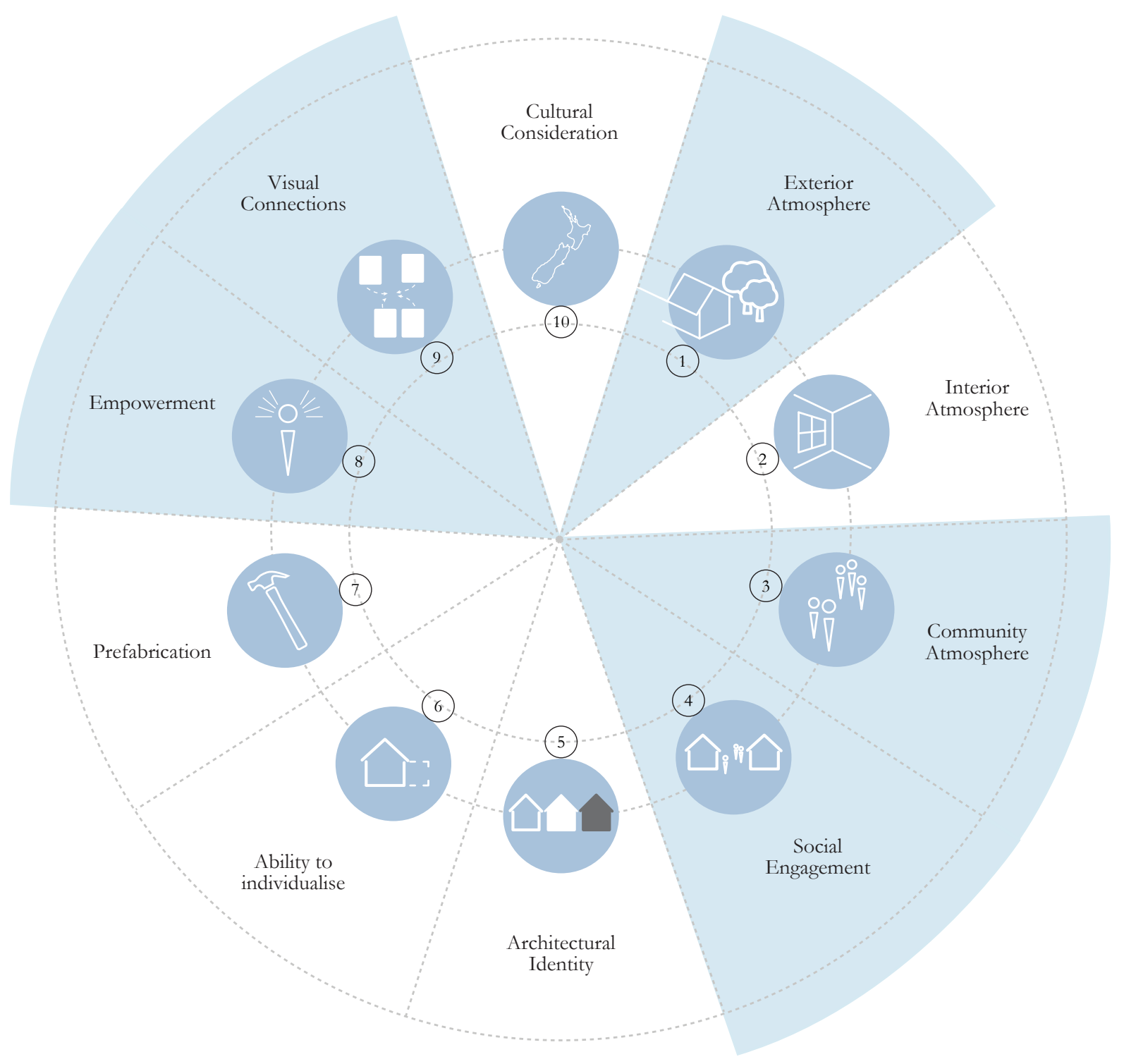

Figure 3.15. Regent Park fulfilling five of the ten criteria, lacking in half the identified conditions to design for social bousing in New Zealand 
PARSONSON architects Itd

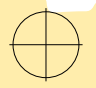

Mount Victoria, Wellington
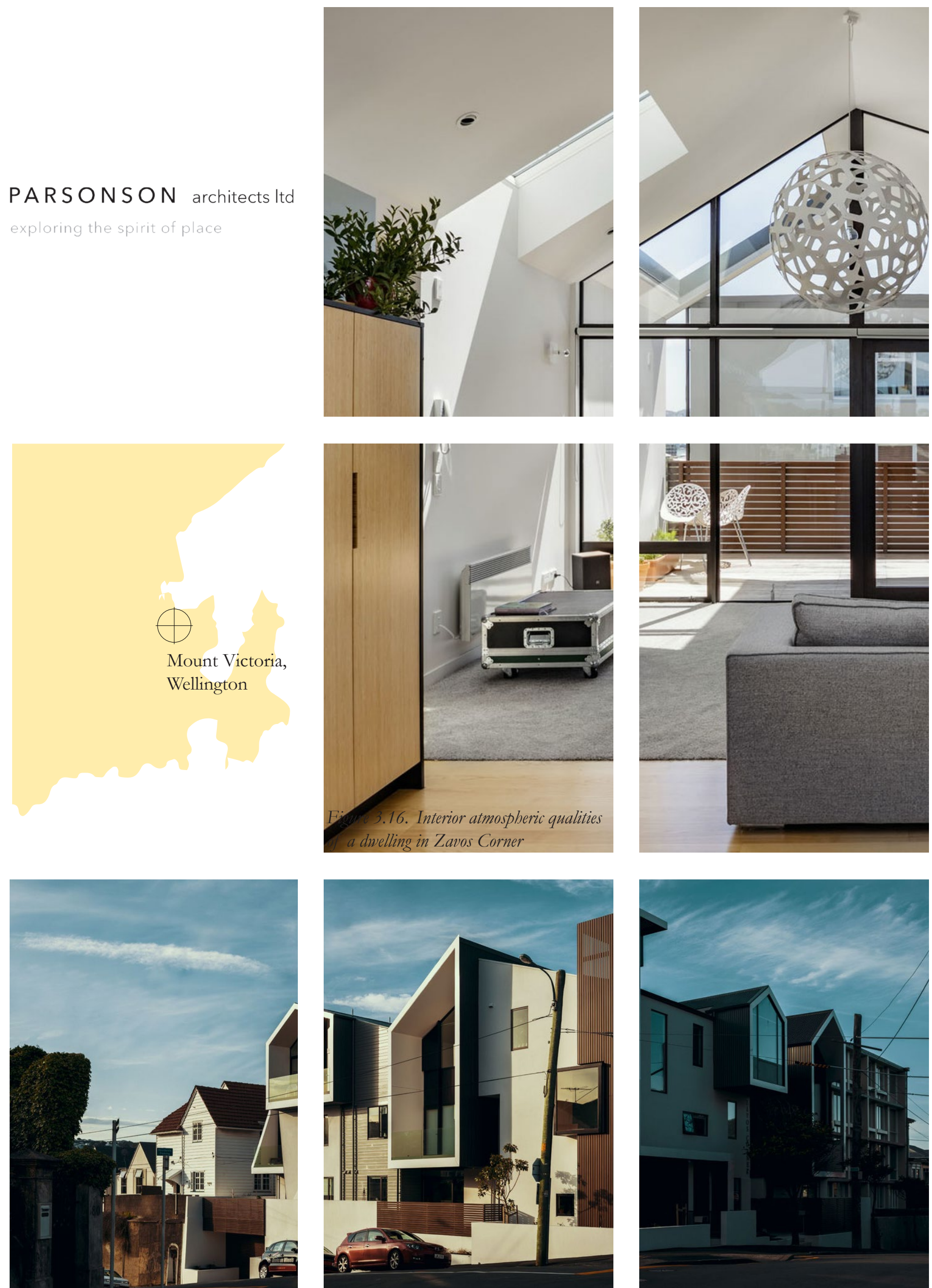
3.5

ZAVOS CORNER, Parsonson Architects

Architect: Parsonson Architects

Location: Mount Victoria, Wellington

Size: $564 \mathrm{~m}^{2}$

No. Dwellings: 8

Density: 142 dwellings per hectare 


\subsubsection{What is the project?}

Zavos Corner is a private medium density housing development in Mount Victoria. The development consists of one two-level apartment and seven single-level apartments that have been spread over 3 stories. The eight apartments range from one to three bedrooms where each dwelling has a different floor plan (Hansen 139).

\subsubsection{What are the atmospheric qualities?}

Community: There is a great sense of community within Zavos as it has been designed as a space enclosing structure around a north facing courtyard with private and public areas. The height of these dwellings provide passive surveillance from the small decks at each end of the living spaces. The high level of thoughtful design has developed a strong sense of community within the development as well as fitting in with the greater neighbourhood.

Exterior: The exterior form of the building has been developed to read as a village than a housing complex to create a connection with the surrounding building and community within Mount Victoria (“Zavos Corner 2015” Housing; par 1). These apartments give a vertical presence on the street front, where they look like individual townhouses or apartments but are actually two interweaving singlefloor dwellings (Hansen 144). This has become an aesthetical interest of the development, creating a whimsical architectural identity for Zavos Corner.

Interior: The interior has been planned to make sure that the spaces "felt open and generous but with privacy between dwellings" (Hansen 144). The building has been arranged around a north facing central area that connects each apartment, resulting in private living and outdoor spaces that are filled with light and various surrounding views. 

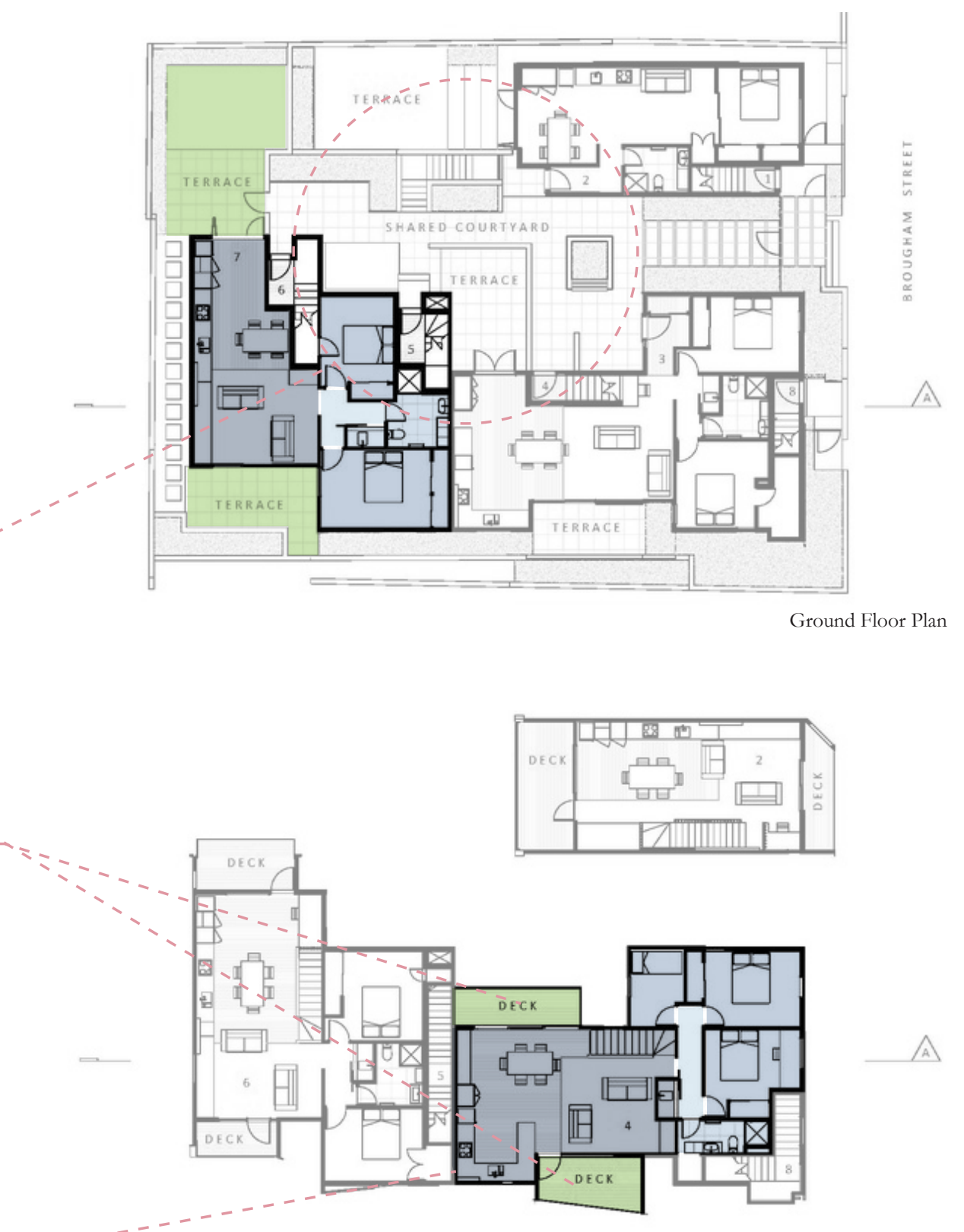

First Floor Plan

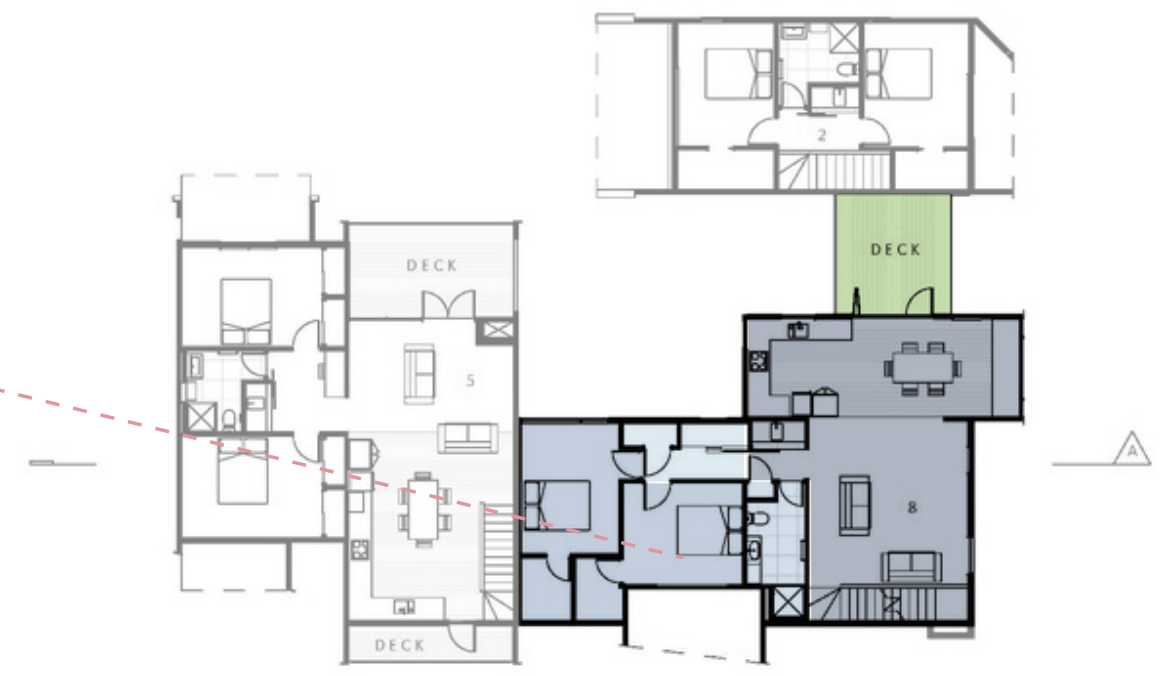

Figure 3.18. Site and Floor Plan analysis of Zavos Corner

Second Floor Plan 


\subsubsection{What are the construction techniques?}

Zavos Corner has used traditional construction methods consisting of light timber framing that has been clad in corrugated iron and plastered concrete panels ("Zavos Corner 2015" Housing; par 1).

This development is already of a high quality and has challenged opinions and thoughts on medium density housing in Wellington, however it would have been one step further to utilise innovative methods of construction.

\subsubsection{Summary}

Overall, Zavos Corner has produced an incredibly high standard of exterior and interior atmospheric qualities. It is the careful planning and individualisation of the interior and exterior that has provided the occupants with a sense of ownership and identity within this development.

The interior atmospheric qualities have been developed with a high quality material finish, as well as the large sense of space. Developing a light space that has the ability to capture various light qualities and surrounding views has developed a sophisticated sense of space that has the ability to be directed into social housing developments. 


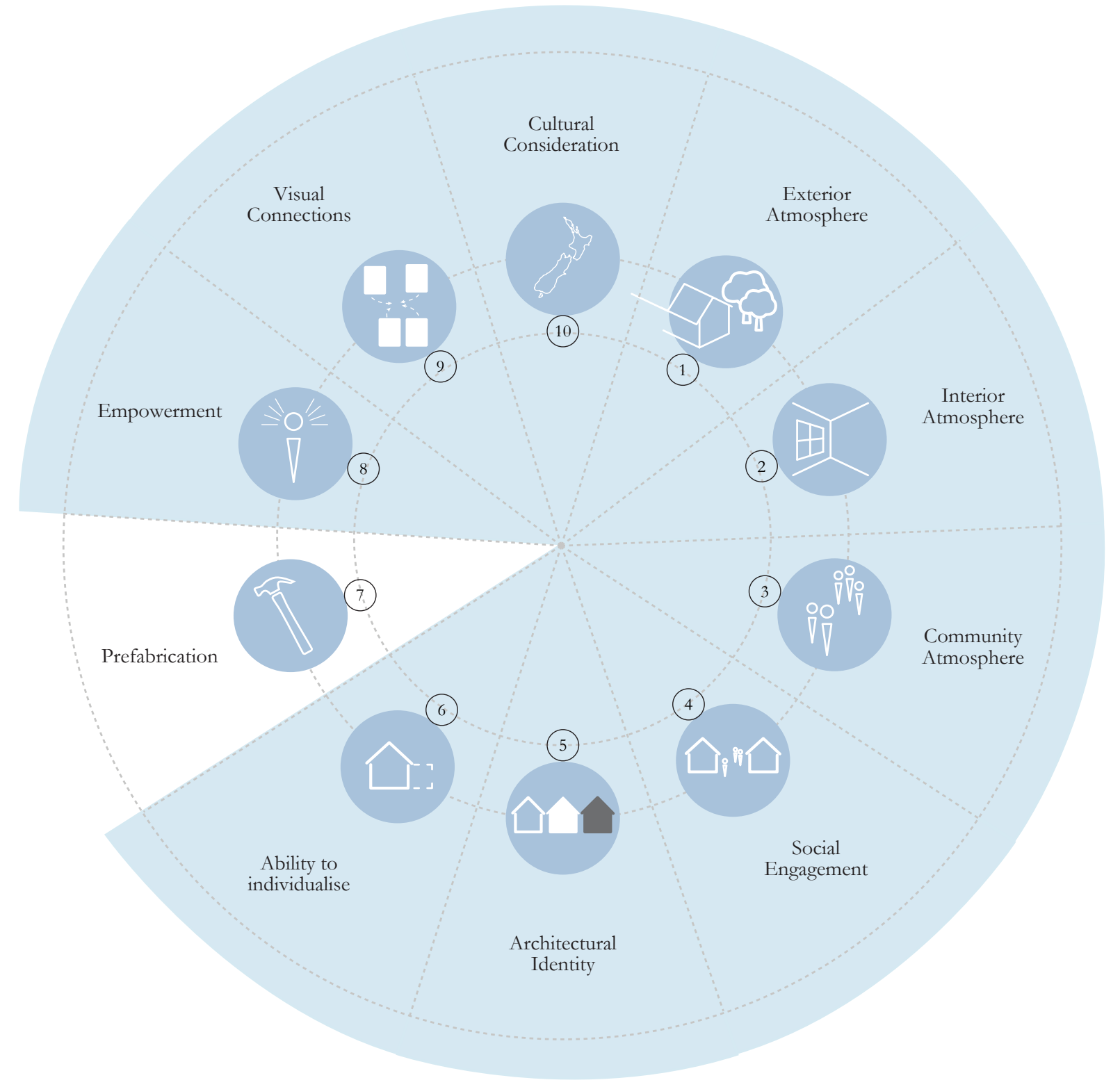

Figure 3.19. Zavos Corner fulfilling nine of the ten criteria, lacking in te use of prefabrication construction. 


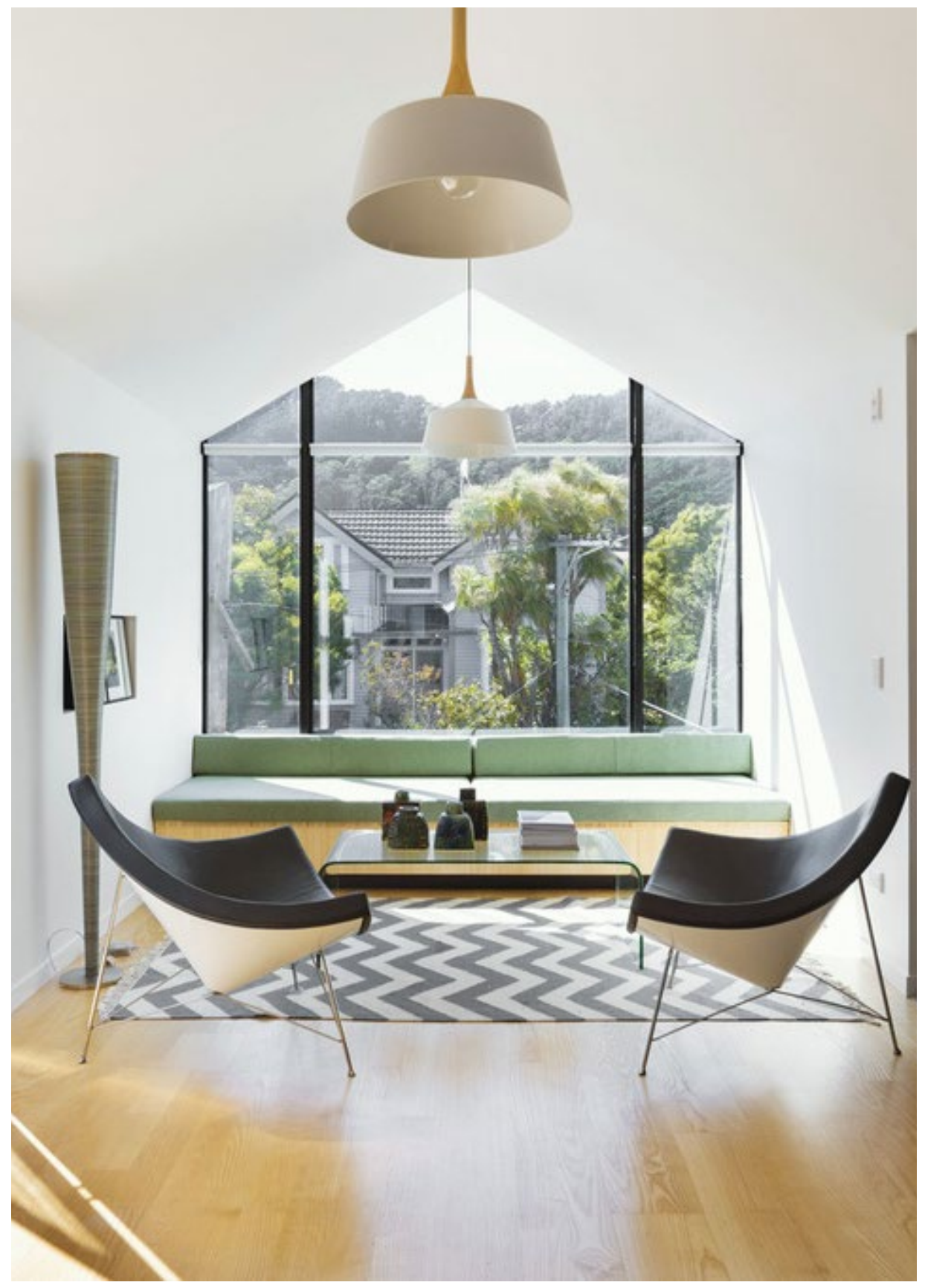

Figure 3.20. Living space of one of seven single floor dwellings in Zavos Corner 


\section{6}

\section{CASE STUDIES}

\section{Conclusions}

These case studies offer a lot of positive atmospheric qualities, previously identified within the literature review. The comparison chart (figure 3.21) defines some important factors for consideration in design and when focusing on creating quality of space through atmosphere. Figure 3.21 summaries these case studies and shows a brief overview of what is currently working within these housing typologies and what each example is lacking.

Community: These case studies have proved that a sense of community within a development is evoked through the massing on the site and how the dwellings begin to respond to each other. It is apparent that space enclosing structure(s) develops a greater sense of community than that of a linear block of dwellings. This has aided how to approach the massing studies of the dwellings on site and highlighted the importance of social interaction and passive surveillance to prompt a greater sense of community.

Exterior: The exterior analysis of these case studies has showed that a cohesive material palate in combination with form and pattern variations develop a high aesthetical interest as well as a sense of identity for the architectural style and occupants. It is important to provide the occupants with the ideals of home to evoke a sense of pride and aspects as small as individual entries to the dwellings and application of personalisation allow this. Interior: The interior atmospheric conditions 
of these case studies have shown the importance of light and solar gain within a space. Natural light qualities have the potential to completely transform how a space is perceived. A development that has made the most of glazing proportions, site orientation and solar gain has shown to have the desired interior atmospheric qualities.

Some of these case studies provide the beginning of collaborative innovation where high quality spaces and construction methodologies are being brought together in harmony to develop an aesthetically interesting and powerful atmospheric space. While others have provided an understanding of what is missing in our current social housing standards. With a bit more consideration, architectural space can become not only accessible but negotiable, and encourage choice, as well as transformation through personal initiative (Kennedy 44). 


$\begin{array}{cccc}\text { TRIANGLE } & \text { TE ARO } & \text { REGENT } & \text { ZAVOS } \\ \text { ROAD } & \text { PA } & \text { PARK } & \text { CORNER }\end{array}$

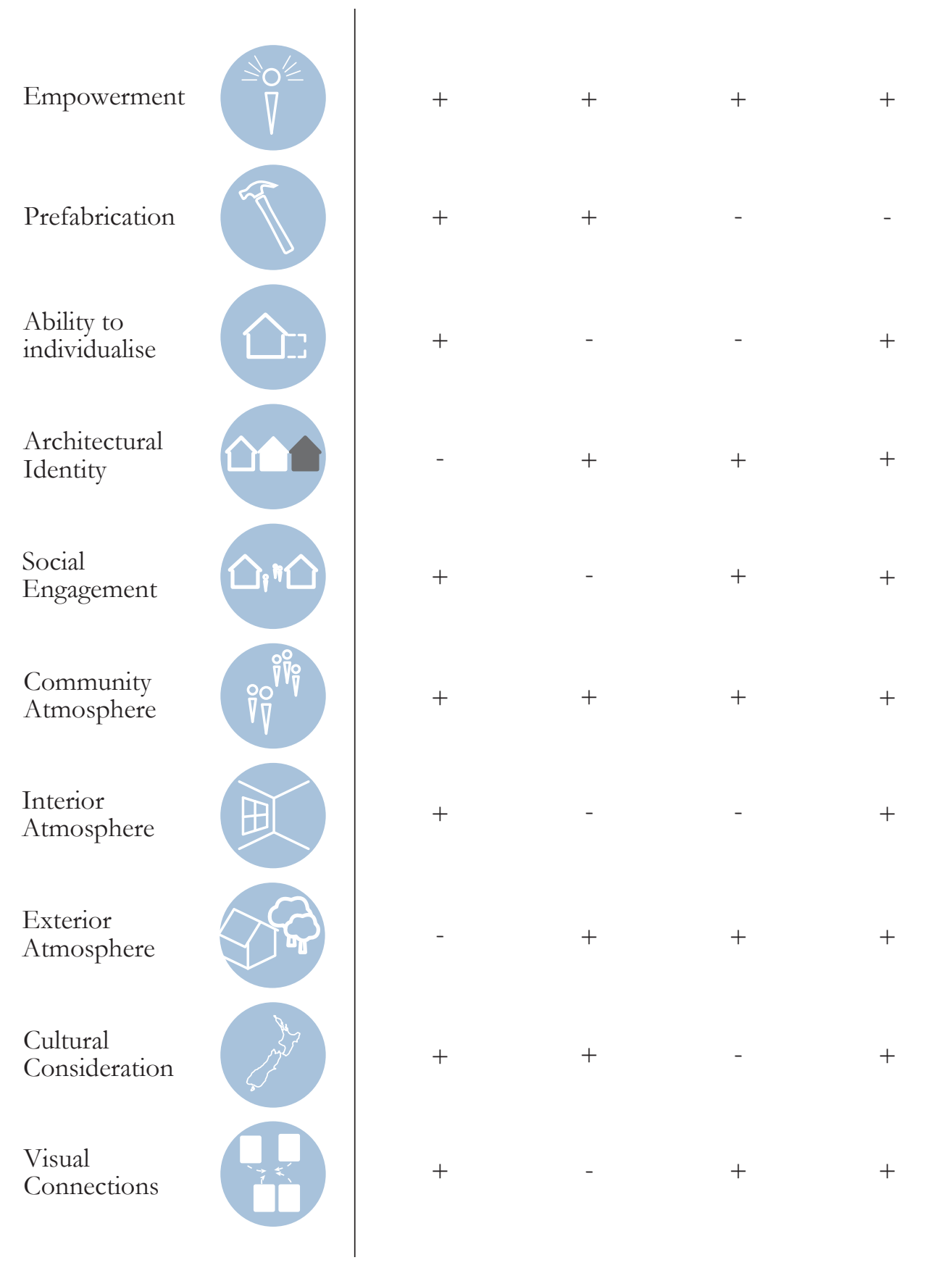

Figure 3.21. A table of the chosen case studies showing a comparison of the ten design criteria 

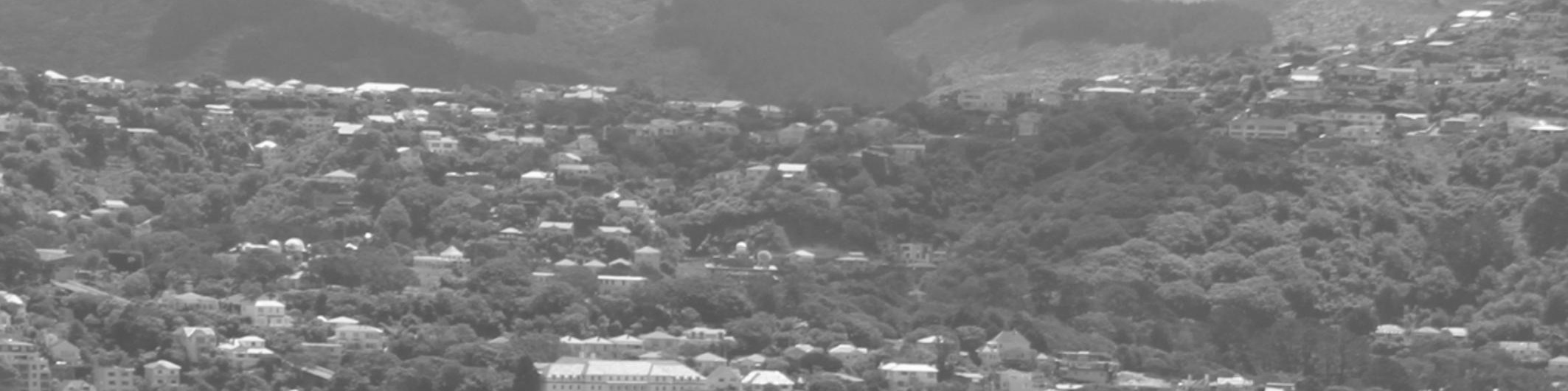
-

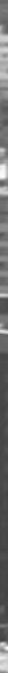

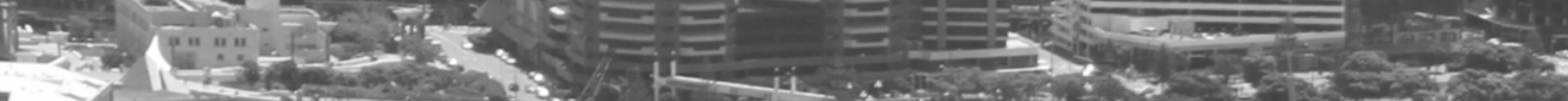
Q

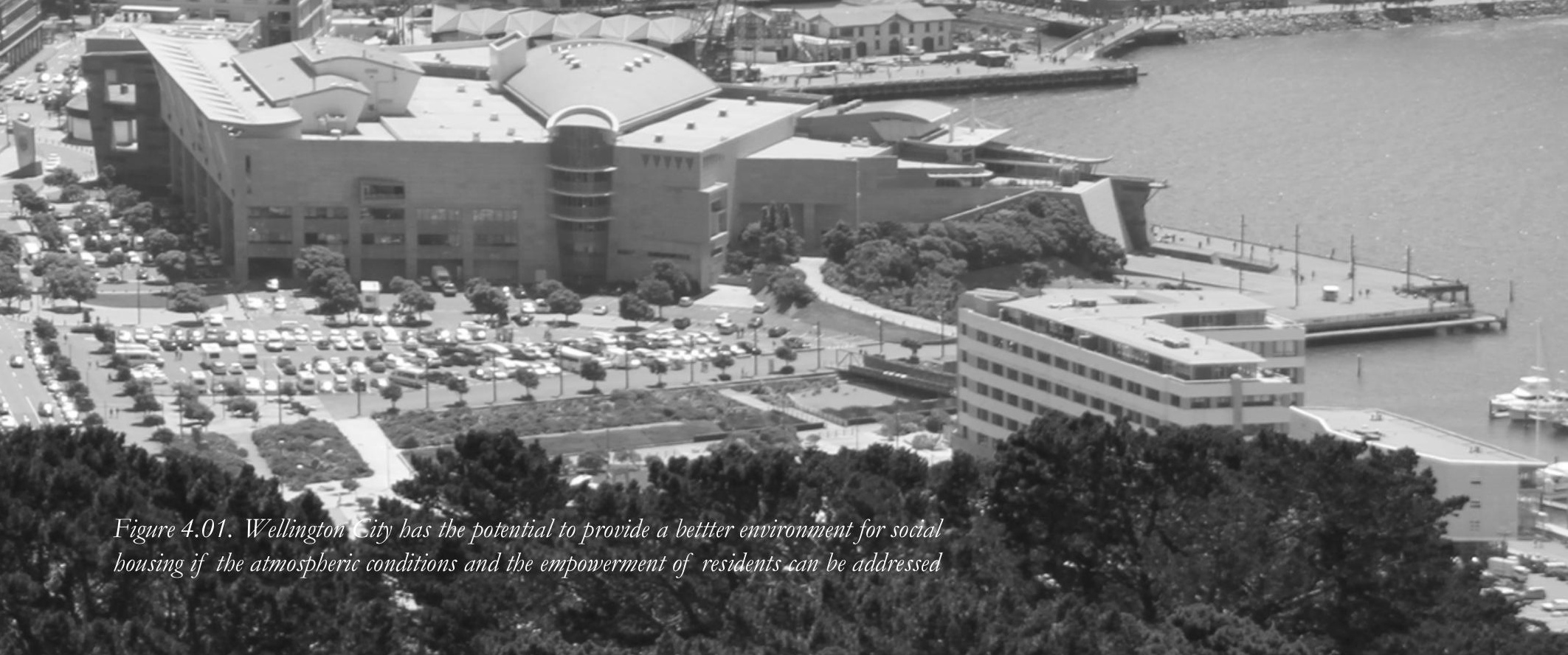


CHAPTER 4.0

Contextual Studies 



\section{1}

\section{URBAN ANALYSIS}

Central Wellington has been selected for its proximity to all the cultural, social, educational and recreational amenity offered by the city centre. Social housing tenants have comparatively low incomes and high needs so it is important that this location can offer diverse amenities to satisfy a wide range of tenants. This location offers a unique set of conditions and challenges to work with when testing the research objectives.

McLean Flats

Pukehinau Flats

This urban analysis aims to establish a site for further investigation and design development. Three exemplar social housing sites have been selected for initial analysis of their suitability to enable a challenging design investigation. McLean Flats, Pukehinau Flats, and Arlington Apartments are all located in Wellington and are in need of redevelopment to provide a quality atmospheric conditions that evoke a sense of empowerment within its occupants.

Figure 4.02. Map of Central Wellington location selected sites 


\section{McLean Flats}

The McLean Flats located on The Terrace, housing 14 one bedroom flats was built in 1944 and influenced by the 'international style' of modernism. These flats were evacuated in 2011 as the building was deemed earthquake prone and unsafe for human habitation.

Constructed on the smallest site, $1,492 \mathrm{~m} 2$, it is by far the most challenging of sites for a housing development. The steep topography, limited daylighting and proximity to amenity provide a unique set of conditions and challenges.

\section{Pukebinan Flats}

The Pukehinau Flats have a site area of $6,990 \mathrm{~m} 2$ and are located at the bottom of the Brooklyn Hill. This site has had alterations and additions since the initial flats were built, however there has been no further developments to improve the atmospheric conditions of the site.

These flats are in close proximity to amenities, yet the site conditions do not provide the complexity and challenges needed for this research project.

\section{Arlington Council Flats}

The Arlington apartments were designed by Ian Athfield in 1970's and made up of various townhouses as well as an apartment block of dwellings.

These apartments are currently under redevelopment and have been split into two phases due to the size of the complex. This site is the has the biggest area of $14,310 \mathrm{~m}^{2}$, which sets a challenging task. 


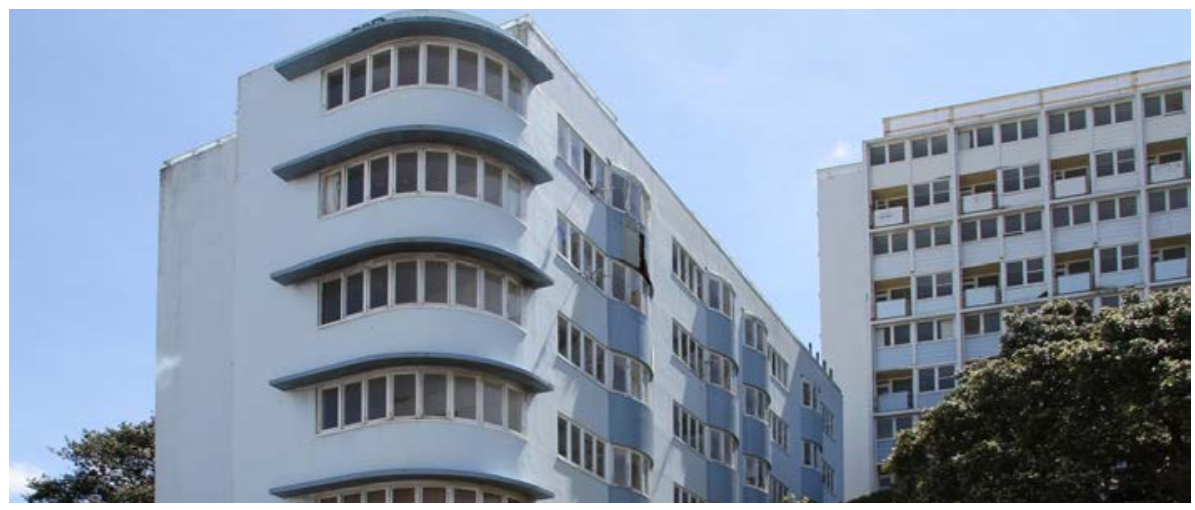

Figure 4.03. McLean Flats evacuated in 2011

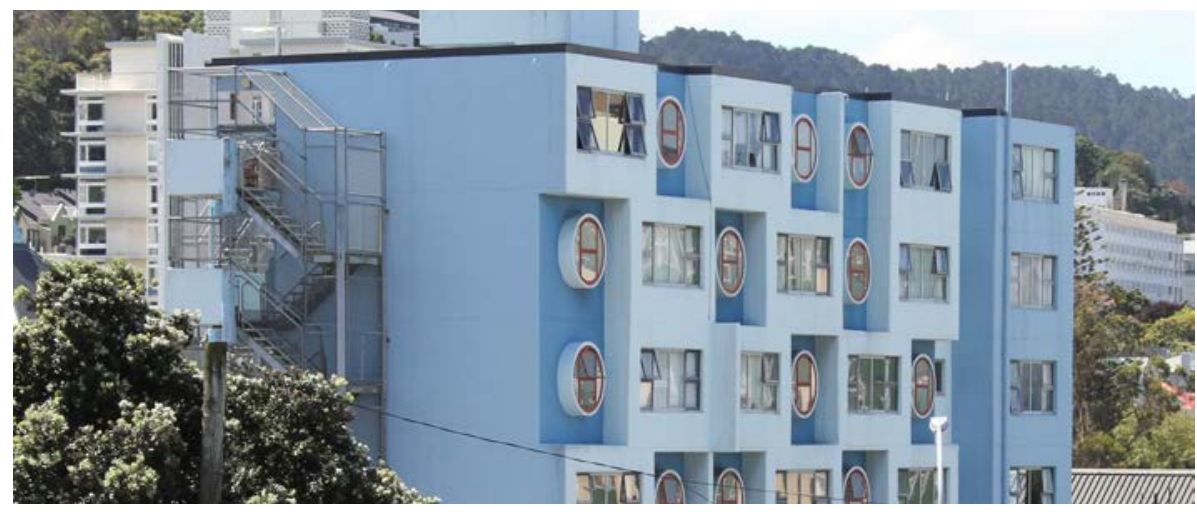

Figure 4.04. Pukehinan Flats still occupied

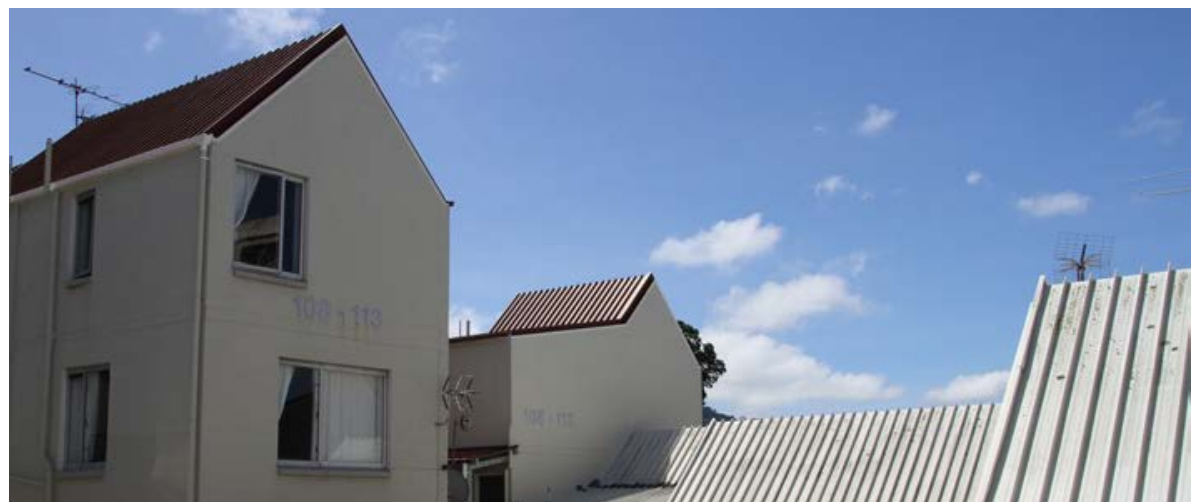

Figure 4.05. Arlington Apartments still occupied 


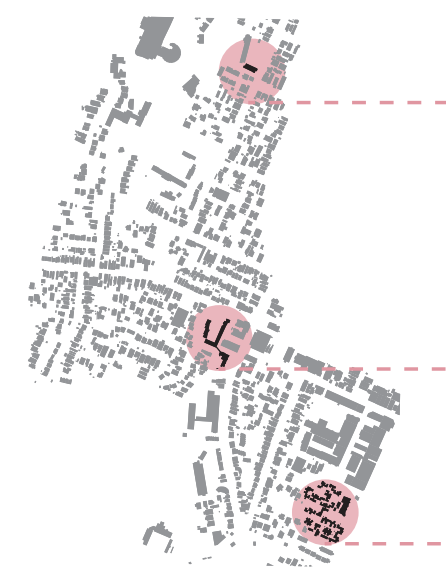

Location

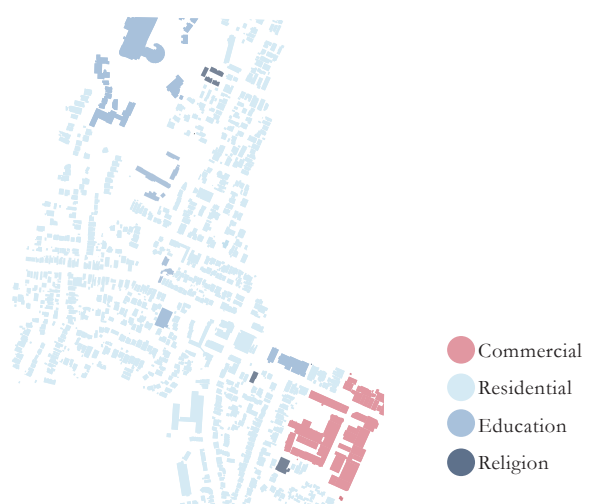

Building Use

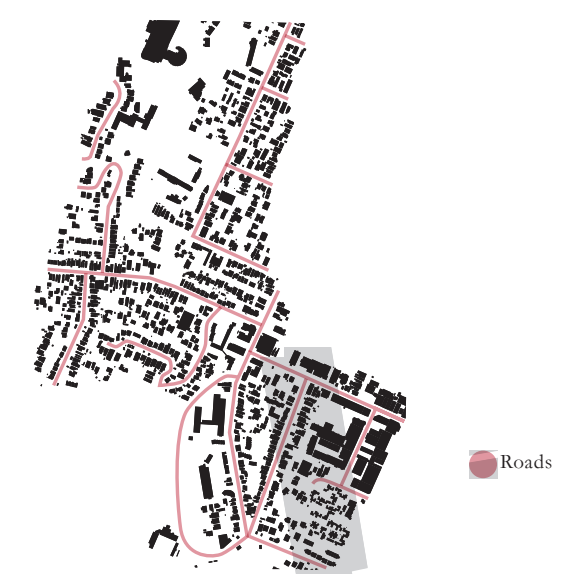

Roading

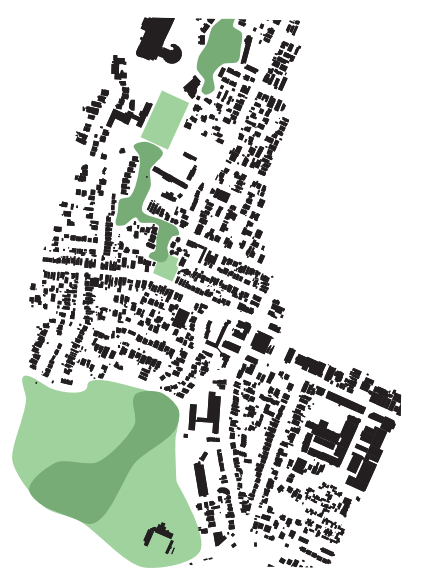




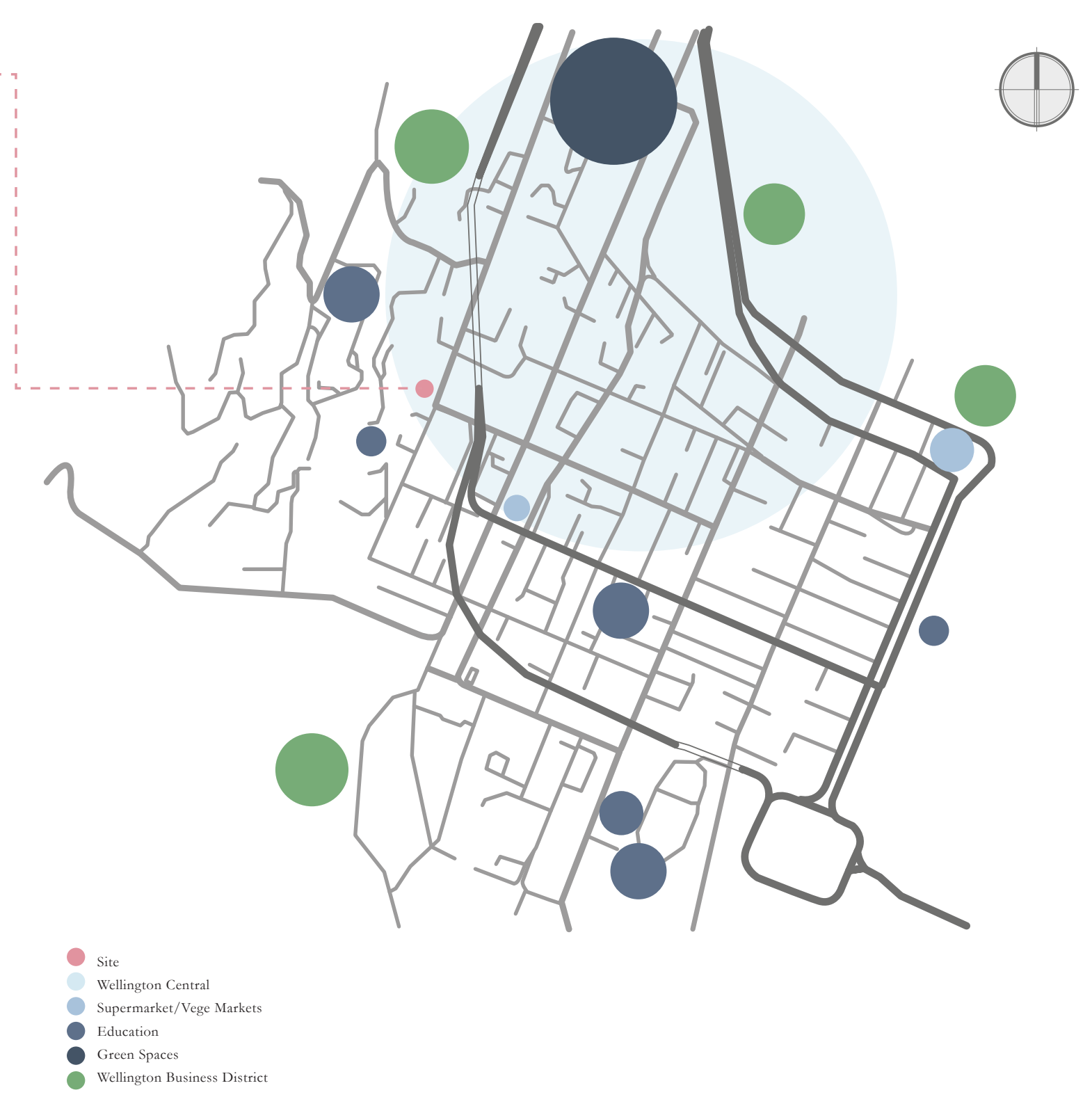

Figure 4.07. McLean Flats ammenity map

Separating distinct elements of the urban structure e surrounding the three sites facilitates a clearer analysis of what contributes to the sense of place of each area; building use, green amenity, and transportation networks.

The McLean Flats site is selected for further investigation and design development. This site offers a range of challenging conditions such as topography, limited solar gain, and site area. McLean Flats is a central city location and will provide diverse challenges to test and develop this research. 


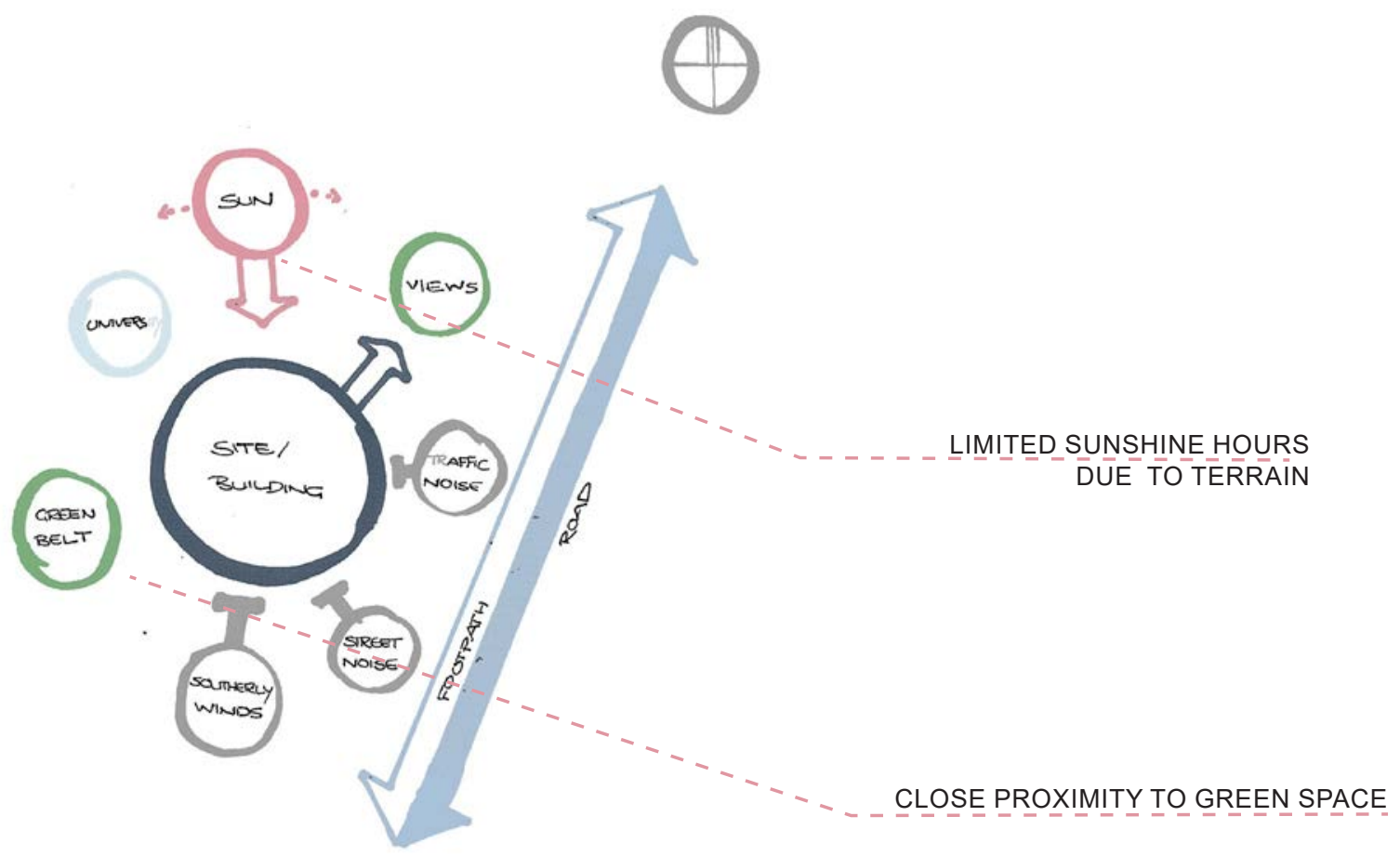

Figure 4.08. Diagram analysising existing site conditions

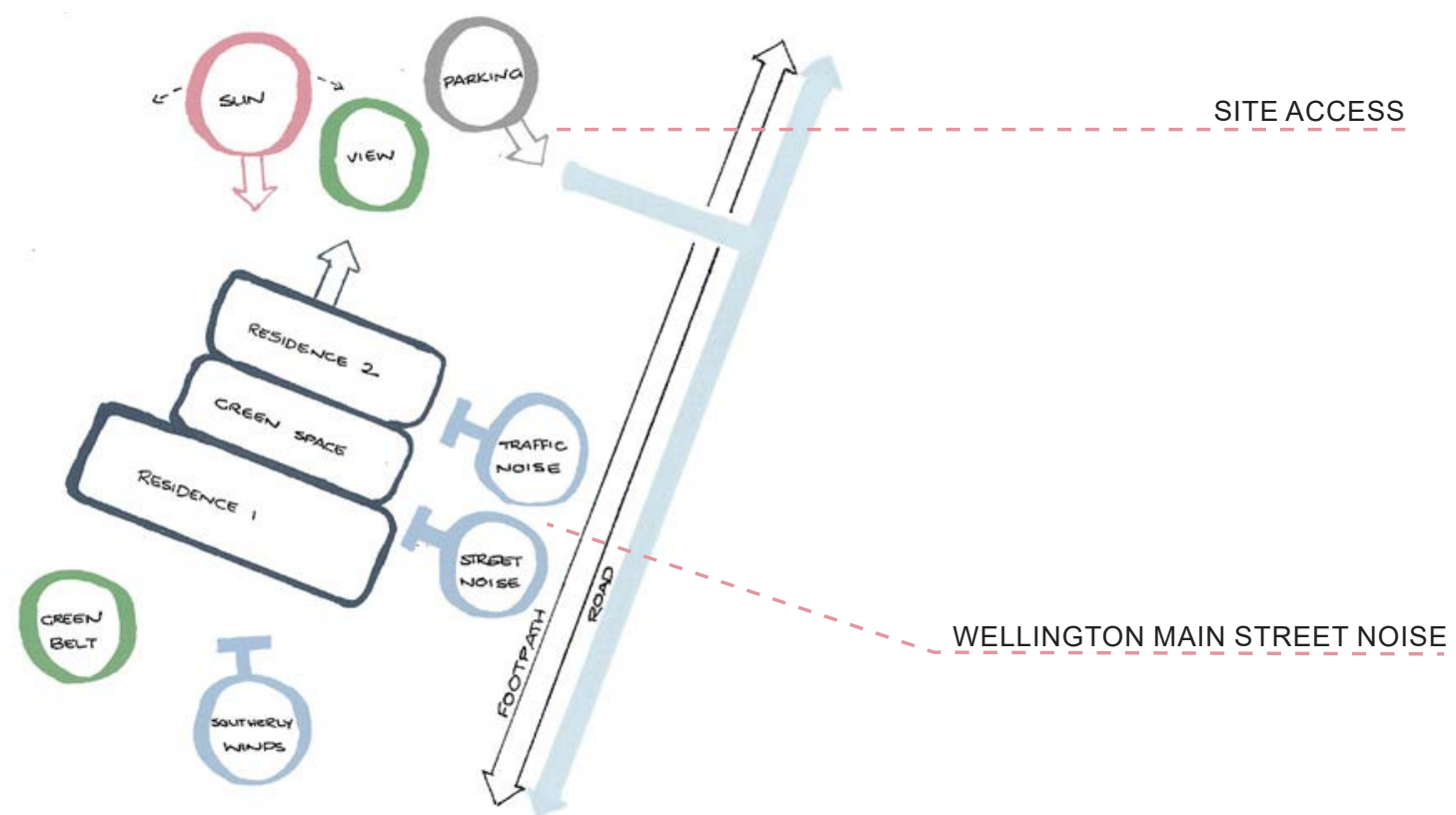

Figure 4.09. Initial massing diagram responding to site conditions 


\section{2}

\section{CONTEXTUAL DIAGRAMS}

To gain an understanding of the site in its existing condition, these diagrams aid in the initial condition testing. These diagrams provide a rough idea of the site surroundings and begin the initial programming to be able to design for the occupants needs and generate a development that can provide the ideals of home, and a sense of community.

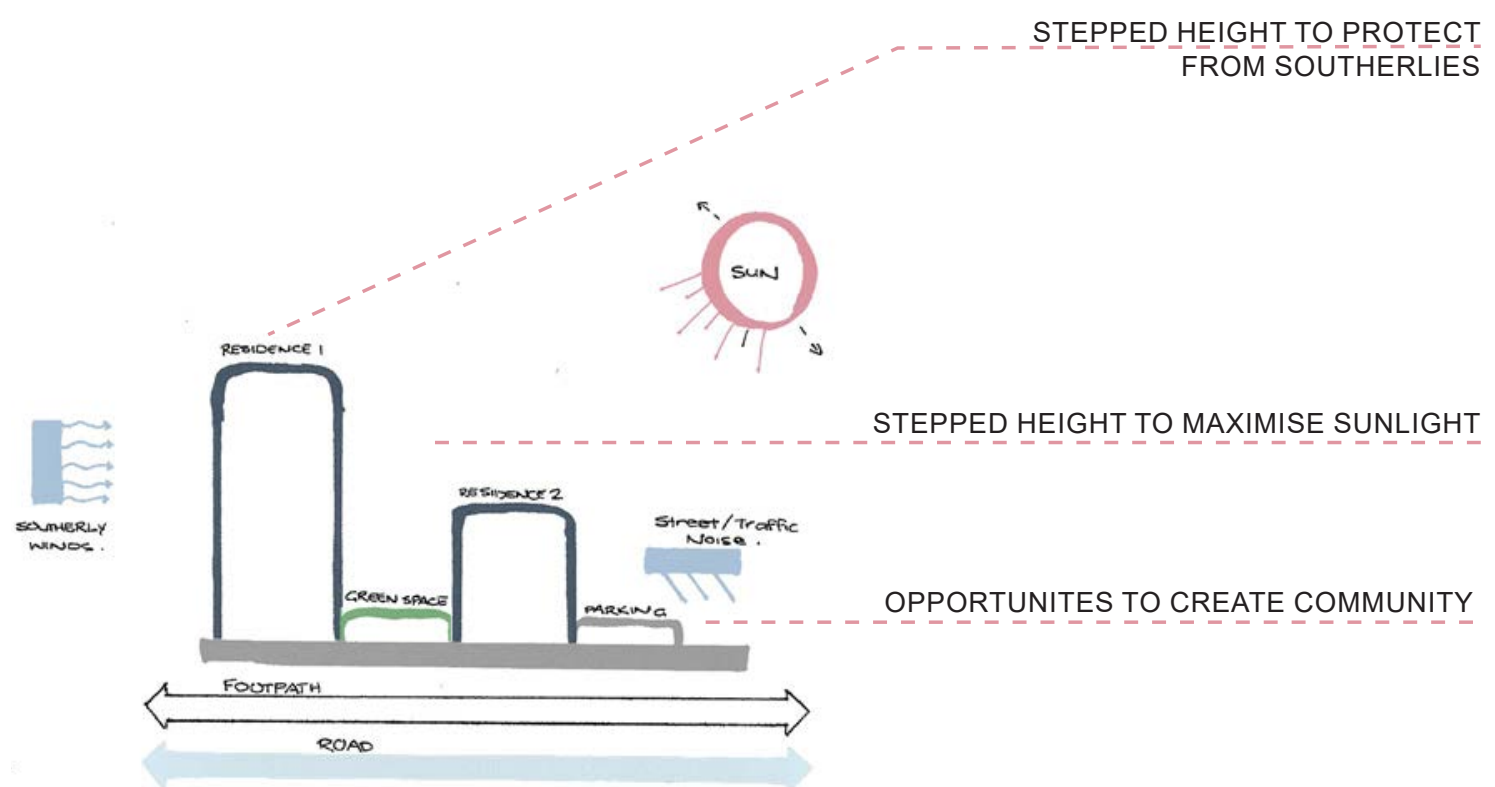

Figure 4.10. A diagramitic massing formation responding to site conditions 


\section{3}

\section{CONSIDERATION FRAMEWORK}

The design process begins with a series of initial site analysis and diagramming (Chapter 4). From these studies emerge two massing iterations which investigate solutions for prefabrication, density, light, privacy (Chapter 5). These ideas are then refined and presented as a design solution for the site (Chapter 6). Finally, reflection identifies strengths and weaknesses of the design outcome, and proposes further solutions for developing a model able to be implement in other sites (Chapter 7).

\section{Consideration Framework}

The design framework established in the precedent studies is referred to throughout the design development phases, both as a set of goals driving design decisions, and as a measure of testing the success of the design outcomes.

It is this consideration framework that has been broken into four predominant design considerations; atmospheric, socio-economic, cultural and prefabrication. All of these conditions rely on each other to produce a successful design solution for this research. It is important that these considerations are referred back to throughout the development phases in accordance with the design framework. 



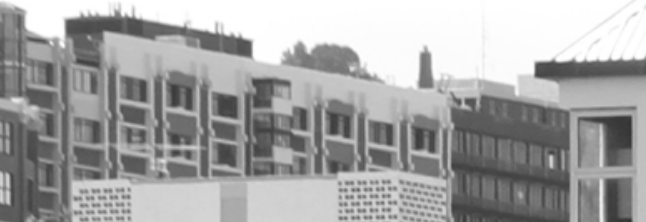
$5+1=1$
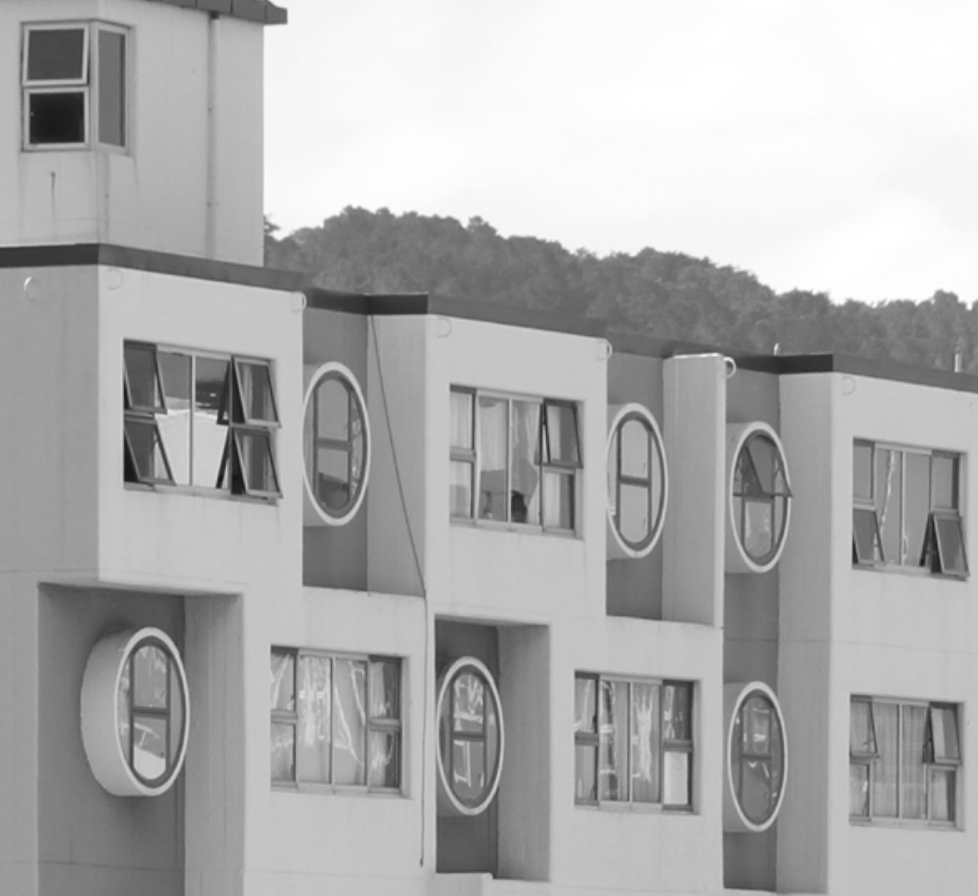

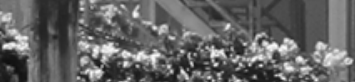

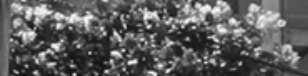

(3)

ax

$4 x+3^{2}$

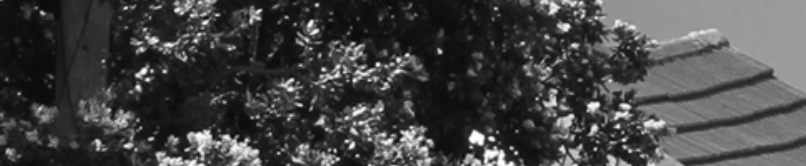

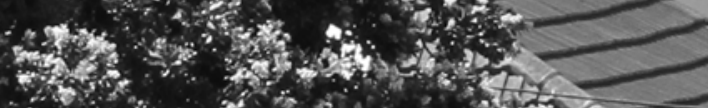


CHAPTER 5.0

Design Processes 
This stage is focused on a design-led exploration of ideas. Two concept schemes are evolved in a series of iteration experiments with dwelling developments., in order to resolve:
a. accessibility;
b. light; and
c. privacy

These also served as an investigation into important architectural qualities such as programme, planning, aesthetics, prefabrication methods and functionality.

\section{Design Framework}

The design framework established in chapter 3 is used as a guideline for design decisions, and to measure the success of the design outcome.

Ten criteria were identified from this framework as they are seen to provide humanistic aspects of a living environment that contribute towards a sense of empowerment.

These criteria are tested through the design process and reviewed to measure if the design outcomes are meeting the design challenges; to provide tenants with a sense of identity and empowerment thereby conveying a sense integration with the wider community. 


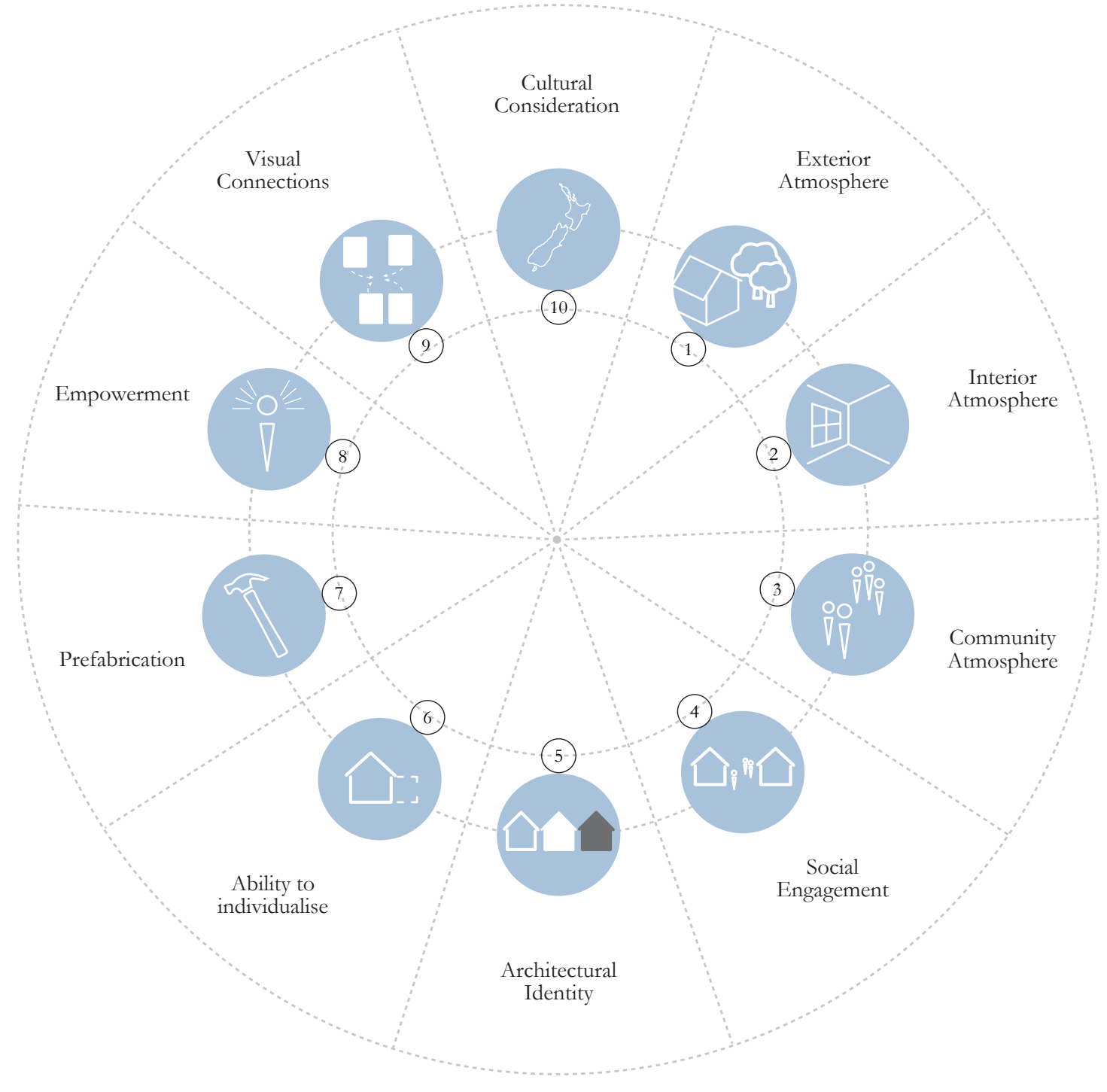

Figure 5.02. Design framework established in chapter 3 to inform the design process 


\section{1}

\section{HYBRID PREFABRICATION}

Introduction

As our current demand for housing goes up previous trends seem to show that these increases have consequences on the quality. It has been made apparent through various attempts and challenges that a singular approach to prefabrication is not going to solve our housing issues and especially our social housing sector. It is through a hybrid approach to prefabrication that the efficiencies needed in social housing and the positive atmospheric conditions, that evoke a sense of dignity amongst tenants, can be achieved efficiently and more successfully.

Hybrid prefabrication is a term typically used for a combination of systems such as a volumetric and panel approach. These systems use volumetric units for highly utilised areas such as the kitchen and bathroom while the rest of the house is constructed with a panel system. A hybrid approach to prefabrication combines the benefits of multiple systems, allowing increased efficiencies and flexibility (Bell 37). For this reason, hybrid prefabrication has a future within the current demand for social housing in New Zealand.

There are various volumetric and panelised methods within New Zealand with Xlam CLT, Metrapanel and UniPod being the most favoured hybrid methods of construction. These panel systems have been brought together in various projects successfully. The UniPod combines both of these panel systems into a pod, this has immensely improved efficiencies and qualities in kitchens and bathrooms. These mixed systems have been utilised to create a hybrid prefabricated system, that is both efficient and innovative, and as they provide opportunity for better atmospheric standards within social housing.

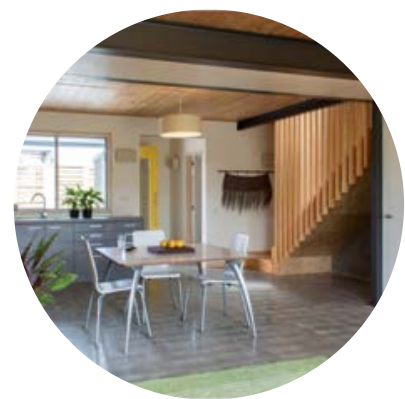

Figure 5.03. XLam CLT - Triangle Road

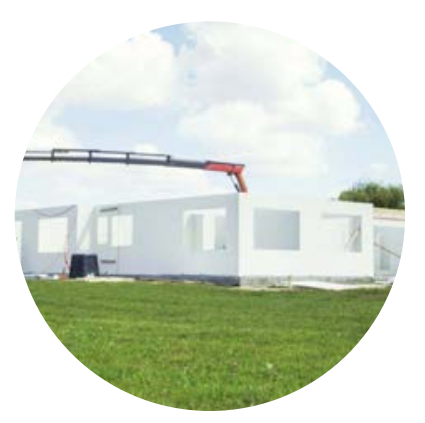

Figure 5.04. Metrapanel - Installation

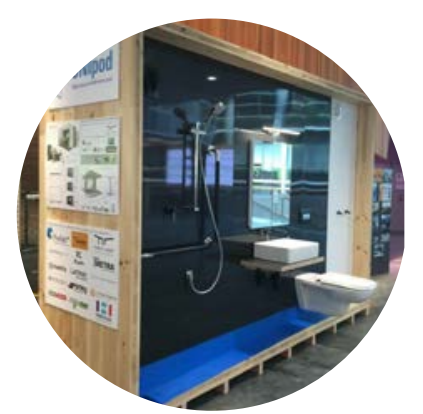

Figure 5.05. UniPod - Prototype 

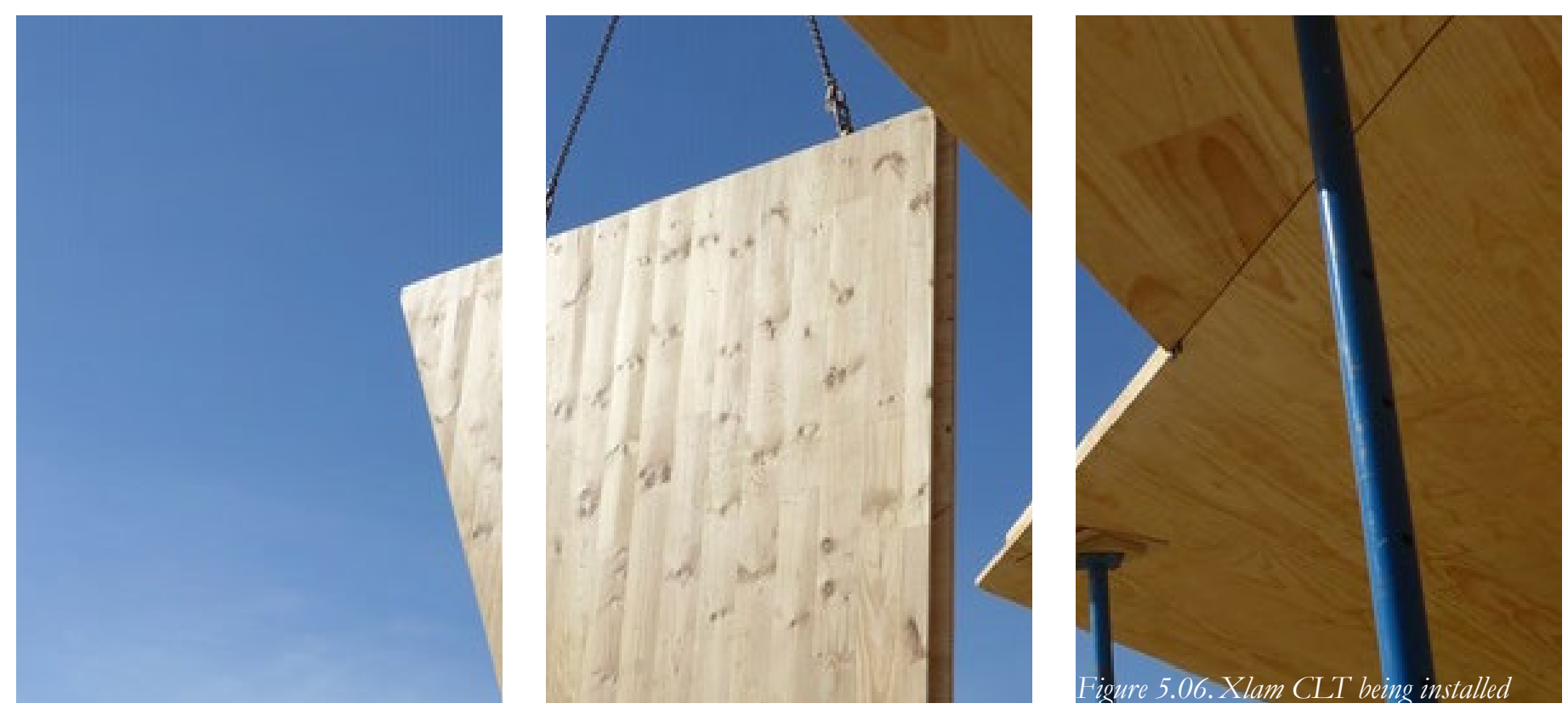

\section{1 .1}

XLam CLT

$+\quad$ Large Span Values

Structural Properties

Accuracy

Aesthetic Value

Atmospheric

Properties
- Associated Costs

Acoustic Performance

Fire Retardant Properties

Volume of Material

Cross-Laminated Timber (CLT) is a solid wood panel that is made from layers of timber laminated together in alternating directions. This engineered timber provides structural properties with life cycle savings that make this system ideal for structural use within social housing.

Having moments of this system exposed within the interior of the dwelling offers a warm aesthetic to the space. Using quality materials in construction enables higher standard of housing and living, and is the first step to abolishing the stigmas of prefabrication and social housing 

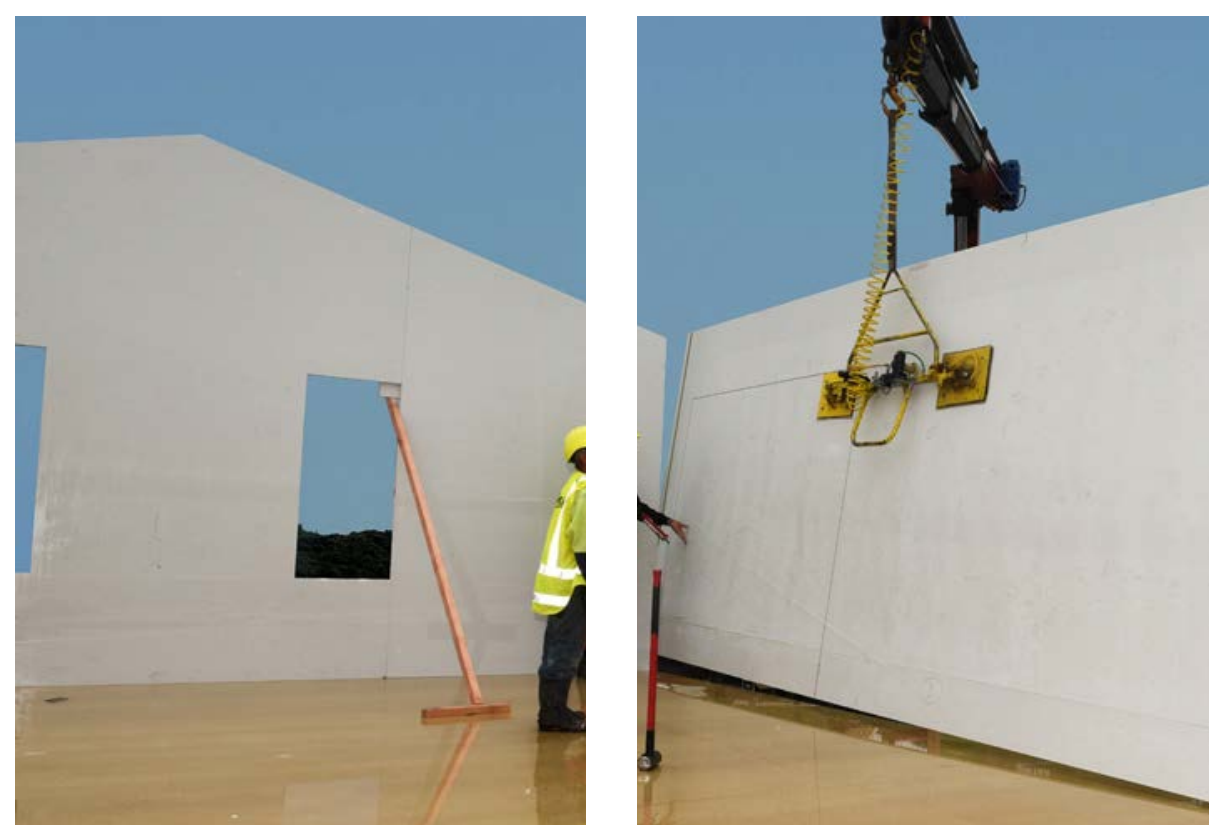

\section{1 .2}

\section{METRAPANEL}

+ Changability

High Thermal

Properties

High Tolerance

Easy Assembly

Cost Efficiency

The Metrapanel system consists of engineered $36 \mathrm{~mm}$ walls to create the interior surface of a building. Using this system construction can be increased by $40-60 \%$. To use this system in the context of social housing, a variation of panels would be required to produce high quality standards.

The Metrapanel system allows for the flexibility needed if this was to be used for future social housing developments. This system does not attempt to control and define the atmosphere of its interior space, instead aid the methods to develop a positive atmospheric space for its occupants.

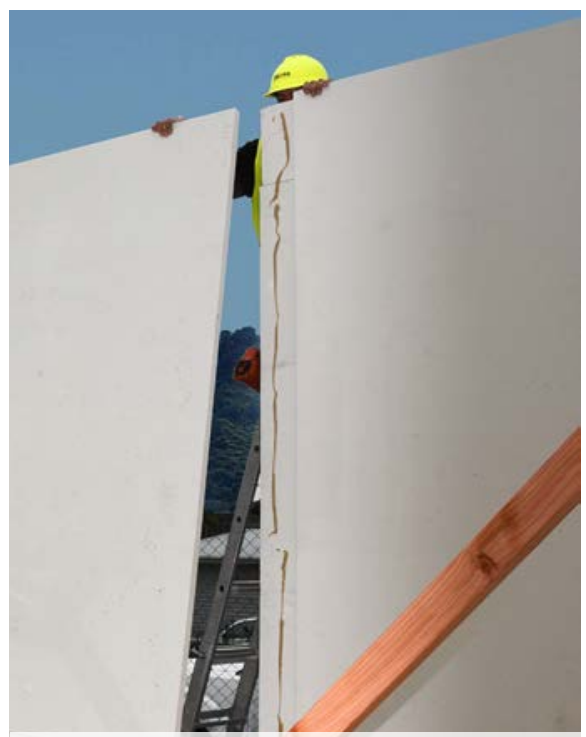

Figure 5.07. Metralpanel wall panels being installed
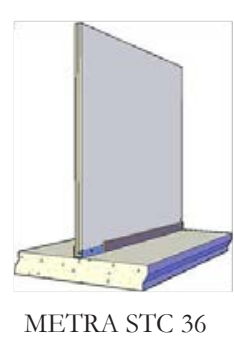

Laminated

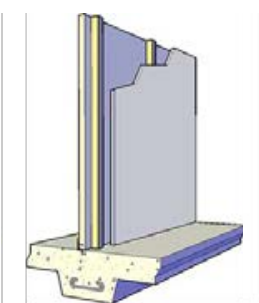

METRA Cavity Wiring \& Plumbing cavity
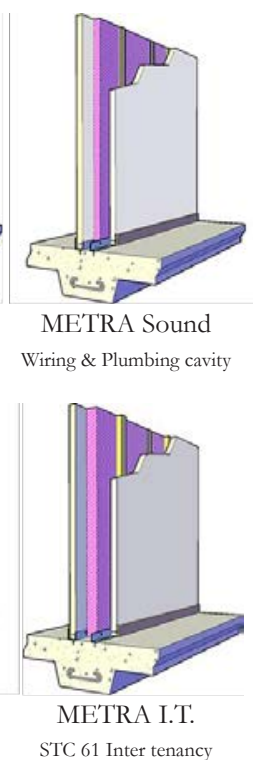

Figure 5.08. Different types of Metra panel wall panels available 

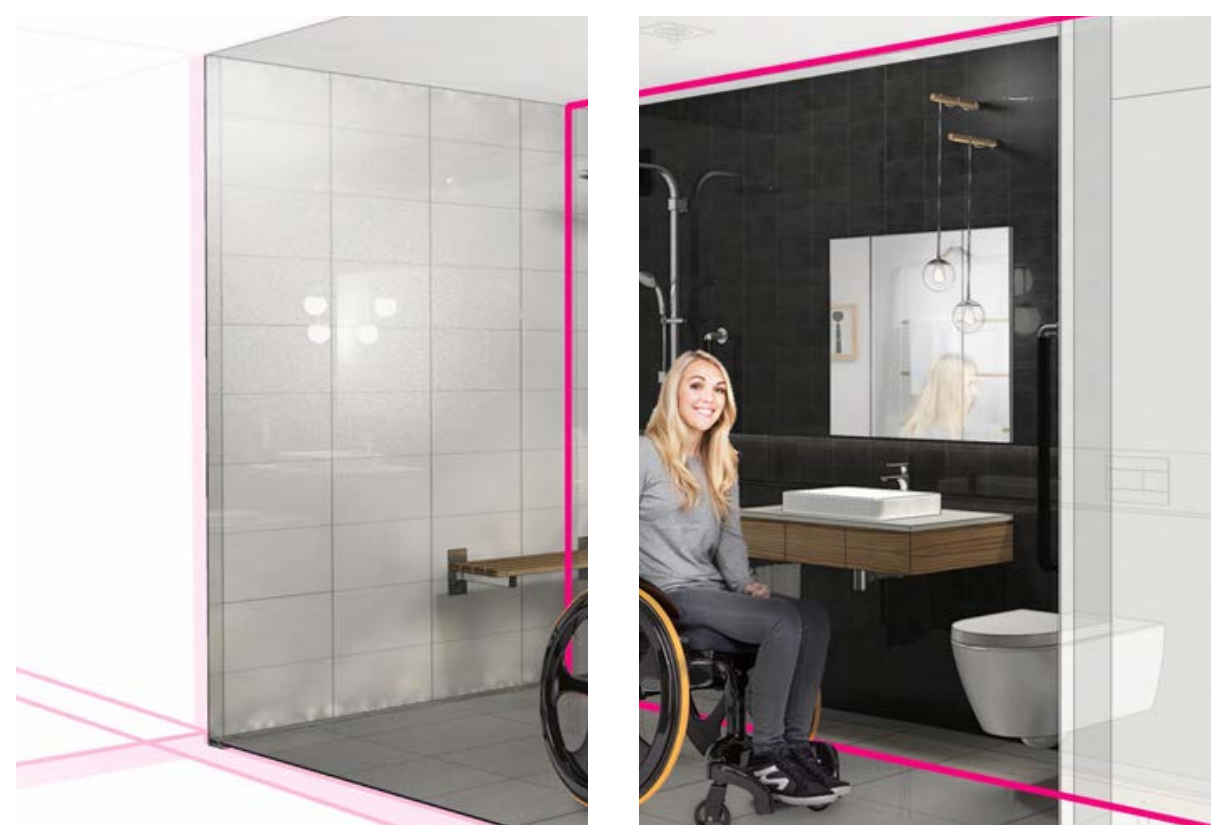

\section{1 .3}

\section{UNIPOD}

$+\quad$ Disability Access

Structural Properties

Service Core

High - Low Spec

Variation

Vertical Stacking
- Prototype Only

Limited Arrangements

Expensive

Needs development

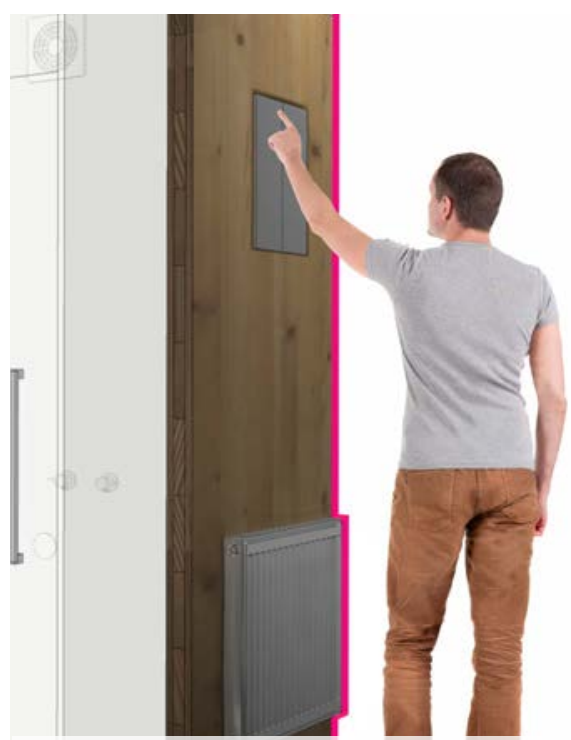

Figure 5.09. Rendered image of the UniPod occupied

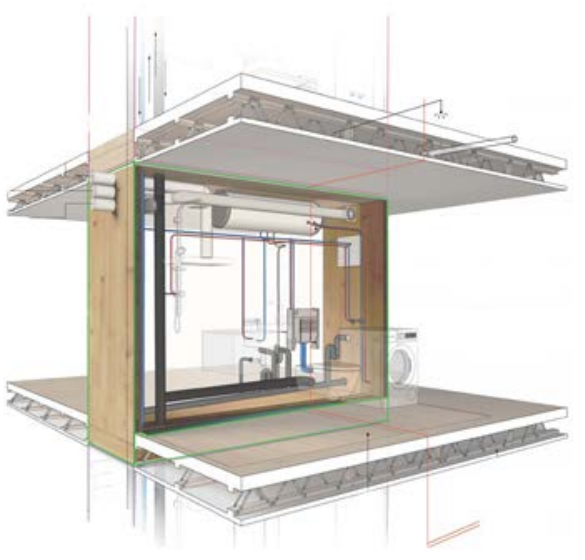

Figure 5.10. Rendered image showing the services through the UniPod

The UniPod was initially selected as part a key
component to this hybrid prefabricated system as the core of each building. It was thought that this system would provide a high standard of quality which in turn is the initial steps to developing positive atmospheric condition in the key areas of a home.

The UniPod is a volumetric unit that has so far only been prototyped. It is the hybrid volumetric unit of XLam CLT and Metrapanel. I It is made up of double skinned Metrawall framed with CLT for stability. The double skinned wall contains a cavity for all the services and acts as the core of the building.

The UniPod encapsulates the essential kitchen and bathroom spaces back to back, however, as this system is only a prototype there is still of room for improvement. 


\section{1 .4}

\section{HYBRID PREFABRICATION}

\section{Conclusions}

Figure 5.10 shows the potential collaboration of these three systems and how they would begin to benefit each other. The CLT for structural purposes, Metrapanel as the interior wall system and the UniPod as an efficient service pod that brings the highly utilised areas of the house onto two walls.

These systems channel innovation, efficiency and the opportunities for development of a hybrid prefabrication system that could set the standard for prefabricated social housing. Applying this system on a challenging site enables testing the opportunities it presents and the possibilities for its adaptation to other sites around New Zealand. These systems combined offers quality, flexibility and a standard that can be set as an achievable bar for better social housing.

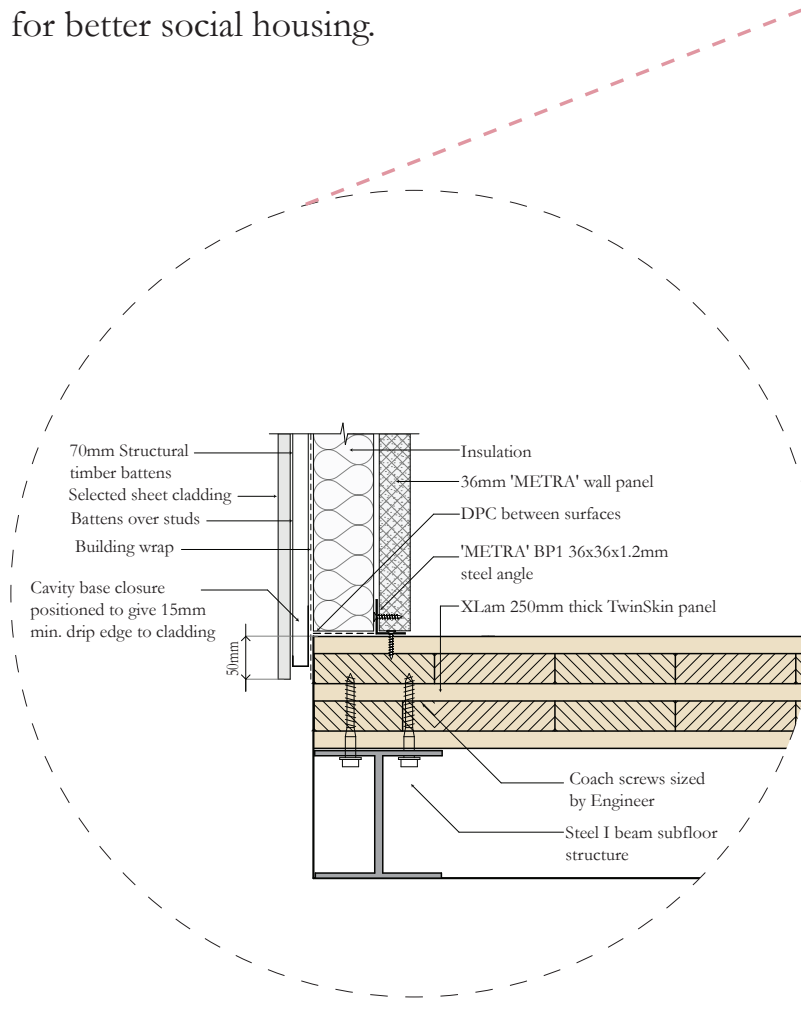

Figure 5.11. System Axonometric with Metrapanel and CLT Detailing 


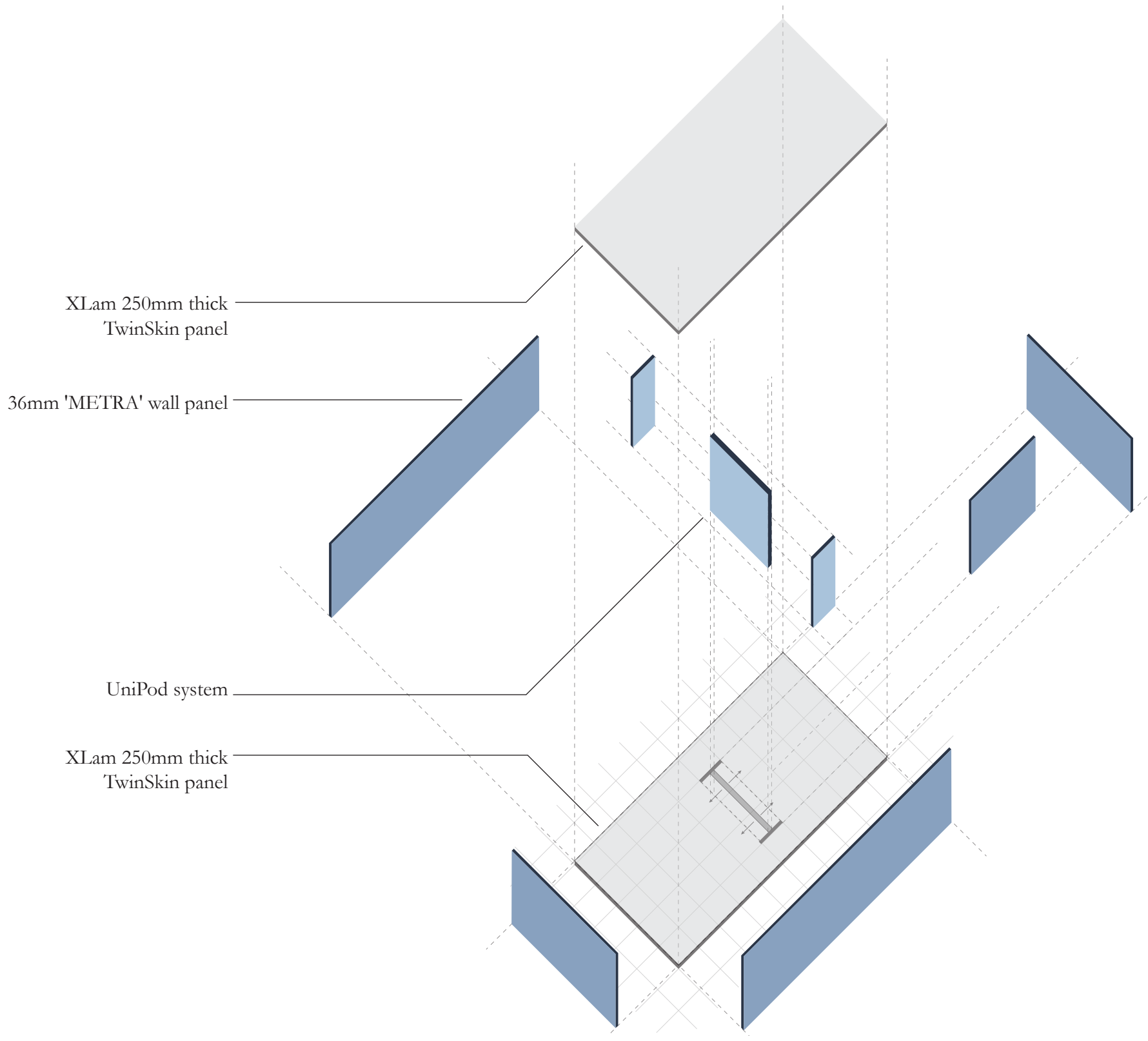

Figure 5.12. Exploded System Axonometric 


\section{2}

\section{MASSING STUDIES}

Massing studies were used to explore and visualise potential volumes and thresholds. These are the conceptual beginnings of the design phase, and start investigating the atmospheric opportunities created within the exterior and interior of a social housing complex and its engagement with the wider community environment.

\section{Test Iterations}

Digital modelling and drawings were used to explore preliminary responses to the existing site conditions. These explorations were informed by the criteria identified in the design framework (Chapter 3), such as creating diverse atmospheric conditions, visual connections, an architectural identity and to evoke a sense of empowerment.

Note that the criterion "prefabrication" has been proposed in the initial stages of chapter 5. The remaining criteria have been reviewed throughout the design process.

These massing studies have been developed in response to a combination of dwelling types ranging from two to three bedrooms and to provide for the needs of a wider scope of people and future changes. 


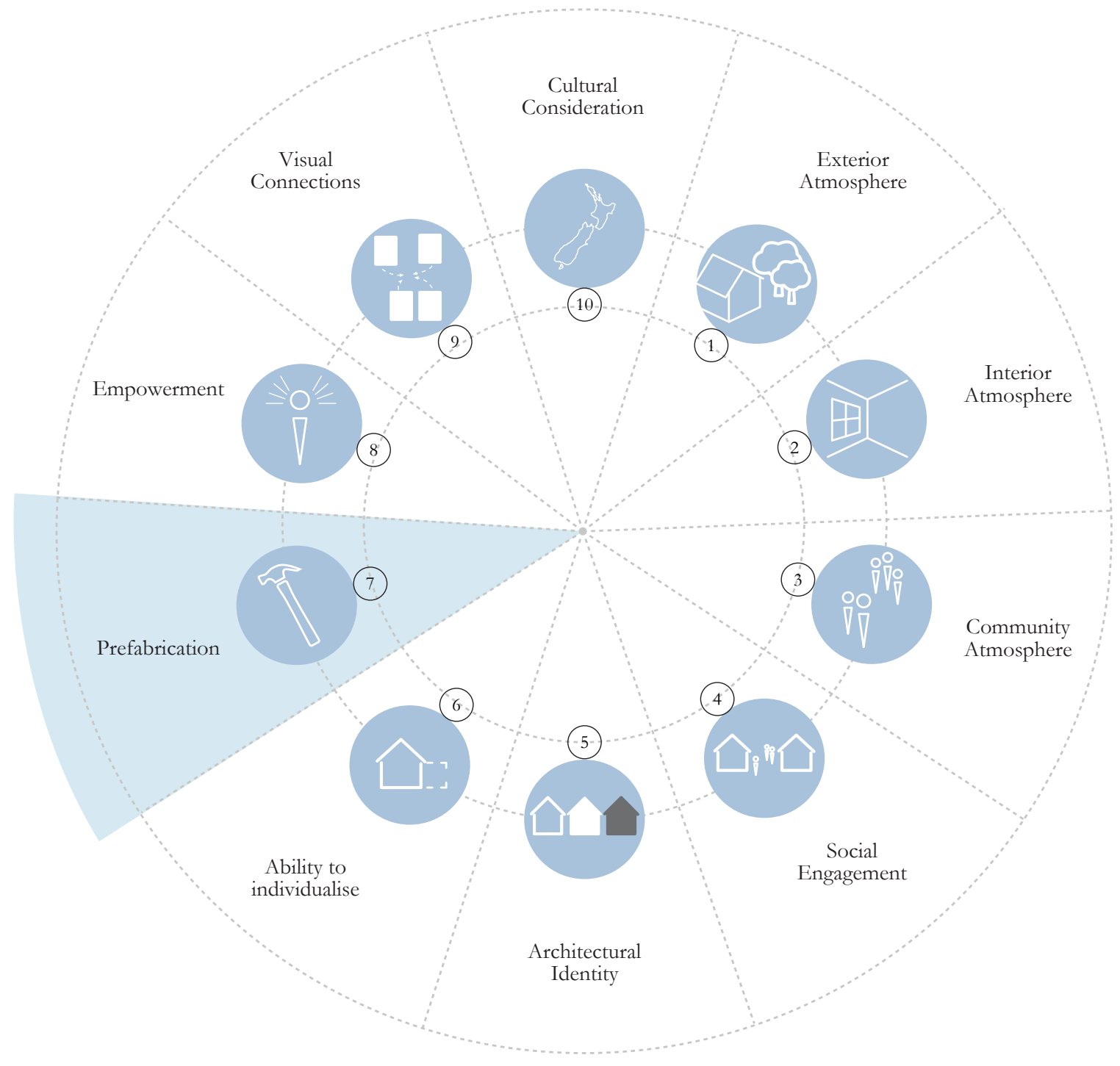

Figure 5.13. Design framework established in chapter 3 to inform the design process; prefabrication methods established 



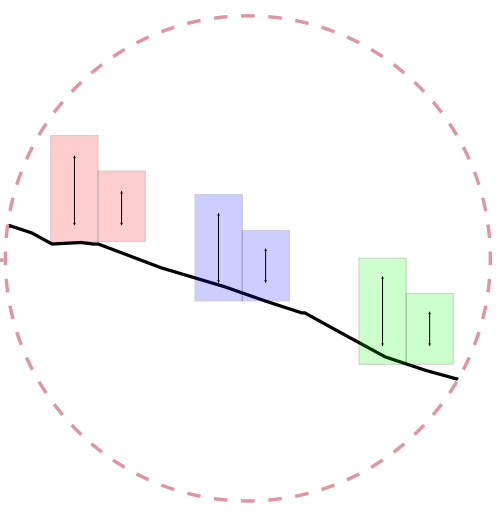

5.2.1: SCHEME 1

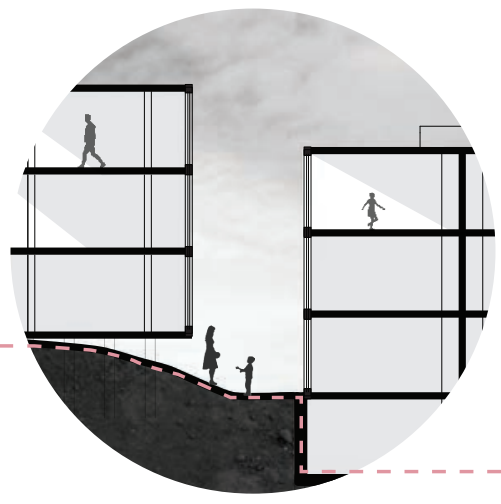

Figure 5.14. Scheme 1: Vertical stack diagram \& example section 


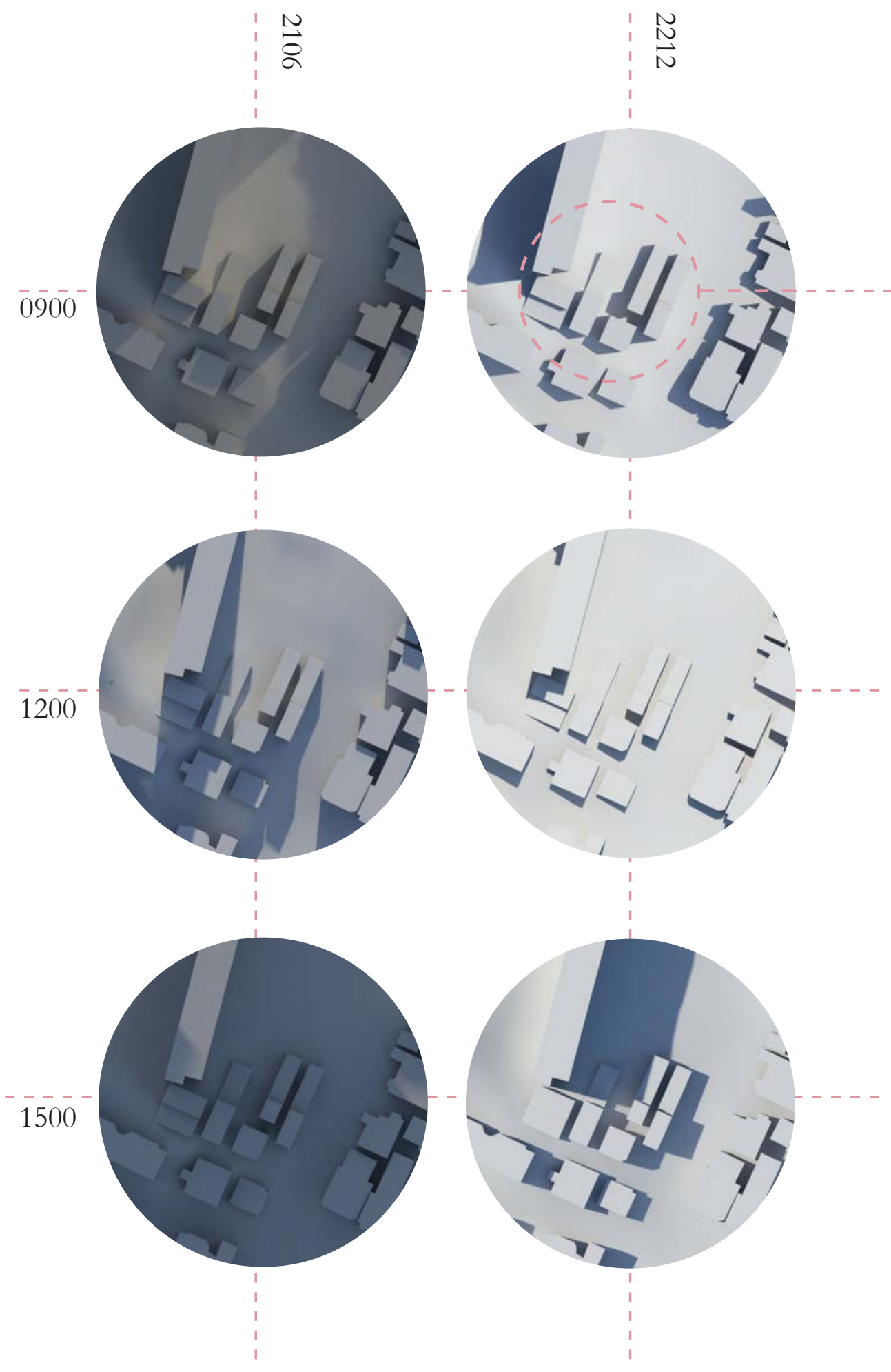

Figure 5.15. Scheme 1: Solar studies of the massed form on site during the Summer and Winter solstice 


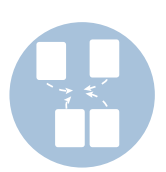

Visual Connections

The programme is designed as a vertical stacking model and terraced using the natural contours of the site to provide visual connections at various level of the site. Currently the shared space is made up of little pockets throughout the site, however there is still opportunities for further development using a larger central space.

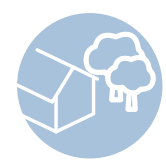

Exterior Atmosphere

This design aims to increase densification from the current conditions but in doing so has produced an undesirable exterior atmosphere within the pockets of shared space.

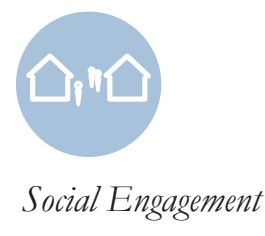

The height and density of this scheme does not provide a high level of social engagement throughout the site. The small pockets of shared space and vertical formation may provide some social engagement through the site but this won't enable the levels of engagement this thesis aims for. 


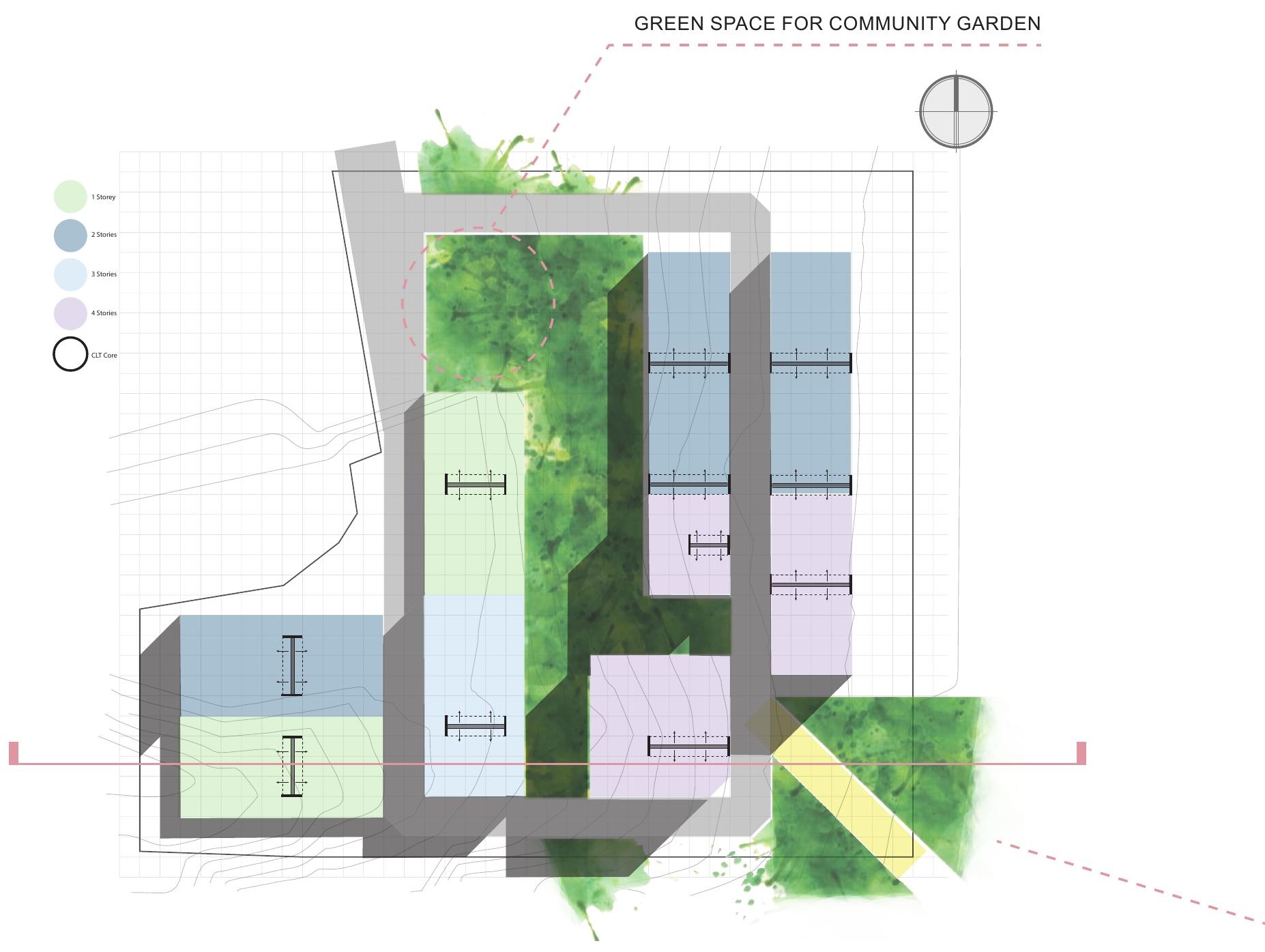

Figure 5.16. Scheme 1: Site plan massing with suggested unipod placement; scale: 1 :

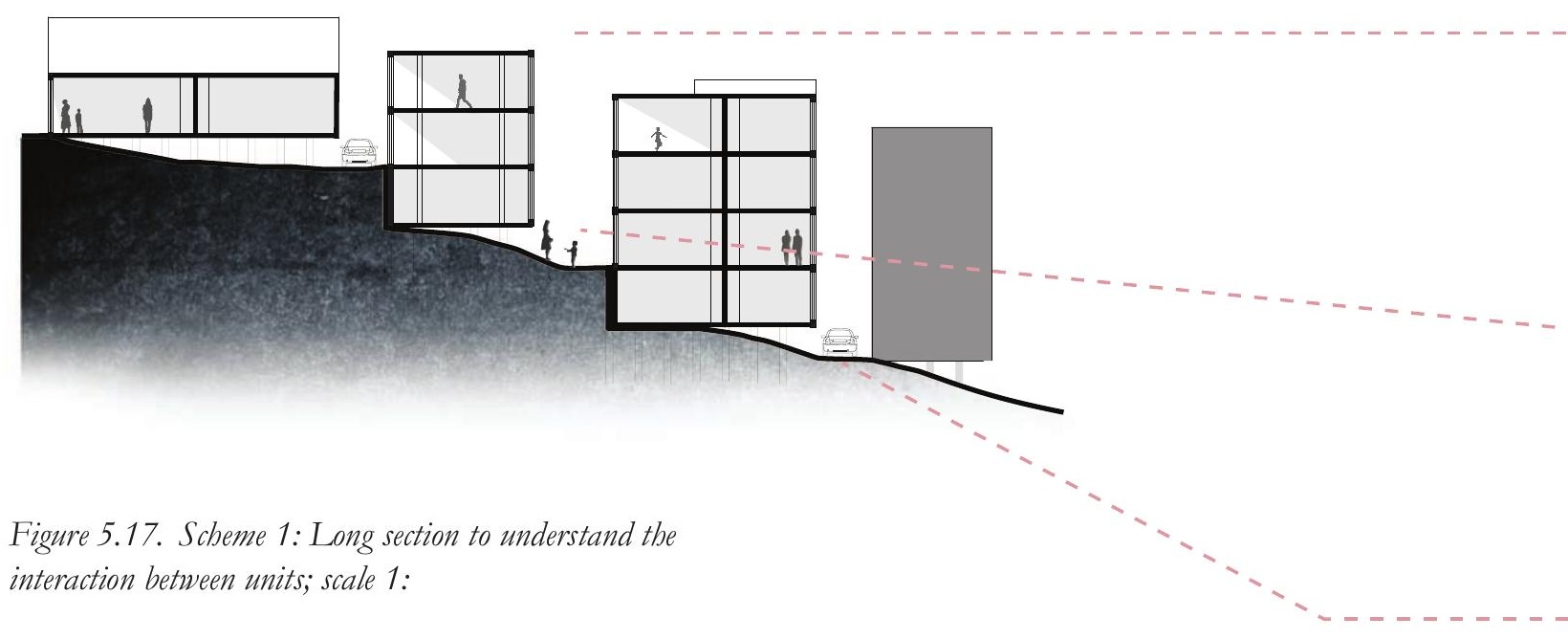




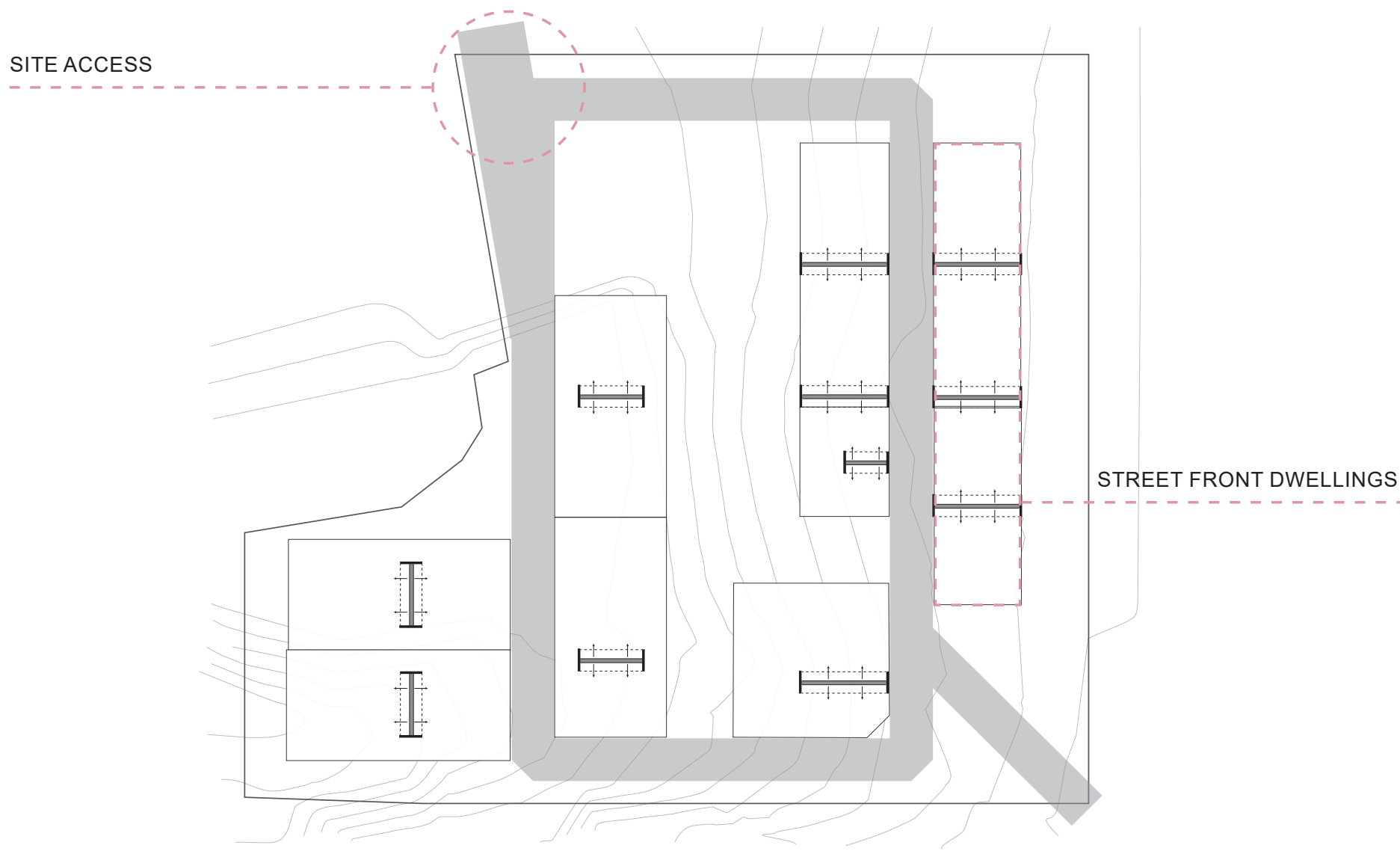

WIDE AND WELCOMING PATH FROM STREET INTO THE COMPLEX 


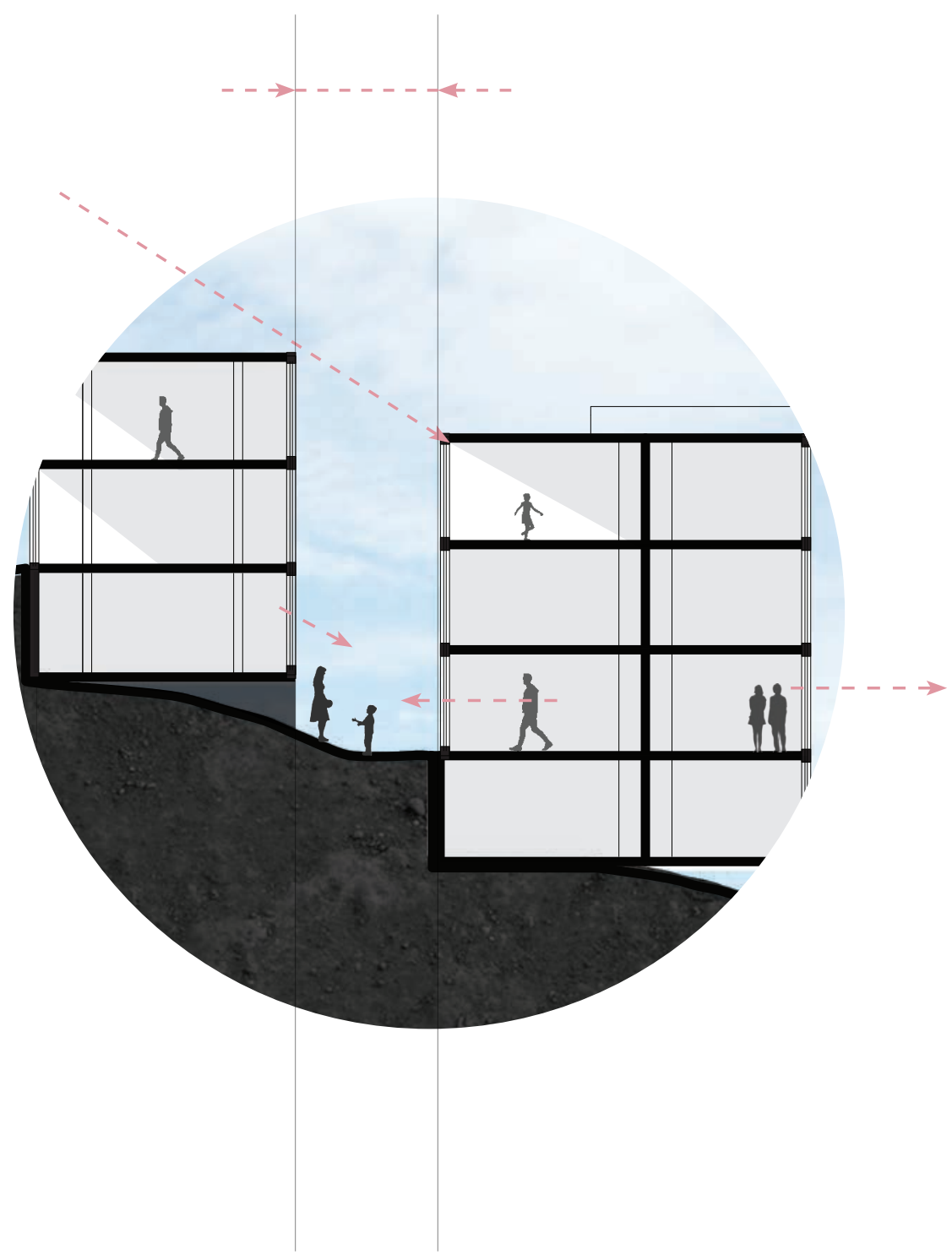

Figure 5.18. Scheme 1: Shared outdoor space/terraced units section 


\section{Scheme 1 Summary}

A particular challenge for the vertical circulation model is balancing heights without creating dark central spaces on the site. The solar analysis and shade diagrams is evidence that the height and density of the buildings blocked the light through most of the day in the summer and winter solstice, creating rather unpleasant environments and experiences for tenants.

Vertical stacking decreases the inter-tenancy acoustic issues, however due to the extreme site conditions it is evident that a vertical approach to massing does not provide all the dwellings with the opportunity to enjoy desired and diverse atmospheric conditions. Decreasing height and density of the dwellings would have a significant impact on the atmospheric conditions of the development.

The challenges of this initial design resulted in the development of the following scheme with focus on balancing competing requirements for access, lights and privacy. 



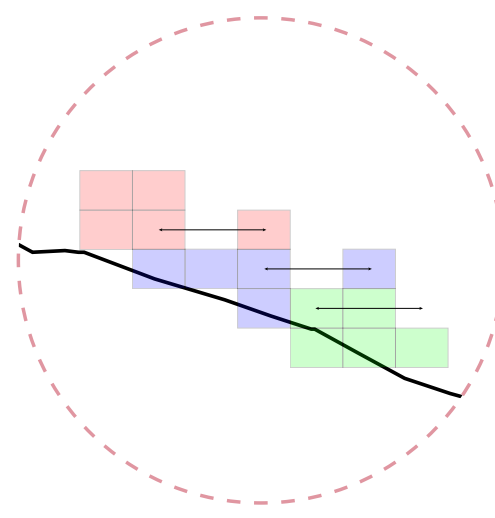

5.2.2: SCHEME 2

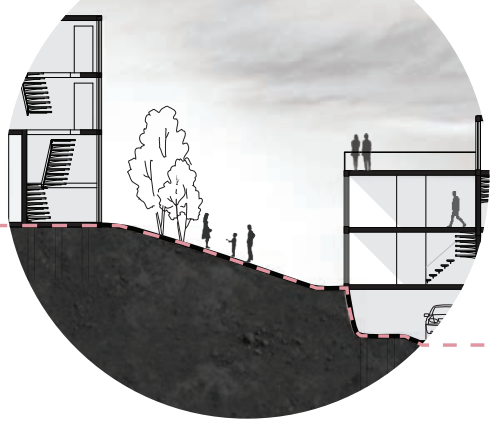

Figure 5.19. Scheme 2: Vertical stack diagram \&o example section 
$\stackrel{ }{\stackrel{\circ}{\circ}}$

$\stackrel{N}{N}$

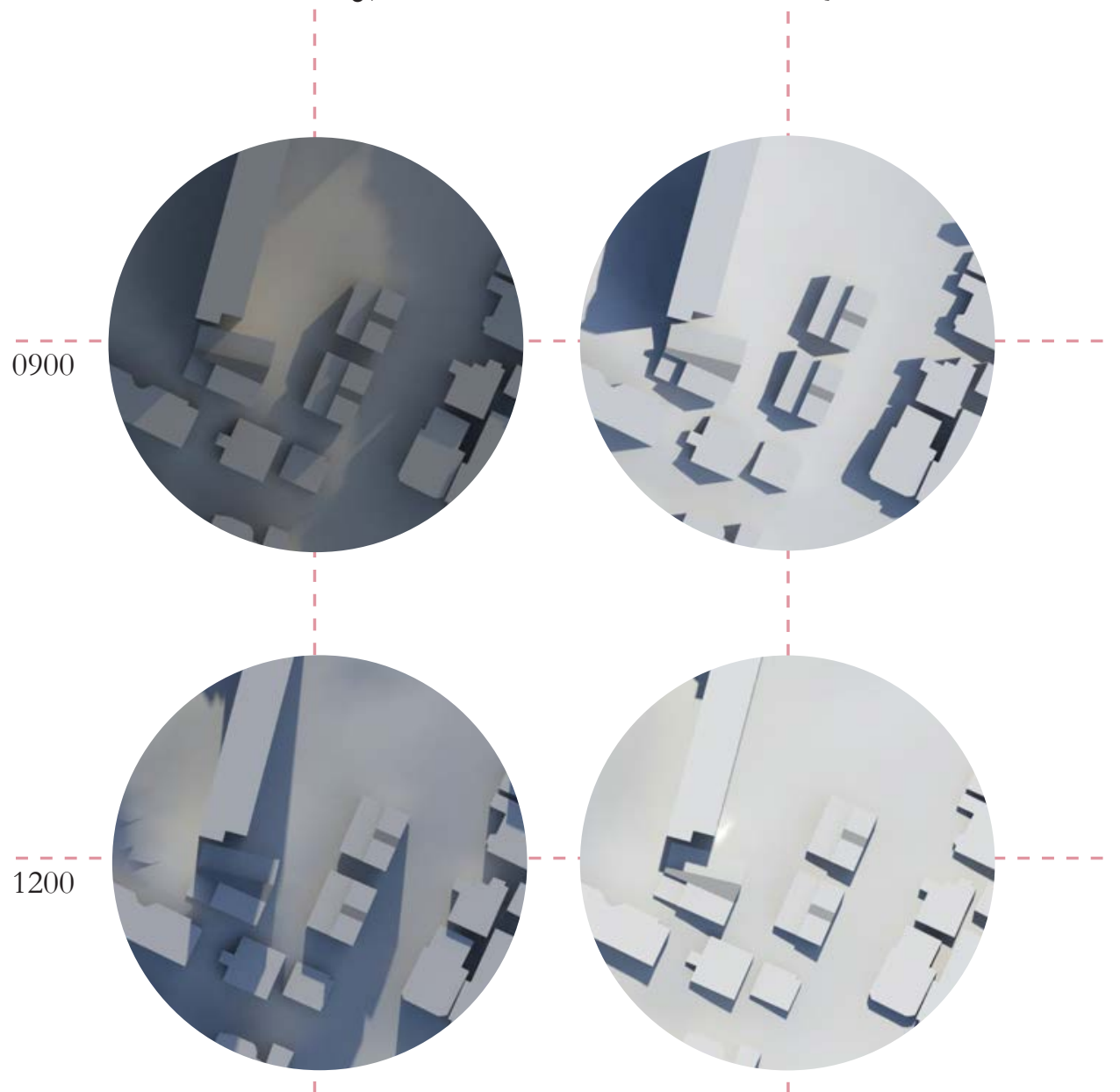

1500
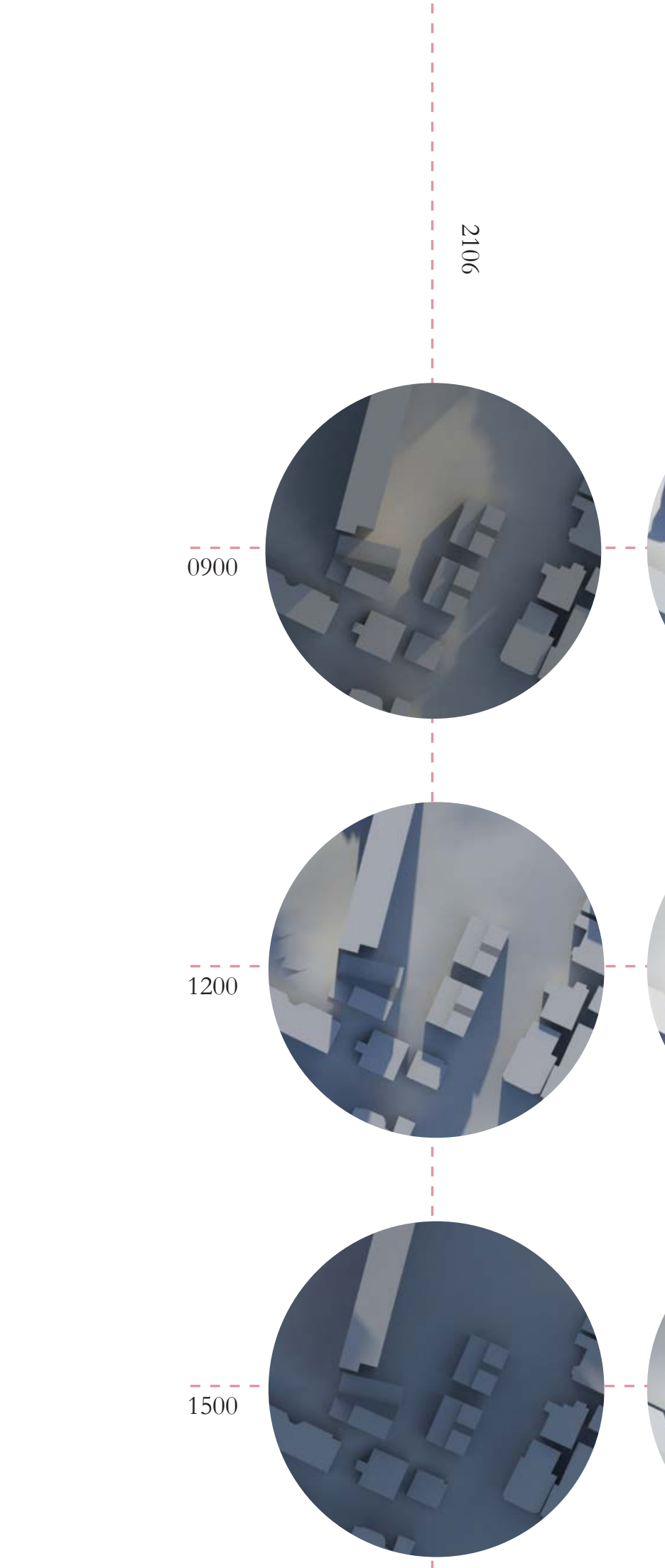
Social Engagement

Scheme 2 has been developed so that the various dwelling typologies begin to rely on each other and create inter-occupancy moments through circulation and shared public spaces. This allows for the density of the site to be increased while spreading the buildings to the edges of the site and creating a central public domain.

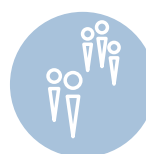

Community Atmosphere

This scheme has been strongly influenced by the advantages laid out in the case studies and has focused on developing a strong sense of community. The massing formation provides a central public space with two additional rooftop spaces for entertainment and community gardens.

Interior Atmosphere

The solar analysis, figure 5.20, has shown that the form and height of buildings need careful consideration to ensure each dwelling captures natural lighting throughout various times of the day. Capturing lighting qualities through the day enhance the interior spatial atmosphere and enables better living environments. 


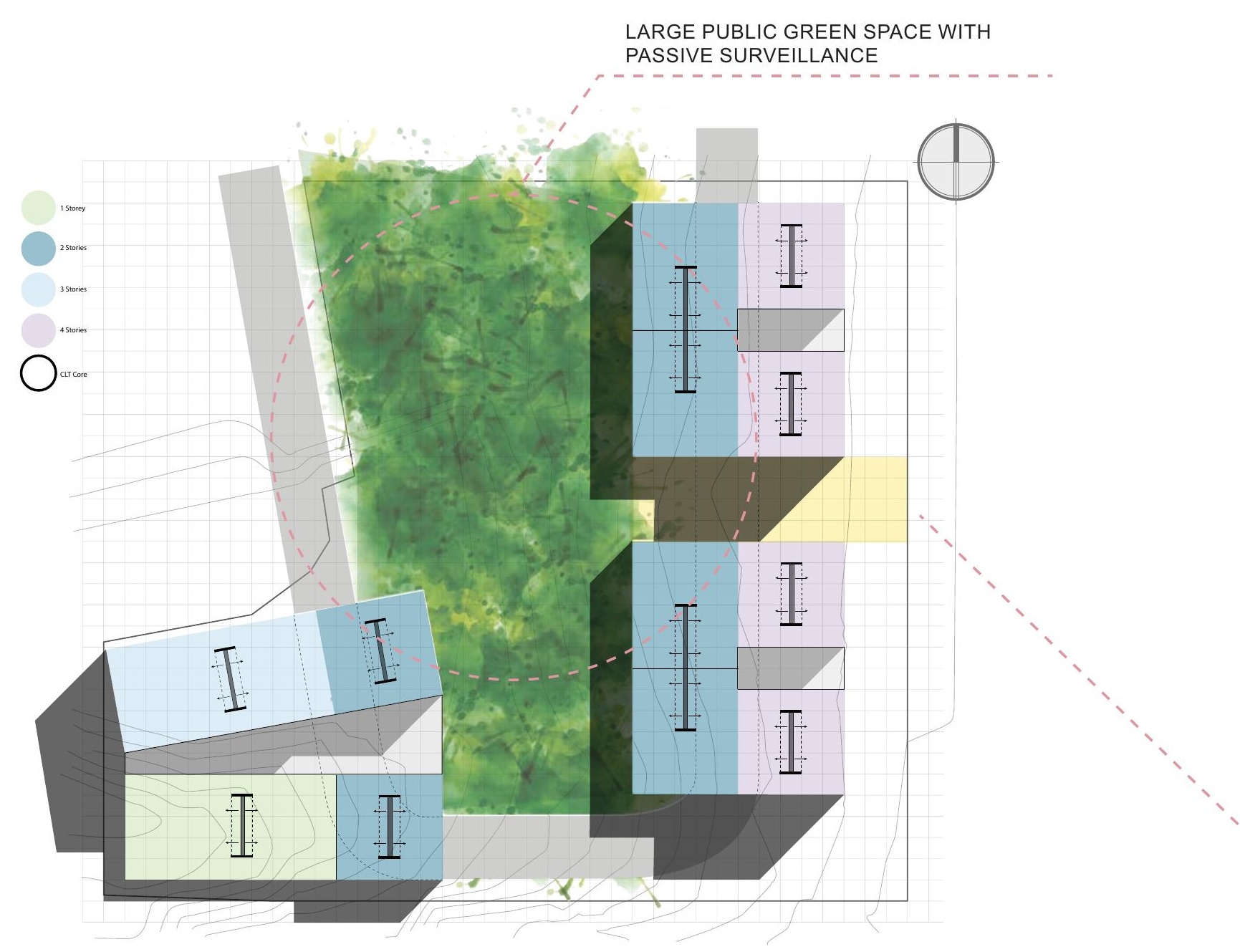

Figure 5.21. Scheme 2: Site plan massing with suggested unipod placement; scale: 1 :

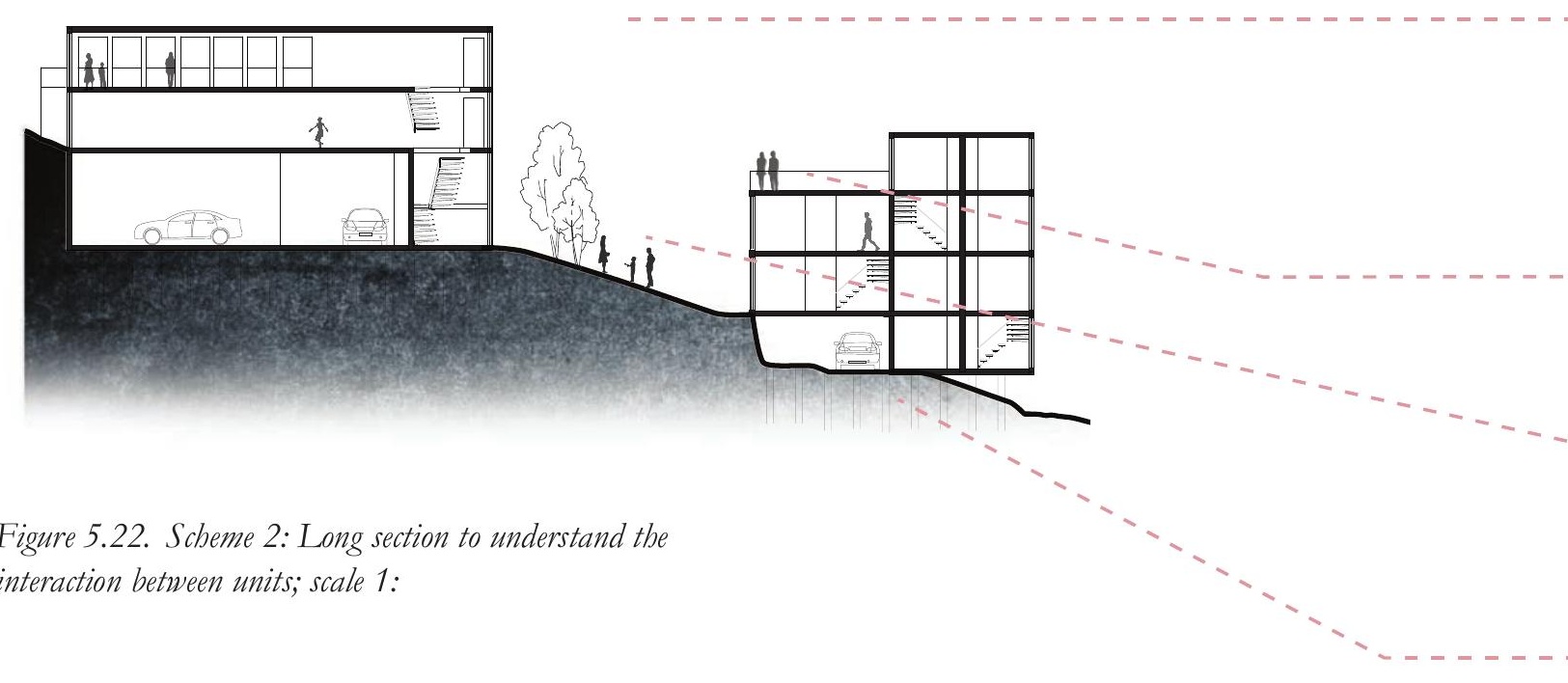




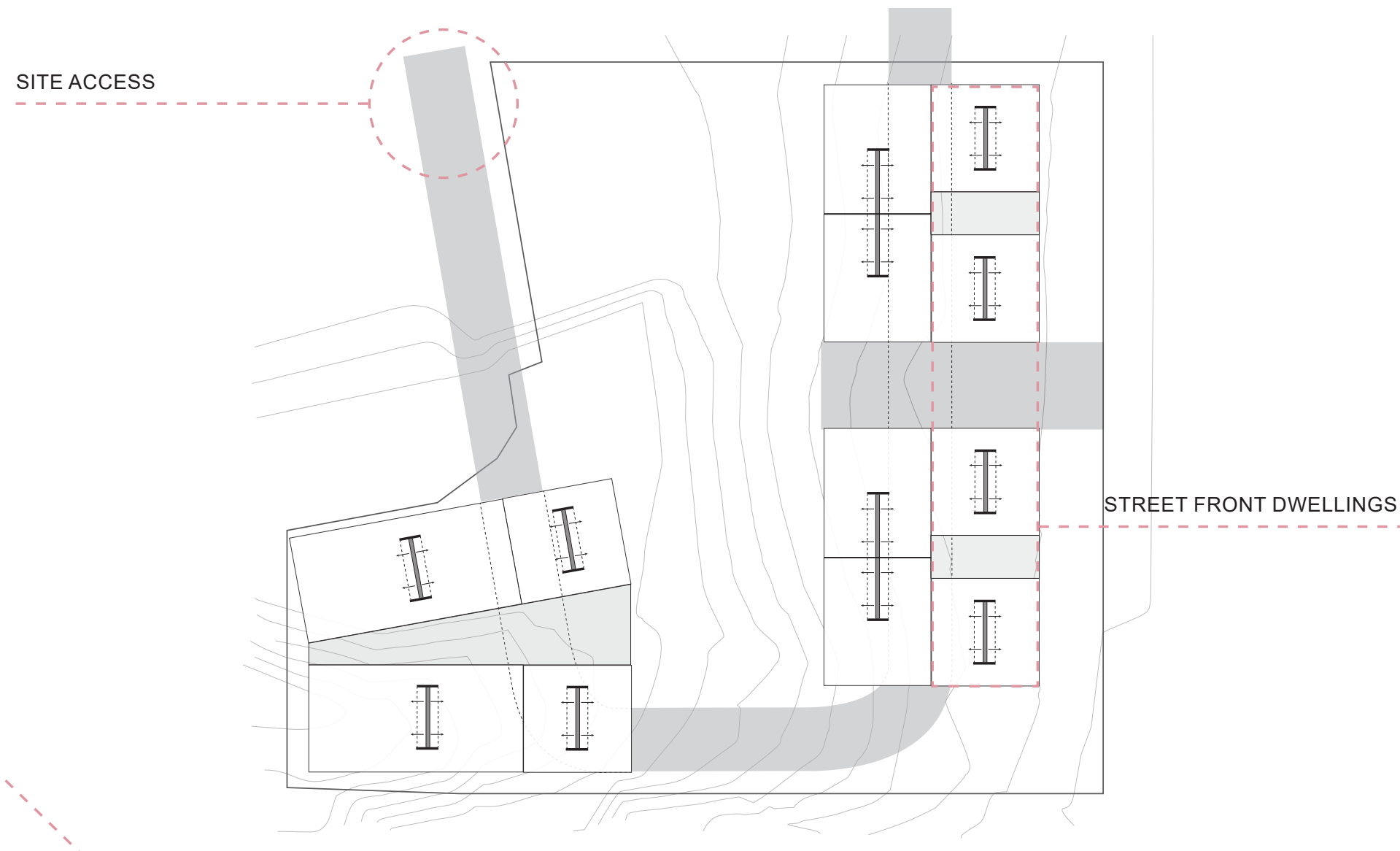

WIDE AND WELCOMING PATH FROM STREET INTO THE COMPLEX

TERRACED WITH EXISTING SITE CONTOURS

ROOFTOP FOR ENTERTAINMENT, COMMUNITY

GARDENS AND PROVIDING PASSIVE

SURVEILLANCE OVER PUBLIC SPACE 


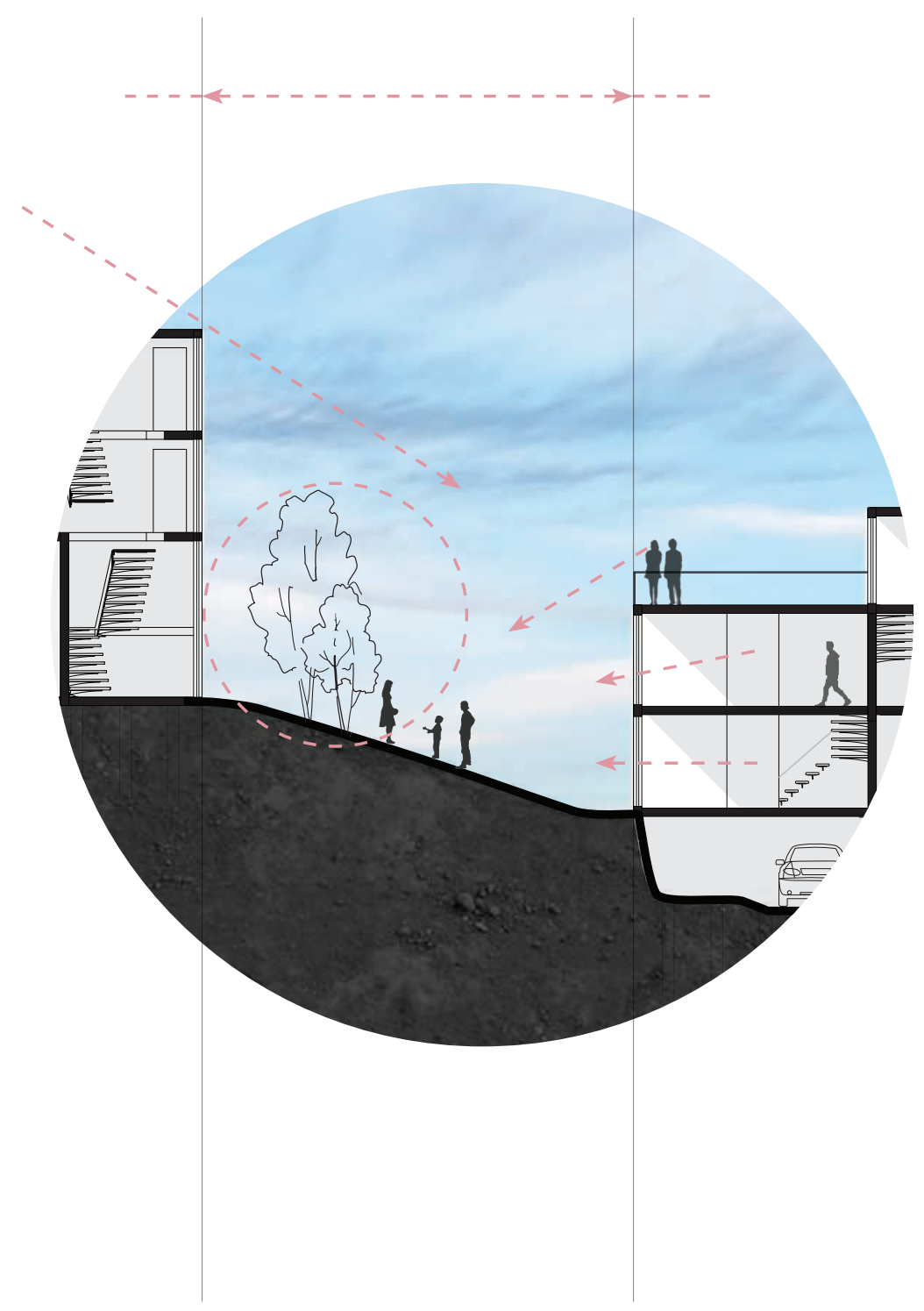

Figure 5.23. Scheme 2: Shared outdoor space/terraced units section 
Scheme 2: Summary

This scheme developed as an opposing idea to scheme 1 . The focus was to create a flow between public and private with centralised atrium circulation acting as threshold spaces. With more development and using various techniques such as levelling, materiality, permeability and planting a balance of public and private can be achieved.

The horizontal nature of this scheme makes it a concept that is more versatile and transferable to other sites around New Zealand. If this scheme can be developed to create the desired atmospheric conditions and evoke a sense a dignity amongst its tenants, it is possible to take this framework and adapt it for social housing developments on other sites. 

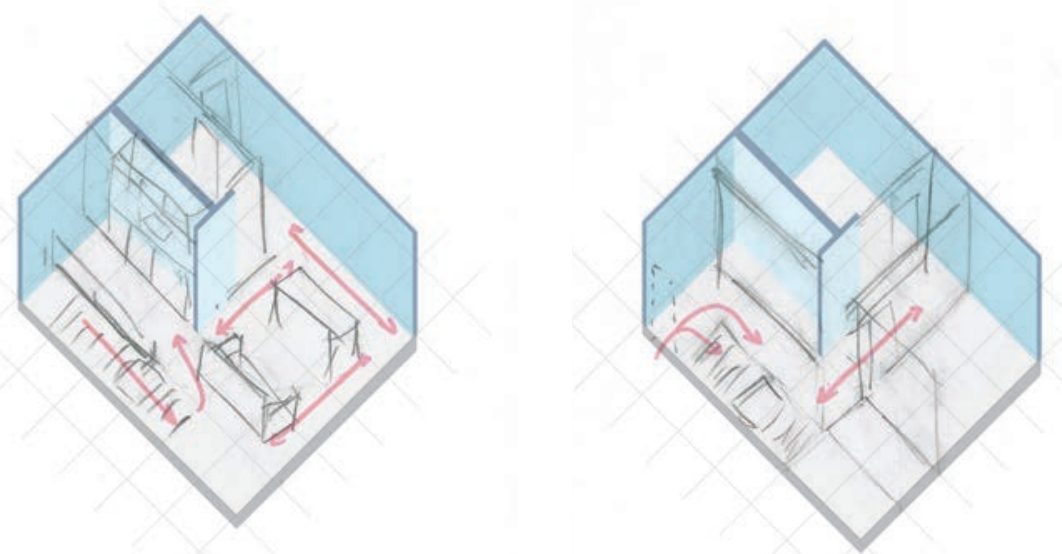

2 Floors 3 Bed
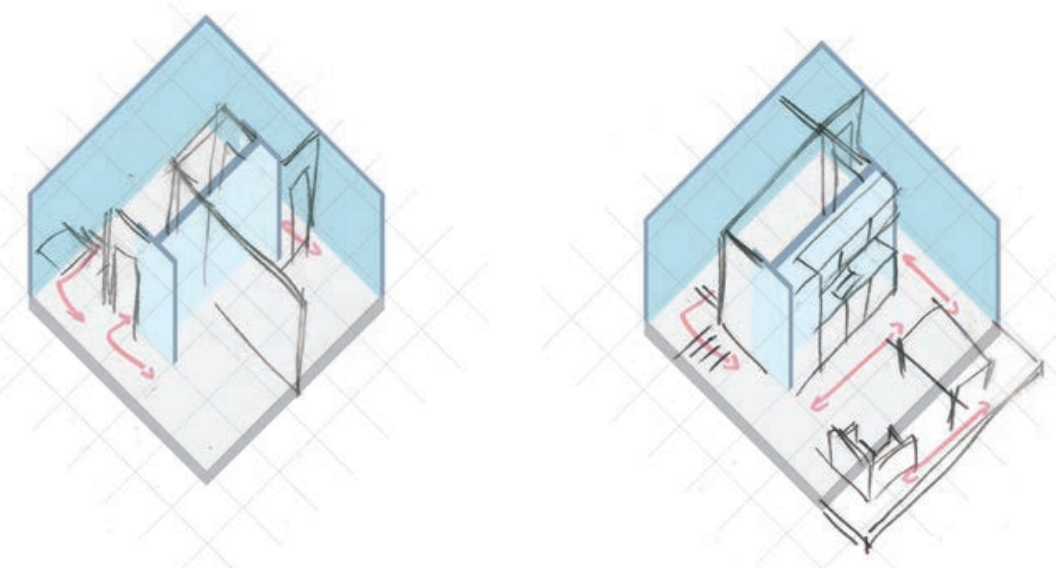

2 Floors 2 Bed

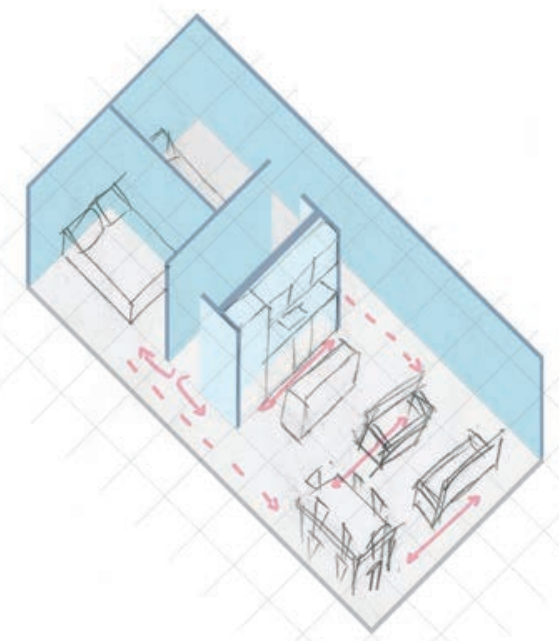

1 Floor 2 Bed

Figure 5.24. Initial sketch ideas of dwelling development for Scheme 2 


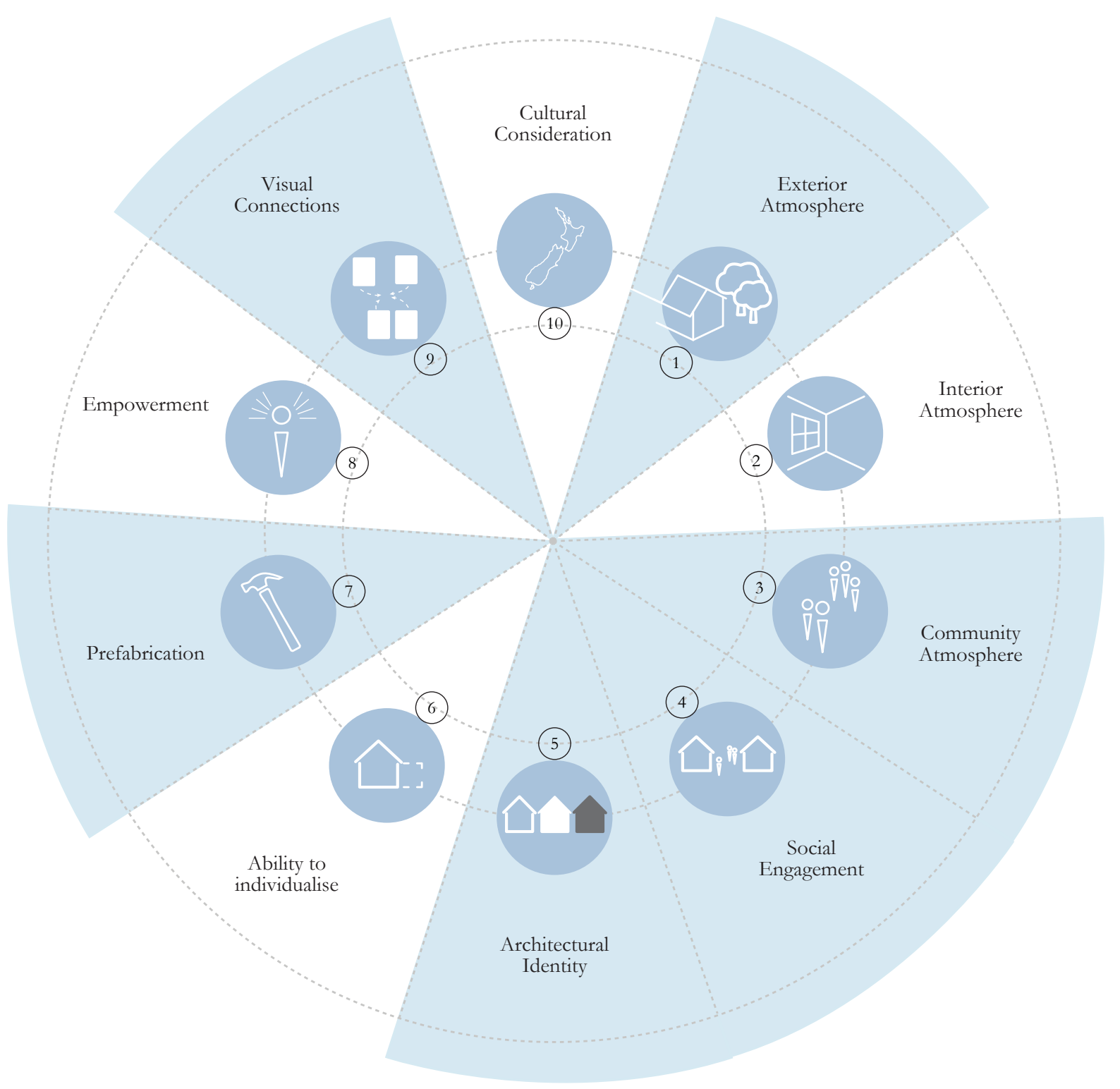

Figure 5.25. Design framework that has been established through the current design phases 


\section{3}

\section{UNIPOD CONFIGURATION Iterations Studies}

The next stage is a design-led exploration to establish desired interior atmospheric qualities. These iterations evolved from the initial sketch ideas to understand how prefabrication could be incorporated into space planning. Starting investigations into prefabrication systems early in the design phase developed an in-depth understanding of these systems and enabled an innovative architectural outcome that is not limited by construction methods.

This investigative study served as an important learning curve as difficulties arose when trying to plan for the services running through the UniPod. The UniPod is a prototype that has not yet been utilised in a built space. While the UniPod would be ideal for a 'cookie cutter' housing scheme stacked one on top of the other, which is not the aim of this research project, a more versatile system needs to be developed.

The UniPod lacks flexibility of use in a home environment particularly where the bathroom is to be the main one in the house, and certain facilitiies need to be e usable and accessible at all times. For example, the washing machine, bathroom and kitchen. At the moment these separate features of the UniPod could not all be utilised at once, and for a three bedroom dwelling, this becomes a significant design limitation. 

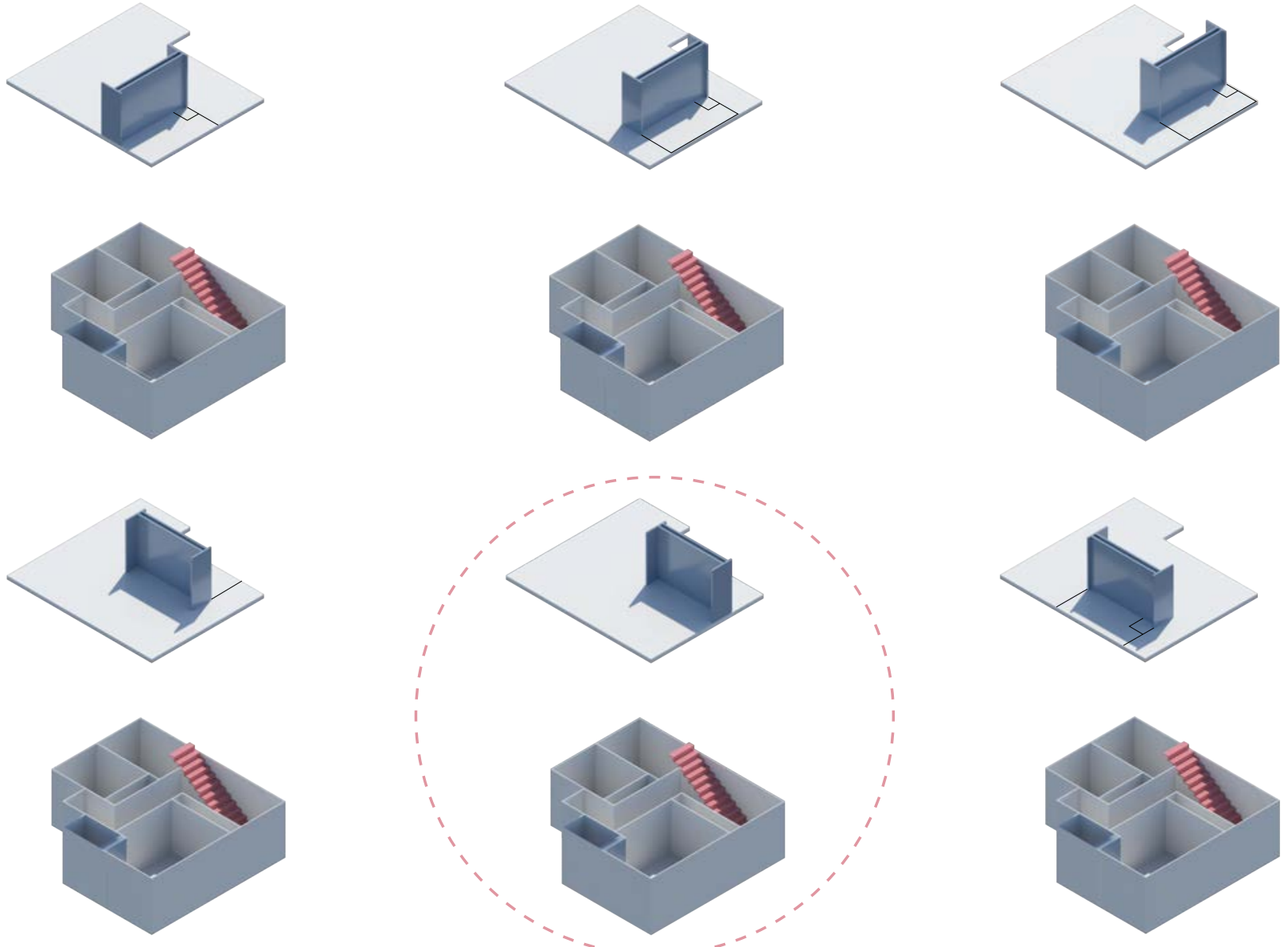

Figure 5.26. UniPod configuration iteration studies; dwelling 1
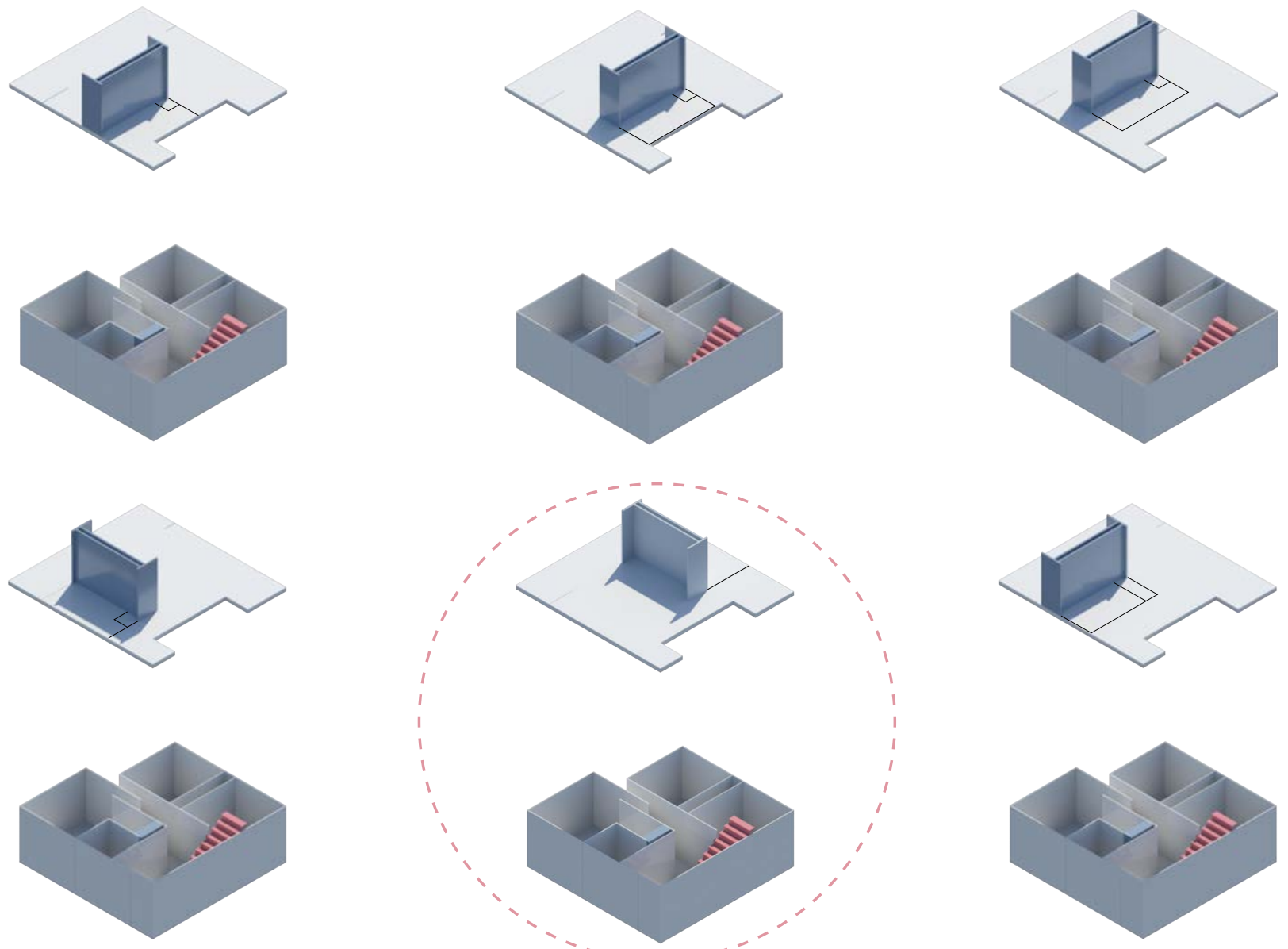

D2.01

Figure 5.27. UniPod configuration iteration studies; dwelling 2 


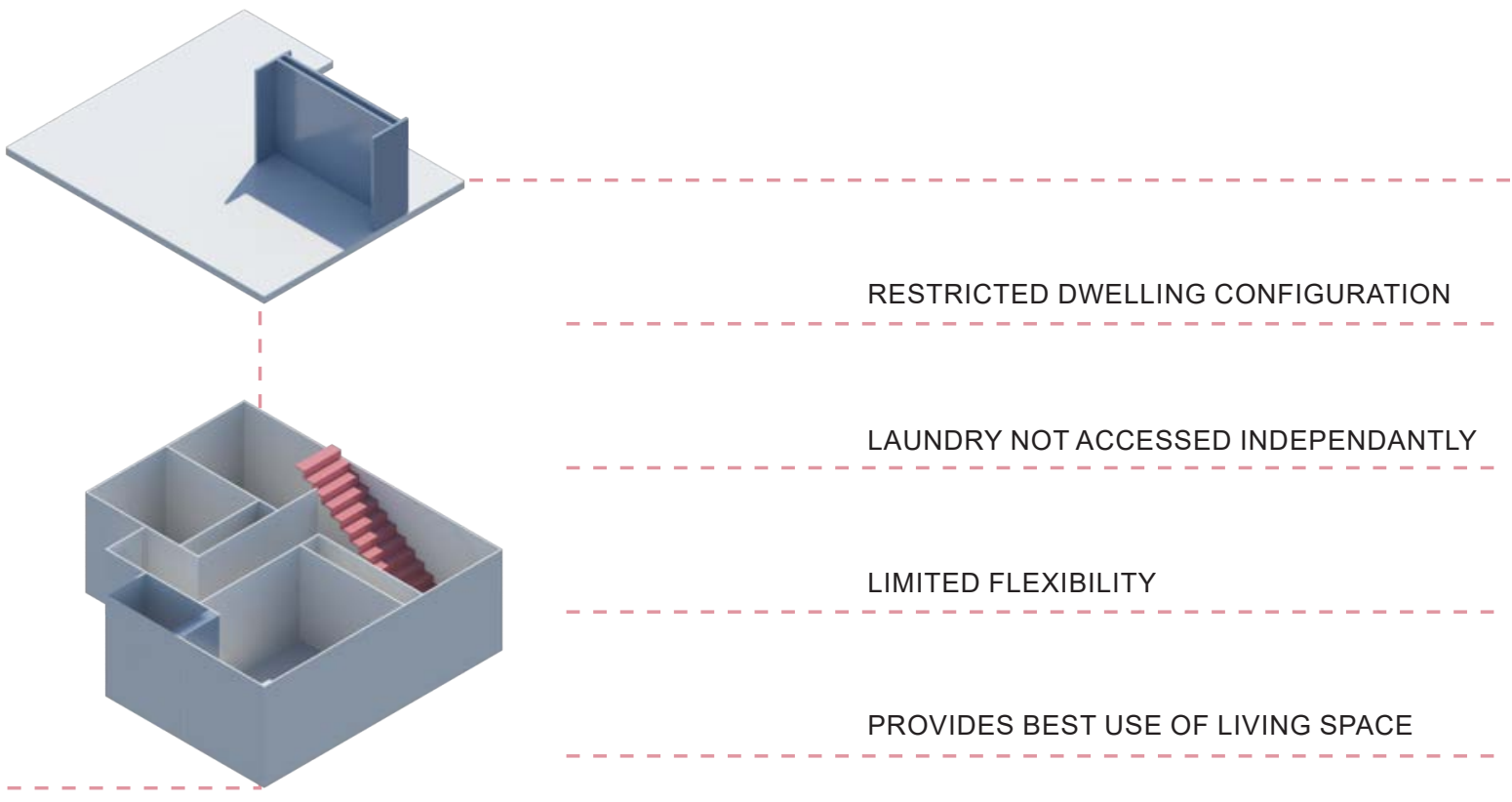

Figure 5.28. Chosen UniPod configuration suitable for dwelling 1

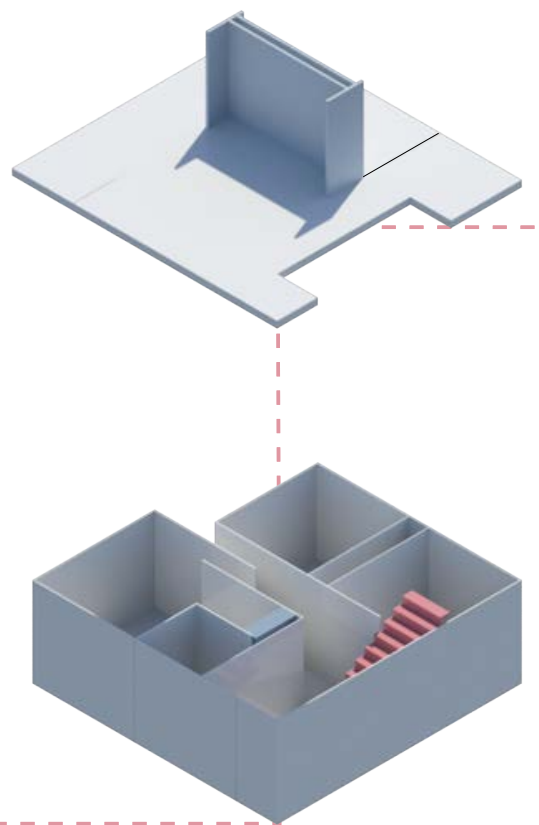

LAUNDRY ACCESSED SEPARATELY

INDEPENDANT USES WITH COMPOMISES

LIMITED FLEXIBILITY

RESTRICTED DWELLING CONFIGURATION

Figure 5.29. Chosen UniPod configuration suitable for dwelling 2 


\section{4}

\section{SERVICEBOX Developmental Process}

Due to the limitations with the UniPod, a unit more adaptable and flexible was needed. This resulted in the development of the 'Servicebox'. It has been design for greater efficiency and flexibility of use. In addition, the design of the Servicebox, offers more living space and provides opportunities that the Unipod could not.

The next stage investigates the issues surrounding the UniPod and shows the evolution of the Servicebox. 


\section{4 .1}

\section{SERVICEBOX}

\section{The Problem}

The UniPod system is designed to combine the necessary functional requirements of a home into a smart wall that encompasses the services and provides the amenity of a bathroom and kitchen. The UniPod provided a glimpse into the future of medium-density housing, however when put into a two storey house plan, issues began to arise.

Figure 5.32 shows the limitations associated with the UniPod prototype, the dominant being restricted floor plan arrangements. These limited arrangements began to dictate the architectural features of the house and control the atmospheric qualities and limits what's achievable.

This thesis focuses on achieving low-cost housing that delivers an architectural identity through diverse atmospheric qualities. The UniPod prototype was a prefabricated system that did not fulfil the objectives of this research. These issues drove the design of the Servicebox, a system that provided efficiency and flexibility to achieve the objectives of this research.
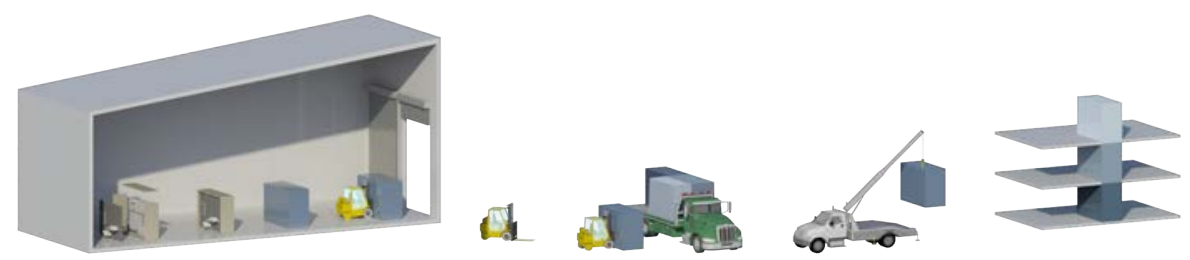

Figure 5.31. Servicebox delivery and installation process 


\section{UNIPOD}

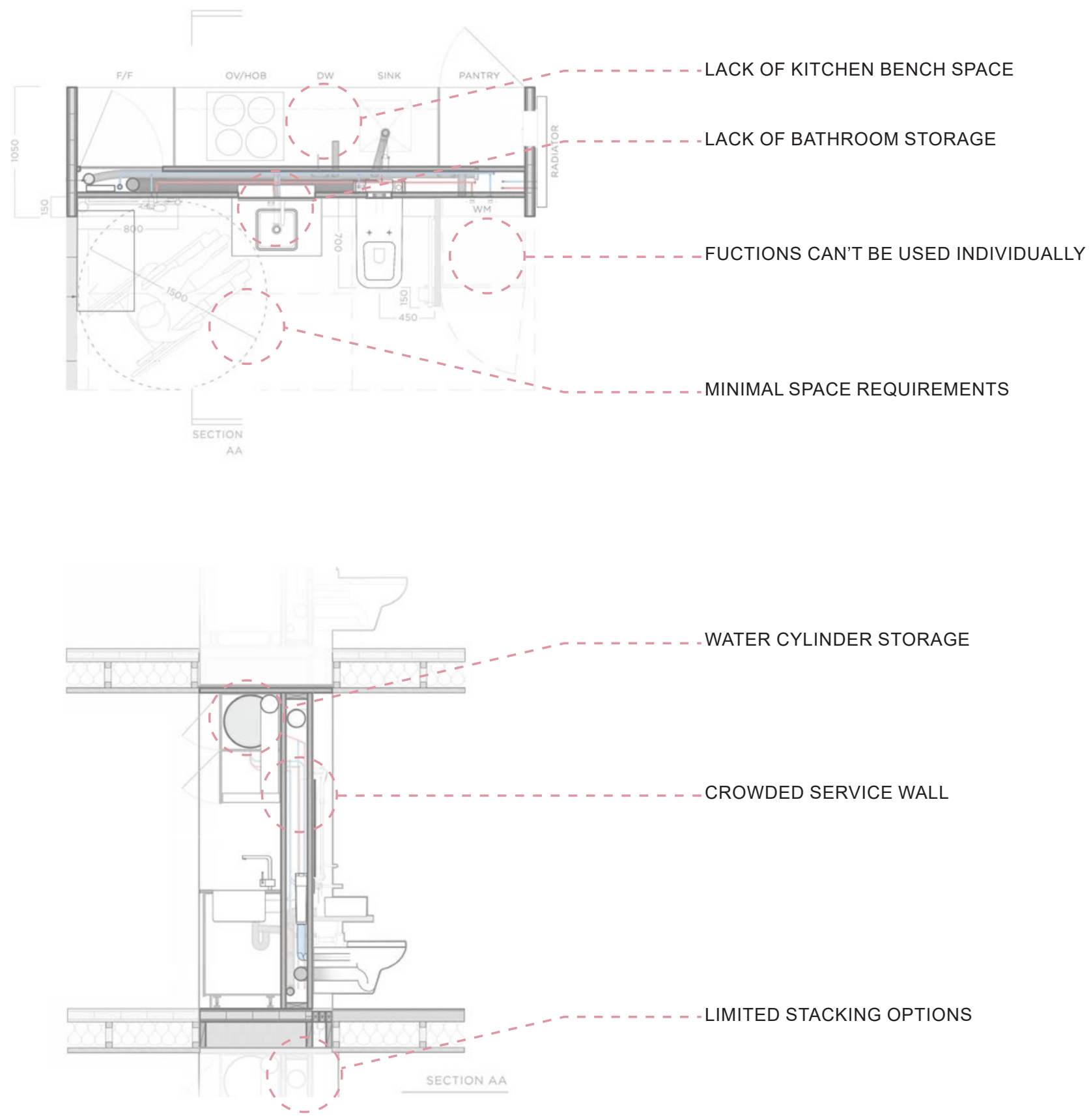

Figure 5.32. UniPod limitations 


\section{4 .2}

\section{SERVICEBOX}

\section{The Solution}

The Servicebox aided in the development of atmospheric qualities within the dwellings. It provided more efficiencies with flexibility and individualisation as shown in figure 5.33.

This exploded axonometric illustrates the benefits of the Servicebox as well as the increased flexibility, additional workspace and storage has been incorporated. The addition of an electric water heater instead of a storage water cylinder provided increased efficiencies with storage and reduced the overall weight of the unit.

The biggest advantage of the Servicebox is that all of its functions (kitchen, bathroom and laundry) can be all used independently and simultaneously. The interior atmospheric advantages achieved with the Servicebox are far superior and is a prefabricated unit that can be used to meet the needs of social housing tenants. 


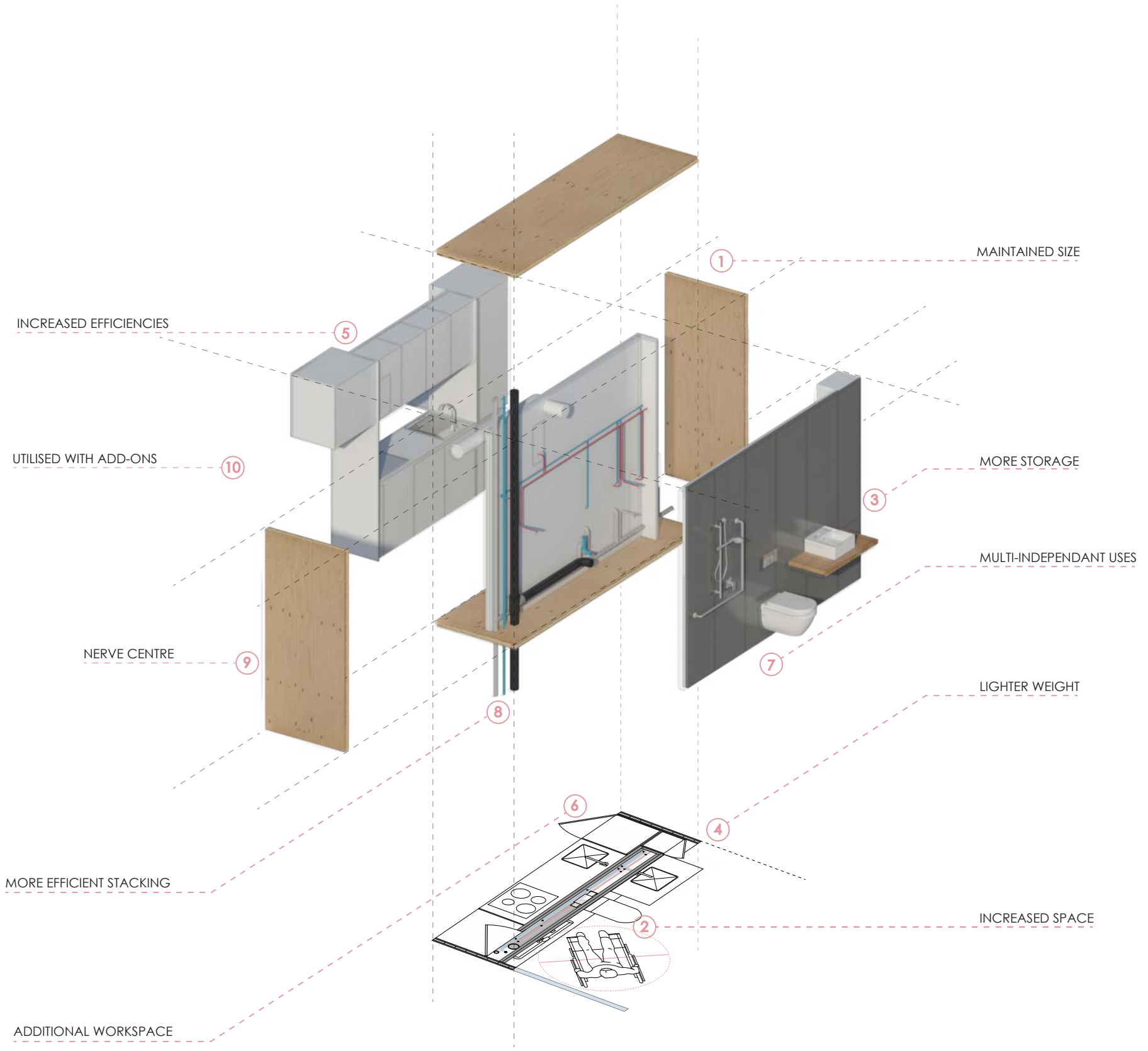

Figure 5.33. Servicebox exploded axonometroc highlighting improvements 


\section{SERVICE BOX}

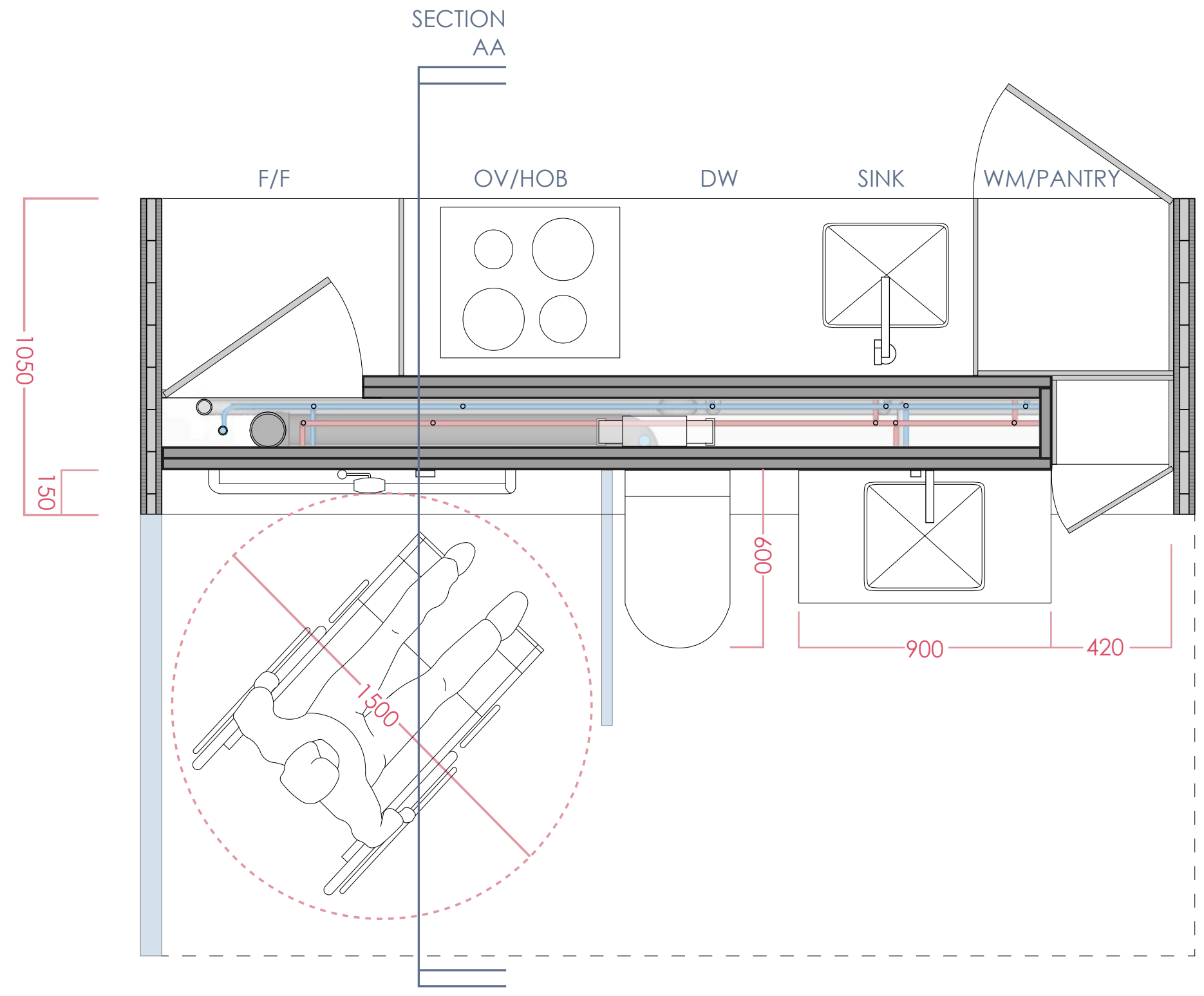

Figure 5.34. Servicebox plan and cross section, scale 1:20 


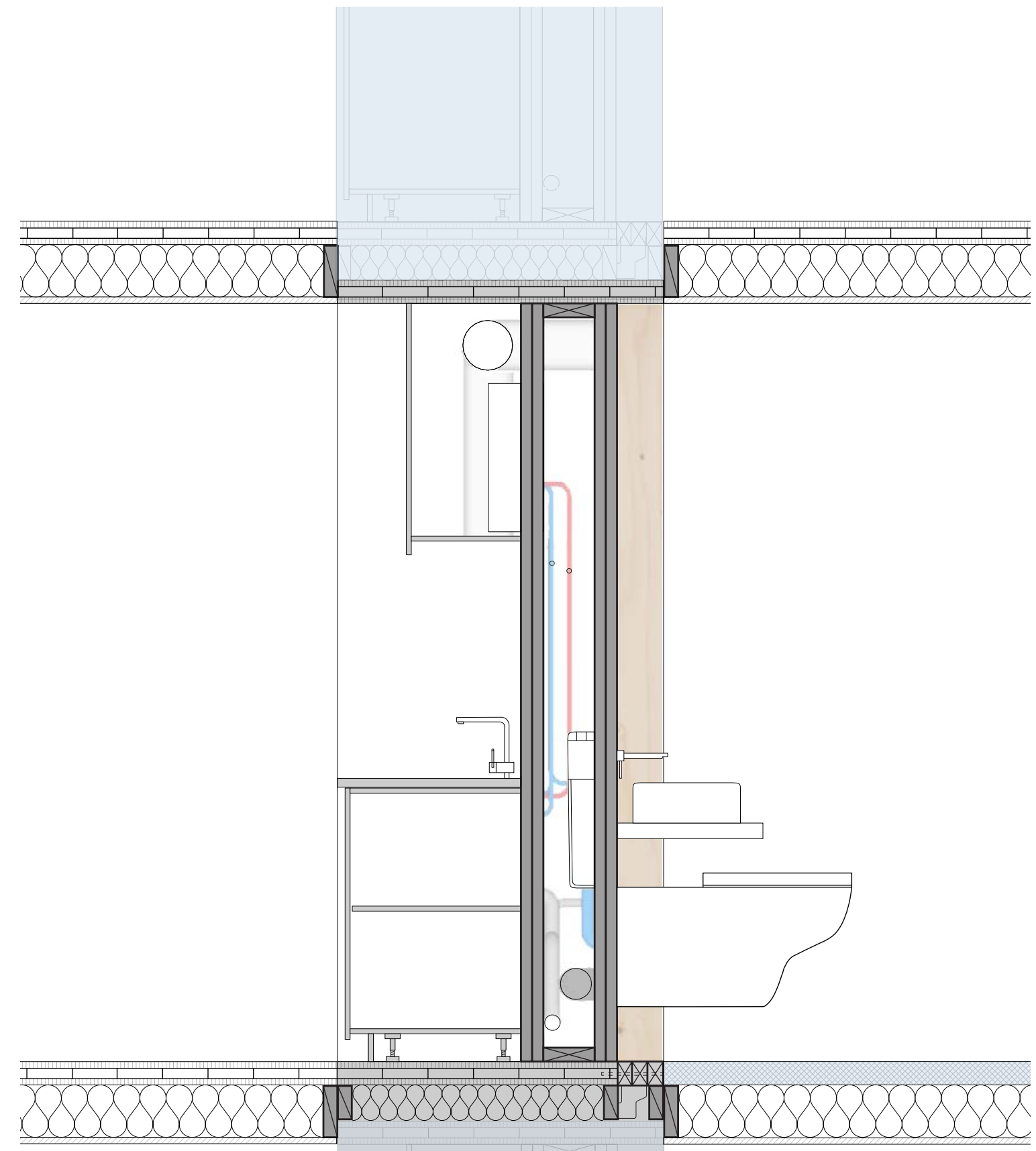

SECTION AA 

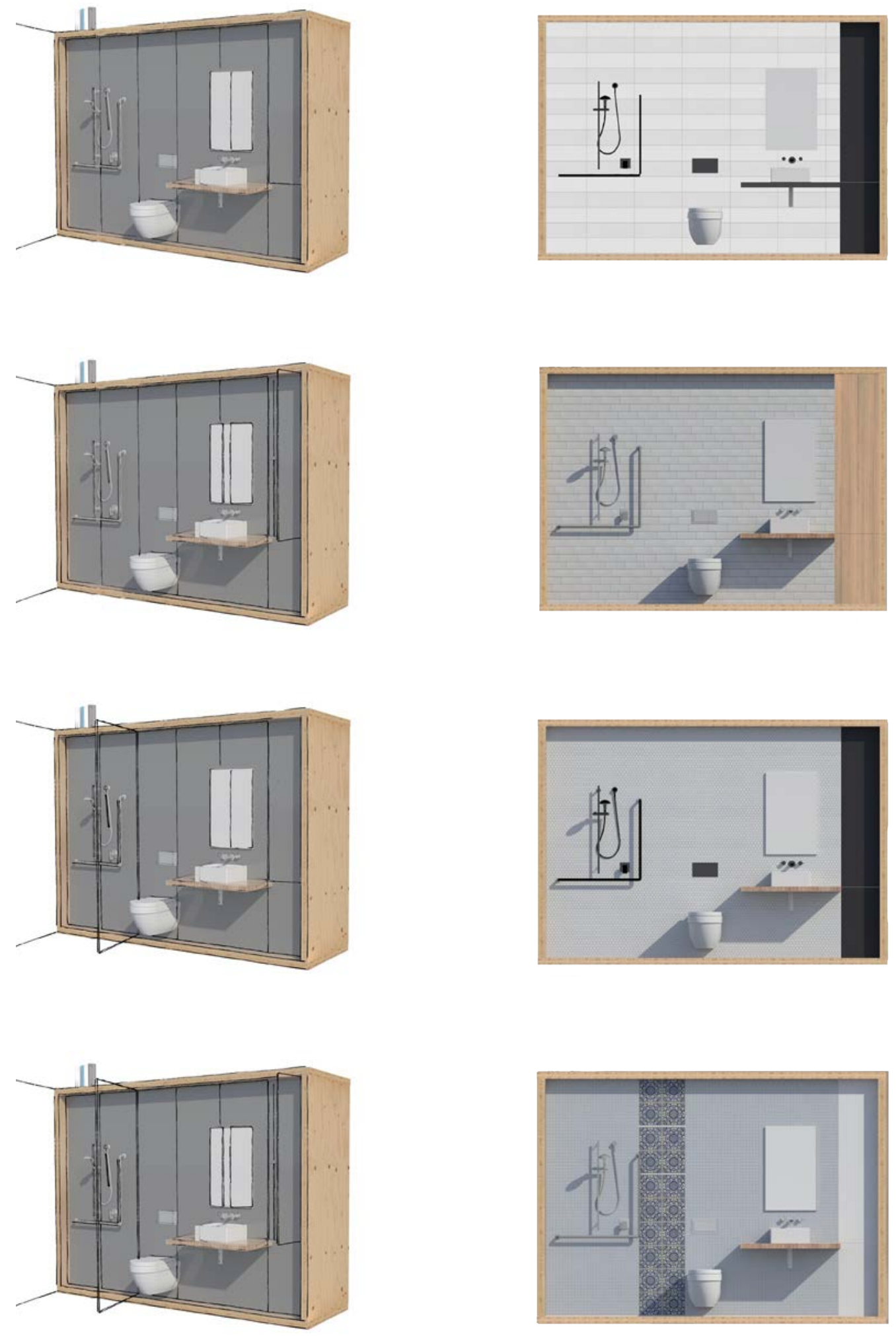


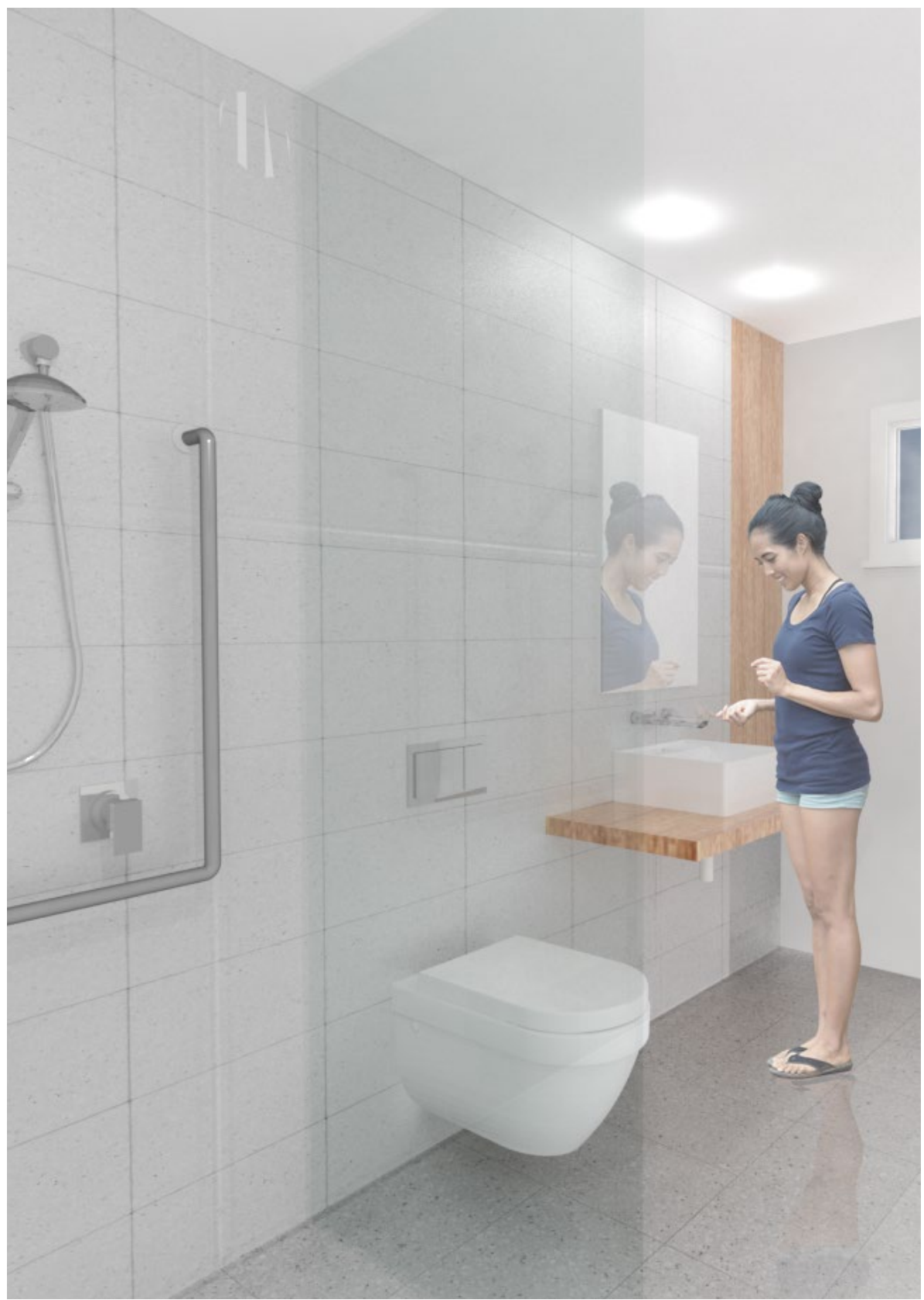

Figure 5.36. Servicebox Bathroom 

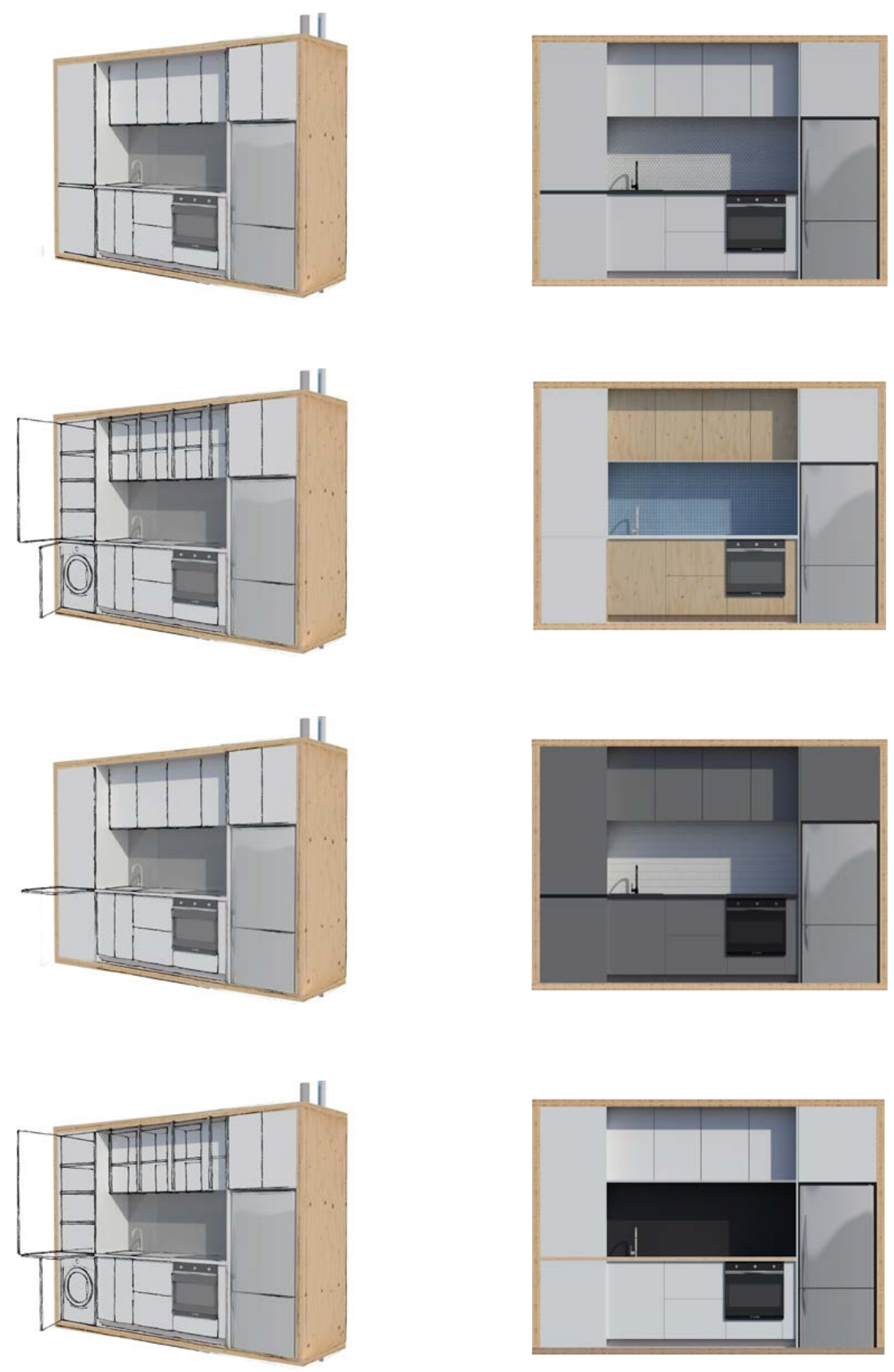


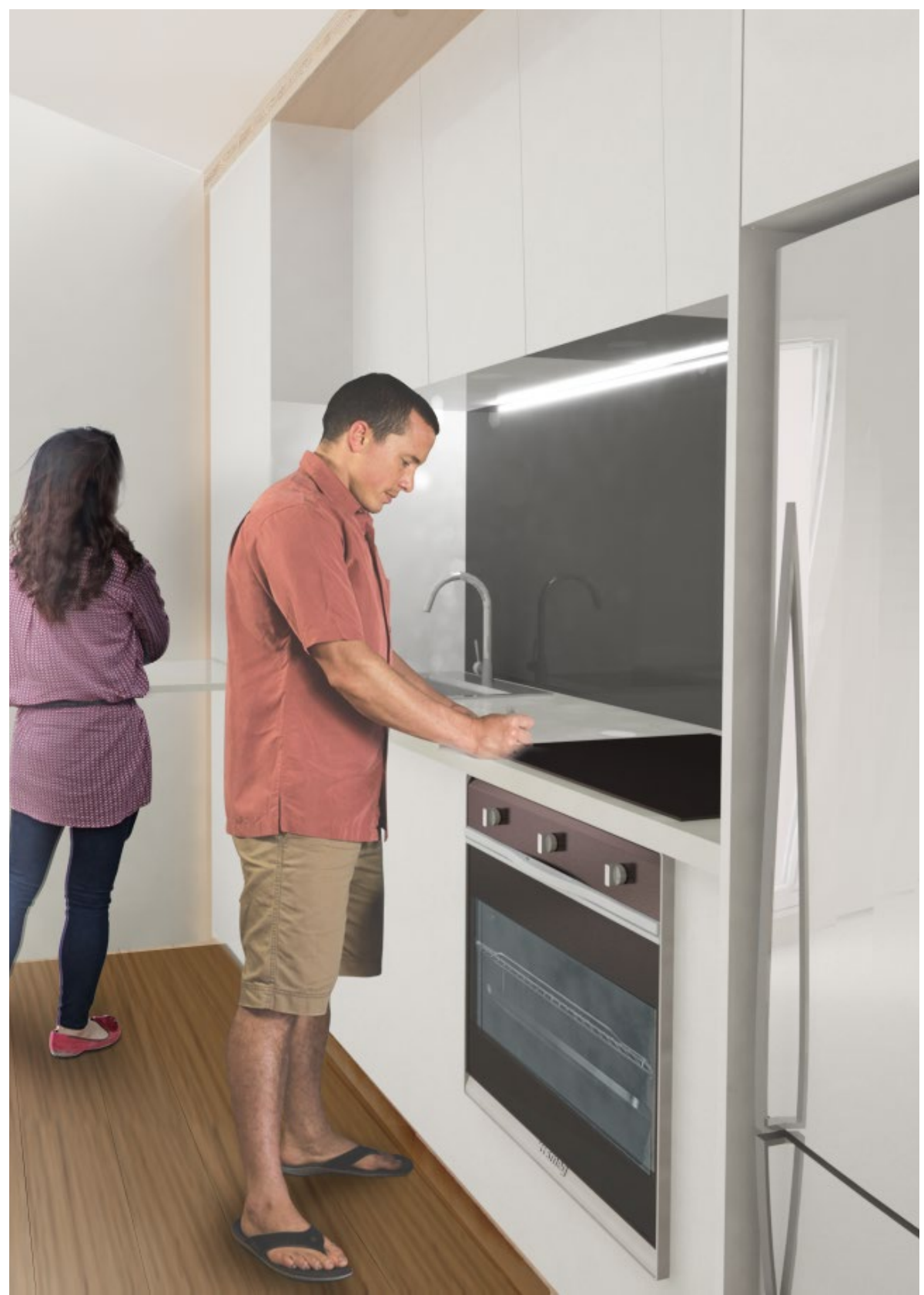

Figure 5.38. Servicebox Kitchen 


\section{5}

\section{DWELLING DEVELOPMENT}

\section{Iteration Studies}

The development of the Servicebox created more flexibility and architectural control when designing. The next stage was a design-led exploration to achieve a dwelling arrangement that achieved desired interior atmospheric qualities. These iterations evolved from the initial UniPod iteration studies, however these iterations had more space planning options.

This investigative study served as an insightful step into producing dwellings for atmosphere. Designing these dwellings with 3D computer modelling, it was possible to simulate light qualities that were achievable in each space.

This process was then executed with the three alternative dwelling typologies to achieve a space arrangement for each that was unique and fulfilled the requirements of the interior atmosphere criterion outlined in the design framework. 

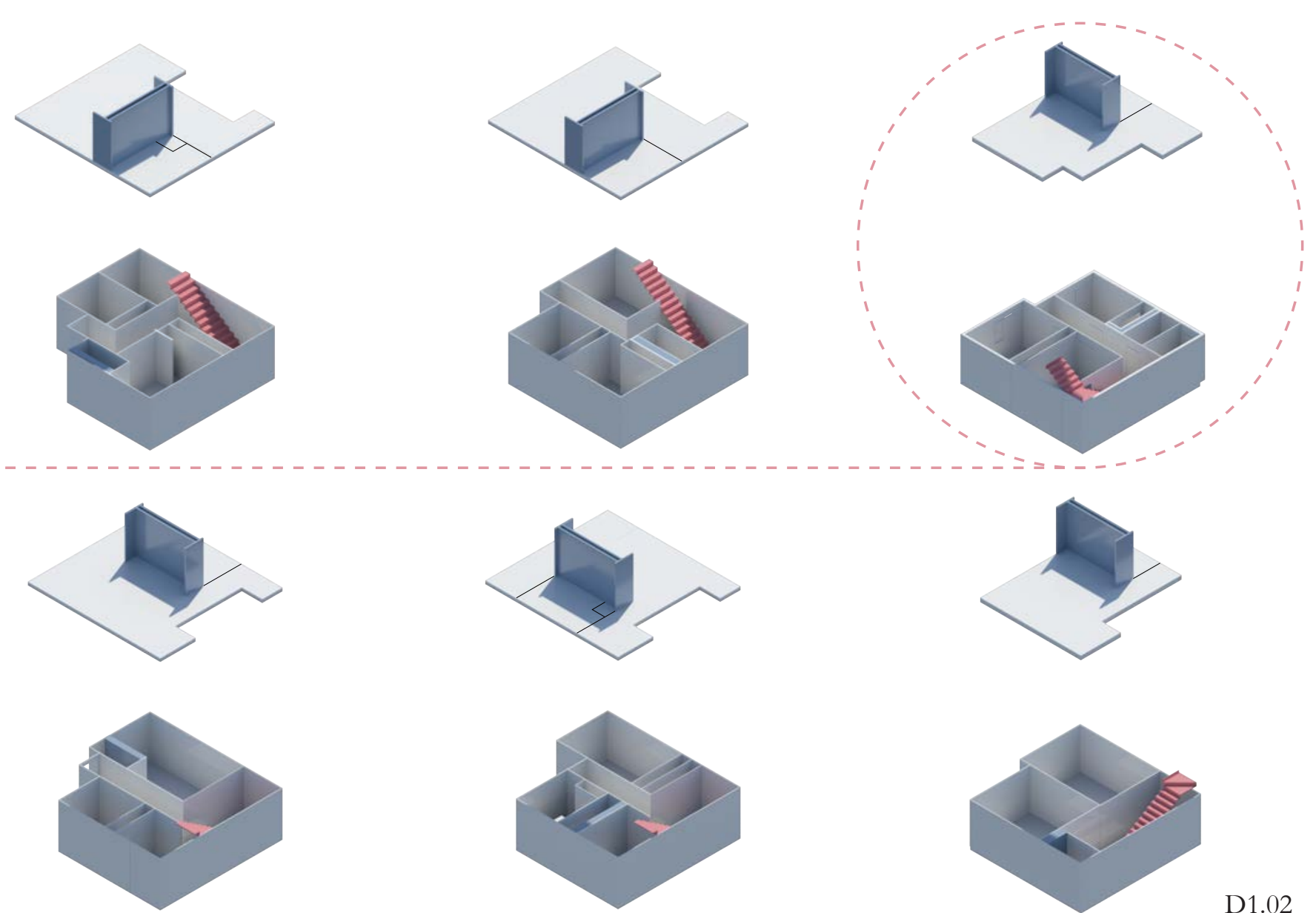

Figure 5.39. Dwelling development iteration studies; dwelling 1
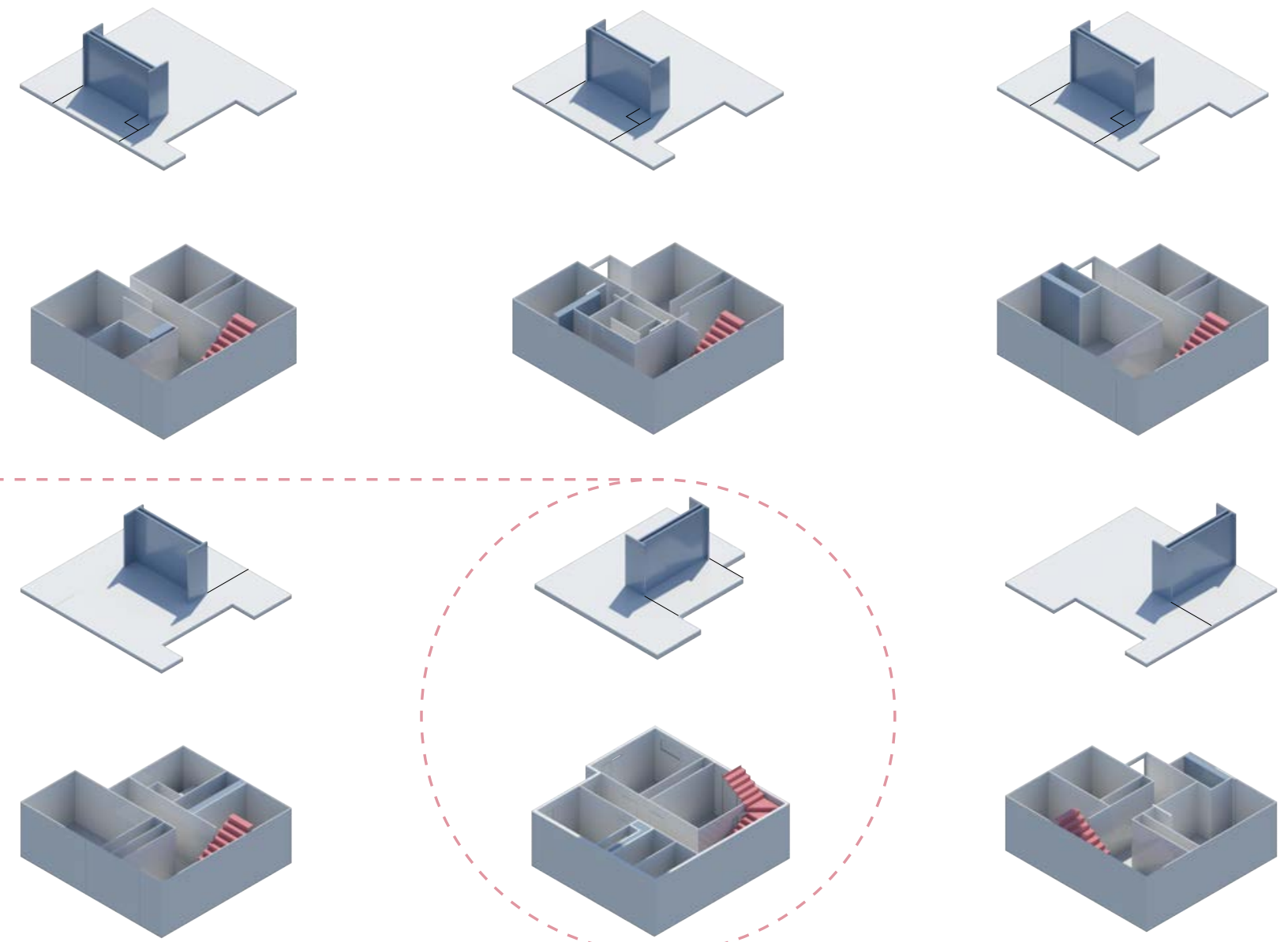

Figure 5.40. Dwelling development iteration studies; dwelling 2 


\section{6}

\section{FORMAL STUDIES}

Consideration of formal architectural qualities begins with objectives drawn from initial case studies that should respond to and sit in harmony with its surroundings.

The surrounding buildings on the project site located on The Terrace follow a diverse aesthetic of architecture. However, the majority of houses on The Terrace are notable for their villa characteristics. The physical characteristics of the villa include timber weatherboard cladding, a welcoming street frontage, and the iconic pitch roof shape. These characteristics can also be linked to initial social housing from 1900's, the prefabricated railway houses. Figure 5.42 shows the four roof types available from these railway houses.

Examples of contemporary architecture were investigated for further inspiration. Key elements include clean lines, simple and durable materiality, and a strong visual axis through the interior out to the landscape. The overall effect is of a modern twist on the traditional railway pitched roof houses.

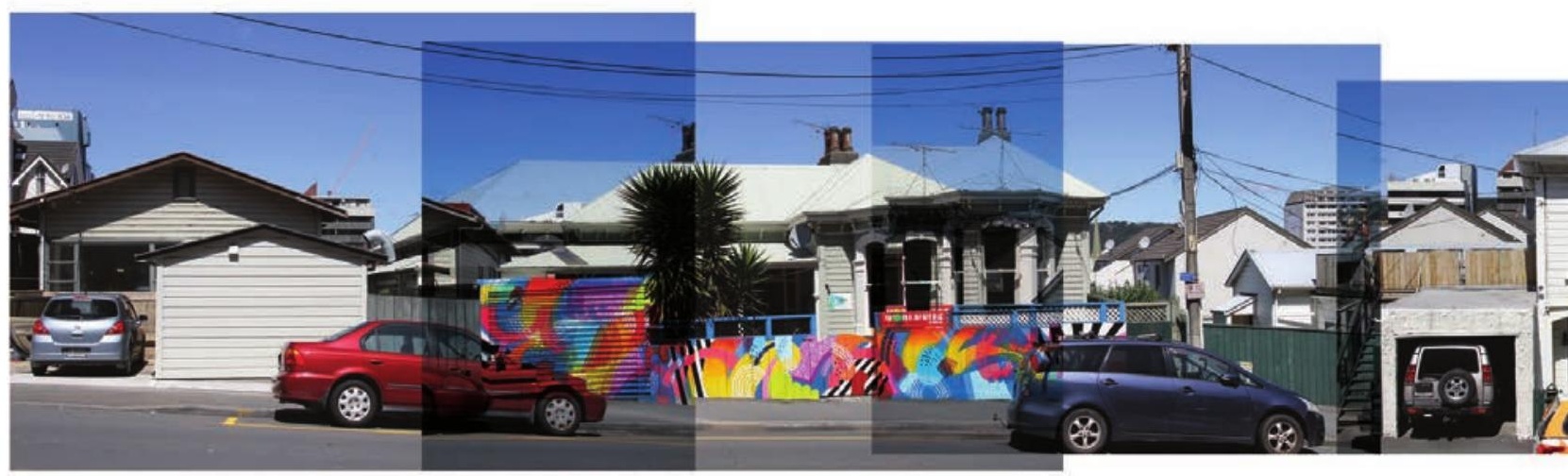

Figure 5.41. A collage of the house elevations provides an overall impression of the streetscape 


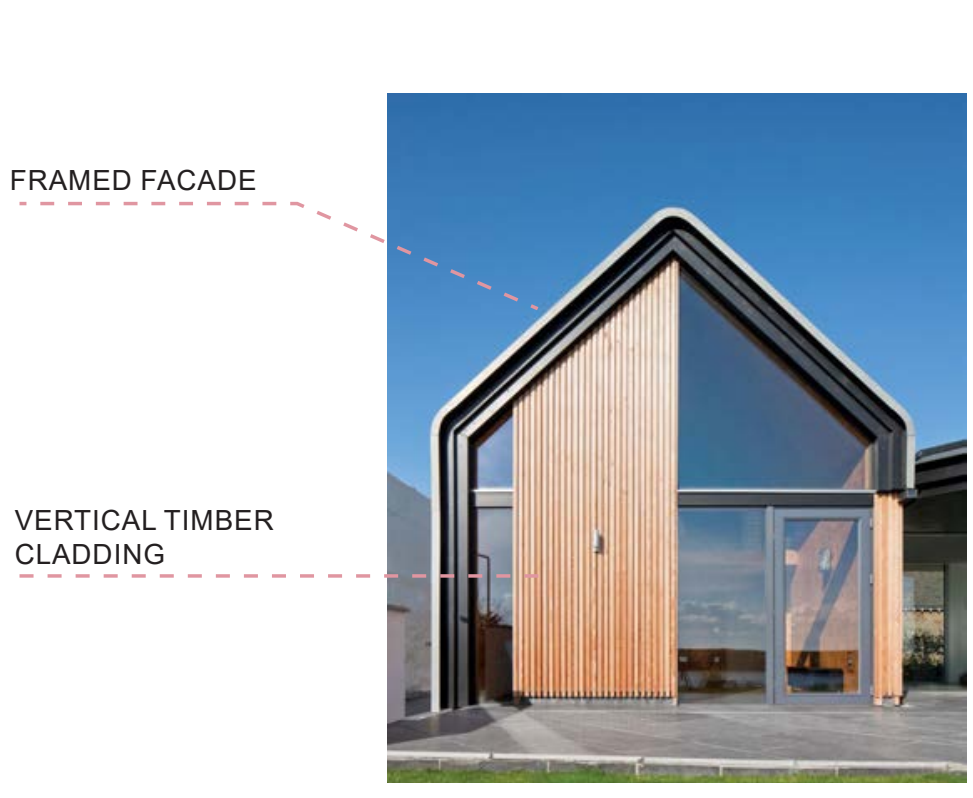

Figure 5.43. Scottish beach house, WT Architecture

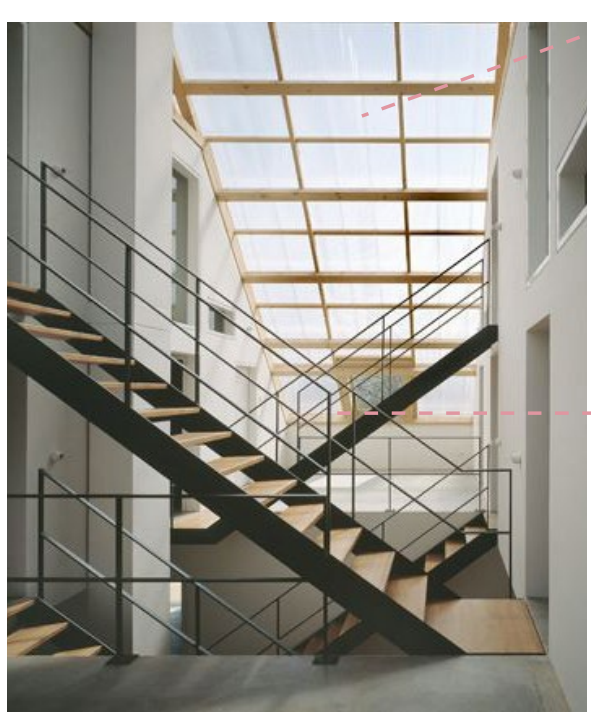

LIGHT ATRIUM

CIRCULATION SPACE

PROMOTING INTERTENANCY INTERATION
Figure 5.44. Patchwork house circulation, architect Pfeifer Roser Kubn
INTERPRETATION OF TRADITION PITCHED ROOF
CONTRASTING CLADDING

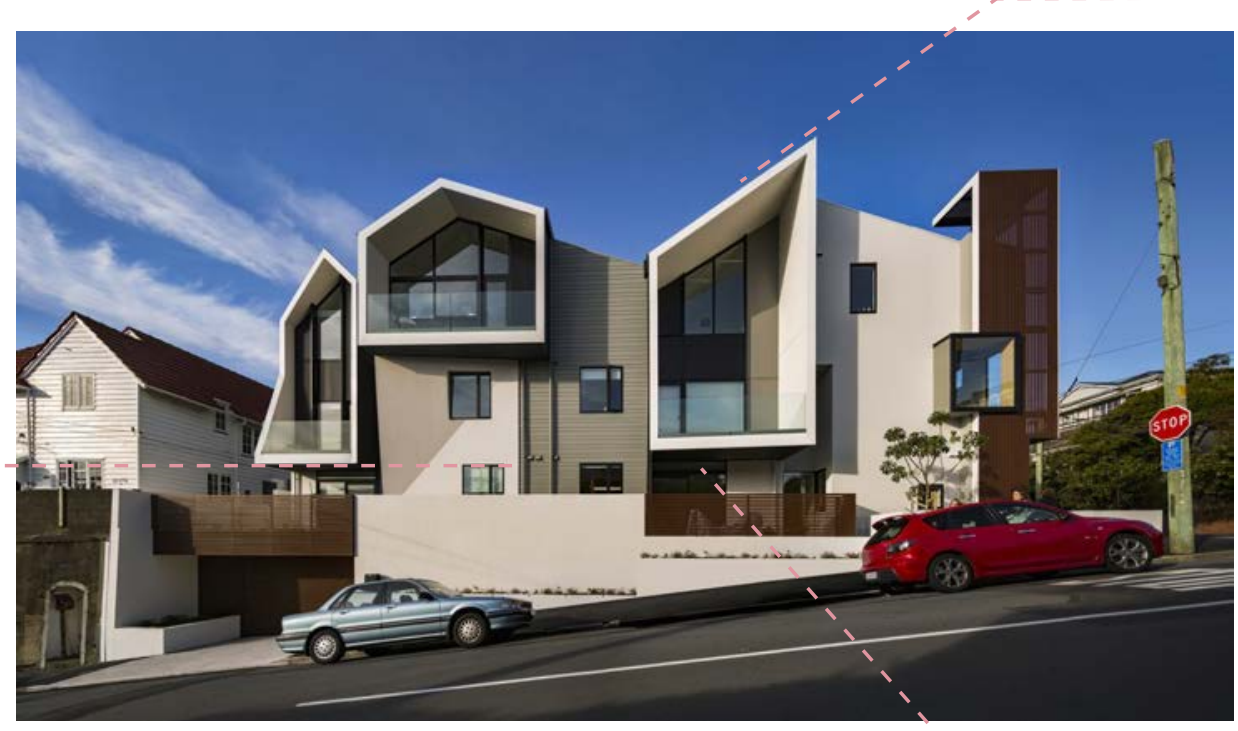

Figure 5.45. Zavos corner: Pirie Street facade 


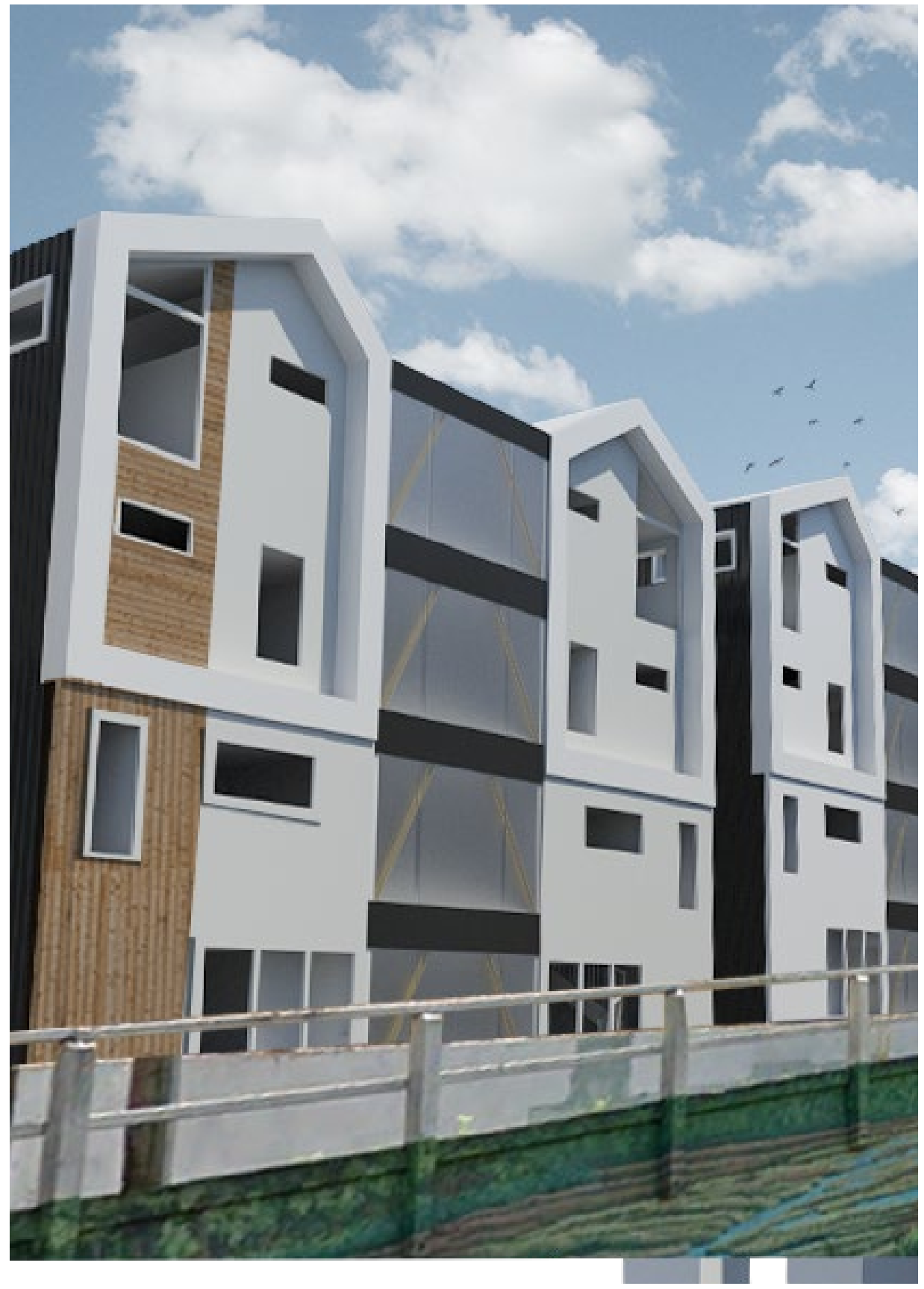

Figure 5.46. Initial facadae develpoment: contemporary with a a traditional roofine and a central atrium circualtion 


\section{7}

\section{DESIGN PROCESS}

\section{Evaluation}

Scheme 2 has been driven by the ten criteria in the design framework. These have been used as driving factors of design outcomes. Figure 5.47 illustrates all ten criteria have been established in the developed design designed.

The final design outcome (chapter 6) illustrates these ten criteria and use these as a measure of success. 


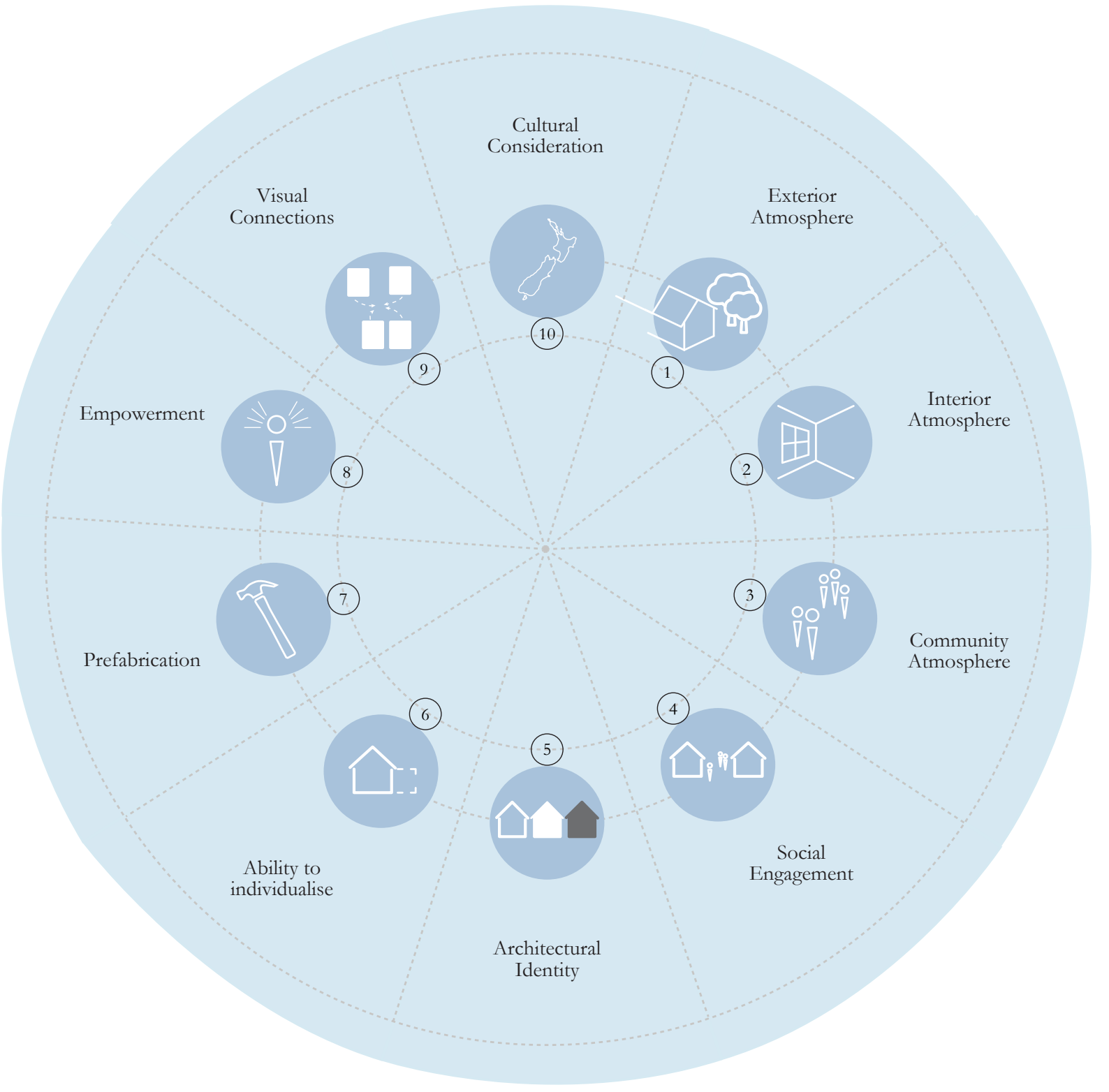

Figure 5.47. Design framework criteria that have been satisfied by the design processes 


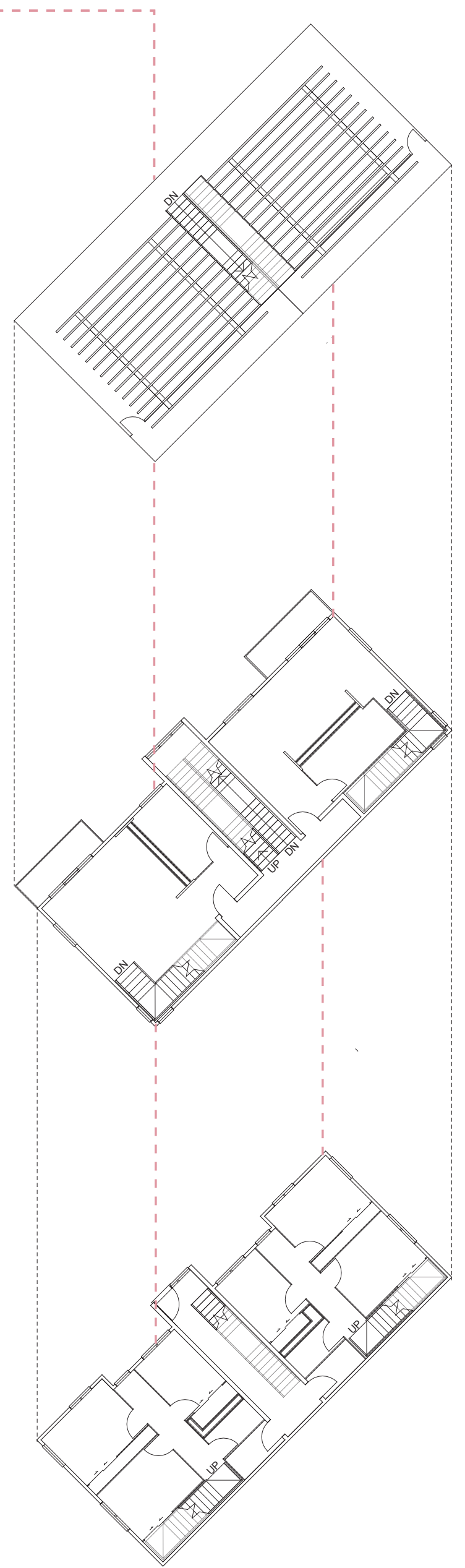

Figure 5.48. Exploded axonometric of the developed floor plans for Block $A$ 



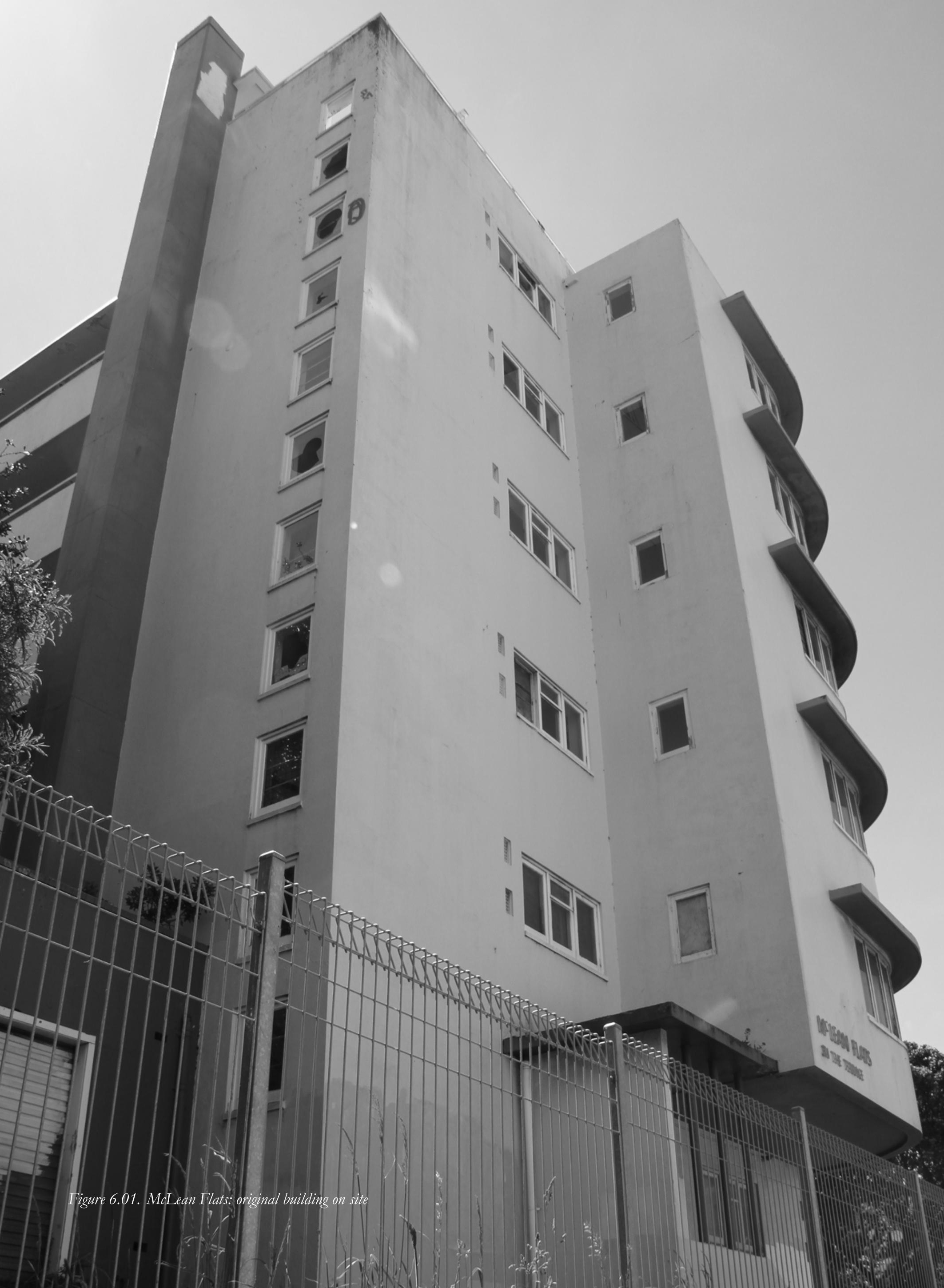


CHAPTER 6.0

Design Outcomes 


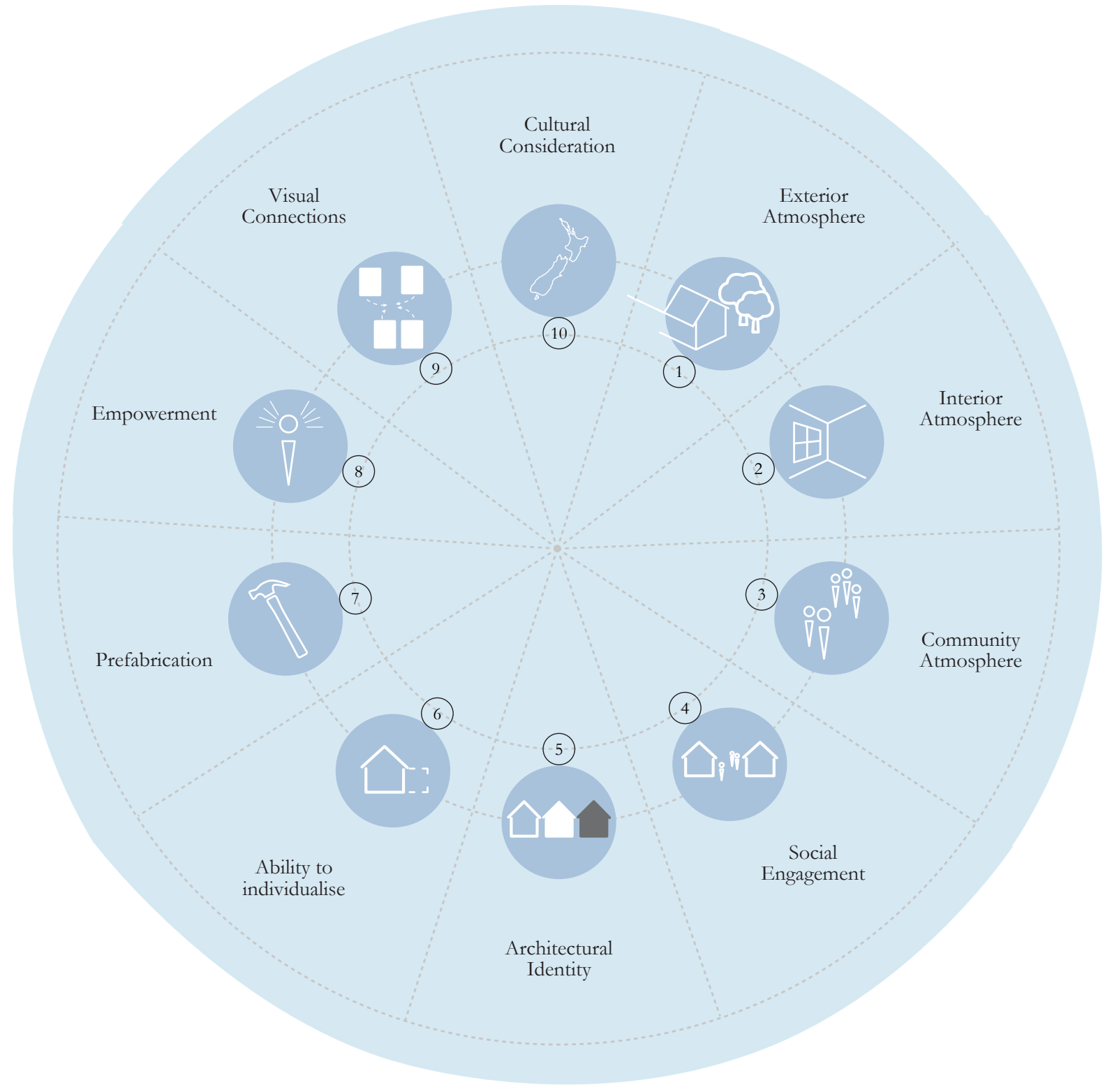

The final design has been assessed in terms of the ten criteria of the design framework. The design framework has been used as a guide to drive the design processes and measure the success of the design outcomes.

Each criterion has been established throughout design development and is indicated how this is achieved through design outcomes. 


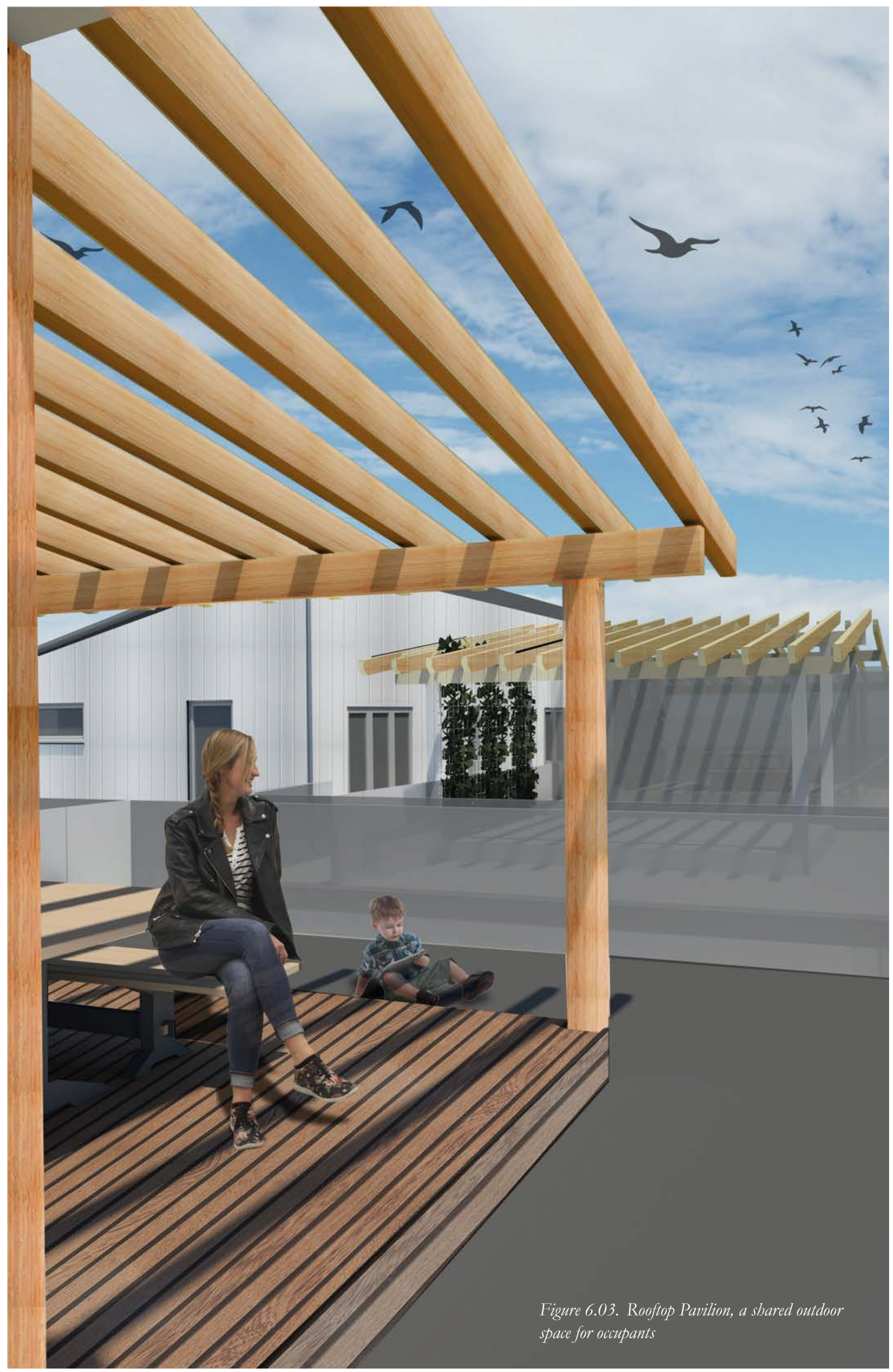


(1)

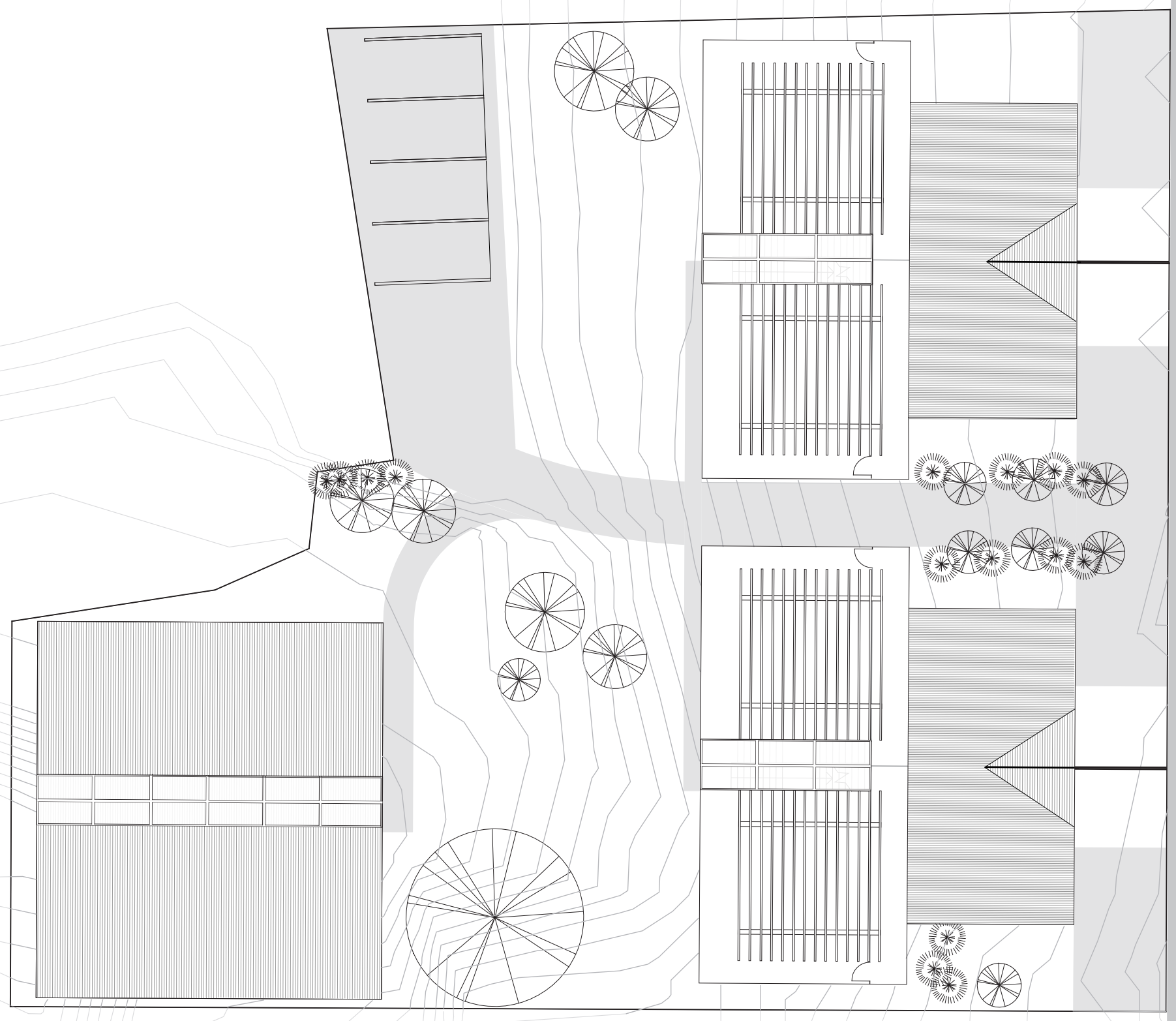




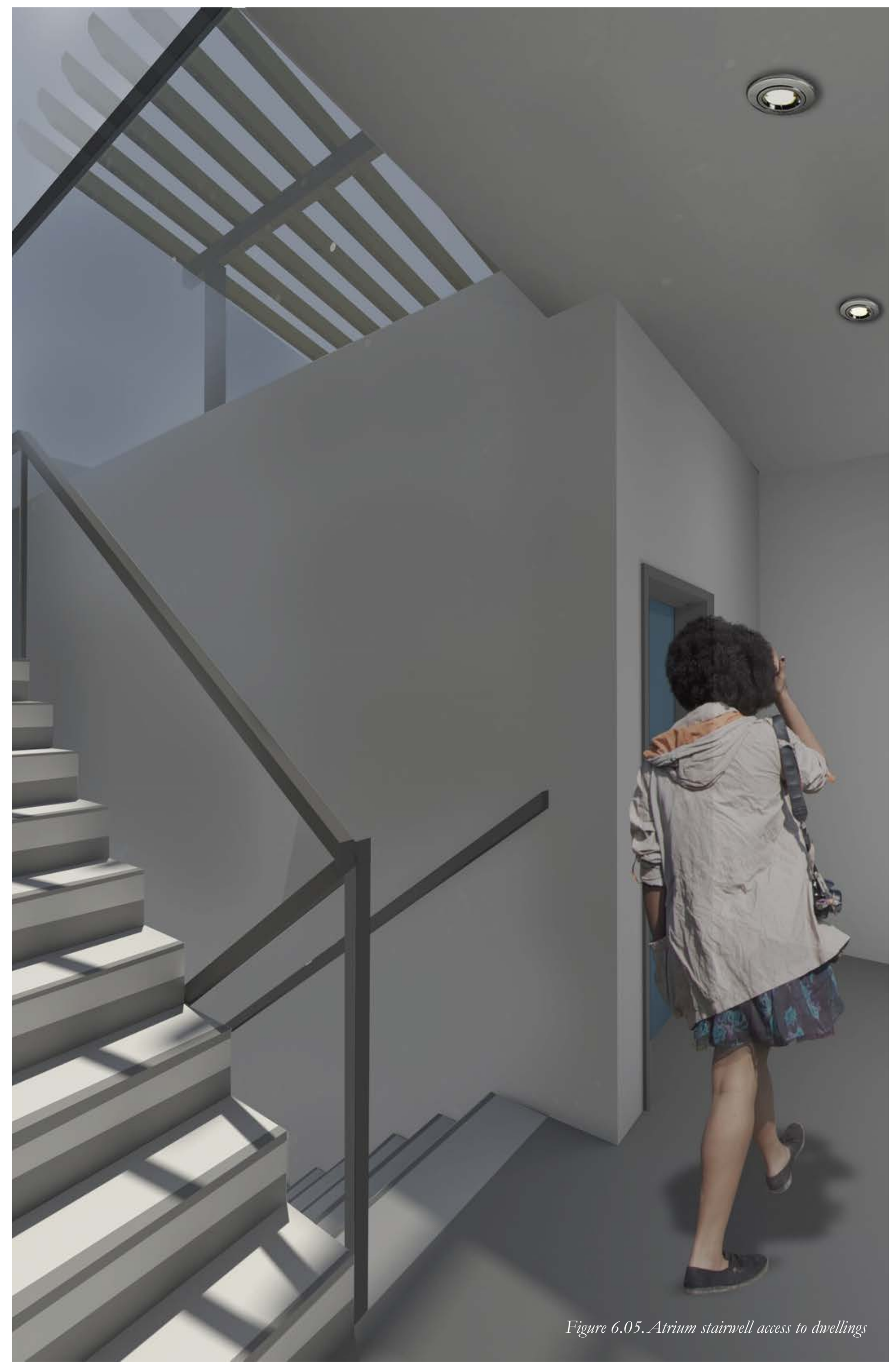




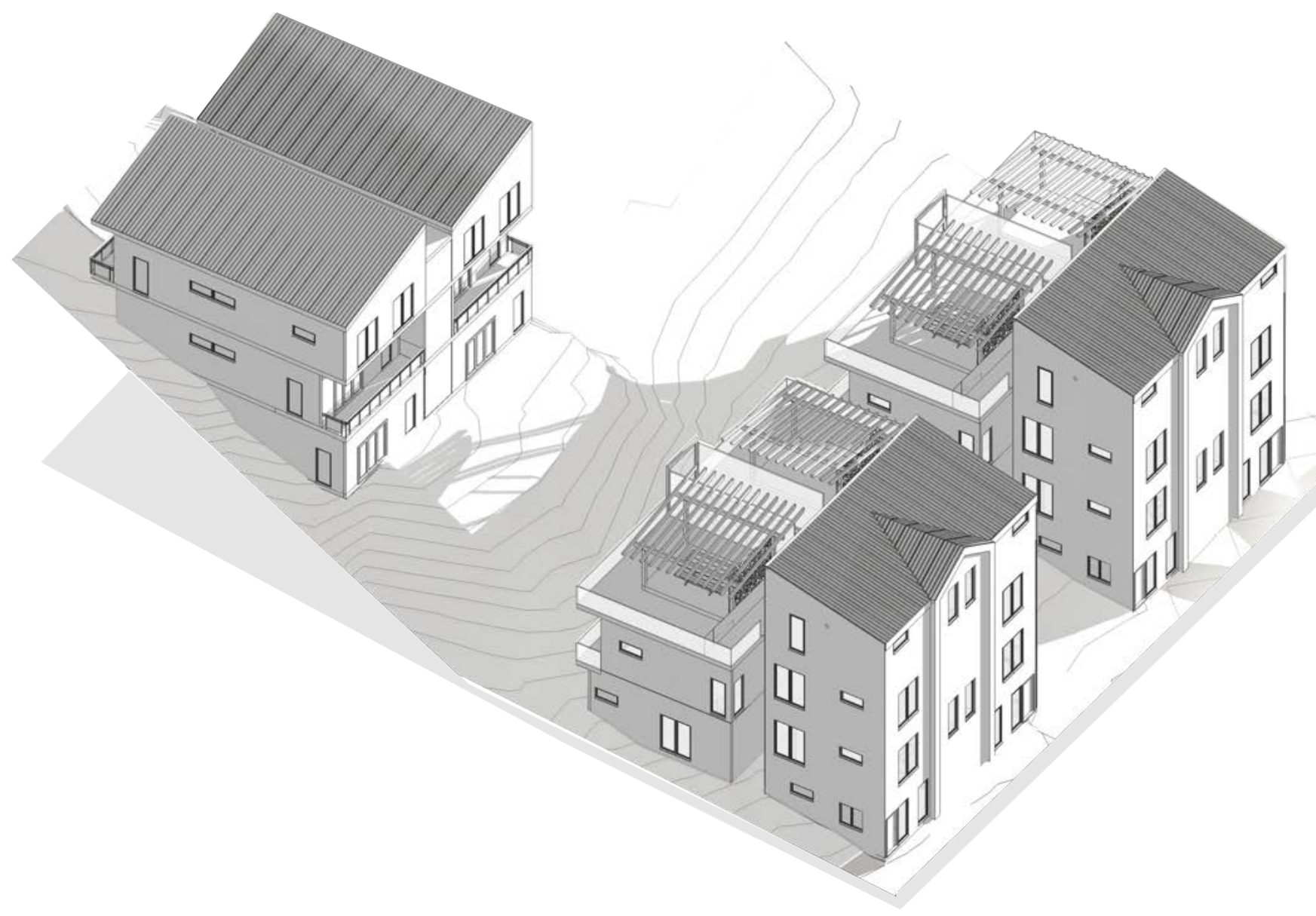

Figure 6.06. Site axonometric showing the overall site composition 

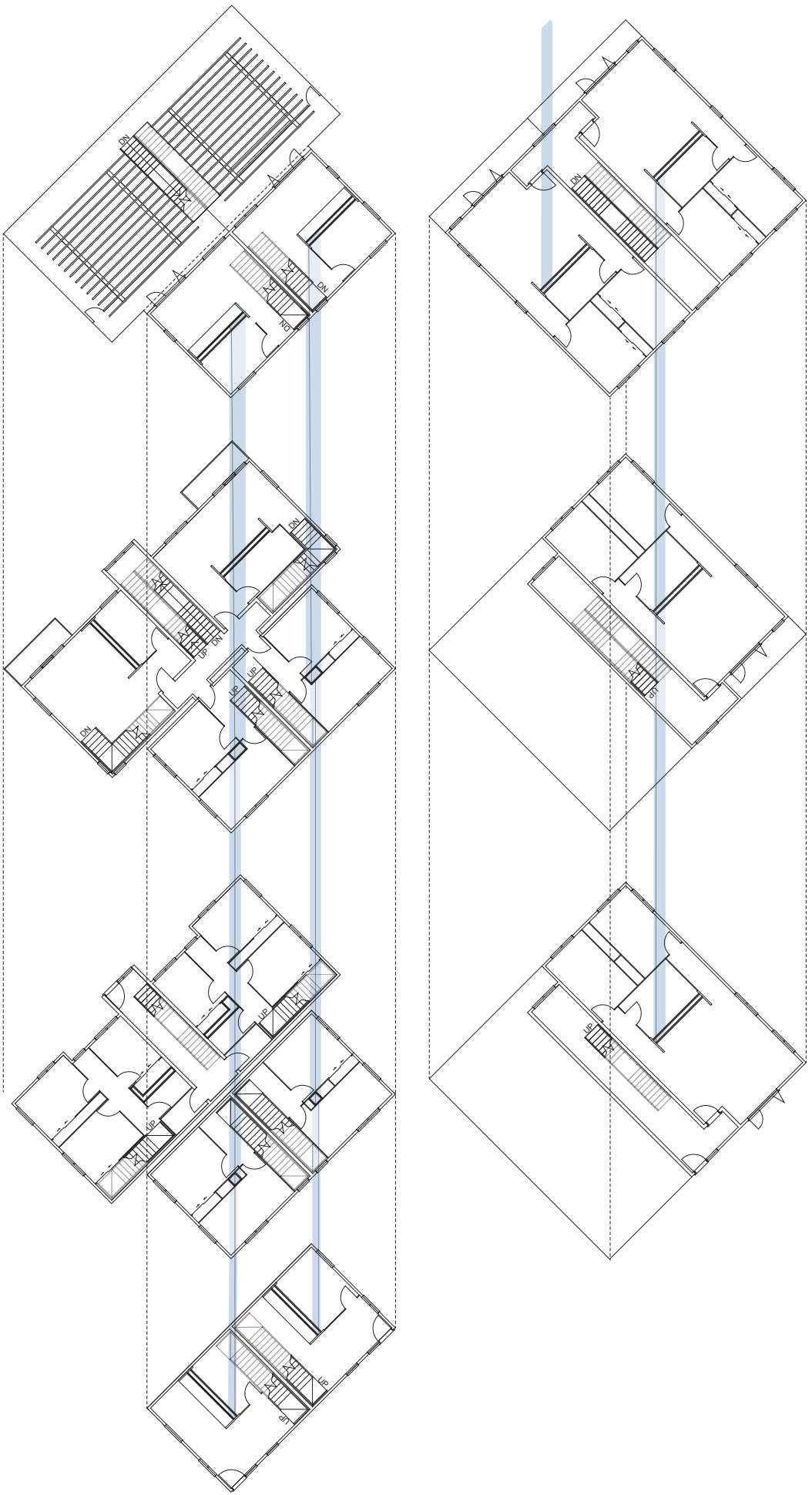

Figure 6.07. Exploded axonometric floor plans of Block $A$ \& $B$ highlighting the service cores throughout each block.

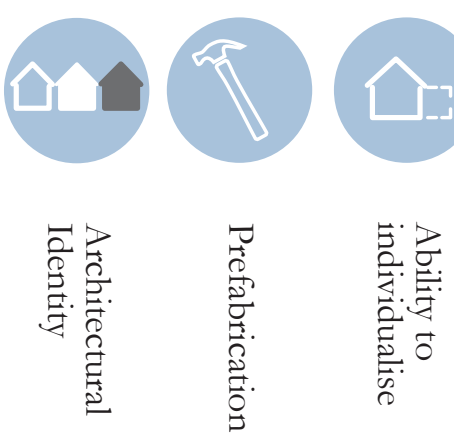






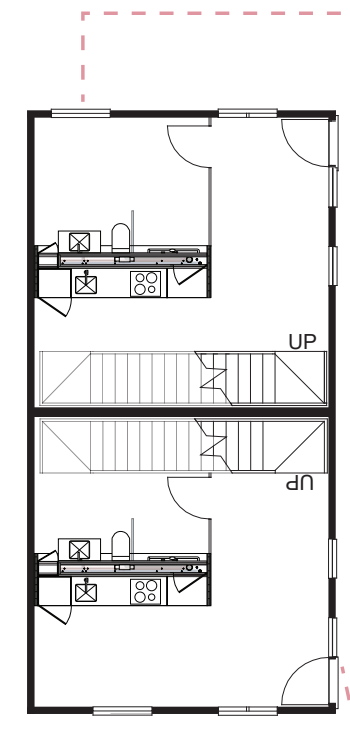

Level 1

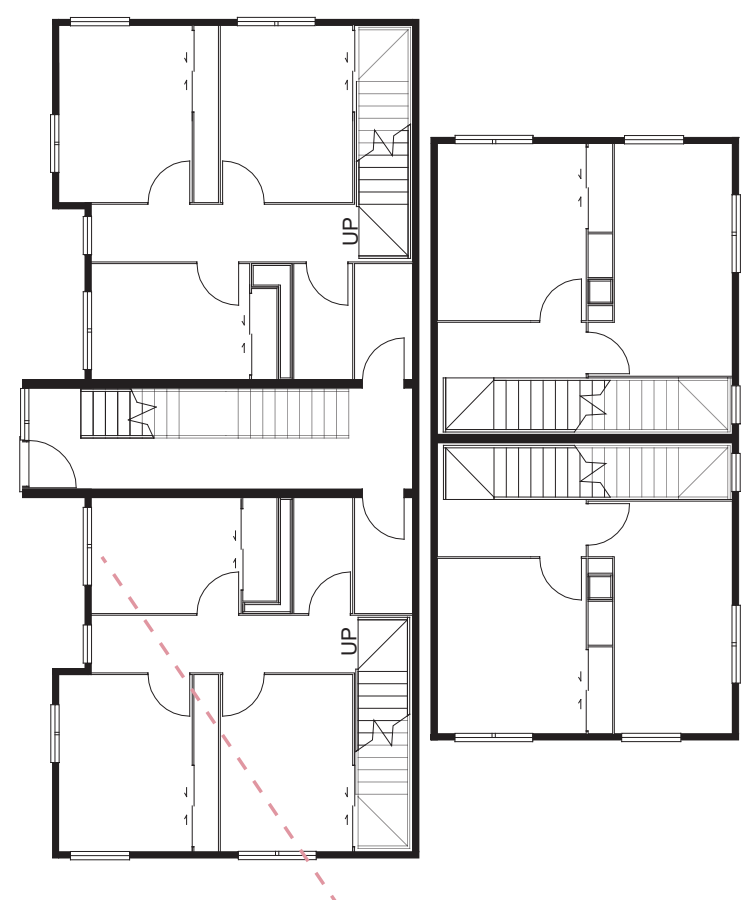

Level 2
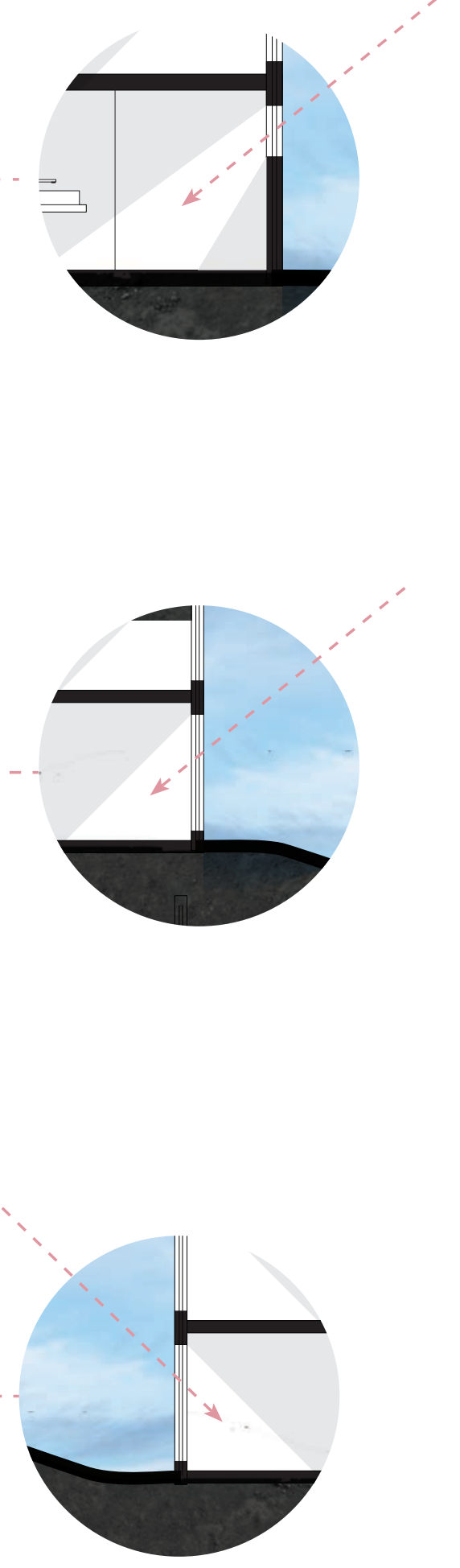


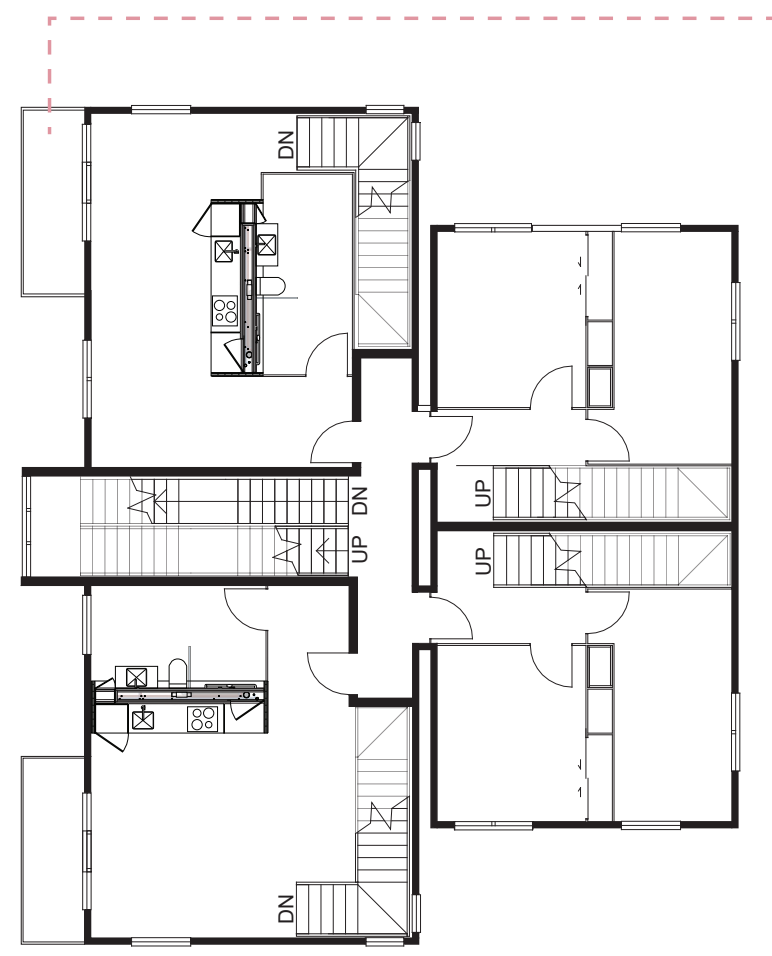

Level 3

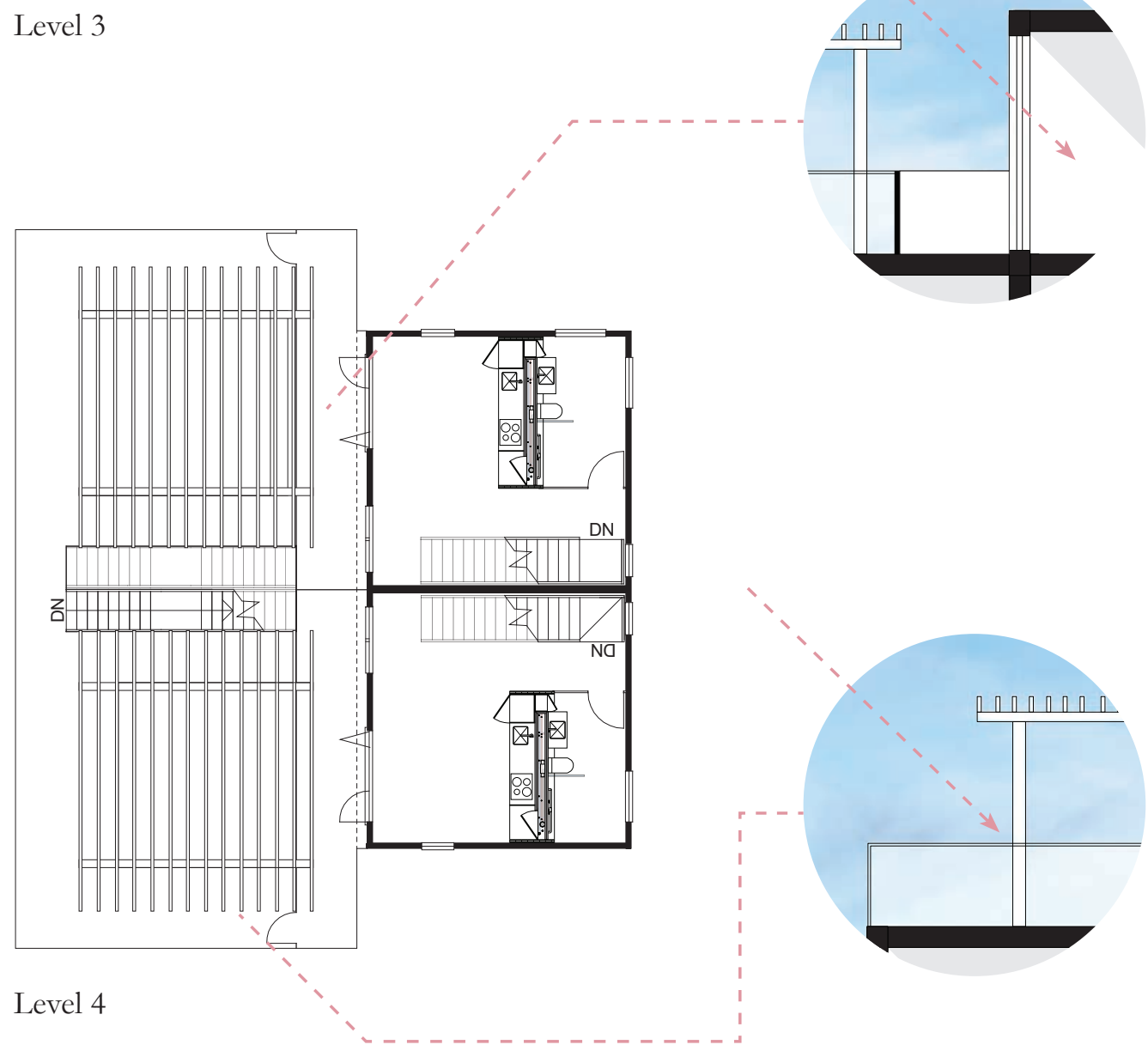





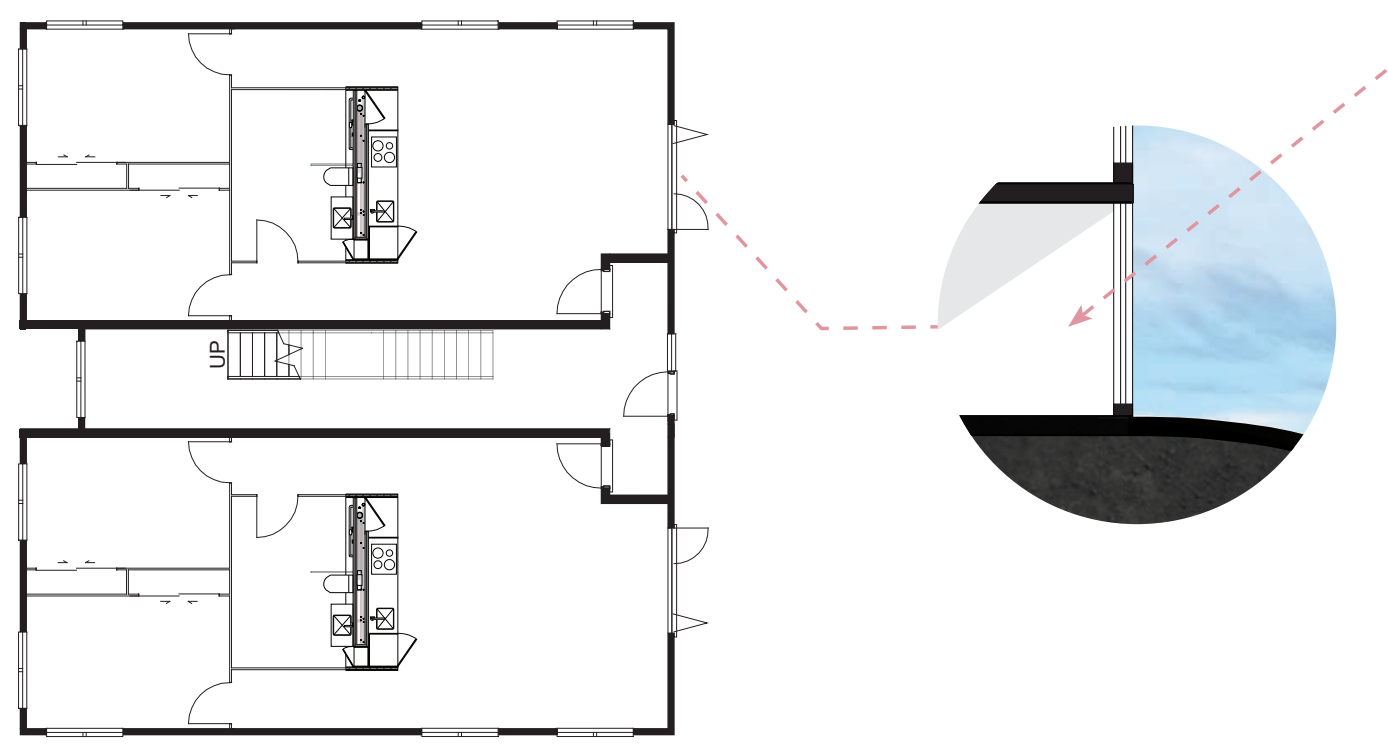

Level 1
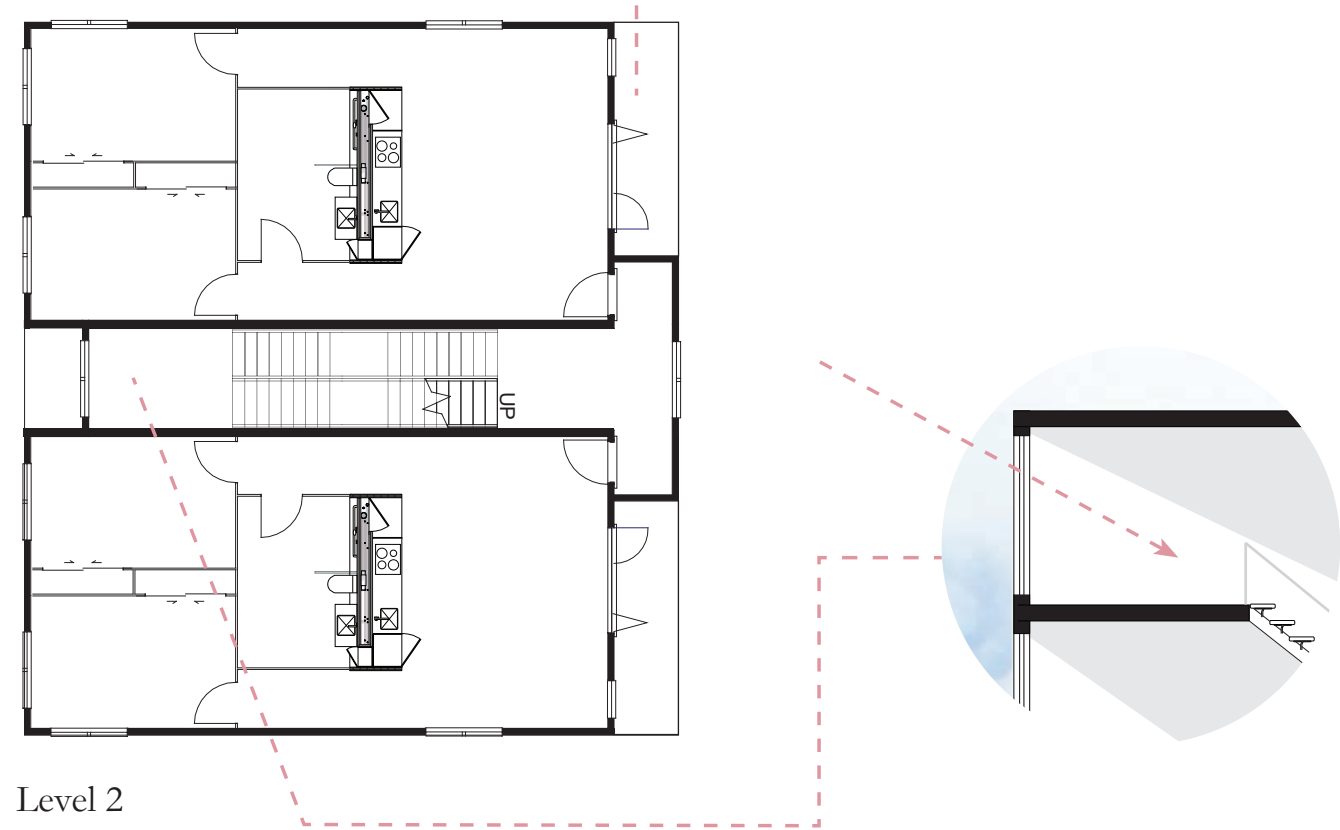


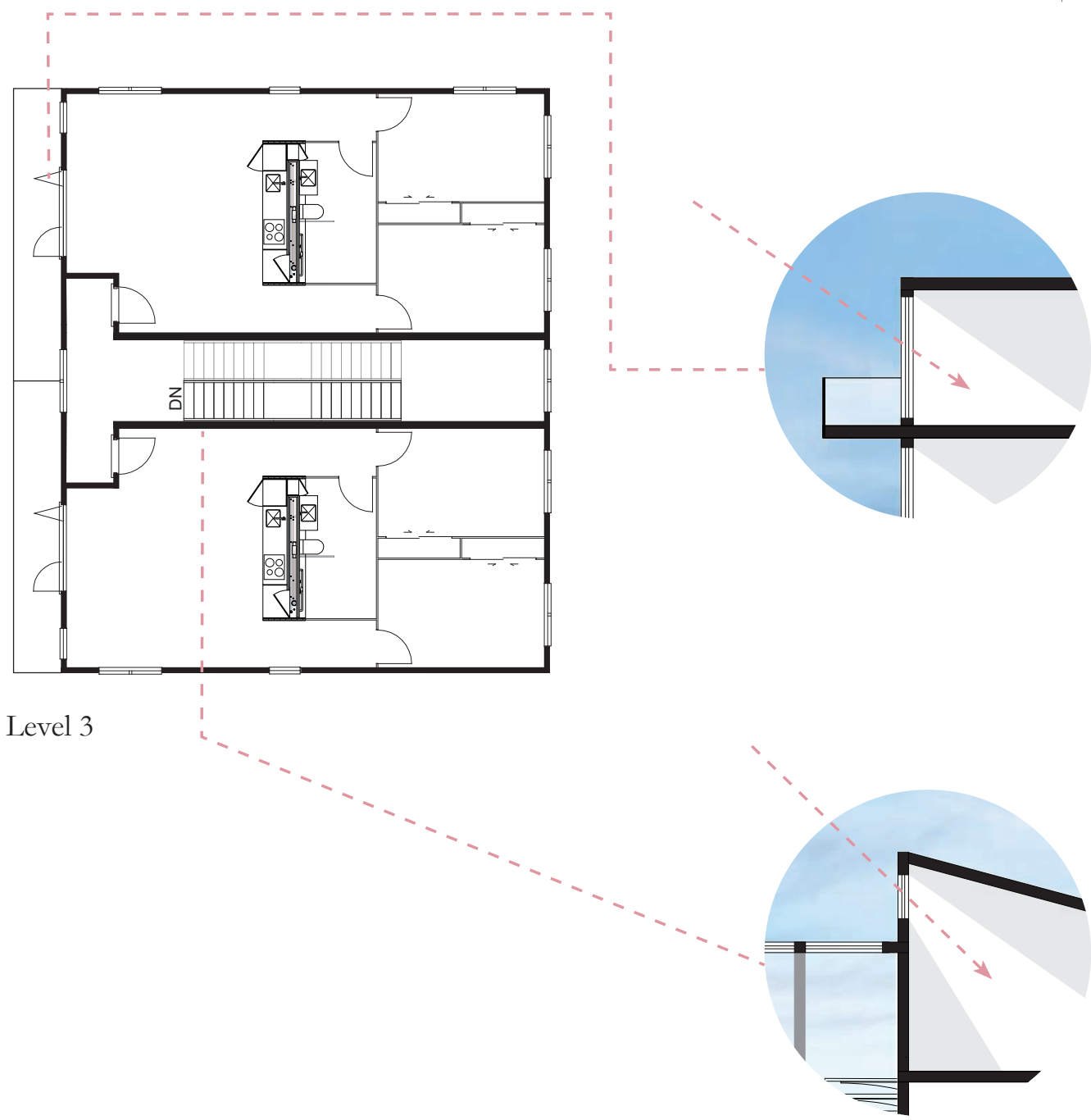




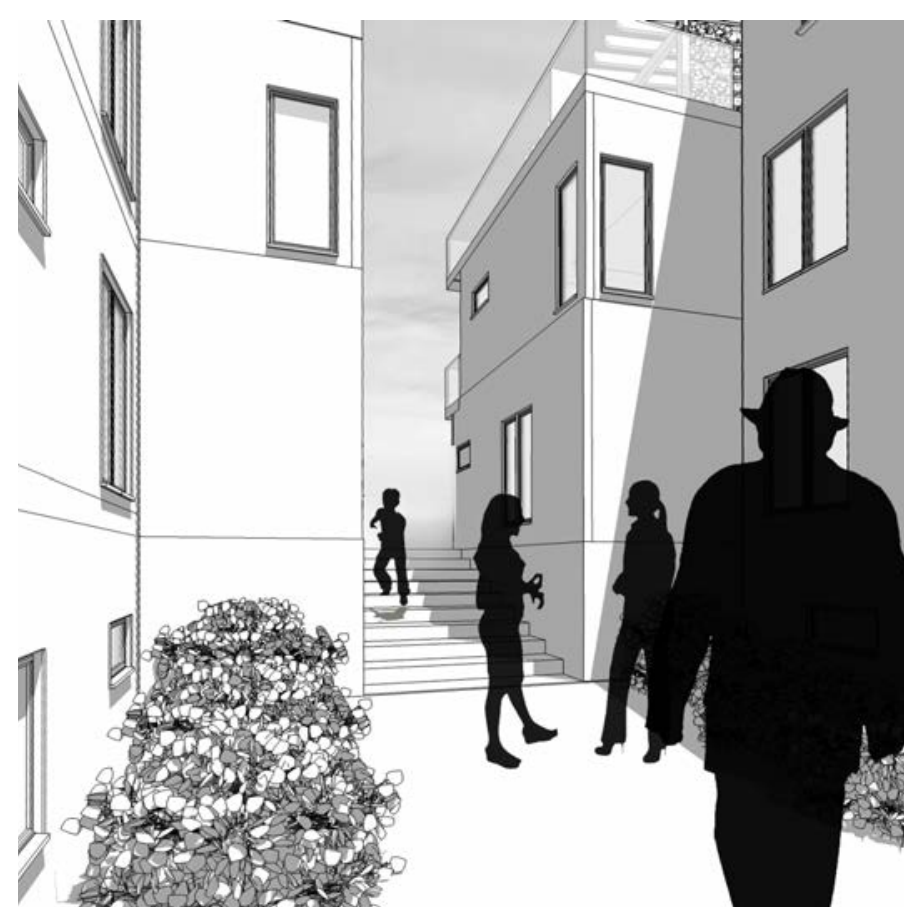

Figure 6.12. Wide entrance from The Terrace through to the central shared space

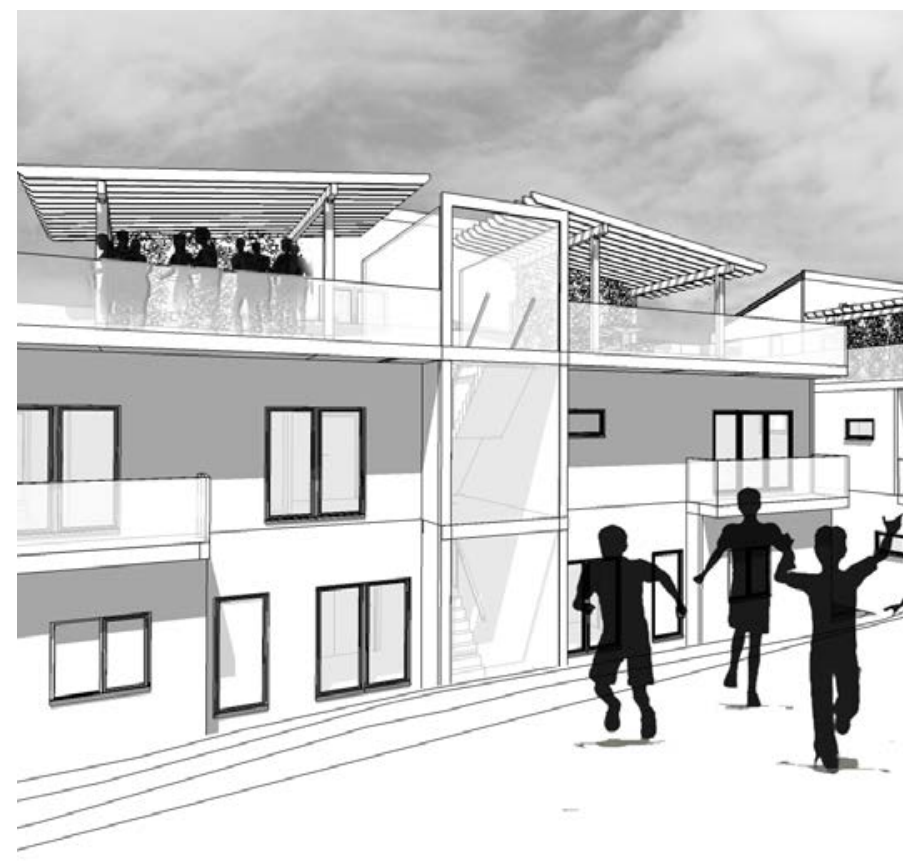

Figure 6.13. The shared space through the centre of the site with passive surveillence from the surrounding dwellings and rooftop

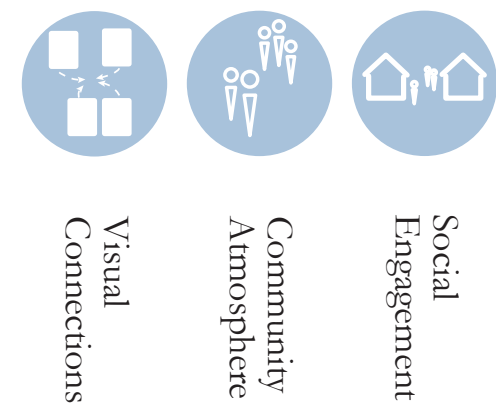




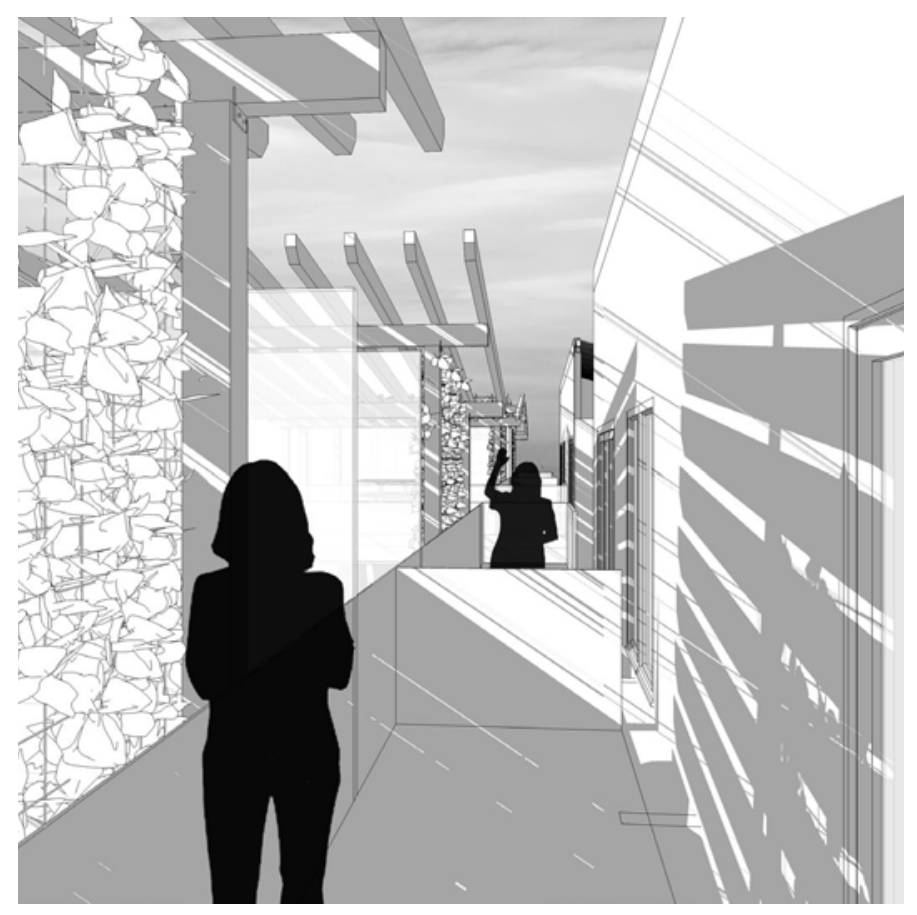

Figure 6.14. Block A private balconies with social and visual connections

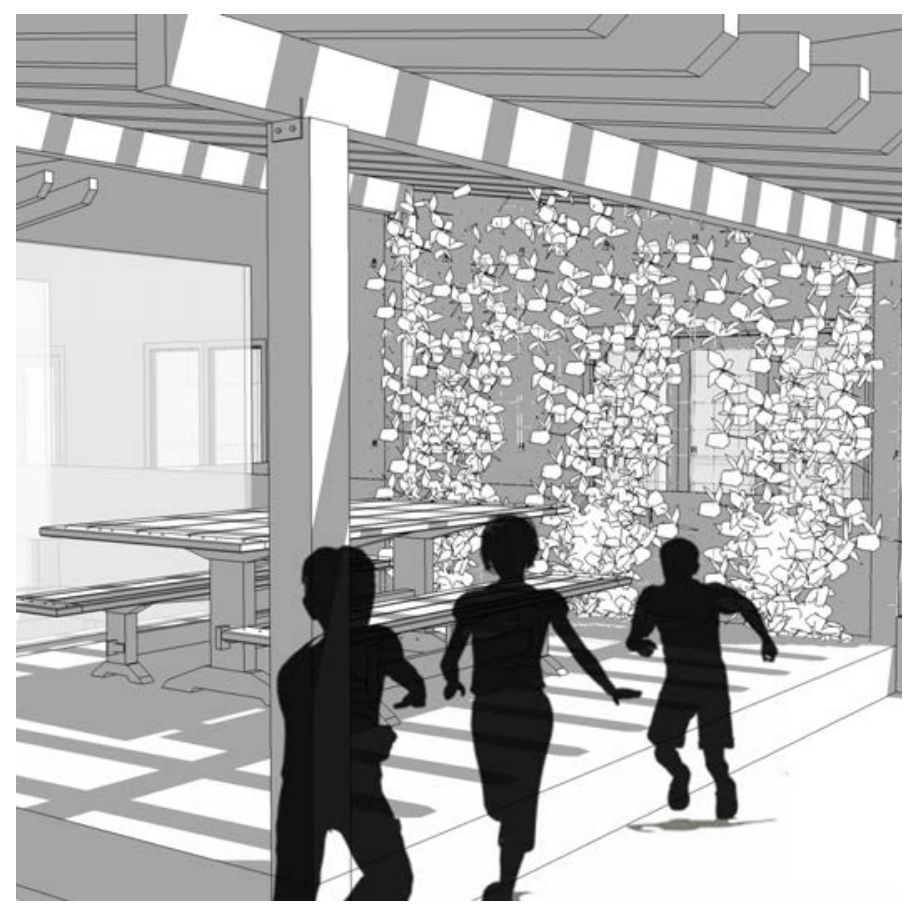

Figure 6.15. Rooftop outdoor $B B Q$ area to cater for large family gathering and intertenancy social engagement

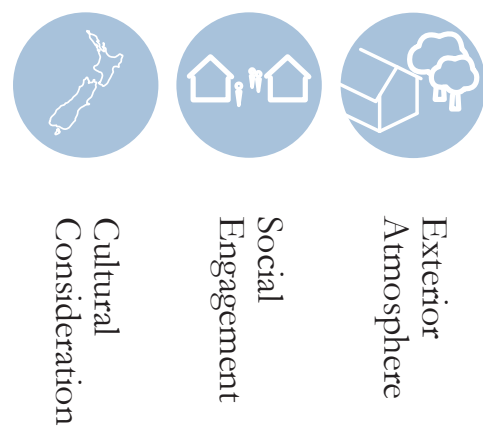




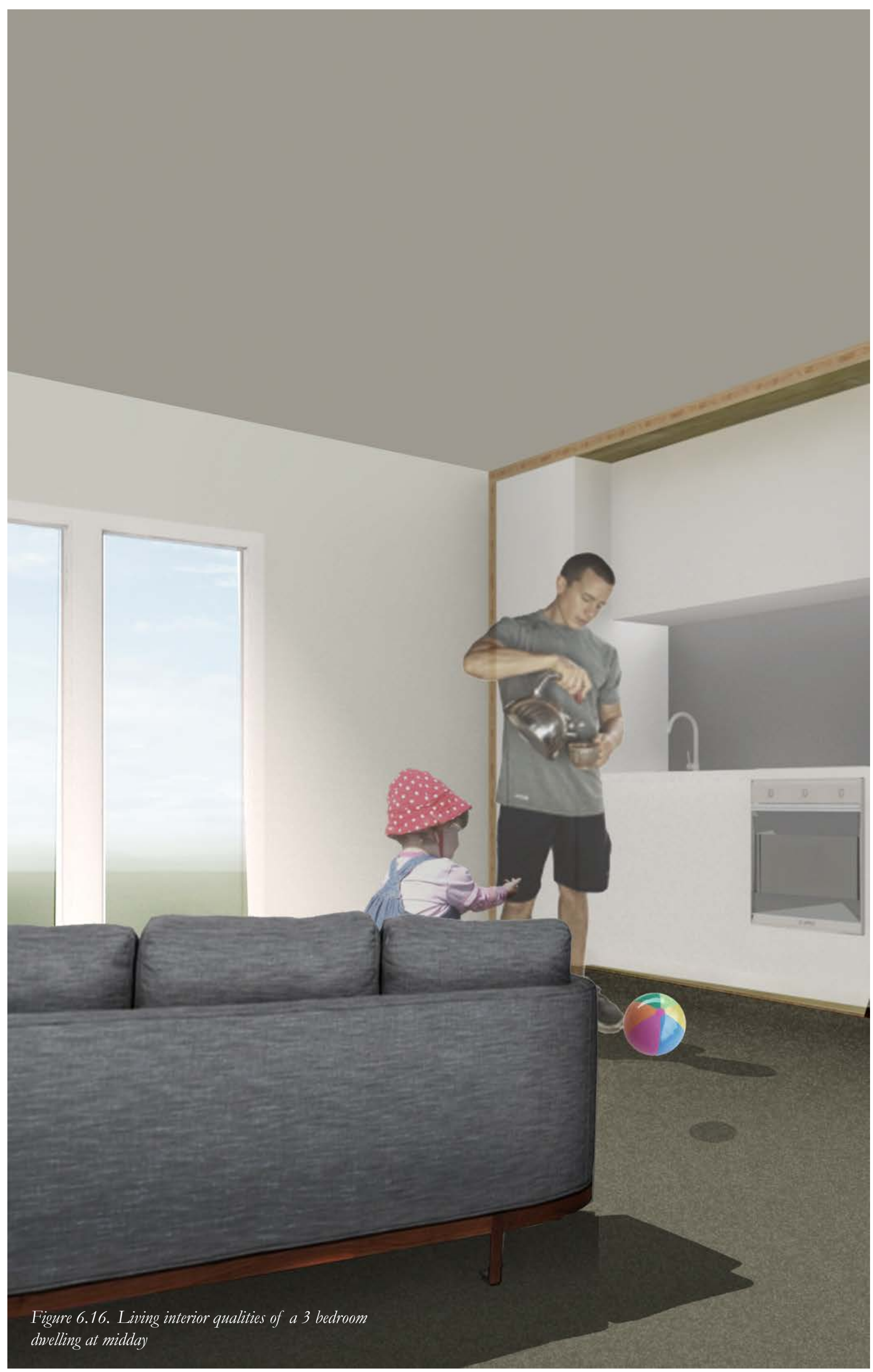




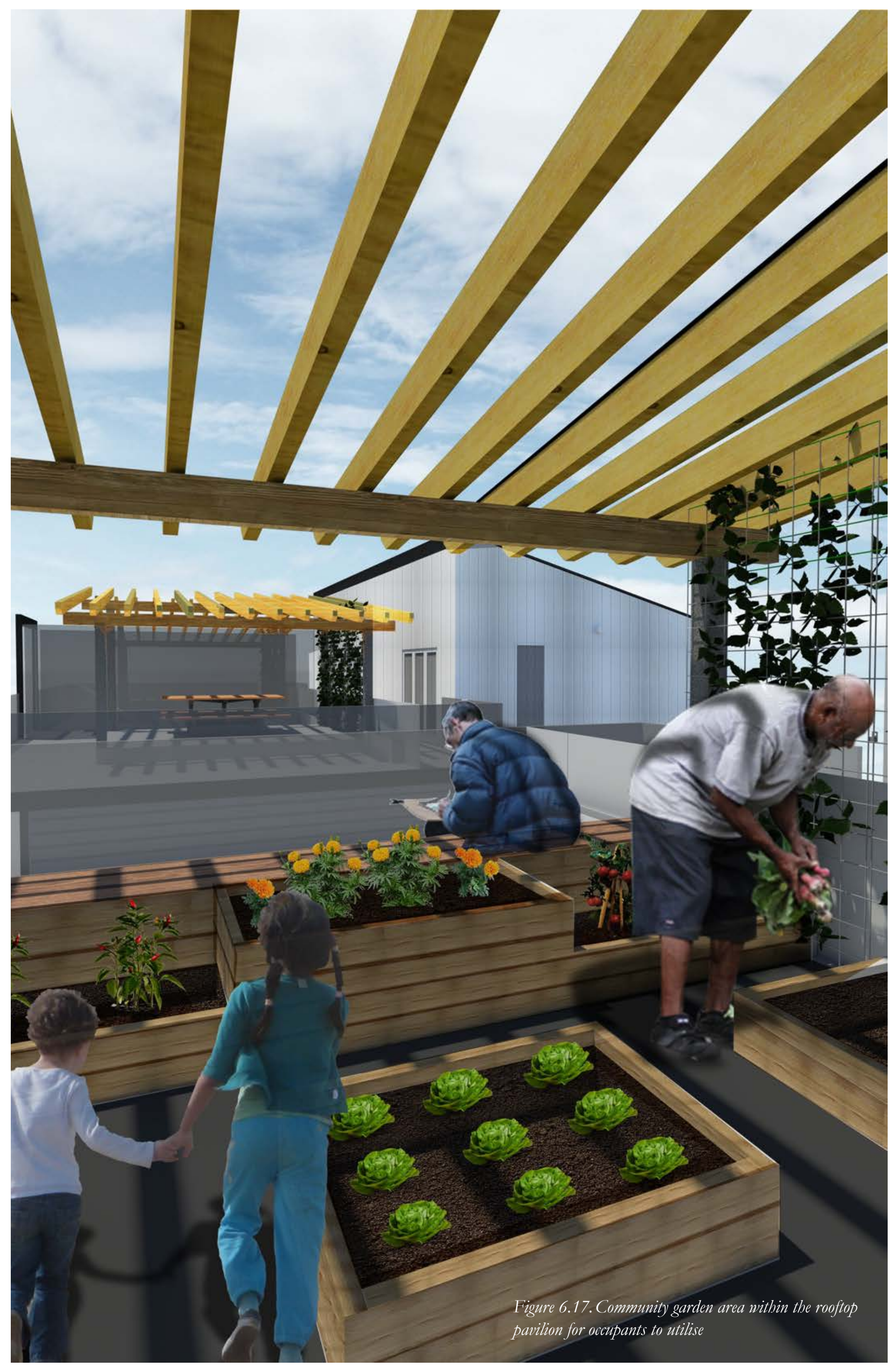




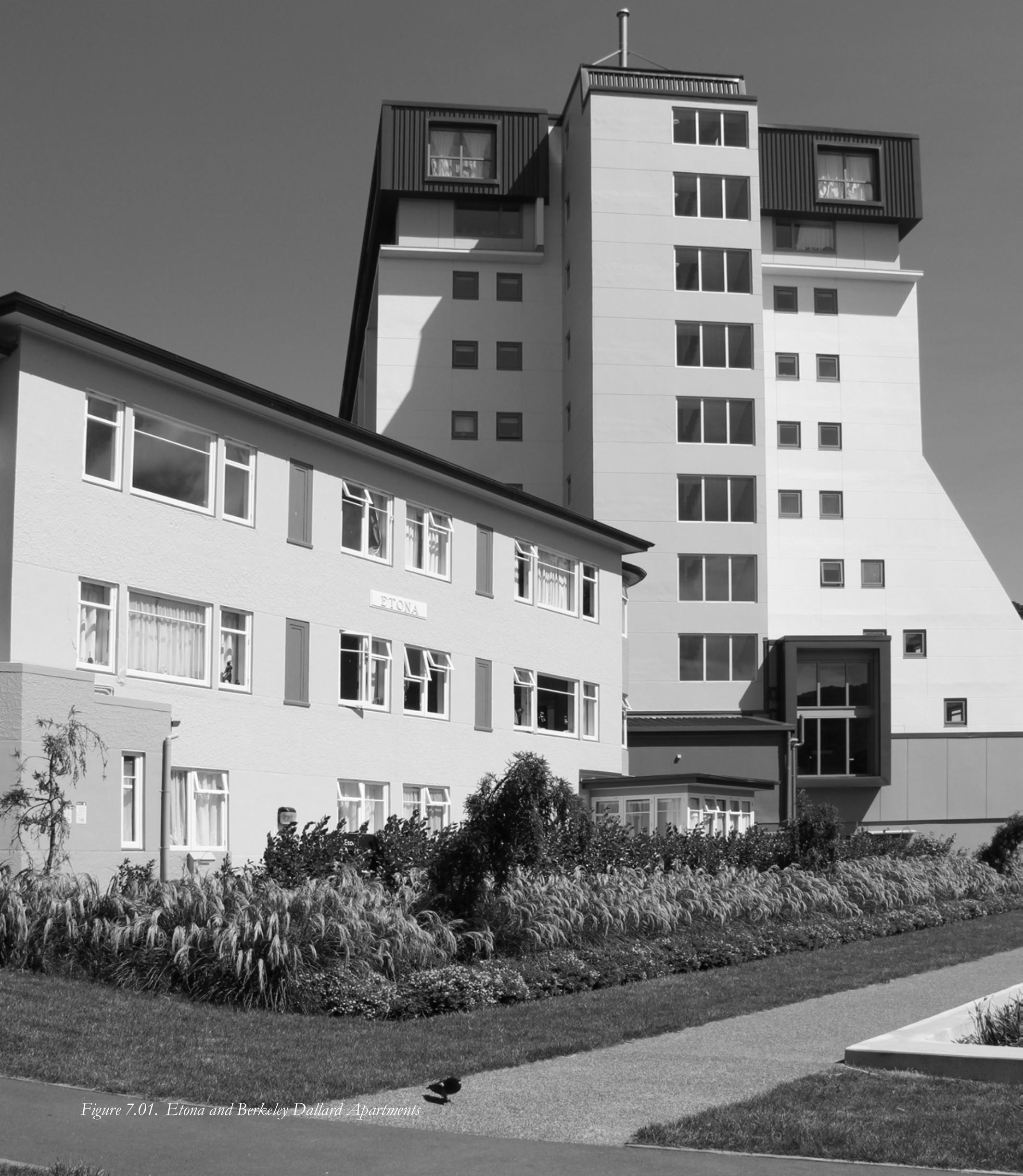


CHAPTER 7.0

Design Conclusions 


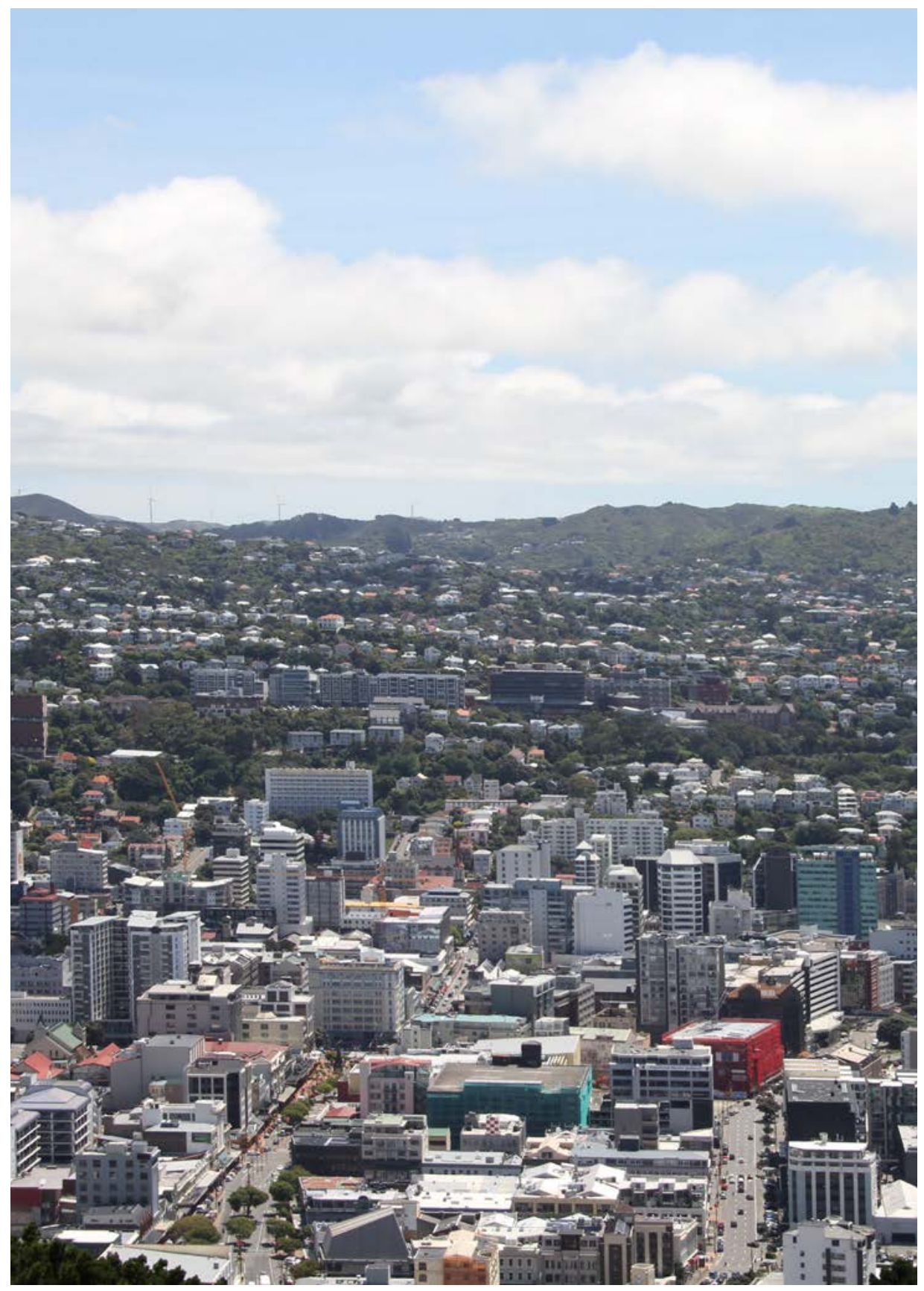

Figure 7.02. Wellington City, the initial scope of this thesis research 


\section{1}

\section{CRITICAL REFLECTION}

While architectural precedents are designing new builds for social housing, it is the occupant's needs and requirements that get lost in these economically focused developments. This thesis reassesses social housing, providing a positive prefabricated architectural response that embodies a sense of community and empowerment. This is an architectural solution that social housing tenants are in dire need of.

This thesis, by approaching social housing from an architectural and prefabrication perspective, makes a unique contribution to this area of research. The prefabrication methods utilised in this research project offers a collaborative approach to a construction system so as not to restrict and dominate the architecture. The development of the Servicebox enabled the flexibility and adaptability needed to create floor plan arrangements that are not restrictive. Further development could see this unit prototyped and marketed for industry use.

The outcome of this thesis is both an architectural building and a social tool; architecture developed to abolish social stigmas associated with social housing and to some extent prefabrication. The literature review outlined many conditions specific to the needs of occupants of social housing and for achieving positive atmospheric qualities desired in this type of housing. The architecture developed addresses these issues through a design framework, (figure 7.03), used to drive the design process, and as a tool to measure the success of the final design outcome. This thesis addresses the social stigmas associated with this context of housing, it presents 


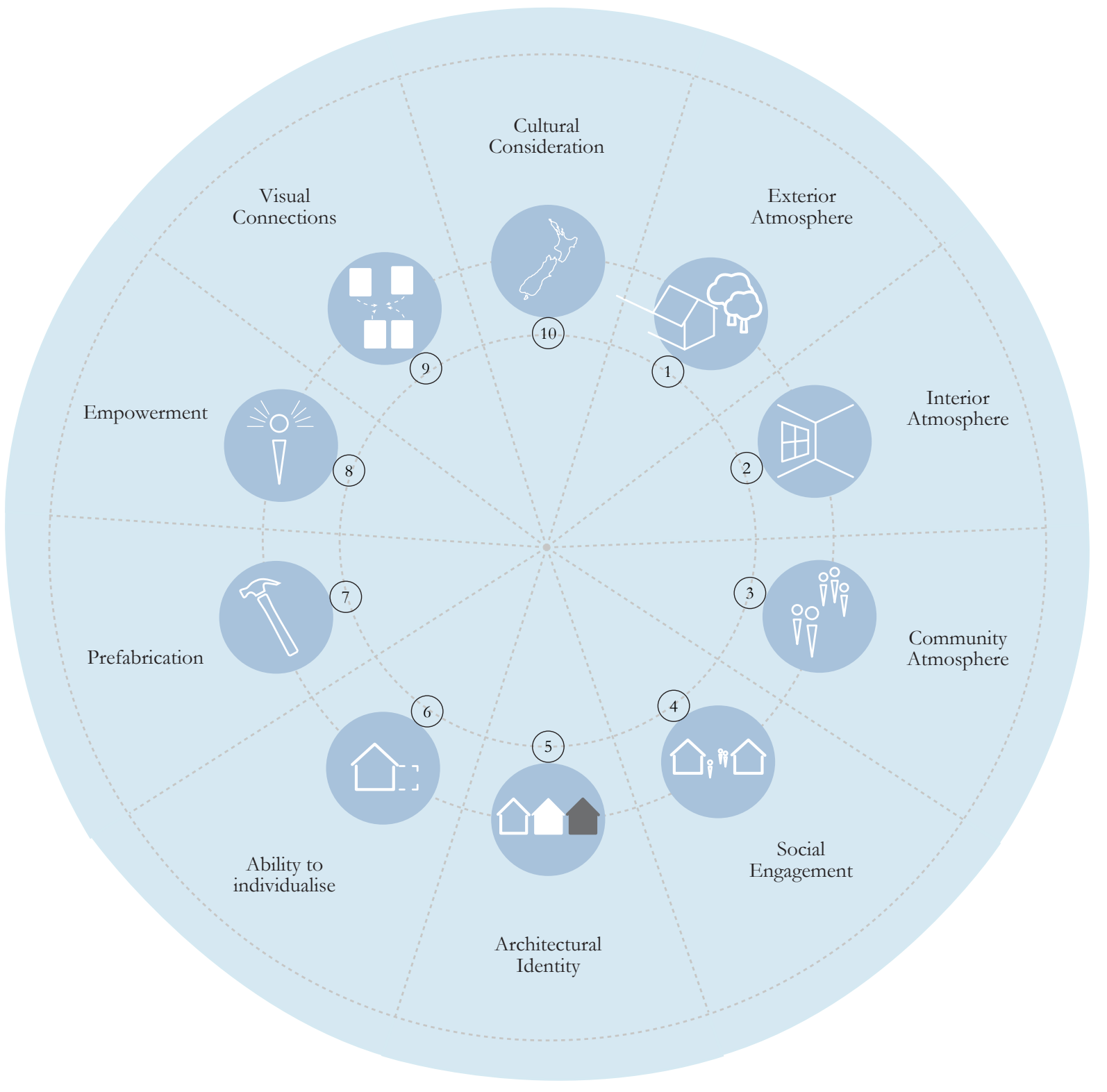

Figure 7.03. Ten criteria of the design framework fulfilled by the final design outcome 
the differences in secure and high quality housing that achieves diverse atmospheric qualities, banishing stigmas and facilitates better communities and empowers occupants

When critiquing architectural precedents against the design framework that was developed, initial links showed that it was not possible to achieve low-cost prefabricated housing that satisfies each criterion. However, using this framework to drive the design processes and critique outcomes enabled the development of a final design that fulfils the criteria established in the design framework. It is the level of success achieved in satisfying these criteria that sets this project apart from current low-cost housing schemes. The methodologies employed, sketching, digital modelling, diagramming, planning, and programming through an iterative design-led process, has resulted in a housing development that meets, contributes and supports the complex needs of social housing occupants and communities. 


\section{2}

\section{SCOPE \& LIMITATIONS}

To stay within the scope of a one year design thesis, this research focused on establishing one example of a housing configuration on an inner city site that meets the research aims and objectives.

The scale, scope and timeframe of this research meant it was not possible to observe and engage with the tenants of current social housing located in Wellington City. Instead, experts in the field of low-income housing were invited to critiqued the project at design reviews and development meetings. Their support, in regard to the legitimacy and consideration of the project, strengthened the belief that the solutions developed in this thesis could be successful solutions, to the identified issues.

The scope of this research is contained to central Wellington, where social housing is predominately being pushed out to the suburbs. While this research is specifically designed for a site in central Wellington, there is potential for application of the design outcome to other cities as well as suburban areas.

This research scope focused on developing diverse atmospheric qualities to address the complex needs of social housing tenants. While this design has been tested in terms of its desirability against the design framework for its proposed occupants, in a theoretical sense, it has not been assessed by potential occupants or reviewed in monetary terms. For this design to accurately reflect the established design framework further, in-depth analysis would need to be carried out and tested with the potential occupants and primary stakeholders of social housing. 


\section{3}

\section{FUTURE DEVELOPMENTS}

The knowledge and developmental systems presented in this thesis offers an opportunity for further research exploration.. In particular, this proposal has addressed one specific site chosen for its challenging conditions, however, different sites and topographies creates their own set of constraints and opportunities. Testing on a range of sites would open a range of potential research possibilities into the manipulation of this hybrid prefabrication model and diversity of atmospheric conditions that are achievable for a positive living environment.

Beyond the scope of this thesis and as further opportunity for research the Servicebox offers interesting design potential. With further development and prototyping this module could be brought to an industry standard suited for social housing throughout New Zealand. In addition, further analysis and design experimentation to investigate the extent to which the design framework developed in this thesis could benefit the social housing sector could be undertaken. The design framework driving this design process was developed through relevant literature and used as a tool to critique case studies against and measure the success of the design outcomes. With further development, this framework as well as the architecture generated through this line of research can become a solution to New Zealand's social housing issues that abolishes the social stigma's attached providing a desired and diverse atmospheric quality needed to empower occupants. 




\section{LIST OF FIGURES}

Unless otherwise stated, all images are authors own.

Figure 1.01. Todays Arlington Council Flats built in 1970 by architect, Ian Athfield

Figure 1.02. Nairn Street Council Flats in the process of redevelopment

Figure 1.03. Central play park for various council housing in Mount Cook

Figure 1.04. Nairn Street Council Flats outdoor space backs onto public walkway

Figure 1.05. Thesis methodology structure diagram showing an overall linear progression, as well as the cyclical referral back to previous research stages

Figure 2.01. Newtown Park Apartments recently upgraded and refurbished by Studio Pacific Architecture

Figure 2.02. New Zealand Social Hosing timeline showing the progression of social housing in New Zealand from 1900 - today

Figure 2.03. Graphs indicating the demographic in need of social housing within Wellington City

Figure 2.04. A tenants personal touch on their outdoor court in the Newtown Park Apartments

Figure 2.05. Prefab can offer more for less chart (Bell and Southcombe 38)

Figure 2.06. The reasons behind inattention to human motivational factors and the consequences (Zavei and Jusan 313)

Figure 2.07. Theoretical model of personalisation in built environment (Zavei and Jusan 317)

Figure 2.08. The 'four well-beings of community sustainability’ model (Bierre et al. 70)

Figure 2.09 External fields as a transition between motivations and behavior (Zavei and Jusan 313) 
Figure 2.10. The four key aspects that are the atmospheric generators important for social housing and the cyclical affect each aspect has on each other

Figure 2.11. Regent Park was a new build that was a part of the Wellington City Council Housing Upgrade Project.

Figure 3.01. Regent Park occupation 4 years after completion

Figure 3.02. Analysis framework to evaluate the selected case studies, showing a seleced segment

Figure 3.03. Kitchen interior of a Triangle Road dwelling ("Triangle Road Community Housing" Community; sec. 2)

Figure 3.04. Living interior of a Triangle Road dwelling ("Triangle Road Community Housing" Community; sec. 2)

Figure 3.05. The homogenous exterior of Triangle Road dwellings ("Triangle Road Community Housing" Community; sec. 2)

Figure 3.06. Site and floor plan analysis of Triangle Road

Figure 3.07. Triangle Rooad fulfilling eight of the ten criteria, lacking in architectural identity and exterior atmosphere

Figure 3.08. Interior living qualities within a dwelling of Te Aro Pā ("Multi-Unit Housing" Our Work; sec. 1)

Figure 3.09. Exterior atmospheric qualities of Te Aro Pā ("Multi-Unit Housing" Our Work; sec. 1)

Figure 3.10. Site and Floor plan analysis of Te Aro Pā

Figure 3.11. Te Aro Pā fulfilling six of the ten criteria, lacking in individualisation, social engagement, interior atmosphere as well as visual connections

Figure 3.12. Regent Park exterior atmospheric qualities (“Regent Park" Projects; sec. 1)

Figure 3.13. Regent Park interior atmospheric qualities (“Regent Park" Projects; sec. 1) 
Figure 3.14. Site and Floor plan analysis of Regent Park

Figure 3.15. Regent Park fulfilling five of the ten criteria, lacking in half the identified conditions to design for social housing in New Zealand

Figure 3.16. Interior atmospheric qualities of a dwelling in Zavos Corner ("Zavos Corner 2015"

Housing; sec 2)

Figure 3.17. External aesthetics and atmospheric qualities of Zavos Corner ("Zavos Corner 2015"

Housing; sec 2)

Figure 3.18. Floor Plan analysis of Zavos Corner ("Zavos Corner 2015" Housing; sec 2)

Figure 3.19. Zavos Corner fulfilling nine of the ten criteria, lacking in te use of prefabrication construction.

Figure 3.20. Living space of one of the seven single floor dwellings in Zavos Corner ("Zavos Corner 2015" Housing; sec 2)

Figure 3.21. A table of the chosen case studies showing a comparison of the ten design criteria

Figure 4.01. Wellington City has the potential to provide a bettter environment for social housing if the atmospheric conditions and the empowerment of residents can be addressed

Figure 4.02. Map of Central Wellington location selected sites

Figure 4.03. McLean Flats evacuated in 2011

Figure 4.04. Pukehinau Flats still occupied

Figure 4.05. Arlington Apartments still occupied

Figure 4.06. Figureground urban breakdown surrounding the three selected sites

Figure 4.07. McLean Flats ammenity map

Figure 4.08. Diagram analysising existing site conditions

Figure 4.09. Initial massing diagram responding to site conditions

Figure 4.10. A diagramitic massing formation responding to site conditions 
Figure 4.11. Design consideration table showing the linear and cyclical nature of how these conditions rely on each other to produce a successful design solution

Figure 5.01. Pukehinau Flats from Nairn Street

Figure 5.02. Design framework established in chapter 3 to inform the design process

Figure 5.03. XLam CLT - Triangle Road ("Triangle Road Community Housing" Community; sec.1)

Figure 5.04. Metrapanel - Installation ("Executive Family Home" Projects; sec. 2)

Figure 5.05. UniPod - Prototype

Figure 5.06. Xlam CLT being installed ("About XLam CLT." XLam CLT; sec. 6 )

Figure 5.07. Metralpanel wall panels being installed ("Big Habitat Build" Projects; sec. 2)

Figure 5.08. Different types of Metra panel wall panels available ("Metrapanel Technical Datasheet." 3)

Figure 5.09. Rendered image of the UniPod occupied (First Light Studio 51)

Figure 5.10. Rendered image showing the services through the UniPod (First Light Studio 53)

Figure 5.11. System Axonometric with Metrapanel CLT Detailing

Figure 5.12. Exploded System Axonometric

Figure 5.13. Design framework established in chapter 3 to inform the design process; prefabrication methods established

Figure 5.14. Scheme 1: Vertical stack diagram \& example section

Figure 5.15. Scheme 1: Solar studies of the massed form on site during the Summer and Winter solstice

Figure 5.16. Scheme 1: Site plan massing with suggested unipod placement; scale: 1 :

Figure 5.17. Scheme 1: Long section to understand the interaction between units; scale 1: 
Figure 5.18. Scheme 1: Shared outdoor space/terraced units section

Figure 5.19. Scheme 2: Vertical stack diagram \& example section

Figure 5.20. Scheme 2: Solar studies of the massed form on site during the Summer and Winter solstice

Figure 5.21. Scheme 2: Site plan massing with suggested unipod placement; scale: 1 :

Figure 5.22. Scheme 2: Long section to understand the interaction between units; scale 1:

Figure 5.23. Scheme 2: Shared outdoor space/terraced units section

Figure 5.24. Initial sketch ideas of dwelling development for Scheme 2

Figure 5.25. Design framework that has been established through the current design phases

Figure 5.26. UniPod configuration iteration studies; dwelling 1

Figure 5.27. UniPod configuration iteration studies; dwelling 2

Figure 5.28. Chosen UniPod configuration suitable for dwelling 1

Figure 5.29. Chosen UniPod configuration suitable for dwelling 2

Figure 5.30. Servicebox exploded axonometric

Figure 5.31. Servicebox delivery and installation process

Figure 5.32. UniPod limitations

Figure 5.33. Servicebox exploded axonometroc highlighting improvements

Figure 5.34. Servicebox plan and cross section, scale 1:20

Figure 5.35. Servicebox Kitchen adaptability and individualisation

Figure 5.36. Servicebox Bathroom 
Figure 5.37. Servicebox Kitchen adaptability and individualisation

Figure 5.38. Servicebox Kitchen

Figure 5.39. Dwelling development iteration studies; dwelling 1

Figure 5.40. Dwelling development iteration studies; dwelling 2

Fiigure 5.41. A collage of the house elevations provides an overall impression of the streetscape

Figure 5.42. N.Z.R. Architectural Branch: Factory cut standard house elevations (Standard House 4)

Figure 5.43. Scottish beach house, WT Architecture ("Kingdom of Light: A Modern Beach House in Scotland." Projects; sec. 2)

Figure 5.44. Patchwork house circulation, architect Pfeifer Roser Kuhn ("Patchwork-Haus in Müllheim.” Projects; pt 5)

Figure 5.45. Zavos corner: Pirie Street facade ("Zavos Corner 2015" Housing; par 2)

Figure 5.46. Initial facadae develpoment: contemporary with a a traditional roofline and a central atrium circualtion

Figure 5.47. Design framework criteria that have been satisfied by the design processes

Figure 5.48. Exploded axonometric of the developed floor plans for Block A

Figure 6.01. McLean Flats: original building on site

Figure 6.02. Ten design critera to assess the design outcome

Figure 6.03. Rooftop Pavilion, a shared outdoor space for occupants

Figure 6.04. Site plan; scale 1:250

Figure 6.05. Atrium stairwell access to dwellings

Figure 6.06. Site axonometric 
Figure 6.07. Exploded axonometric floor plans of Block A \& B highlighting the service cores throughout each block

Figure 6.08. Site axonometric highlighting Block A

Figure 6.09. Block A floor plans; scale 1:150

Figure 6.10. Site axonometric highlighting Block B

Figure 6.11. Block B floor plans; scale 1:150

Figure 6.12. Wide entrance from The Terrace through to the central shared space

Figure 6.13. The shared space through the centre of the site with passive surveillence from the surrounding dwellings and rooftop

Figure 6.14. Block A private balconies with social and visual connections

Figure 6.15. Rooftop outdoor BBQ area to cater for large family gathering and intertenancy social engagement

Figure 6.16. Living interior qualities of a 3 bedroom dwelling at midday

Figure 6.17. Community garden area within the rooftop pavilion for occupants to utilise

Figure 7.01. Etona and Berkeley Dallard Apartments

Figure 7.02. Wellington City, the initial scope of this thesis research

Figure 7.03. Ten criteria of the design framework fulfilled by the final design outcome 



\section{BIBLIOGRAPHY}

“About XLam CLT.” XLam Cross Laminated Timber Panels, 2016, xlam.co.nz/ xlam-clt.html

Anderson, Ben. "Affective Atmospheres". Emotion, Space and Society 2.2 (2009): 77-81. Web. 5 Oct. 2016.

Bell, Pamela. "Kiwi Prefab : Prefabricated Housing in New Zealand : An Historical and Contemporary Overview with Recommendations for the Future." Master of Architecture thesis, Victoria University of Wellington, 2009. Print.

Bell, Pamela and Mark Southcombe. Kiwi Prefab: Cottage to Cutting Edge: Prefabricated Housing in New Zealand. Auckland, N.Z: Balasoglou Books, 2012. Print.

Bergdoll, Barry et al. Home Delivery. New York: Museum of Modern Art, 2008. Print.

Bergeijk, Herman van. Herman Hertz̧berger. 1st ed. Basel: Birkhäuser, 1997. Print.

Bierre, Sarah, et al, editors. Homes People Can Afford: How to Improve Housing in New Zealand. Steele Roberts Aotearoa, 2013. Print.

Böhme, Gernot. Architectural Atmospheres : On The Experience And Politics Of Architecture. Basel: Birkhäuser, 2014. Print.

--- "The theory of atmospheres and its applications." Interstices: Atmospheres and Affect, vol. 15, 2014, pp. 92-99.

Borch, C. "Organizational Atmospheres: Foam, Affect And Architecture". Organization 17.2 (2009): 223-241. Web. 10 Sept. 2016.

Bowman, Ian. Patrick Street Historic Precinct: Conservation Principles and Design Guidelines. Lower Hutt City Council, 1990. Print.

"Case Study: Regent Park." Auckland Design Manual, Auckland City Council, aucklanddesignmanual.co.nz/resources/case-studies/regent-park\#/ resources/case-studies/regent-park 
“Executive Family Home.” Metrapanel, metrapanel.co.nz/projects/excutivefamily-home.

Fill, Barbara. Seddon's State Houses: The Workers Dwellings Act 1905 \& the Heretaunga Settlement. New Zealand Historic Places Trust, 1984. Print.

First Light Studio. UniPod Team Six, PrefabNZ, 6 May 2016, prefabnz.com/ Downloads/Assets/3349/1/1._Anna_Farrow_The_UNIpod_Journey. pdf

Hackney, Rod. "New role for architects as team leaders in self-help housing rehabilitation." Ekistics, vol. 48, no. 287, 1981, pp. 112-116.

Hackney, Rod, and Fay Sweet. The Good, the Bad, and the Ugly: Cities in Crisis. London: F. Muller, 1990. Print.

Hackney, Rod, and Wiek Röling. "Community Architecture and its Role in Inner City Regeneration.” RSA Journal, vol. 137, no. 5391, 1989, pp. 149-162.

Hansen, Jeremy. “View Finder.” HOME, 2016, pp. 134-144

Kennedy, David. "The Young Child's Experience of Space and Child Care Center Design: A Practical Meditation." Children's Environment Quarterly, vol. 8, no. 1, 1991, pp. 37-48.

Kieran, Stephen and James Timberlake. Refabricating Architecture. New York: McGraw-Hill, 2004. Print.

"Kingdom of Light: A Modern Beach House in Scotland." Interior Design, 29 Jul 2015, interiordesign.net/slideshows/detail/8604-kindom-of-lightbeach-house-in-scotland $/$ ? single $=$ true

Metrapanel. "Metrapanel Technical Datasheet." Metra Panel System, Metrapanel Ltd. Jul 2015, metrapanel.co.nz/images/pdfs/Metrapanel_ Technical_Data_Sheet.pdf

---Metrapanel Construction: Design and Construction Manual. 2nd ed, Metrapanel Ltd, 2015, Metrapanel Technical Library, metrapanel.co.nz/images/pdfs/ METRA_Design_Construction_Manual_Version_2_.pdf

Ministry of Social Development. "Social Housing Register Overview." Ministry of Social Development: Housing Assessment, New Zealand Government, 2016, housing.msd.govt.nz/information-for-housing-providers/ 
register/index.html

--- "Social Hosing Register." Ministry of Social Development: Housing Assessment, New Zealand Government, 2016, housing.msd.govt.nz/informationfor-housing-providers/register/index.html

“Multi-Unit Housing." Walker Architecture and Design Ltd, 29 Nov 2016, rogerwalker.co.nz/multi-unit-houses/.

"Patchwork-Haus in Müllheim.” Kubn Und Lehmann, 2008, kul-architekten.de/ index.php?id $=25 \& \mathrm{~L}=$ en.

PrefabNZ. Levers for PREFAB. How offsite construction can deliver better cost-effective housing to more New Zealanders, 2015.

--- 5 year impact report. Levers For Prefab Action Plan (Stage One), 2015.

--- New Zealand's Pipeline for Retirement and Social Housing. Staring down the barrel of New Zealand's Retirement and Social Housing Pipeline, 2015.

--- PREFAB ROADMAP. A WAY FORWARD for PREFABRICATION in NEW ZEALAND (2013-2018), 2013.

--- Value for PREFAB. How offsite construction can deliver better costeffective housing to more New Zealanders, 2014.

Productivity Commission, New Zealand. Housing affordability inquiry. The New Zealand Productivity Commission. 2012.

“Regent Park.” Designgroup Stapleton Elliott, 2013, designgroupstapletonelliott. co.nz/regent-park.

Schneider, Friederike et al. Floor Plan Manual Housing. 4th ed. Basel: Birkhäuser, 2011. Print.

Schneider, Tatjana and Jeremy Till. Flexible Housing. 1st ed. Oxford, UK: Architectural Press, 2007. Print.

--- "Flexible Housing: Opportunities And Limits". arq: Architectural Research Quarterly 9.02 (2005): 157. Web. 7 Mar. 2016.

Schrader, Ben. We Call It Home: A History of State Housing in New Zealand. Reed Publishing, 2005. Print. 
Smith, Ryan E. Prefab Architecture: A Guide to Modular Design and Construction. Hoboken, N.J:: John Wiley \& Sons, 2010. Print.

Standard House, Plan AB/1123. Factory Cut. Plan Book. N.Z.R. Architectural Branch, 1895

Statistics New Zealand. "2013 Census QuickStats about housing." Statistics New Zealand: Tataurgauna Aoeteroa, Statistics New Zealand, 2014, stats.govt. $\mathrm{nz} /$ census/2013-census/profile-and-summary-reports/quickstatsabout-housing.aspx.

“Te Aro Pā papakāinga - the power of partnership.” Te Tumu Paeroa, 14 Oct 2016, tetumupaeroa.co.nz/news/te-aro-pa-papakainga-powerpartnership/

Till, Jeremy and Tatjana Schneider. "Flexible Housing: The Means To The End". arq: Arcbitectural Research Quarterly 9.3-4 (2005): 287. Web. 7 Mar. 2016.0

"Triangle Road Community Housing." Strachan Group Architects, sgaltd.co.nz/ triangle-road/.

Tsukamoto, Yoshiharu and Momoyo Kaijima. Atelier Bow-Wow: Behaviorology. New York: Rizzoli, 2010. Print.

--- Graphic Anatomy. 1st ed. Tokyo: TOTO Shuppan, 2007. Print.

Vision West Community Trust. Vision West Triangle Road Community Housing, Massey, Auckland 2016. 2016.

Wigley, Mark. The Architecture of Deconstruction : Derrida's Haunt. Cambridge, Mass.: Cambridge, Mass. : MIT Press, 1993. Print.

--- “The Architecture of Atmosphere.” Daidalos, no. 68, 1998, pp. 18-27.

Zavei, Sayyed Javad Asad Poor, and Mahmud Mohd Jusan. "Exploring Housing Attributes Selection Based on Maslow's Hierarchy of Needs." Procedia Social and Behavioral Sciences, vol. 42, 2012, pp. 311-319.

“Zavos Corner 2015.” Parsonson Architects Ltd, 2016, p-a.nz/zavos-corner. 

